K/SUB / 81-7685/1-02

\title{
A STUDY OF THE HYDROLYSIS OF URANIUM
}

\author{
HEXAFLUORIDE BY FOURIER TRANSFORM
}

\section{INFRARED SPECTROSCOPY}

A Thesis

Presented for the

Mastir of Science

Degree

The Unfversity of Tennessee, Knoxville

This document is PUBLICLY RELEASABLE is Steele

Authorizing Official

Date:

$9-12-07$

\section{Stephen Paul Anderson}

August 1982

\section{DISCLAIMER}

This report was prepared as an account of work sponsored by an agency of the United States Government. Neither the United States Government nor any agency thereof, nor any of their iployees, makes any warranty, express or implied, or assumes any legal liability or responsility for the accuracy, completeness, or usefulness of any information, apparatus, product, or process disclosed, or represents that its use would not infringe privately owned rights. Reference herein to any specific commercial product, process, or service by trade name, trademark, manufacturer, or otherwise does not necessarily constitute or imply its endorsement, recommendation, or favoring by the United States Government or any agency thereof. The views and opinions of authors expressed herein do not necessarily state or reflect those of the United States Government or any agency thereof. 


\section{DISCLAIMER}

This report was prepared as an account of work sponsored by an agency of the United States Government. Neither the United States Government nor any agency Thereof, nor any of their employees, makes any warranty, express or implied, or assumes any legal liability or responsibility for the accuracy, completeness, or usefulness of any information, apparatus, product, or process disclosed, or represents that its use would not infringe privately owned rights. Reference herein to any specific commercial product, process, or service by trade name, trademark, manufacturer, or otherwise does not necessarily constitute or imply its endorsement, recommendation, or favoring by the United States Government or any agency thereof. The views and opinions of authors expressed herein do not necessarily state or reflect those of the United States Government or any agency thereof. 


\section{DISCLAIMER}

Portions of this document may be illegible in electronic image products. Images are produced from the best available original document. 


\section{DEDICATION}

The author wishes to dedicate this work to the memory of Joseph Anderson whose support and encouragement were always gratefully appreciated. 
The author wishes to express his sincere gratitude to $\mathrm{Dr}$. George K. Schweitzer for his advice, guidance, and trust during the course of this work.

Appreciation is also extended to Dr. William H. McCulla and his co-workers at $\mathrm{K}-25$ and to the Union Carbide Nuclear Division, Oak Ridge Gaseous Diffusion Plant $(\mathrm{K}-25)$ whose financial support made this work possible. Thanks is also extended to Dr. Gleb Mamantov for making some of his instrumentation available which allowed this study to be conducted.

The author also wishes to express his gratitude to $\mathrm{Dr}$. Arlene Garrison and Dr. Richard Crocombe for their help and guidance during the course of this work. Thanks is also extended to Myron L. Cherry for his help during the Summer of 1981. Appreciation is also extended to Dr. Schweitzer and Dr. Garrison for editing this manuscript and to Rene Hensley for typing it. 
ABSTRACT

The reaction of uranium hexafluride with water has been studied by using Fourier transform infrared (FT-IR) spectroscopy. Several different methods for accomplishing this task have been carried out. In addition, interpretations of the results have been made. These interpretations have been based on literature values for the reactants and for compounds analogous to possible products.

It was shown that classical matrix-isolation techniques proved to be unsatisfactory for studying this reaction. Other methods were developed in order to obtain results. They were: (1) the codeposition of pure $\mathrm{UF}_{6}$ and $\mathrm{H}_{2} \mathrm{O}$ on a cold window at $16^{\circ} \mathrm{K}$, (2) the codeposition of argon matrix to sample ratios of $10: 1$ to $2: 1$ of $\mathrm{UF}_{6}$ and $\mathrm{H}_{2} \mathrm{O}$ at $-16^{\circ} \mathrm{K}$, and (3) the annealing of the samples produced by (1) and (2) while they were being scanned with FT-IR.

other methods which were tried and found to be non-productive are also presented. Also, an experiment in which an attempt to volatilize $\mathrm{UOF}_{4}$ in vacuo is presented. This volatilization was attempted in a cryostat at $16^{\circ} \mathrm{K}$ with the hope of isolating $\mathrm{UOF}_{4}$ in a matrix on a cold window.

FT-IR spectra obtained in these experiments are presented and discussed. The results obtained are: (1) $\mathrm{UF}_{6}$ and $\mathrm{H}_{2} \mathrm{O}$ show no propensity to react at cryogenic temperatures because of thermodynamic factors, (2) they do react at temperatures above $150^{\circ} \mathrm{K}$, (3) there is a concentration factor that influences their reaction, (4) their reaction seems to be relatively complex and the reaction 
pathway involves several comparatively stable species, (5) these species are evidenced by possible U-F, UO $2, U-O$ and other IR bands, and (6) the attempted volatilization of UOF $_{4}$ supports prior indications that the molecule undergoes disproportionation into $\mathrm{UF}_{6}$ and other products when heated. Finally, possibilities of extending these experiments are discussed. 
A. Properties of $\mathrm{UF}_{6}, \mathrm{UOF}_{4}, \mathrm{UO}_{2} \mathrm{~F}_{2}$, and $\mathrm{UO}_{3} \ldots .$.

1. $\mathrm{UF}_{6}$

2. $\mathrm{UOF}_{4}$

3. $\mathrm{UO}_{2} \mathrm{~F}_{2}$

4. $\mathrm{UO}_{3}$

B. Properties of Analogous $\mathrm{MF}_{6}, \mathrm{MOF}_{4}, \mathrm{MO}_{2} \mathrm{~F}_{2}$, and $\mathrm{MO}_{3}$ Compounds

1. $\mathrm{NpF}_{6}$ and $\mathrm{PuF}_{6}$

2. $\mathrm{WF}_{6}$ and $\mathrm{MoF}_{6}$

3. $\mathrm{NpOF}_{4}$ and $\mathrm{PuOF}_{4}$

4. $\mathrm{WOF}_{4}$ and $\mathrm{MOOF}_{4}$

5. $\mathrm{NpO}_{2} \mathrm{~F}_{2}$ and $\mathrm{PuO}_{2} \mathrm{~F}_{2}$

6. $\mathrm{WO}_{2} \mathrm{~F}_{2}$ and $\mathrm{MoO}_{2} \mathrm{~F}_{2}$

7. $\mathrm{MoO}_{3}$ and $\mathrm{WO}_{3}$

C. Matrix Isolation . . . . . . . . . 23

D. Proposed Studies . . . . . . . . . . . 24

II. INSTRUMENTATION ... . . . . . . . . . . 26

A. Design Considerations . . . . . . . . . 26

B. Description ............. . . 33

III. EXPERIMENTAL PROCEDURE . . . . . . . . . . . 46

A. Gas Phase Experiment . . . . . . . . . 46

B. Matrix-Isolated Water In Argon . . . . . . 47

C. Matrix-Isolated $\mathrm{UF}_{6}$ in Argon . . . . . . . . 49

D. Matrix-Isolated $\mathrm{UF}_{6}$ and Water in Argon . . . . 50

E. Matrix-Isolated Water in Nitrogen ....... . 51

F. Matrix-Isolated $\mathrm{UF}_{6}$ in Nitrogen . . . . . . 52

G. Matrix-Isolated $\mathrm{UF}_{6}$ and Water in Nitrogen . . . 52

H. Matrix-Isolated $\mathrm{UF}_{6}$ and Water in Xenon . . . . 53 
I. Pure $\mathrm{UF}_{6}$ and Water .............. 53

J. Merging Streams of $\mathrm{UF}_{6}$ and Water . . . . . . 55

K. Low-Ratio Deposition Studies . . . . . . 56

L. Low-Rat1o Mixing Nozzle Experiments . . . . . 57

M. $\mathrm{UOF}_{4}$ Volatility Study . . . . . . . . . . 58

IV. RESULTS AND DISCUSSION . . . . . . . . . . . 59

A. Results . . . . . . . . . . . . . . 59

1. Preliminary $\mathrm{UF}_{6}$ Vapor Experiments

2. $\mathrm{UF}_{6}-\mathrm{Ar}$ Matrix-Isolation Studies

3. Matrix-Isolated $\mathrm{H}_{2} \mathrm{O}$ in Argon

4. $\mathrm{UF}_{6}$ and $\mathrm{H}_{2} \mathrm{O}$ Co-deposited in Argon

5. Matrix-Isolated $\mathrm{UF}_{6}$ in Nitrogen

6. $\mathrm{UF}_{6}$ and $\mathrm{H}_{2} \mathrm{O}$ Matrix-Isolated in Nitrogen

7. Co-deposition of $\mathrm{UF}_{6}$ and $\mathrm{H}_{2} \mathrm{O}$ Sans Matrix

8. Matrix-Isolated $\mathrm{UF}_{6}$ and $\mathrm{H}_{2} \mathrm{O}$ in Xenon

9. $\mathrm{UF}_{6}$ and $\mathrm{H}_{2} \mathrm{O}$ Merging Streams Co-deposition Experiment

10. Low-Ratio $\mathrm{UF}_{6}$ and $\mathrm{H}_{2} \mathrm{O}$ Experiment

11. Low-Ratio Nozzle Studies

12. UOF 4 Volatility Studies

B. Discussion . . . . . . . . . . . 158

LIST OF REFERENCES . . . . . . . . . . . . 166

VITA . . . . . . . . . . ...... 172 
TABLE

PAGE

I. Heat and entropy of fusion of $\mathrm{UF}_{6}, \mathrm{NpF}_{6}, \mathrm{PuF}_{6} \ldots .$.

II. Fundamental vibrational frequencies $\left(\mathrm{cm}^{-1}\right)$ and metal-fluorine bond distances $(\AA)$ for

$\mathrm{UF}_{6}, \mathrm{NpF}_{6}$, and $\mathrm{PuF}_{6} \ldots . . . . . . . . . .$.

III. Fundamental vibrational frequencies $\left(\mathrm{cm}^{-1}\right)$

of $\mathrm{MoF}_{6}$ and $\mathrm{WF}_{6}$.................

IV. Physical and thermochemical constants of $\mathrm{WF}_{6}$, $\mathrm{MoF}_{6}$, and $\operatorname{ReF}_{6}$.................. 16

v. Thermochemical constants for $\mathrm{MoOF}_{4}$, and $\mathrm{WOF}_{4} \ldots \ldots 18$

VI. Fundamental frequencies $\left(\mathrm{cm}^{-1}\right)$ of monomeric $\mathrm{WOF}_{4}$ and $\mathrm{MoOF}_{4}$................. 20

VII. IR absorptions $\left(\mathrm{cm}^{-1}\right)$ of important species found in previous investigations and $\mathrm{UF}_{6}$ hydrolysis study .................. 
1. Local environment of uranium atom in solid UOF 4 . . 4

2. (a) Infrared spectrum of $\mathrm{UOF}_{4}$ in $\mathrm{KBr}$ disc

(b) Raman spectrum of polycrystalline sample of $\mathrm{UOF}_{4}$................... 6

3. Cross section of layer structure of $\mathrm{UO}_{2} \mathrm{~F}_{2}$..... 8

4. Top view of lower level of dual gas manifold cart • . 29

5. Side view of lower level of cart . . . . . . . 30

6. Top view of upper level of dual gas manifold . . . . 31

7. Side view of water manffold . . . . . . . . . 34

8. Side view of $\mathrm{UF}_{6}$ manifold . . . . . . . . . . 36

9. Front and side views of CsI sample window holder ...................

10. Side and top views of refrigeration unit cover and deposition port ...............

11. Arrangement used to merge and $\mathrm{mix} \mathrm{UF}_{6}$ and $\mathrm{H}_{2} \mathrm{O}$ sample streams . . . . . . . . . . . . 42

12. Post-deposition port mixing nozzle . . . . . . . 44

13. Deposition port and sample holder for $\mathrm{UOF}_{4}$ vapor studies ....................

14. FT-IR spectrum of initial sample of $\mathrm{UF}_{6}$ gas at 10-torr placed in sample cell .......... 60

15. FT-IR spectrum after several admissions of small amounts of air . . . . . . . . . . . .

16. FT-IR spectrum after several large pulses of air ........................

17. FT-IR spectrum after cell was pressurized to atmosphere ....................

18. FT-IR spectrum of initial sample of $\mathrm{UF}_{6}$ gas at 50-torr placed in sample cell 
19. FT-IR spectrum of sample after only small pulses of air were admitted ...........

20. FT-IR spectrum of sample which was recorded after the sample cell was exposed to alr for approximately one minute . . . . . . . . .

21. Matrix-isolated FT-IR spectrum of Ar $: \mathrm{UF}_{6}$ at $500: 1$. . . . . . . . . . . . . 71

22. Enlargement of $\mathrm{UF}_{6}$ absorption . . . . . . . . 72

23. Enlargement of impurity region . . . . . . . . 73

24. Matrix-1solated FT-IR spectrum of Ar: $\mathrm{UF}_{6}$ at $100: 1$

25. (a) Enlargement of $\mathrm{UF}_{6}$ absorption, before annealing. (b) Enlargement of $\mathrm{UF}_{6}$ absorption after annealing to $25^{\circ} \mathrm{K}$

26. Matrix-isolated FT-IR spectrum of a 1000: 1 sample of $\mathrm{Ar}: \mathrm{H}_{2}$

27. Enlargement of 3800-3500 wavenumber region ......

28. Enlargement of the 1650-1550 wavenumber region, Ar: $\mathrm{H}_{2} \mathrm{O}=1000: 1$

29. Enlargement of 3800-3500 wavenumber region after annealing to $32{ }^{\circ} \mathrm{K}$. . . . . . . . . . . . .

30. Enlargement of 1650-1550 wavenumber region after annealing to $32^{\circ} \mathrm{K}$. . . . . . . ......

31. Matrix-isolated FT-IR spectrum of a 100:1 sample of $\mathrm{Ar}: \mathrm{H}_{2} \mathrm{O}$. . . . . . . . . . .

32. Enlargement of 3800-3400 wavenumber region .....

33. Enlargement of 1650-1550 wavenumber region, $\mathrm{Ar}: \mathrm{H}_{2} \mathrm{O}=100: 1 . . . . . . . . . . . .$.

34. Enlargement of 3800-3400 wavenumber region after annealing to $30^{\circ} \mathrm{K}$. . . . . . . . . . .

35. Enlargement of 1650-1550 wavenumber region after annealing to $30^{\circ} \mathrm{K}$. . . . . . . . . . . 
36. Matrix-1solated FT-IR spectrum of 20:1 sample of $\mathrm{Ar}: \mathrm{H}_{2} \mathrm{O}$. . . . . . . . . . . . . . 89

37. Enlargement of 3800-3000 wavenumber region . . . . . 90

38. Enlargement of 1700-1550 wavenumber region . . . . 91

39. Matrix-1solated FT-IR spectrum of Ar:UF 6 (500:1) and $\mathrm{Ar}: \mathrm{H}_{2} \mathrm{O}(100: 1)$ held at $16^{\circ} \mathrm{K}$. . . . . 93

40. Enlargement of the 1800-500 wavenumber

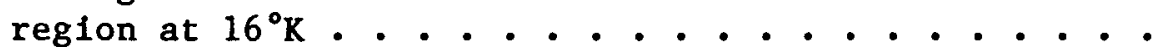

41. Enlargement of $1800-500$ wavenumber region after annealing to $26^{\circ} \mathrm{K}$. . . . . . . . . .

42. Enlargement of the $1800-500$ wavenumber region after annealing to $34^{\circ} \mathrm{K}$..........

43. Enlargement of the 1800-500 wavenumber region after annealing to $37^{\circ} \mathrm{K}$..........

44. Matrix-1solated FT-IR spectrum of 700-500 wavenumber region of 100:1 sample of $\mathrm{N}_{2}: \mathrm{UF}_{6}, \ldots$. .

45. Same region after sample was annealed to $24^{\circ} \mathrm{K}$. . . .

46. Spectrum of same sample after it was annealed to $28^{\circ} \mathrm{K}$................

47. Matrix-isolated FT-IR spectrum of $\mathrm{UF}_{6}: \mathrm{N}_{2}$ $(1: 100)$ and $\mathrm{H}_{2} \mathrm{O}: \mathrm{N}_{2}(1: 500)$ at $16^{\circ} \mathrm{K}$......... 103

48. Enlargement of $\mathrm{H}_{2} \mathrm{O}$ absorptions . . . . . . . . . 105

49. Enlargement of 1700-1500 wavenumber region after sample was annealed to $30^{\circ} \mathrm{K}$. . . . . . . 106

50. FT-IR spectrum of neat deposited sample of $\mathrm{UF}_{6}$ and $\mathrm{H}_{2} \mathrm{O}$ prior to any annealing .........

51. Enlargement of the 1000-400 wavenumber region prior to annealing

52. Enlargement of $1000-400$ wavenumber region after sample had been annealed to $150^{\circ} \mathrm{K}$. . . . . 110

53. Enlargement of 1000-400 wavenumber region after sample had been annealed to about $165^{\circ} \mathrm{K}$ 
54. Enlargement of 1000-400 wavenumber region after sample had been annealed to about $180^{\circ} \mathrm{K}$. . . . . . . . . . . . . .

55. Enlargement of 1000-400 wavenumber region after sample had been annealed to about $195^{\circ} \mathrm{K}$

56. Enlargement of 1000-400 wavenumber region after sample had been annealed past $220^{\circ} \mathrm{K}$

57. (a) Matrix-isolated FT-IR spectrum of $\mathrm{Xe}: \mathrm{UF}_{6}$ and $\mathrm{Xe}: \mathrm{H}_{2} \mathrm{O}$ held at $16^{\circ} \mathrm{K}$. (b) Spectrum taken after sample was annealed past $150^{\circ} \mathrm{K}$....................

58. (a) Spectrum of same region after annealing further. (b) Spectrum of same region after annealing past $200^{\circ} \mathrm{K}$. . . . . . . . . . . . . . . .

59. Matrix-isolated FT-IR spectrum of sample of $\mathrm{UF}_{6}: \mathrm{H}_{2} \mathrm{O}: \mathrm{Ar}(1: 1: 100)$ that was mixed in-line prior to deposition ...............

60. Matrix-isolated FT-IR spectrum of identical sample that was mixed in-line prior to deposition ......................

61. Matrix-isolated FT-IR spectrum of similar sample in which the $\mathrm{UF}_{6}$ and $\mathrm{H}_{2} \mathrm{O}$ were deposited sequentially . . . . . . . . . . .

62. FT-IR spectrum that was recorded after only pure $\mathrm{Ar}$ was passed through the $\mathrm{H}_{2} \mathrm{O}$ side and deposited

63. Matrix-isolated FT-IR spectrum of 100:1 Ar:UF6 and 1000:1 Ar: $\mathrm{H}_{2} \mathrm{O}$ samples were mixed and deposited at $16^{\circ} \mathrm{K}$................

64. Matrix-isolated FT-IR spectrum of $A r: \mathrm{UF}_{6}: \mathrm{H}_{2} \mathrm{O}$ (100:1:1) sample in which the samples were mixed in a $100-\mathrm{cm}$ tube prior to deposition.....

65. Spectrum recorded after sample had been annealed somewhat ................. 
66. Matrix-1solated FT-IR spectrum of sämple similar to the sample recorded in Figure 64 . . . . . 129

67. Spectrum recorded after sample annealed somewhat . . 130

68. Spectrum recorded after sample had been annealed to about $35^{\circ} \mathrm{K}$..............

69. Enlargement of 950-600 wavenumber region of 1000:1:1 of $\mathrm{Ar}: \mathrm{UF}_{6}: \mathrm{H}_{2} \mathrm{O}$ sample that was mixed in $100-\mathrm{cm}$ tube prior to deposition .........

70. FT-IR spectrum of 100:1 Ar: UF 6 and pure water samples that were mixed in a heated $30-\mathrm{cm}$ tube prior to deposition . . . . . . . . . .

71. Spectrum of sample similar to the one recorded in Figure 70 . . . . . . . . . .

72. Spectrum of same sample after it was annealed somewhat . . . . . . . . . . . . 136

73. FT-IR spectrum of $5: 1 \ldots$ Ar: $\mathrm{UF}_{6}$ and a $2: 1$ Ar: $: \mathrm{H}_{2} \mathrm{O}$ sample that was co-deposited at $16^{\circ} \mathrm{K}$........

74. FT-IR spectrum of sample under same experimental conditions as in Figure 73 . . . . . . . . . .

75. FT-IR spectrum of $\mathrm{UF}_{6}: \mathrm{H}_{2} \mathrm{O}: \mathrm{Ar}(1: 1: 2)$ sample

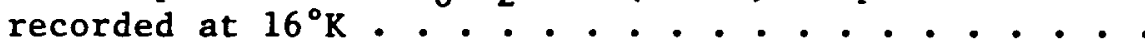

76. FT-IR spectrum of sample under same experimental conditions as in Figure 75 . . ............

77. FT-IR spectrum of sample under same experimental conditions as in Figure 76 . . . . . . . . . . .

78. FT-IR spectrum of $3: 1 \quad \mathrm{Ar}: \mathrm{UF}_{6}$ and $2: 1 \mathrm{Ar}: \mathrm{H}_{2} \mathrm{O}$ samples which were co-deposited at $16^{\circ} \mathrm{K}$

79. FT-IR spectrum of the sample after it had been warmed to approximately $130^{\circ} \mathrm{K}$.........

80. Spectrum recorded after sample had been warmed to about $180^{\circ} \mathrm{K}$. . . . . . . . . . . .

81. Spectrum recorded after sample had been warmed further .................... 
82. Spectrum recorded after sample had been warmed to about $200^{\circ} \mathrm{K}$. . . . . . . . . . . 149

83. Spectrum recorded after sample had been warmed past $220^{\circ} \mathrm{K}$. . . . . . . . . . . . 150

84. Infrared spectrum of $\mathrm{K}^{+} \mathrm{UF}_{5} \mathrm{O}^{-}$and $\mathrm{NF}_{4}{ }^{+} \mathrm{UF}_{5} \mathrm{O}^{-}$ samples recorded by Wilson and associates . . . . 156

85. FT-IR spectrum of $2: 1 \quad \mathrm{Ar}: \mathrm{UF}_{6}$ and $2: 1 \mathrm{Ar}: \mathrm{H}_{2} \mathrm{O}$ sample that was co-deposited through

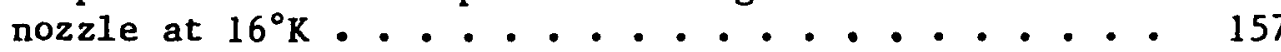

86. FT-IR spectrum of volatilized UOF $_{4}$ sample 


\section{CHAPTER I}

\section{INTRODUCTION}

A. Properties of $\mathrm{UF}_{6}, \mathrm{UOF}_{4}, \mathrm{UO}_{2} \mathrm{~F}_{2}$ and $\mathrm{UO}_{3}$

Uranium hexafluoride and its hydrolysis products have recelved considerable interest recently due to the escalating production in uranium-enrichment facilities around the world. If an accidental leakage of uranium hexafluoride gas into the atmosphere occurred, it would be important to know something about its thermodynamic and kinetic stability as well as the stabilities of its reaction products. It is believed that $\mathrm{UF}_{6}$ would have the greatest propensity to react with water giving a possible reaction pathway perhaps describable as:

$$
\begin{aligned}
& \mathrm{UF}_{6}+\mathrm{H}_{2} \mathrm{O} \\
& \mathrm{UOF}_{4}+\mathrm{H}_{2} \mathrm{O} \\
& \mathrm{UO}_{2} \mathrm{~F}_{2}+\mathrm{H}_{2} \mathrm{O}
\end{aligned}
$$

1. $\underline{U F}_{6}$

Uranium hexafluoride is a colorless solid that melts at approximately $64.5^{\circ}-64.8^{\circ} \mathrm{C}^{1}$ and sublimes at $56.54^{\circ} \mathrm{C}$ at one atmosphere pressure.2 The densities of the solid and liquid are 5.060 and $3.595 \mathrm{~g} / \mathrm{cm}^{3}$, respectively; ${ }^{3}$ the vapor pressure is reported to be 17.65 torr at $0^{\circ} \mathrm{C}$ and 111.9 torr at $25^{\circ} \mathrm{C} .2$

The molecules appear to be slightly distorted octahedrons in the solid state, 4 but they probably possess a regular octahedral geometry in both the liquid and gaseous states. 5 
Fundamental vibrational frequencles of gaseous $\mathrm{UF}_{6}$ correspond to Raman shifts at $66.71\left(\nu_{1}, A_{1 g}\right), 532.5\left(\nu_{2}, E_{g}\right)$ and $202\left(\nu_{5}, F_{2 g}\right)$ $\mathrm{cm}^{-1}$, and IR bands at $624\left(\nu_{3}, F_{1 u}\right)$ and $186.2\left(\nu_{4}, F_{1 u}\right) \mathrm{cm}^{-1.6}$ The ${ }^{19}$ F-NMR spectrum of $\mathrm{UF}_{6}$ has been reported by Seppelt and Bartlett; 7 both ${ }^{238} \mathrm{UF}_{6}$ and ${ }^{235} \mathrm{UF}_{6}$ in a $\mathrm{CFCl}_{3}$ solvent produced singlets at $-764.0 \pm 5 \mathrm{ppm}$; however, the line widths of ${ }^{238} \mathrm{UF}_{6}$ and ${ }^{235} \mathrm{UF}_{6}$ were reported to be 12 and $550 \mathrm{ppm}$, respectively.

The most recent matrix-isolation studies of $\mathrm{UF}_{6}$ were performed by Paine 8 and associates at the Los Alamos Scientific Laboratory. Their investigations were performed in dilute Ar matrices at $14^{\circ} \mathrm{K}$. They believe that their IR spectra support the formation of aggregates of $\mathrm{UF}_{6}$ molecules in matrix samples and also reveal that strong perturbations exist for different hosts, and that stretching frequencies are more susceptible to matrix shifts than bending frequencies. They report vibrations at $66.6\left(\nu_{1}, A_{1 g}\right), 530\left(v_{2}, E_{g}\right)$, $619\left(\nu_{3}, F_{1 u}\right), 183.5\left(\nu_{4}, F_{1 u}\right), 200\left(\nu_{5}, F_{2 g}\right)$ and $143.2\left(\nu_{6}, F_{2 u}\right)$ $\mathrm{cm}^{-1}$.

It has long been known that $\mathrm{UF}_{6}$ hydrolyzes in the presence of excess water to form uranyl fluoride, but whether it reacts further to uranium trioxide is somewhat nebulous. Difficulties of ten arise in storing $\mathrm{UF}_{6}$ in glass because of the cyclic process:

$$
\begin{aligned}
& \mathrm{SiO}_{2}+4 \mathrm{HF} \quad \rightarrow \quad \mathrm{SiF}_{4}+2 \mathrm{H}_{2} \mathrm{O} \\
& \mathrm{UF}_{6}+2 \mathrm{H}_{2} \mathrm{O} \quad+\quad \mathrm{UO}_{2} \mathrm{~F}_{2}+4 \mathrm{HF} \text {. }
\end{aligned}
$$

This problem can be solved by storing $\mathrm{UF}_{6}$ over $\mathrm{KF}$ or $\mathrm{NaF}$ which absorbs HF and halts the hydrolysis cycle. Recently, as a result of the work done by P.W. Wilson, ${ }^{9} \mathrm{UF}_{6}$ has been hydrolyzed to uranium 
oxide tetrafluoride $\left(\mathrm{UOF}_{4}\right)$ and 1 ts structure has been verified by Paine and associates.10 P.W. Wilson prepared UOF 4 by the hydrolysis of $\mathrm{UF}_{6}$ suspended in an HF slurry.

There are no known adducts of $\mathrm{UF}_{6}$ with $\mathrm{H}_{2} \mathrm{O}$ or $\mathrm{HF}$; however, the congruently melting compound $\mathrm{UF}_{6} \cdot \mathrm{XeF}_{2}$ has been reported.11

A report which was submitted by Okamato and Keyose 12 evaluated the release of $\mathrm{UF}_{6}$ vapor into the atmosphere in postulated accidents under a wide variety of different conditions. These postulated accidents dealt with the rupture of a $\mathrm{UF}_{6}$ gas line connected to a hot $\mathrm{UF}_{6}$ cylinder. The amount of gaseous $\mathrm{UO}_{2} \mathrm{~F}_{2}$ and $\mathrm{HF}$ released to the environment was estimated.

2. $\underline{\mathrm{UOF}}_{4}$

As previously described, uranium oxide tetrafluoride has been synthesized by the hydrolysis of $\mathrm{UF}_{6}$ in the condensed phase. It is an incongruently melting solid that is only slightly soluble in anhydrous HF. Analysis of the thermal gravimetric analysis (TGA) trace supports a two-step thermal decomposition, but a three-step decomposition has also been proposed.9 The products of the decomposition are $\mathrm{UF}_{6}$ and $\mathrm{UO}_{2} \mathrm{~F}_{2}$. Unlike other transition metal oxide tetrafluorides, UOF $_{4}$ is reported to be non-volatile, and gas-phase or matrix spectra have not been obtained. 9

The structure (Figure 1) of the solld compound synthesized by Wilson has been determined by X-ray diffraction by Paine, Ryan, and Asprey 10 and verified by neutron diffraction by Levy, Taylor, and Wilson.13 They proposed a pentagonal bipyramid of light atoms surrounding the uranium atom - the atoms in the axial positions are 


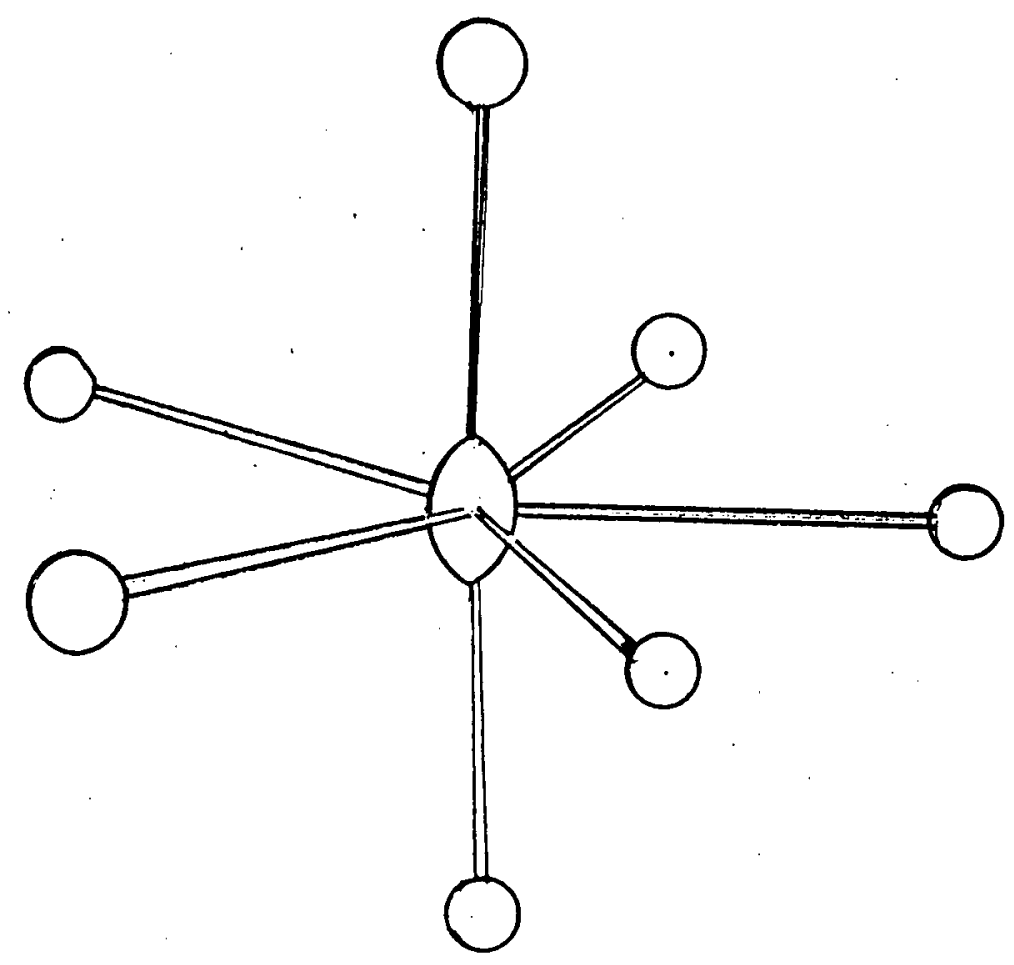

Figure 1. Local environment of urantum atom in solid UOF ${ }_{4}$. Urantum atom (center) surrounded by pentagonal bipyramid of light atoms; the oxygen atoms lie in the axial positions and the fluorine atoms rest in the equatorial plane. 10 
$1.870 \AA$ and $1.884 \AA$ from the uranium atom; in the pentagonal plane one terminal atom exists $2.05 \AA$ from uranium and four bridging atoms occur at approximately $2.271 \pm 0.001 \AA$. They proposed that the oxygen atom is in a terminal axial position, and also concluded that the oxygen atoms alternated between the up and down positions. They concluded that four of the equatorial fluorine atoms were bridging and one was non-bridging. This structure was labelled alpha $\left(\alpha-U O F_{4}\right)$. A second polymorph has been synthesized and characterized via X-ray diffraction by Taylor and Wilson and designated beta $\left(B-U O F_{4}\right) .14$ This form was prepared by slow growth of crystals of $\alpha-\mathrm{UOF}_{4}$ partially dissolved in anhydrous HF; these crystals are yellow and very hygroscopic. This molecule was determined to be tetragonal and isostructural with $8-U F_{5}$; it was also proposed to be pentagonal bipyramidal but two non-bridging fluorines occupy the axial position and a non-bridging oxygen occupies an equatorial position along with four bridging fluorines. The non-bridging axial fluorines showed a bond distance of $1.92 \AA$; the oxygen bond distance was reported to be $1.87 \AA$ and the equatorial fluorine bond distances were reported at $2.18 \AA$.

Both the IR and Raman spectra (Figure 2) of $\alpha-U O F_{4}$ have been determined by Paine 10 and associates; the IR spectrum of $\alpha-U^{18} \mathrm{OF}_{4}$ has also been reported by Jacob and Polligkeit.15 The IR spectrum of a powder sample at $25^{\circ} \mathrm{C}$ is characterized by bands at 893,667 , 558,478 , and $375 \mathrm{~cm}^{-1}$. Jacob and Polligkeit assign the band at $891 \mathrm{~cm}^{-1}$ (893) as a terminal $\mathrm{U}-0$ stretch on the basis of isotopic shifts. The two bands at 667 and $558 \mathrm{~cm}^{-1}$ were assigned to the 

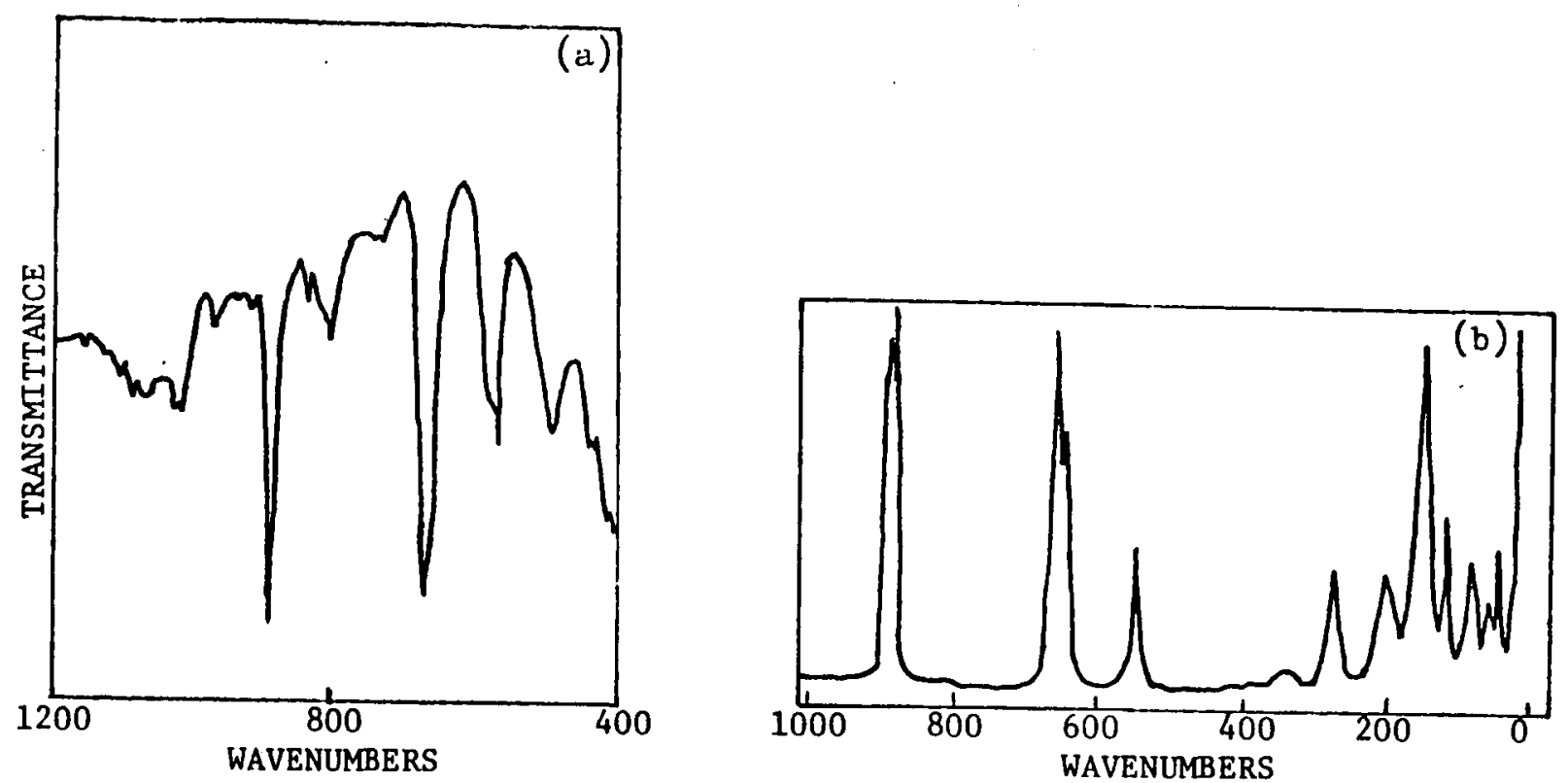

Figure 2. (a) Infrared spectrum of $\mathrm{UOF}_{4}$ in $\mathrm{KBr}$ disc. (b) Raman spectrum of polycrystalline sample of $\mathrm{UOF}_{4} \cdot 10$ 
terminal U-F stretch and broad bands at 472 and $375 \mathrm{~cm}^{-1}$ were assigned to U-F-U bridge modes. The Raman spectrum of a polycrystalline sample showed shifts at 552,660 , and $389 \mathrm{~cm}^{-1}$. No known matrix studies have been reported on $\mathrm{UOF}_{4} \cdot$ Also, Paine et al.8 stated that lowering the sample temperature to $-196^{\circ} \mathrm{C}$ produced some additional sharpening in their spectra.

Since $\mathrm{UOF}_{4}$ is a very hygroscopic compound, upon standing for several minutes in moist air it will react to produce hydrated uranyl fluoride $\left(\mathrm{UO}_{2} \mathrm{~F}_{2} \cdot \mathrm{nH}_{2} \mathrm{O}\right)$. Therefore, it is difficult to achieve a clean IR spectrum with KBr, polyethylene, or polytetrafluoroethylene discs which usually show a uranyl band at $940 \mathrm{~cm}^{-1}$ that is due to hydrolysis.10 More careful handling and use of mulling agents might lead to better results.

3. $\underline{\mathrm{UO}}_{2} \mathrm{~F}_{2}$

The hydrolysis reaction of $\mathrm{UF}_{6}$ to uranyl fluoride is exothermic and releases about $50 \mathrm{kcal} / \mathrm{mole}$ of heat at $25^{\circ} \mathrm{C} .16$ Uranyl fluoride Is a pale yellow non-melting solid that undergoes thermal decomposition at high temperatures.17

Uranyl fluoride was reported to have rhombohedral symmetry; ${ }^{18}$ the molecular structure (Figure 3) consists of a semi-distorted hexagonal bipyramid; the uranyl group is perpendicular to the bisecting plane of fluorine atoms arranged around the uranium atom in a puckered hexagon that resembles the chair configuration in cyclohexane. The fluorine atoms purportedly alternate above and below the bisecting plane around the uranium atom, but a following study by Taylor ${ }^{19}$ contradicted this arrangement. He concluded via 


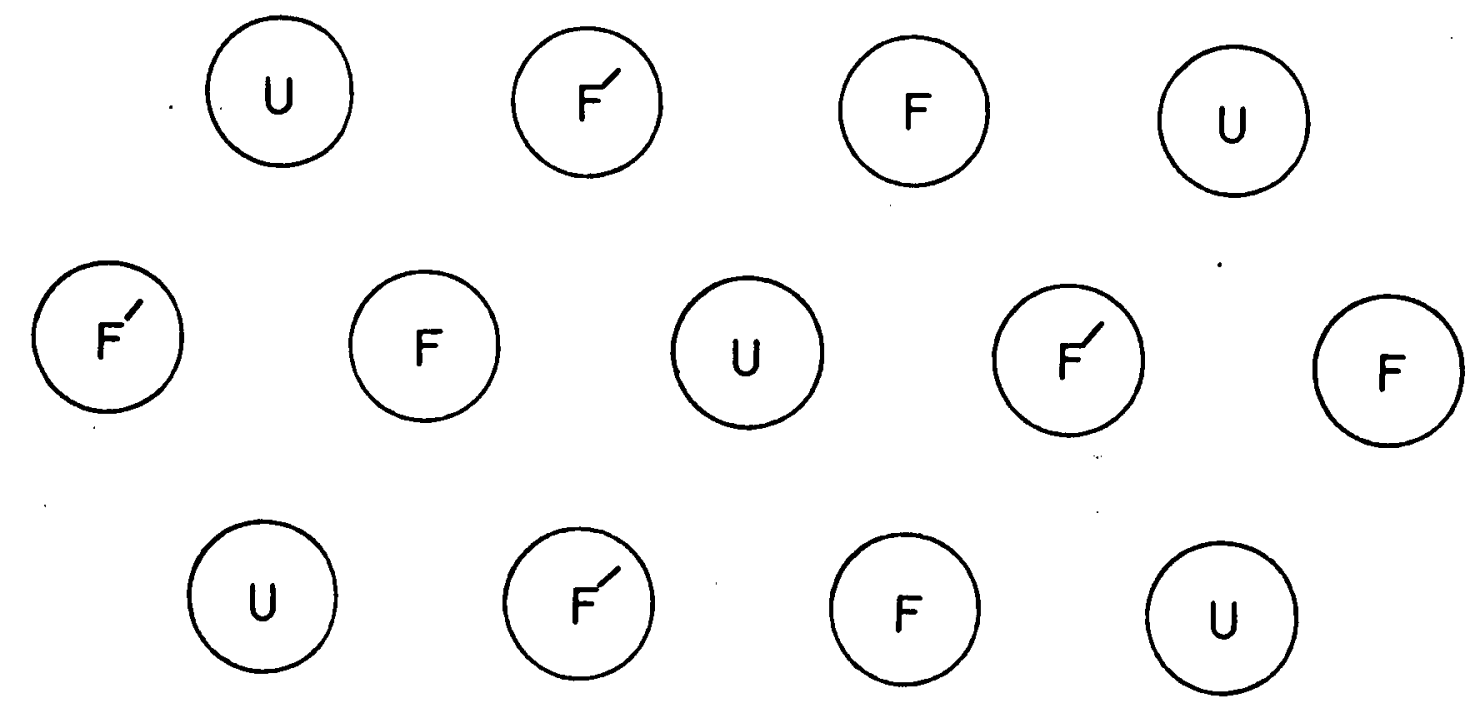

Figure 3. Cross section of layer structure of $\mathrm{UO}_{2} \mathrm{~F}_{2}$. The uranium atoms (U) rest in the same plane (page). The oxygen atoms (not plctured) lie directly above and below the uranium atoms. The fluorine atoms alternately lie 0.61 angstroms above (F) and below ( $F^{-}$) the plane of urantum atoms. 20 
neutron diffraction that the arrangement of fluorine atoms is not puckered but that they are co-planar with the uranium atoms.

Several Investigations have reported the IR spectrum of $\mathrm{UO}_{2} \mathrm{~F}_{2}$, and the most characteristic peak is the one assigned to the urany 1 stretch at $990 \mathrm{~cm}^{-1.20} \mathrm{Ohwada}^{21}$ described the far-IR spectrum of $\mathrm{UO}_{2} \mathrm{~F}_{2}$ as having three bands located at 260,234 , and $146 \mathrm{~cm}^{-1}$. Ohwada assigned the band at $260 \mathrm{~cm}^{-1}$ to the U-F stretching vibration $\left(E_{\mathrm{u}}, v_{7}\right)$, and the 234 and $146 \mathrm{~cm}^{-1}$ peaks were assigned to the $0-U-0 \quad\left(E_{u}, v_{8}\right)$ and $F-U-F \quad\left(A_{2} u, v_{4}\right)$ bending vibrations, respectively.

$\mathrm{UO}_{2} \mathrm{~F}_{2}$ is soluble in water and its solubility increases with temperature. 22 Hydrated complexes of the form $\mathrm{UO}_{2} \mathrm{~F}_{2} \cdot \mathrm{nH}_{2} \mathrm{O}(\mathrm{n}=2,3)$ have been prepared by dissolving uranium trioxide $\left(\mathrm{UO}_{3}\right)$ in aqueous HF.23 $\mathrm{UO}_{2} \mathrm{~F}_{2}$ also forms a combined adduct with $\mathrm{HF}$ and $\mathrm{H}_{2} \mathrm{O}$ $\left(\mathrm{UO}_{2} \mathrm{~F}_{2} \cdot 2 \mathrm{HF} \cdot 4 \mathrm{H}_{2} \mathrm{O}\right) \cdot 24 \quad \mathrm{UO}_{2} \mathrm{~F}_{2}$ will hydrolyze in the presence of steam heated above $450^{\circ} \mathrm{C}$ to form uranium trioxide and $\mathrm{HF} .25$

4. $\mathrm{UO}_{3}$

Uranium trioxide, possibly the final product in the hydrolysis of $\mathrm{UF}_{6}$, exists in at least $s 1 x$ crystal forms $\left(\alpha-\mathrm{UO}_{3}\right.$ to $\varepsilon-\mathrm{UO}_{3}$ and high pressure $\xi-\mathrm{UO}_{3}$ ) and an amorphous form. 26 It is difficult to produce the compound in pure form due to its phase instability - it must be produced at moderate temperatures $\left(400-700^{\circ} \mathrm{C}\right) .23$ The most stable form $\gamma-\mathrm{UO}_{3}$ is a yellow powder, $B-\mathrm{UO}_{3}$ is an orange-red powder, and $\alpha-\mathrm{UO}_{3}$ is a tan powder. It is difficult to obtain an accurate density measurement due to its phase impurity; however, it 
is approximately $7.29 \mathrm{~g} \mathrm{~cm}^{-3}$ at $15^{\circ} \mathrm{C}^{25}$ for what appears to be $\alpha-\mathrm{UO}_{3}$. The vapor pressure of $\mathrm{UO}_{3}$ at $1600^{\circ} \mathrm{K}$ is $10^{-4}$ atm. 25

Matrix-isolation studies of $\mathrm{UO}_{3}$ have been performed by Gabelnick and associates 27-29 and confirmed by others.30 The following assignments were made by Gabelnick and associates: $\nu_{1}\left(A_{1}\right)=$ 843.5, $\nu_{2}\left(A_{1}\right)=745.6, \quad \nu_{4}\left(B_{1}\right)=852.6, \quad \nu_{3}\left(A_{1}\right)=186.2, \quad \nu_{5}\left(B_{1}\right)=211.6$, and $\nu_{6}\left(B_{2}\right)=151.5 \mathrm{~cm}^{-1}$. Gabelnick and associates 28 determined $\mathrm{UO}_{3}$ to be T-shaped in the matrix. The two oxygens in line with the uranium are equivalent and have a shorter $U-O$ bond length than the oxygen which rests at a right angle to them.

B. Properties of Analogous $\mathrm{MF}_{6}, \mathrm{MOF}_{4}, \mathrm{MO}_{2} \mathrm{~F}_{2}$, and $\mathrm{MO}_{3}$ Compounds

1. $\mathrm{NpF}_{6}$ and $\mathrm{PuF}_{6}$

Both neptunium and plutonium hexafluoride are very similar to uranium hexafluoride in many ways. Some of their thermodynamic properties are compared in Table I. 31 Notice that the melting points of the three compounds decrease in the order $\mathrm{UF}_{6}>\mathrm{NpF}_{6}>\mathrm{PuF}_{6} \cdot$ This can be attributed to the increase in covalent character due to a lanthanide-type contraction observed in these elements.31 An anomaly is observed for the vapor pressure of $\mathrm{NpF}_{6}$ because it is not intermediate between $\mathrm{UF}_{6}$ and $\mathrm{PuF}_{6}$ but is greater than either of them. This quirk has not been explained.

IR and Raman data for the three gaseous actinide hexafluorides are listed in Table II along with metal-fluorine bond distances derived from electron diffraction studies. 6 The Raman spectra of liquid and gaseous $\mathrm{NpF}_{6}$ were observed by Gasner and Frlec. 32 Malm, 
TABLE I

HEAT AND ENTROPY OF FUSION OF UF $6, \mathrm{NpF}_{6}$ AND $\mathrm{PuF}_{6} 31$

\begin{tabular}{|c|c|c|c|c|}
\hline & $\begin{array}{c}\text { Temperature } \\
{ }^{\circ} \mathrm{C}\end{array}$ & $\begin{array}{l}\text { Vapor Pressure } \\
\text { torr }\left(25^{\circ} \mathrm{C}\right)\end{array}$ & $\underset{\operatorname{cal} \operatorname{mol}^{-1}}{\Delta \mathrm{H}}$ & 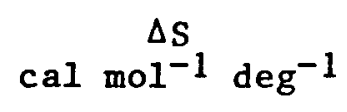 \\
\hline $\mathrm{UF}_{6}$ & 64.0 & 111.9 & 4555 & 13.51 \\
\hline $\mathrm{NpF}_{6}$ & 54.0 & 126.8 & 4112 & 12.53 \\
\hline $\mathrm{PuF}_{6}$ & 50.8 & 104.9 & 4456 & 13.72 \\
\hline
\end{tabular}


TABLE II

FUNDAMENTAL VIBRATIONAL FREQUENCIES $\left(\mathrm{cm}^{-1}\right)$ AND METAL-FLUORINE BOND DISTANCES ( $\AA$ ) FOR $\mathrm{UF}_{6}, \mathrm{NpF}_{6}$ AND $\mathrm{PuF}_{6} 6$

\begin{tabular}{ccccccccc}
\hline Compound & $\begin{array}{c}\nu_{1} \\
(R)\end{array}$ & $\begin{array}{c}\nu_{2} \\
(R)\end{array}$ & $\begin{array}{c}\nu_{3} \\
(I R)\end{array}$ & $\begin{array}{c}\nu_{4} \\
(I R)\end{array}$ & $\begin{array}{c}\nu_{5} \\
(R)\end{array}$ & $\begin{array}{c}\nu_{6} \\
\text { (inactive) }\end{array}$ & $\begin{array}{c}M-F \\
(\AA)\end{array}$ \\
\hline $\mathrm{UF}_{6}$ & 667.1 & 532.5 & 624 & 186.2 & 202 & $(142)$ & 1.996 \\
$\mathrm{NpF}_{6}$ & 654 & 535 & 624 & 198.6 & 208 & $(164)$ & 1.981 \\
$\mathrm{PuF}_{6}$ & $(628)$ & $(523)$ & 616 & 206.0 & $(211)$ & $(173)$ & 1.971 \\
\hline
\end{tabular}


Weinstock, and Claassen 33 have studied the IR spectra of gaseous $\mathrm{NpF}_{6}$ and $\mathrm{PuF}_{6}$. They used a nickel absorption cell fitted with $\mathrm{AgCl}$ windows. Their attempt to obtain the Raman spectrum of $\mathrm{PuF}_{6}$ failed because the compound absorbs in the visible region and undergoes photochemical decomposition. Their report compared their results to previous UF6 spectra, and because of the similarities, they concluded that both $\mathrm{NpF}_{6}$ and $\mathrm{PuF}_{6}$ have regular octahedral symmetry. $\mathrm{NpF}_{6}$ and $\mathrm{PuF}_{6}$ hydrolyze in the presence of water, and like $\mathrm{UF}_{6}$ must be stored in dry quartz or Pyrex over anhydrous $\mathrm{NaF}$ or $\mathrm{KF}$ to prevent the cyclic process described earlier. Usually they hydrolyze according to the reaction:

$$
\mathrm{MF}_{6}+2 \mathrm{H}_{2} \mathrm{O} \rightarrow \mathrm{MO}_{2} \mathrm{~F}_{2}+4 \mathrm{HF}(\mathrm{M}=\mathrm{Np}, \mathrm{Pu}) \cdot 34
$$

Recently, investigators 35,36 have produced compounds with the formula $\mathrm{MOF}_{4}$ according to the reaction:

$$
\mathrm{MF}_{6}+\mathrm{H}_{2} \mathrm{O} \stackrel{\mathrm{HF}}{\rightarrow} \mathrm{MOF}_{4}+2 \mathrm{HF} .
$$

This process is identical to the one used for production of UOF 4 in which an HF slurry is employed to suppress further hydrolysis.

\section{2. $\underline{W F}_{6}$ and $\underline{M O F}_{6}$}

Tungsten hexafluoride $\left(W_{6}, M . W .=297.92 \mathrm{~g} / \mathrm{mol}\right.$ ) is a white solid that melts at $2.0 \pm 0.3^{\circ} \mathrm{C}$ and bolls at $17.06 \pm 0.05^{\circ} \mathrm{C} .47$ According to Barber and $\mathrm{Cady}^{37}$ the vapor pressure is 1029.2 torr at $25.24^{\circ} \mathrm{C}$.

The vapor phase IR and Raman spectra of $\mathrm{WF}_{6}$ have been reported by several investigators (see Table III).38 Recently, Bernstefn and Meredith ${ }^{39}$ have obtained Raman spectra of $\mathrm{WF}_{6}$ (also $\mathrm{UF}_{6}$ and $M o F_{6}$ ) In the solid phase at $77^{\circ} \mathrm{K}$, and at this temperature they determined $\mathrm{UF}_{6}$ and $\mathrm{WF}_{6}$ to have $\mathrm{D}_{4 \mathrm{~h}}$ and $\mathrm{O}_{\mathrm{h}}$ geometries, respectively. 
TABLE III

FUNDAMENTAL VIBRATIONAL FREQUENCIES $\left(\mathrm{cm}^{-1}\right)$ OF MOF 6 AND WF $_{6} 38$

\begin{tabular}{lcccccc}
\hline Compound & $\begin{array}{c}\nu_{1} \\
(R)\end{array}$ & $\begin{array}{c}\nu_{2} \\
(R)\end{array}$ & $\begin{array}{c}\nu_{3} \\
(I R)\end{array}$ & $\begin{array}{c}\nu_{4} \\
(I R)\end{array}$ & $\begin{array}{c}\nu_{5} \\
(R)\end{array}$ & $\begin{array}{c}\nu_{6} \\
\text { (inactive) }\end{array}$ \\
\hline WF $_{6}$ & 769 & 760 & 712 & 256 & 322 & 261 \\
MoF $_{6}$ & 736 & 641 & 742 & 269 & 319 & 240 \\
\hline
\end{tabular}


In a study Selig and associates 40 concluded that hydrolysis of $\mathrm{WF}_{6}$ in anhydrous $\mathrm{HF}$ produces the oxontum salt $\mathrm{H}_{3} \mathrm{O}^{+} \mathrm{WOF}_{5}$, which undergoes thermal decomposition at $150^{\circ} \mathrm{C}$ probably to yield $\mathrm{WO}_{2} \mathrm{~F}_{2}$. According to Canterford and Colton, ${ }^{41} \mathrm{WF}_{6}$ in the presence of $\mathrm{H}_{2} \mathrm{O}$ hydrolyzes to $\mathrm{WO}_{2} \mathrm{~F}_{2}$ :

$$
\mathrm{WF}_{6}+2 \mathrm{H}_{2} \mathrm{O} \rightarrow \mathrm{WO}_{2} \mathrm{~F}_{2}+4 \mathrm{HF} \quad \mathrm{K}_{\mathrm{eq}}=6 \times 10^{2} \text {. }
$$

Therefore there is a direct analogy between the hydrolysis of $\mathrm{UF}_{6}$ and $\mathrm{WF}_{6}$.

Molybdenum hexafluoride is similar to $\mathrm{WF}_{6}$ in many ways, and a number of its physical constants is compared to those of $\mathrm{WF}_{6}$ in Table IV. Raman analysis of crystalline $\mathrm{MoF}_{6}$ supports an $\mathrm{O}_{h}$ symmetry. 39 The thermochemical constants of $\mathrm{MoF}_{6}$ are compared to those of $\mathrm{WF}_{6}$ in Table IV.41

The characteristic peaks in the IR spectrum of $M_{0} F_{6}$ resemble those of $\mathrm{WF}_{6}$. There are bands at $742\left(v_{3}\right), 269\left(v_{4}\right)$, and $240\left(v_{6}\right)$ $\mathrm{cm}^{-1}$, whereas $\mathrm{WF}_{6}$ shows peaks at $712\left(\nu_{3}\right), 256\left(\nu_{4}\right)$ and $261\left(\nu_{6}\right) \mathrm{cm}^{-1}$. A comparison of the values in Table IV reveals that the $M-F$ bond lengths of the transition metal hexafluorides increase upon descending the group; however, one must be cautious about predicting the relative reactivities of the three hexafluorides from this, because the bond length factor is offset by the increased stability of the higher oxidation state as one descends a group in the transition-metal block. Therefore the reactivity decreases in the order $\mathrm{MoF}_{6}<\mathrm{WF}_{6}<\mathrm{UF}_{6}$. Vibrational spectra are compared in Table III. Unlike $\mathrm{WF}_{6}, \mathrm{MoF}_{6}$ hydrolyzes in the absence of $\mathrm{HF}$ to yield $\mathrm{MoOF}_{4}$, and then hydrolyzes further to $\mathrm{MoO}_{2} \mathrm{~F}_{2} \cdot 41$ 
TABLE IV

PHYSICAL AND THERMOCHEMICAL CONSTANTS OF $\mathrm{WF}_{6}, \mathrm{MoF}_{6}$ AND ReF 641

\begin{tabular}{|c|c|c|c|c|c|}
\hline Molecule & M-F distance & $\stackrel{\mathrm{M} . P .}{{ }^{\circ} \mathrm{C}}$ & $\begin{array}{r}\mathrm{V} . \mathrm{P} \\
\text { torr } \\
\left(20^{\circ} \mathrm{C}\right)\end{array}$ & $\begin{array}{c}\Delta \mathrm{H} \\
\mathrm{kcal} / \mathrm{mole}\end{array}$ & $\begin{array}{c}\Delta S \\
\mathrm{cal} / \mathrm{deg} / \mathrm{mole}\end{array}$ \\
\hline $\mathrm{MoF}_{6}$ & 1.820 & 17.5 & 446 & 6.360 & 20.6 \\
\hline $\mathrm{WF}_{6}$ & 1.833 & 2.3 & & 6.250 & 21.5 \\
\hline $\operatorname{ReF}_{6}$ & 1.832 & 19.0 & 269 & 6.366 & 19.8 \\
\hline
\end{tabular}


3. $\mathrm{NPOF}_{4}$ and $\underline{\mathrm{PuOF}}_{4}$

The oxide tetrafluorides of plutonium and neptunium have been prepared by the slow hydrolysis of their respective hexafluorides in an anhydrous $\mathrm{HF}$ slurry.36,42 According to Burns and O'Donnel1,36 PuOF $_{4}$ is a chocolate-brown solid with a very low vapor pressure at room temperature. Peacock and Edelstein 42 reported that $\mathrm{NpOF}_{4}$ is a brownish-purple solid that when allowed to stand in molst air leads to discoloration and the appearance of a new crystalline phase.

$X$-ray powder studies revealed that both oxide tetrafluorides are isostructural with the trigonal form of uranium oxide tetrafluoride $\left(\alpha-\mathrm{UOF}_{4}\right)$.

All three oxide tetrafluorides $\left(\mathrm{MOF}_{4}, \mathrm{M}=\mathrm{Np}, \mathrm{Pu}, \mathrm{U}\right)$ hydrolyze in molst air; however, only $\mathrm{PuOF}_{4}$ is unstable in the presence of anhydrous $H F$ at room temperature. It reacts in the following manner :

$$
2 \mathrm{PuOF}_{4} \stackrel{\mathrm{HF}}{\rightarrow} \mathrm{PuF}_{6}+\mathrm{PuO}_{2} \mathrm{~F}_{2} \cdot 36
$$

$\mathrm{UOF}_{4}$ has the greatest thermal stability of the three, NpOF 4 being intermediate in stability.

4. WOF 4 and $\underline{M O O F}_{4}$

Molybdenum and tungsten oxide tetrafluoride are white crystalline solids that can be prepared by the controlled hydrolysis of their respective hexafluorides.43 Their thermodynamic constants are very similar (see Table V). 44

Alexander and associates 45 have proposed with support from vibrational analysis that molecular $\mathrm{MoOF}_{4}$ and $\mathrm{WOF}_{4}$ have $\mathrm{C}_{4 \mathrm{v}}$ symmetry in the vapor phase and most probably in the solid phase. Paine and 
TABLE V

THERMOCHEMICAL CONSTANTS FOR MOOF 4 AND WOF 444

\begin{tabular}{lcccccc}
\hline Molecule & B.P. & $\Delta \mathrm{H}$ fus & $\Delta \mathrm{H}$ vap & $\Delta \mathrm{H}$ sub & $\Delta \mathrm{S}$ fus & $\Delta \mathrm{S}$ vap \\
\hline MoOF 4 & 186.0 & 1.020 & 12.090 & 13.110 & 2.768 & 26.3 \\
WOF $_{4}$ & 185.9 & 2.260 & 14.230 & 16.490 & 5.981 & 31.0 \\
\hline
\end{tabular}

$\Delta \mathrm{H}$ in $\mathrm{kcal} \mathrm{mole}^{-1}$

$\Delta S$ in cal $\mathrm{deg}^{-1} \mathrm{~mole}^{-1}$

B.P. in ${ }^{\circ} \mathrm{C}$ 
MCDowel146 have stated that the solid phase metal atom is octahedrally surrounded. Four equatorial fluorines rest at right angles to each other; one of the equatorial fluorines is bridging while an additional bridging fluorine occurs trans to an apical oxygen.

Studies by Robiette $\left(\mathrm{WOF}_{4}\right)^{47}$ and Iijima $\left(\mathrm{MOOF}_{4}\right)^{48}$, utilizing electron diffraction, verified $\mathrm{C}_{4 \mathrm{v}}$ symmetry and obtained precise geometrical data for both gaseous $\mathrm{WOF}_{4}$ and gaseous $\mathrm{MoOF}_{4}$. Iijima described $\mathrm{MoOF}_{4}$ as square pyramidal in the gas phase but sald it is distorted in the solid due to bridging via fluorine to another molecule. Alexander and associates 45 performed gas and solid-phase Raman and IR analysis together with matrix-isolated Raman and IR studies on $\mathrm{MoOF}_{4}$ and $\mathrm{WOF}_{4}$, and their results are shown in Table VI. In this study they revealed that the $W-0$ stretching frequency is independent of phase and, therefore, since the gas phase is principally monomeric, concluded that neither the solid nor the melt is oxygen bridged.

The controlled hydrolysis of WOF $_{4}$ yields $\mathrm{WO}_{2} \mathrm{~F}_{2} \cdot 49$ This was accomplished by distilling stoichiometric quantities of $\mathrm{H}_{2} \mathrm{O}$ in anhydrous $\mathrm{HF}$ onto $\mathrm{WOF}_{4}$ at $-196^{\circ} \mathrm{C}$ in FEP tubes. $\mathrm{MoO}_{2} \mathrm{~F}_{2}$ has not been prepared in this manner. Reaction of the difluoro dioxo forms with $\mathrm{XeF}_{2}$ yields $\mathrm{MOF}_{4} \cdot \mathrm{XeF}_{2}(\mathrm{M}=\mathrm{Mo}, \mathrm{W})$. which have been characterized by Holloway and Atherton. 50

5. $\mathrm{NpO}_{2} \mathrm{~F}_{2}$ and $\mathrm{PuO}_{2} \mathrm{~F}_{2}$

Very little.is known about the chemical and physical properties of neptunyl or plutonyl fluoride. Pink $\mathrm{NpO}_{2} \mathrm{~F}_{2}$ and white $\mathrm{PuO}_{2} \mathrm{~F}_{2}$ possess rhombehedral symmetry. 51 
TABLE VI

FUNDAMENTAL FREQUENCIES $\left(\mathrm{cm}^{-1}\right)$ OF MONOMERIC

WOF $_{4}$ AND $\mathrm{MoOF}_{4} 45$

\begin{tabular}{cccc}
\hline Mode & Symmetry & WOF 4 & MoOF 4 \\
\hline$v_{1}$ & $a_{1}$ & 1055 & 1048 \\
$v_{2}$ & $a_{1}$ & 733 & 714 \\
$v_{3}$ & $a_{1}$ & 248 & 264 \\
$v_{4}$ & $b_{1}$ & 631 & \\
$v_{5}$ & $b_{1}$ & 328 & \\
$v_{6}$ & $b_{2}$ & 291 & 720 \\
$v_{7}$ & e & 698 & 294 \\
$v_{8}$ & e & 298 & 236 \\
$v_{9}$ & e & 236 & \\
\hline
\end{tabular}


Both oxyfluorides are soluble in water. The phase diagrams of the compounds have been studied extensively. Plutonyl fluoride forms an adduct of the form $\mathrm{PuO}_{2} \mathrm{~F}_{2} \cdot \mathrm{H}_{2} \mathrm{O}$ and also a water-HF adduct of the form $\mathrm{PuO}_{2} \mathrm{~F}_{2} \cdot 2 \mathrm{HF} \cdot \mathrm{H}_{2} \mathrm{O}$.

6. $\mathrm{MOO}_{2} \mathrm{~F}_{2}$ and $\mathrm{WO}_{2} \mathrm{~F}_{2}$

Remarkably little investigation has been done on the dioxo fluorides of molybdenum(VI) and tungsten(VI) and the most recent study still leaves much to be desired.49 Atherton and Holloway49 performed NMR, IR, and mass spectrometry along with chemical analysis; however, the spectra were not included in their report because of poor results. They prepared $\mathrm{MoO}_{2} \mathrm{~F}_{2}$ by reaction of $\mathrm{MoO}_{2} \mathrm{Cl}_{2}$ with anhydrous $\mathrm{HF}$. The substance does not melt or sublime at temperatures up to $310^{\circ} \mathrm{C}$ in a vacuum.

The IR spectrum supports a solid state polymeric structure. They compared their spectra with those of $\mathrm{MoO}_{2} \mathrm{Cl}_{2}$ and $\mathrm{MoO}_{2} \mathrm{Br}_{2}$ and assigned a broad absorption at $835 \mathrm{~cm}^{-1}$ to a bridging Mo-0-Mo stretching vibration. The F-19 NMR spectrum of $\mathrm{MoO}_{2} \mathrm{~F}_{2}$ in $\mathrm{HF}$ and $\mathrm{SO}_{2} \mathrm{ClF}$ mixture reveals a broad singlet at $-131.5 \mathrm{ppm}$ versus $\mathrm{CFCl}_{3}$. Their studies of $\mathrm{WO}_{2} \mathrm{~F}_{2}$ revealed little about the compound. Vibrational spectra were poor and no ${ }^{19} \mathrm{~F}-\mathrm{NMR}$ analyses were performed.

7. $\underline{\mathrm{MOO}}_{3}$ and $\underline{\mathrm{WO}}_{3}$

Molybdenum trioxide is a white solid which turns yellow upon heating; its melting point is $795^{\circ} \mathrm{C} .52$ Tungsten trioxide is a pale lemon-yellow powder.53 It melts at about $1470^{\circ} \mathrm{C}$ and boils at approximately $1427^{\circ} \mathrm{C} .54$ Both oxides are insoluble in pure water but 
dissolve in alkaline solutions to give tungstates or molybdates. 53 The densities of $\mathrm{WO}_{3}$ and $\mathrm{MoO}_{3}$ are 6.47 and $4.69 \mathrm{~g} / \mathrm{cm}^{3}$, respectively. 55

The $\mathrm{MoO}_{3}$ crystal structure is described as rhombic with lattice constants: $a=3.9, b=13.8, c=3.7 \AA . \quad \mathrm{WO}_{3}$ is described as monoclinic below $700^{\circ} \mathrm{C}$ (lattice constants $a=7.285, \quad b=7.517$, $c=3.835 \AA)$ and tetragonal above $700^{\circ} \mathrm{C} \quad(a=5.250, \quad c=3.915 \AA) .56$ Loopstra and Boldine, 57 who performed neutron diffraction studies, described $\mathrm{WO}_{3}$ as a "deformed $\mathrm{ReO}_{3}$ type structure... the $\mathrm{W}-0$ bonds form zigzag chains in three directions ... in the $x$ direction the bonds are of equal length ... in the $y$ and $z$ directions they are alternately short and long." Both $\mathrm{MoO}_{3}$ and $\mathrm{WO}_{3}$ are polymeric in the vapor phase; they are of the form $\left(\mathrm{MO}_{3}\right)_{n}$ where $\mathrm{n}=3,4,5.58$

Mattes and Schroeder 59 performed vibrational analysis on solid $\mathrm{WO}_{3}$ and $\mathrm{MoO}_{3}$; their spectra can be compared with the Raman spectra of the vapors that were done by Krasser. 60

Unlike $\mathrm{UO}_{3}, \mathrm{MoO}_{3}$ and $\mathrm{WO}_{3}$ have only one and two known forms, respectively. The most stable structure of the $\mathrm{UO}_{3}$ polymorphs is $\alpha-\mathrm{UO}_{3}$ and it is comparable to the high temperature form of $\mathrm{WO}_{3}$; the $\mathrm{B}^{-\mathrm{UO}_{3}}$ polymorph can be compared to the low temperature form of $\mathrm{WO}_{3}$. Weltner and McLeod61 have performed IR studies on matrix-isolated samples of $\mathrm{WO}, \mathrm{WO}_{2}, \mathrm{WO}_{3}, \mathrm{~W}_{2} \mathrm{O}_{6}, \mathrm{~W}_{3} \mathrm{O}_{8}, \mathrm{~W}_{3} \mathrm{O}_{9}$ and $\mathrm{W}_{4} \mathrm{O}_{12}$. They concluded that there is insufficient evidence to assign any definite geometry to $\mathrm{WO}_{3}$ in the matrix. 


\section{Matrix Isolation}

Matrix isolation is the process of preparing a sample in which a molecule is isolated, immobilized and held in an inert rigid matrix usually at low temperatures. The molecule of interest to host ratio is typically very low and usually ranges anywhere from $1: 50$ to $1: 10,000$. Specles which may otherwise exist for only a few fleeting moments may be preserved practically indefinitely, since bimolecular collisions are virtually nullified. Most conventional types of spectroscopy, namely, IR, Raman, UV-visible, and ESR may be used in association with matrix isolation. Modern matrix isolation was developed independently in 1954 by Norman and Porter 62 and by Whittle, Dows, and Pimentel.63 Pimentel's group was responsible for developing most of the modern-day technique, and also for formulating criteria that must be met for isolation of species using noble gases or nitrogen as the host matrix. From their research came the first reported characterization by IR spectroscopy of a free radical (HCO) held in a rigid matrix at low temperatures.

The criteria for the host lattice in this study are rigidity, inertness, good thermal conductivity, appropriate volatility, and ability to accommodate guest species. Ideally the guest species should be isolated in a host matrix that is transparent to the spectroscopic measurement to be used. Several criteria have been advanced by Downs and Peake 64 for experimental conditions that must be met to achieve the best possible results: (1) The deposition rates must be slow ( $1-5$ mol of matrix gas per hour) for isolation of small molecules. (2) The deposition temperature must be low 
enough so that the sample is condensed fast enough to restrict diffusion of molecules during condensation, and that it be cold enough to inhibit subsequent diffusion of trapped species. (3) The matrix ratio must be scrutinized because it has a profound effect on the degree of isolation.

The most significant effect that matrix-isolating the samples has upon IR spectra is the absence of rotational bands in all but the simplest of molecules. The resulting vibrational bands are very sharp and correspond to pure molecular vibrations. One area where IR spectroscopy has been useful with matrix isolation is in samplewarming or annealing experiments in which diffusion allows bimolecular reactions. An annealing experiment can allow one to slow a reaction to the point where one can detect a reaction intermediate that could not otherwise be detected.

\section{Proposed Studies}

(1) Matrix-1solated samples with ratios ranging anywhere from matrix to sample $(\mathrm{M} / \mathrm{S})$ equal to $10: 1$ to $1000: 1$ matrix gas with water and matrix gas with urantum hexafluoride will be deposited at $16^{\circ} \mathrm{K}$ and the Fourier transform infrared (FT-IR) spectrum recorded. Both argon and nitrogen will be used as the host matrix. Annealing experiments will then be performed with these samples. (2) Matrix-isolated samples with matrix to sample ratios ranging from $10: 1$ to $1000: 1$ of argon:water $\left(\mathrm{Ar}: \mathrm{H}_{2} \mathrm{O}\right)$ and argon: $\mathrm{UF}_{6}$ (Ar:UF 6 ) will be deposited simultaneously at $16^{\circ} \mathrm{K}$ and then warmed in order to induce chemical reaction. Nitrogen will also be used as a 
host matrix. (3) Pure water and $\mathrm{UF}_{6}$ will be deposited simultaneously sans matrix and annealing experiments will be conducted. (4) Matrix-isolated samples of $\mathrm{UF}_{6}: \mathrm{Ar}$ and $\mathrm{H}_{2} \mathrm{O}: \mathrm{Ar}$ will be merged into one stream just prior to deposition in order to allow more time for them to react. The amount of time that the streams will be allowed to mix will be varied by using varlous lengths of tubing. (5) Low ratio samples of $\mathrm{UF}_{6}: \mathrm{Ar}$ and $\mathrm{H}_{2} \mathrm{O}: \mathrm{Ar}$ ranging from $2: 1$ to $10: 1$ will be co-deposited and annealing experiments will be performed. (6) A nozzle will be fitted over the deposition tubes inside the cryostat sample chamber to allow the streams to mix immediately before deposition. (7) An attempt will be made to volatilize a pure sample of uranium oxide tetrafluoride $\left(\mathrm{UOF}_{4}\right)$ inside the cryostat sample chamber in order to isolate individual or small aggregates of $\mathrm{UOF}_{4}$ molecules. 


\section{A. Design Considerations}

The unit designed for the $\mathrm{UF}_{6}$ hydrolysis matrix-isolation FT-IR spectroscopy experiments was a dual-gas manifold coupled with a cryostat-refrigeration unit for preparing and holding the sample. This was used in conjunction with an FT-IR spectrometer. Several aspects needed to be considered when designing and constructing the dual-gas manifold refrigeration unit for $U_{6}$ hydrolysis studies. These considerations were: (1) that the system be as inert as possible towards the highly reactive $\mathrm{UF}_{6}$ gas, (2) that the system be able to operate at low pressures $\left(10^{-4}\right.$ torr or lower) in order to ensure purity of samples, (3) that every precaution be taken to ensure safety for apparatus users, (4) that the unit be mobile in order to use it in conjunction with the FT-IR spectrometer, (5) that the unit be flexible as well as adaptable in order to be able to do a variety of experiments, (6) that the refrigeration unit be able to cool the sample container to a temperature of $15^{\circ} \mathrm{K}$ in a reasonable amount of time $(2 \mathrm{hrs})$, and to also have moderate control over sample temperature during annealing experiments, and (7) that the unit be easy to use in order to provide the ability to reproduce the experiments rather easily.

If the $\mathrm{UF}_{6}$ side of the gas manifold was to be as inert as possible to reaction with the $U_{6}$ gas, it was important to choose 
stainless steel valves since they are very resistant to UF6 attack. It would also have been better to use stainless steel tubing and fittings but the budget would not allow this. Instead, copper tubing and brass fittings were used and were reasonably inert to the $\mathrm{UF}_{6}$ because the manifold was passivated with pure fluorine gas for a 48 hour period prior to any $\mathrm{UF}_{6}$ being introduced into the system. Also a stainless steel mixing tank was used, and no glass flow meter was employed since it would react with $\mathrm{UF}_{6}$.

In order to obtain the low pressures needed for the experimental work, a dual pumping system was used. The primary pump was a rotary pump with a capability to lower the pressure to about one micron. The secondary pump was a diffusion pump with the ability to lower the pressure from one micron to approximately $10^{-5}$ torr under ideal conditions with the limiting factor being the vapor pressure of the pump oil which is $8 \times 10^{-6}$ torr. The system was also designed so that the diffusion pump could be disengaged at higher pressures ( $>50 \times 10^{-3}$ tor $\left.r\right)$ and then re-engaged after the primary pump had lowered the pressure to about $50 \times 10^{-3}$ torr.

A liquid nitrogen trap was installed to collect any gaseous material, primarily $\mathrm{UF}_{6}$ or its hydrolysis products which might be toxic. Also, the trap helped to achieve the low pressures needed by cryo-pumping at liquid nitrogen temperatures to desorb gases from the vacuum manifold. Leak testing of the system was done by a variety of techniques. First, as the manifold was being constructed, small sections of the manifold were tested for leaks before they were incorporated into the whole. Second, after the 
manifold was completely constructed, sections of the manifold were isolated and leak tested, and then later larger sections were tested. Two different brands of leak detectors were used. The first was a Veeco (MS-90) which has a good pumping capacity but poor sensitivity and was used to detect the larger leaks. Later, after the larger leaks were found, a Leybold-Heraeus was used because of its greater sensitivity. It must be noted here that after the manifold had been constructed, the major leaks found, and the pump engaged, it was important to allow the pump to evacuate the lines for about one week in order to remove species adsorbed on the inner surfaces of the gas manifold. This procedure often saves time because it keeps the operator from confusing pressure due to adsorbed species with leaks.

The manifold and refrigeration unit were mounted on a steelframed cart since the spectrometer could not be solely dedicated to this study. The cart had two levels. The bottom level (Figures 4 and 5) was used to carry the compressor unit, the rotary and diffusion pumps, and the liquid nitrogen trap. One-half inch aluminum rods were used to construct a support for the gas manifold on the upper level (Figure 6). Also, on the upper level, a corrugatedsteel mount which had been previously constructed, but had to undergo slight modification, was placed to support the cryostat. Another desirable feature of the manifold-refrigeration unit was its flexibility. It was designed with a number of outlets so that it could be used for several different purposes simultaneously. It could be used to handle just about any gas, with relative safety 


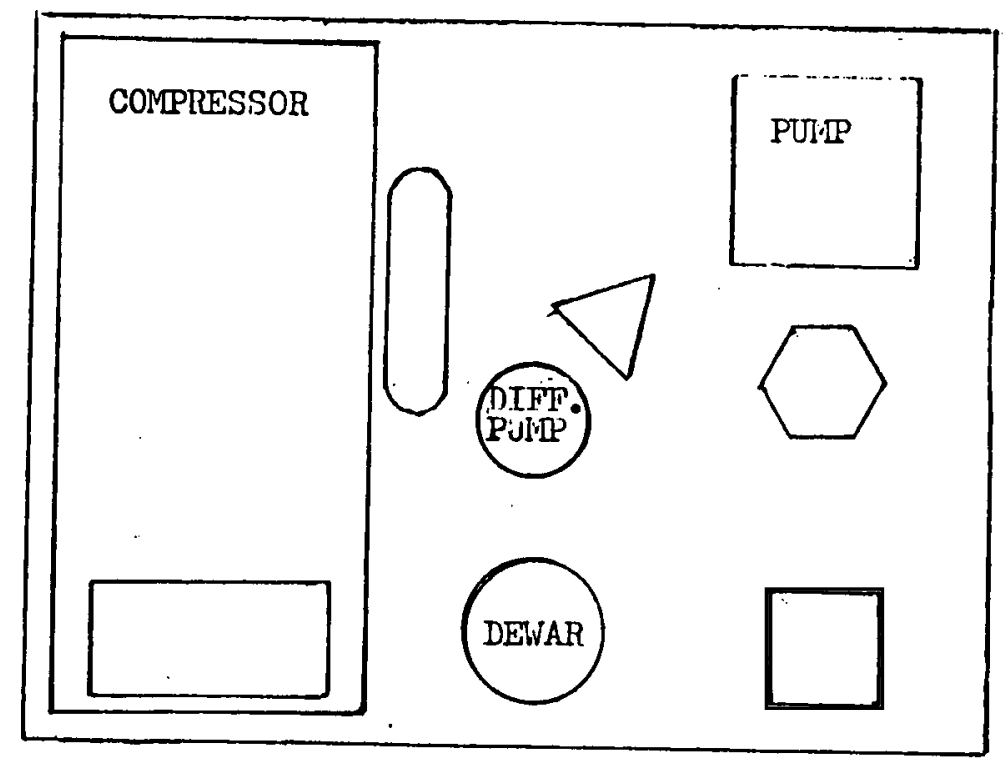

Figure 4. Top view of lower of dual gas manifold cart. 

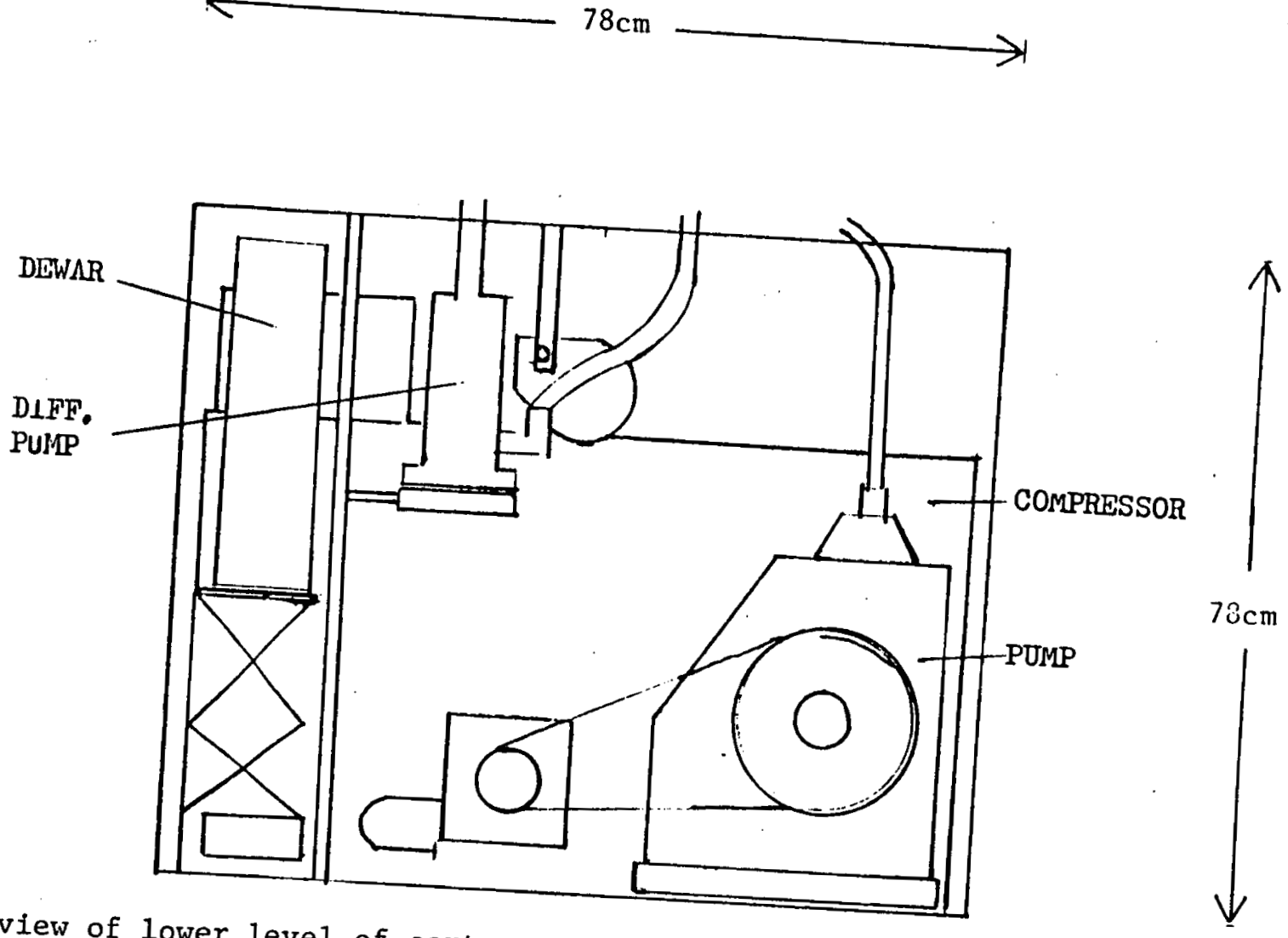

Figure 5. Side view of lower level of cart. 


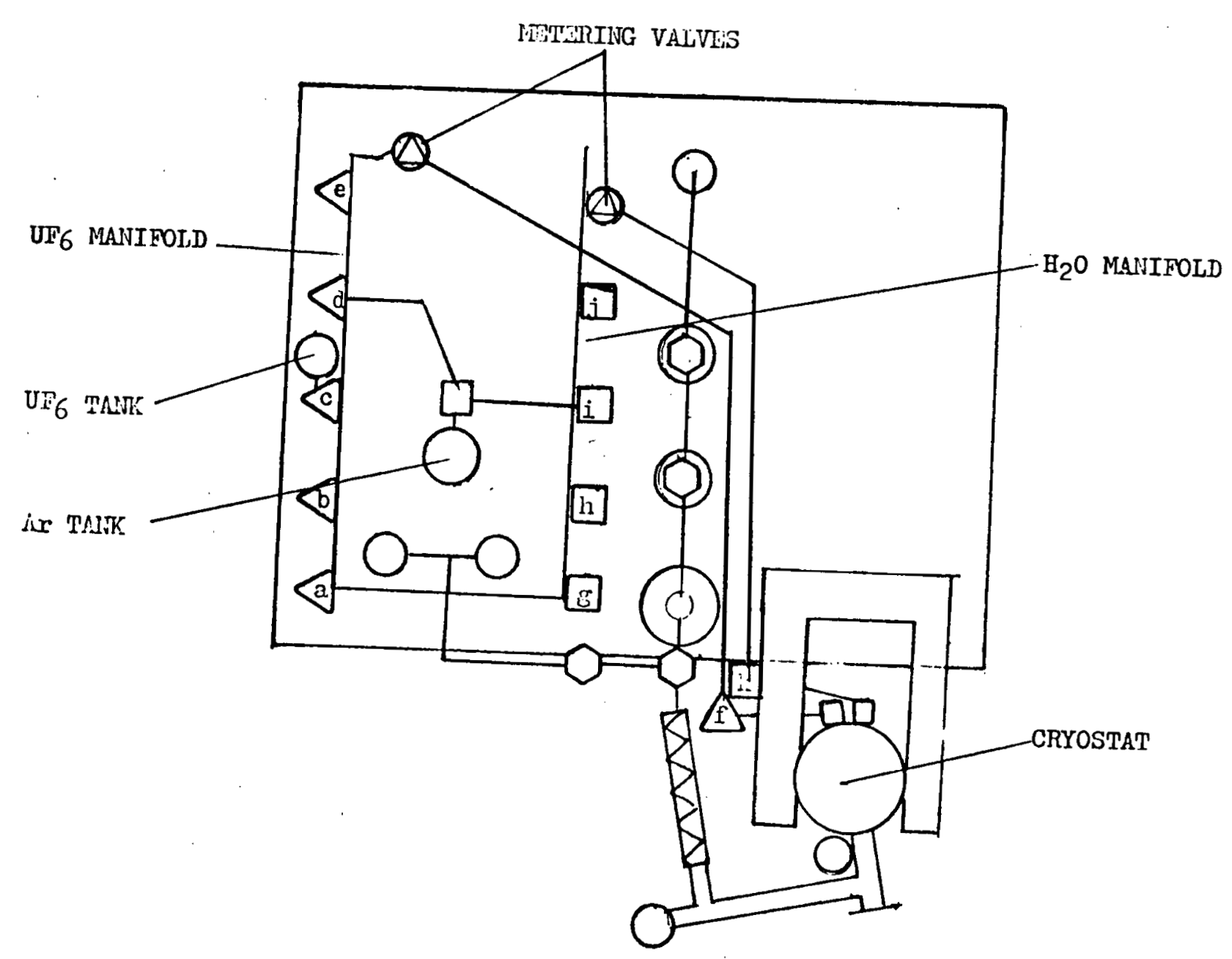

Figure 6. Top view of upper level of dual gas manifold. 
and ease. Also, the fact that the unit was mobile added further to its flexibility, and since many of the joints on the manifold used Swagelok (Crawford Fitting Co., Solon, Oh1o) and Cajon (Cajon Co., Macedonia, Ohio)-type fittings, the unit could be altered rather easily to fit other needs.

Another desirable feature of the unit was that the compressorcryostat unit work efficiently so that the cooling be easy and rapid. It was also necessary that one be able to control the temperature as much as possible. Therefore, an Air Products (Air Products and Chemicals, Inc., Allentown, PA) temperature controller was employed.

One of the most important considerations when designing the system was that the unit be easy to use and that the experiments be easy to reproduce. This consideration was accomplished by several. methods. First, all of the valves in the gas manifold were mounted above the upper level so they would be easy to reach which is especially convenient if the user has to perform several manual operations in rapid sequence. Also, the valves and tubing on the $\mathrm{UF}_{6}$ and water sides were panel-mounted at eye level. Metering valves were used on both sides of the dual-gas manifold, and a glass-flow meter was mounted on the water side of the dual manifold unit. Three different types of pressure gauges were also used: (1) the first which was installed on both the $\mathrm{UF}_{6}$ and water sides of the manifold was a Robertshaw (Robertshaw Co., Knoxville, Tenn.) Acragage which measures pressures from 760 torr to 1 torr, (2) the second was a Hastings (Teledyne Hastings-Raydist, Virginia) pressure gauge which 
measures pressure from $100 \mu \mathrm{m}\left(10^{-1}\right.$ torr $)$ to $1 \mu \mathrm{m}\left(10^{-3}\right.$ torr $)$, and finally, (3) the third was a Penning (CVC, Inc., New York) type which was used to measure pressures from $10^{-3}$ torr to $10^{-6}$ torr. These gauges were necessary to reproduce the experiments.

\section{B. Description}

The type of FT-IR spectrometer that was employed was a Digilab FTS-20C/V (Dig1lab Inc., Cambridge, Mass.). It was equipped with a nichrome wire source and TGS pyroelectric bolometer detector. A $\mathrm{KBr}$ beam splitter was used, and interferograms were subjected to "boxcar" truncation before transformation. Spectra were recorded at either $1 \mathrm{~cm}^{-1}$ or $4 \mathrm{~cm}^{-1}$ resolution.

The primary pump chosen was a Sargent-Welch model 1402 rotary pump (see Figure 5); an accumulation of debris developed, which was probably uranyl fluoride, in the pump's oil case. This material adsorbed on the inner surface of the oil case, and successive oil changes failed to remove the material. After the manifold had been exposed to atmospheric pressure, it took several days for the pumps to evacuate the system to approximately 0.2 millitorr.

The secondary pump chosen was a V.I.C. DA-100 air-cooled twoinch oil diffusion pump (see Figure 5); it can accommodate a pumping speed of 150 liters/sec at $5 \times 10^{-5}$ torr. The primary pump and diffusion pump were installed so that the diffusion pump could be bypassed (Figure 7) at higher pressures. This modification produced some difficulties. Because of the location of the diffusion pump a flexible rubber hose had to be used to connect the exhaust outlet of 

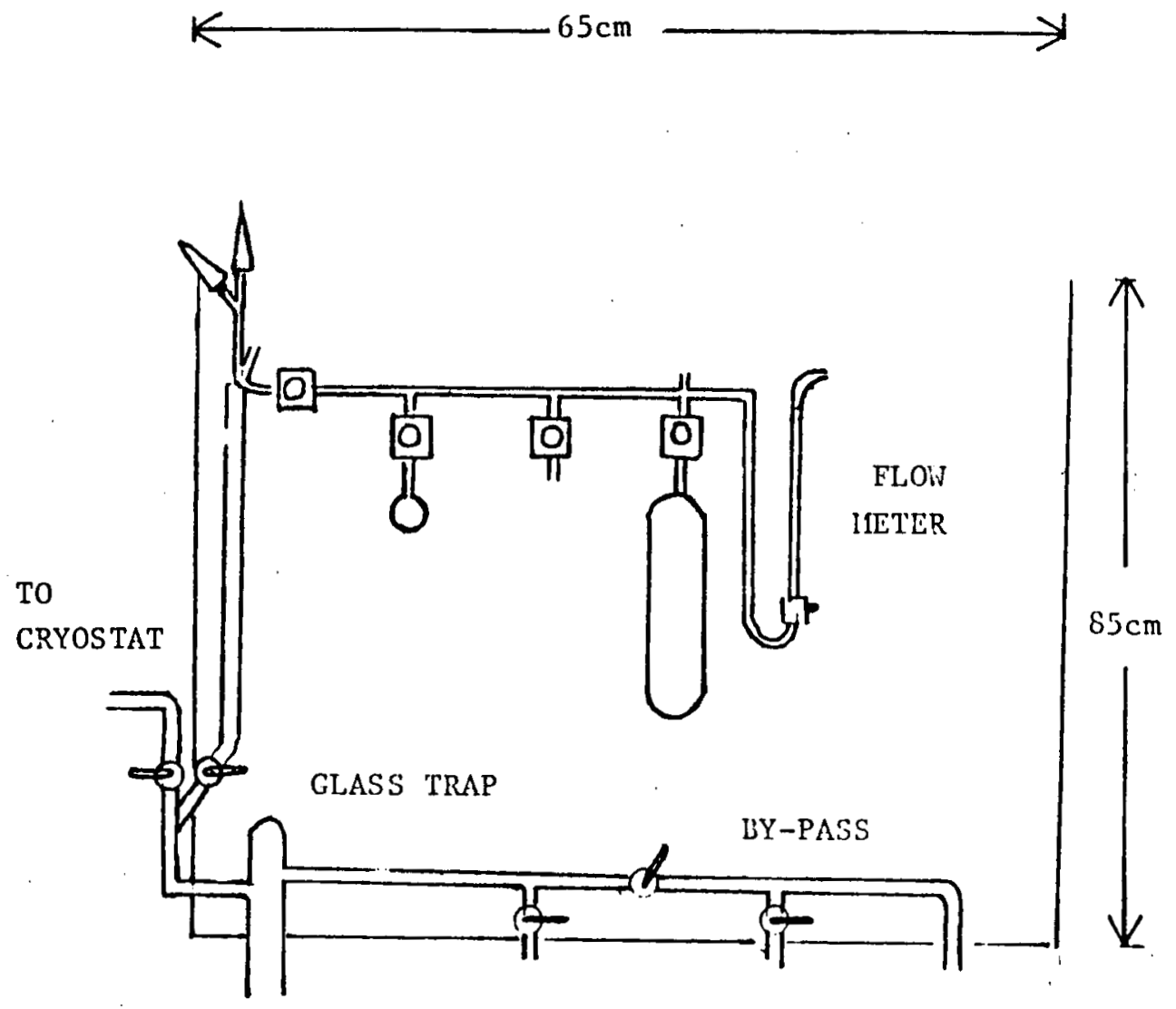

Figure 7 . Side view of water manifold. 
the diffusion pump to the copper tubing coupled to the forepump (see Figure 5). This rubber tubing was probably a factor in the inabil1ty of the pumping system to evacuate the manifold below $10^{-5}$ torr. Secondly, the trap which was located next to the diffusion pump 1mposed some strain on the pump as the trap reached its capacity. A small fan was used to cool the diffusion pump (Figure 5).

The liquid nitrogen trap which was located between the manifold-cryostat and the pumps was a conventional glass trap in design (Figure 5), and its outer jacket was 10.5 inches long and two inches in diameter. The primary purpose of the trap was to collect $\mathrm{UF}_{6}$ or any other harmful materials. It was believed that the $\mathrm{UF}_{6}$ would not react significantly with the glass trap or the silicone-based stopcock grease at liquid nitrogen temperature, but, since a relatively small amount of debris was found in the trap, it lends doubt about the ability to trap $U_{6}$ in that fashion, especially at low concentrations.

The pump and trap section (see Figure 7) of the manifold was constructed of 1/2-inch copper tubing joined by brass Swagelok fittings and brass Circle Seal (Circle Seal, California) 9200 series plug shutoff valves.

The UF 6 manifold (Figure 8) included 1/4-inch copper tubing joined by brass Swagelok fittings and stalnless-steel Autoclave Engineers... (Autoclave Engineers Co., Erie, Pennsylvania) packed valves. A.E. valves are very durable and were chosen because of their resistance to attack from the $\mathrm{UF}_{6}$ and ease of replacement of packing. Valve "a" (see Figure 6) was used as a cut-off between the 

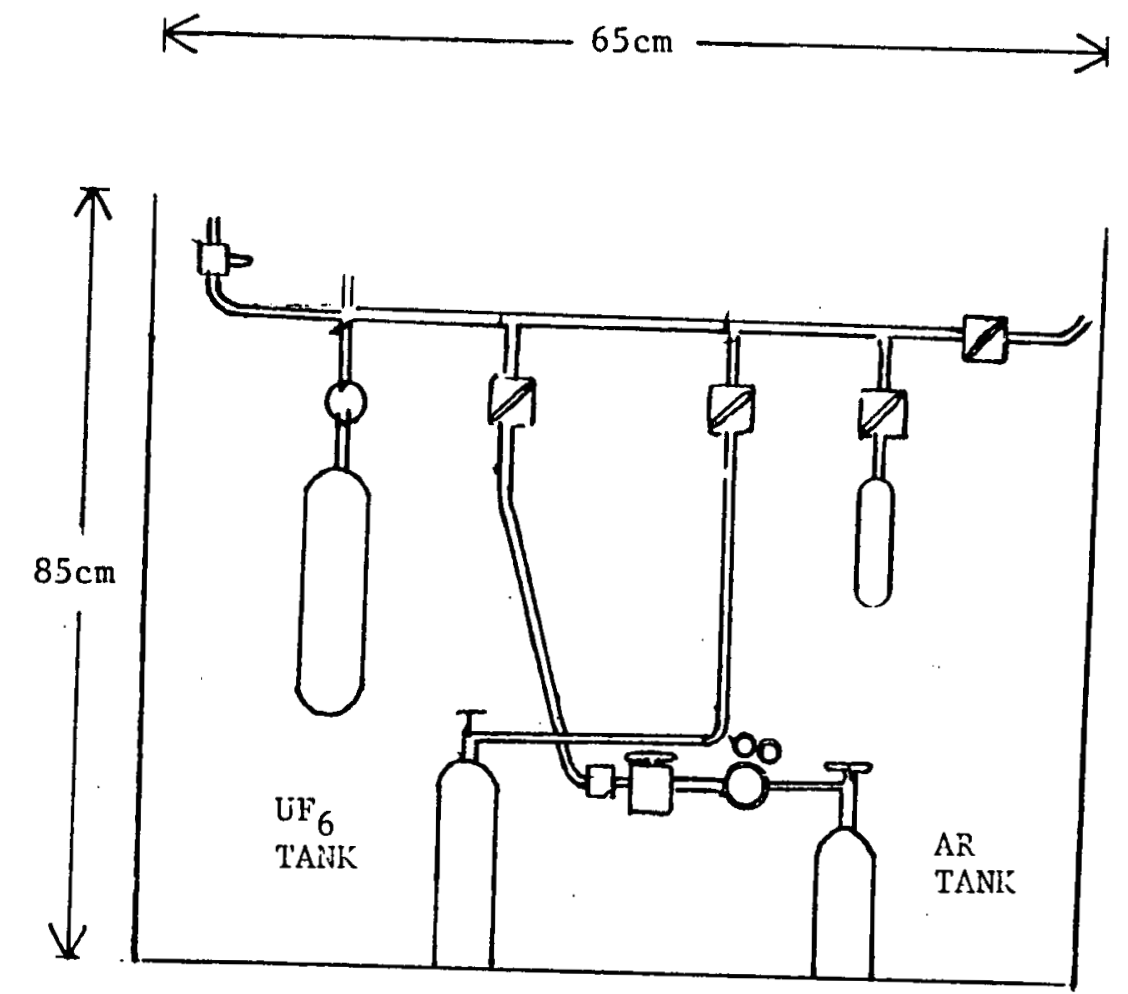

Figure 8. Side view of $\mathrm{UF}_{6}$ manifold. 
$\mathrm{UF}_{6}$ side and the rest of the manifold. Valve " $b$ " was connected to the auxilliary outlet. It was used to connect a gas tank containing fluorine. The fluorine was employed to passivate the UF 6 manifold, but the outlet was malnly designed as a multi-purpose outlet. Valve "c" was connected to the $\mathrm{UF}_{6}$ gas tank outlet. There was a valve on the tank itself, but the stainless-steel A.E. valve was added as an extra precaution. The $\mathrm{UF}_{6}$ flow could be regulated with either valve. Valve " $d$ " was used to regulate the flow of matrix gas. Valve "e" was a Hoke (Hoke Inc., New Jersey) 3700 series packed valve that was used to regulate the flow from the mixing tank (The mixing tank was made of aluminum and had a volume of $500 \mathrm{ml}$ ). The metering valve was a brass Nupro MG series with a stainless steel stem. No glass flow meter was used because $\mathrm{UF}_{6}$ will react with glass. A Robertshaw Acragage gauge was employed to monitor the UF 6 flow, and it was also used to determine or establish the matrix mixtures. Valve "f", also an A.E. valve, was used to isolate the $\mathrm{UF}_{6}$ manifold from atmosphere when the deposition line was not connected to the cryostat sample compartment.

In between the $\mathrm{UF}_{6}$ and water side of the manifold, vacuum gauge tubes from Penning and Hastings gauges were positioned on 1/4-1nch copper tubing in order to be able to read pressures when evacuating either or both sides of the manifold.

The water side of the manifold (see Figure 7) consisted of a slightly different arrangement than the $\mathrm{UF}_{6}$ side. It consisted of 1/4-inch copper tubing joined by brass Swagelok fittings and brass valves; the valves were Nupro (Nupro Co., Willoughby, Ohio) "H" 
serles bellows valves. Valve " $g$ " was used to isolate the $\mathrm{H}_{2} \mathrm{O}$ manifold from the rest. Valve "h" regulated the flow of water vapor Into the manifold, and a 25-ml glass bulb container was used to hold the water and was jolned to the manifold by a Cajon Ultra-Torr fitting. Valve " 1 " was used to regulate the matrix gas into the water side. The matrix gas tank was connected to both sides of the mantfold through the same line (see Figure 6), and a Nupro valve was used to isolate the matrix gas when the gas was not in use. Also, a brass Nupro valve was used to regulate the flow from the mixing tank. The mixing tank was identical to the one used on the $\mathrm{UF}_{6}$ side. A glass-flow meter was obtained from Lab Crest (catalogue no. 448-001); it had a maximum flow rate of $43.5 \mathrm{~cm}^{3} / \mathrm{min}$. of air at STP. The metering valve which just preceded the flow meter was identical to the one used on the UF6 side. Valve " $j$ " was used to regulate the $\mathrm{H}_{2} \mathrm{O}$-matrix mixture from the mixing tank. The final valve (k) on the water side was a brass Nupro valve which was used to isolate the water manifold when the deposition line was not in use.

Because the cryostat refrigeration unit had to be elevated and turned slightly when being placed in the spectrometer, a flexible stainless steel tube (see Figure 6) was used to connect the vacuum manifold to the cryostat. This tubing was a Cajon 321 stainless steel tube one-inch in diameter and 12 inches long.

The cryostat-refrigeration unit was a Cryodyne Helium Refrigerator Mode1 350 manufactured by Cryogenic Technology. It works on the principle of cooling as helium gas is expanded through 
a nozzle. . It could cool the sample window from room temperature to $16^{\circ} \mathrm{K}$ in approximately 90 minutes. The sample window holder (Figure 9) and refrigeration unit cover (Figure 10) were constructed in house. The cover was constructed of stalnless steel, and the CsI window holder was. made from oxygen free high conductivity (OFHC) copper. The stalnless-steel cover included four portholes. Two of the portholes held CsI windows which were in line with the CsI sample window and IR beam. Another porthole contained a glass observation window, and the final porthole was used as the deposition port. The deposition port was covered by a brass plate with two 1/8-inch stainless-steel tubes passing through. The tubes were aligned, so that the sample mixture could be deposited onto the sample window without interfering with the infrared beam path. Passage of the sample through the tubes could be regulated using stainless-steel Nupro "H" series valves.

In order to connect the deposition lines from the manifold to the deposition port, Cajon VCR vacuum couplings were used. The deposition lines were made from 1/4-inch copper tubing up to the brass Nupro valve on the water side and the stainless-steel A.E. valve on the $\mathrm{UF}_{6}$ side. Following these valves, 1/8-inch stainlesssteel tubing and stainless-steel fittings were used. Silver-plated nickel gaskets were employed in the VCR coupling.

In the in-line studies, the $\mathrm{UF}_{6}$ and $\mathrm{H}_{2} \mathrm{O}$ deposition lines were merged into one (see Figure 11); this was accomplished by using 1/8-inch stainless-steel tubing and stainless-steel fittings. Variable lengths of 1/8-inch stainless-steel tubing could be 

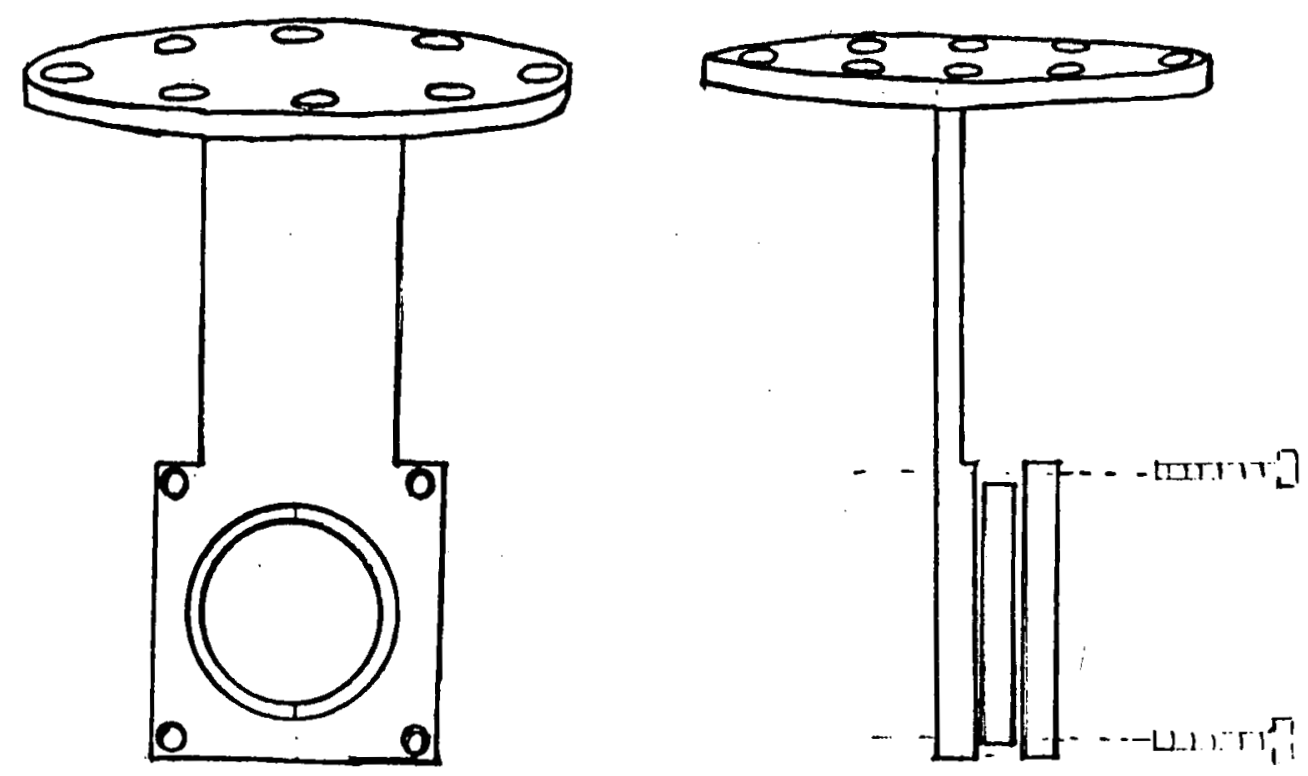

Figure 9. Front and side views of CsI sample window holder. 

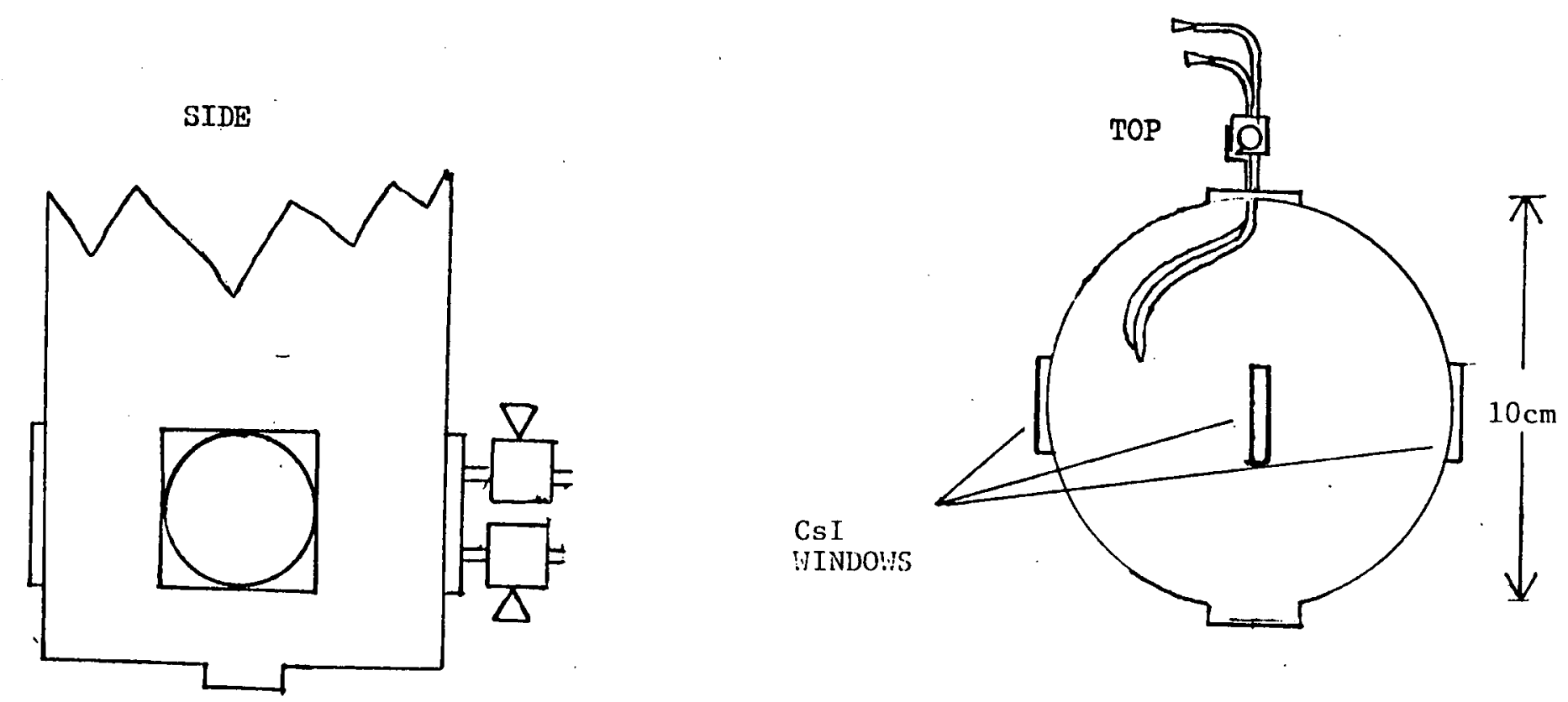

Figure 10. Side and top views of refrigeration unit cover and deposition port. 


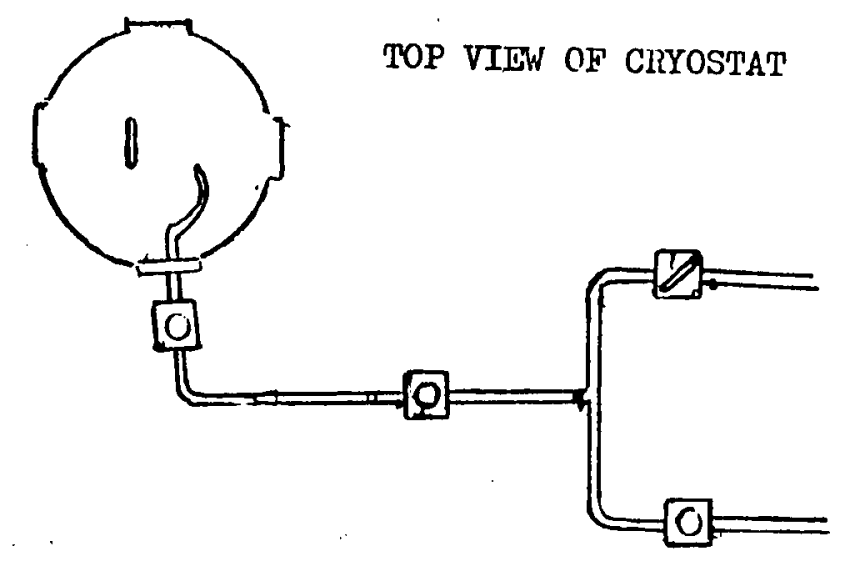

Figure 11. Arrangement used to merge and $\operatorname{mix} \mathrm{UF}_{6}$ and $\mathrm{H}_{2} \mathrm{O}$ sample streams. 
inserted into the fittings in order to alter the conditions of the experiments, namely the mixing time of the sample stream. Then the sample mixture could be fed into either deposition tube on the deposition port.

The post-deposition port mixing nozzle was constructed of aluminum (Figure 12). It was approximately $1 / 2-1$ nch in diameter and one inch long. It was constructed so that it would fit over the ends of the deposition tubes in the sample chamber and consequently merge the two sample streams into one prior to deposition. The exit outlet was only about 1/16-inch in diameter. When the postdeposition port mixing nozzle was secured in position, it rested only about $1 / 2$-inch away from the CsI window.

The deposition port constructed for the $U \mathrm{~F}_{4}$ vapor studies consisted of a brass plate (see Figure 13) similar to the original deposition port. However, instead of holding two stainless-steel tubes, this plate consisted of one 1/8-inch stainless-steel tube and a Cajon 3/8-inch Bore-Thru adapter. A 3/8-inch copper tube containing a sample furnace could be inserted through the adapter. The copper tube (see Figure 13) was approximately 18 inches long, and on one end a trough was hollowed out in order to hold the small platinum-resistance heating-type furnace. On the other end a Ceramaseal (Ceramaseal, N.Y., N.Y.) 800 series straight-wall insulator was connected to a rod that traveled through the tube and connected to the furnace. The rod was insulated from the tube by small viton (Kontes) o-rings placed around the rod. A variable rheostat was used to regulate the current through the platinum-wound furnace. 


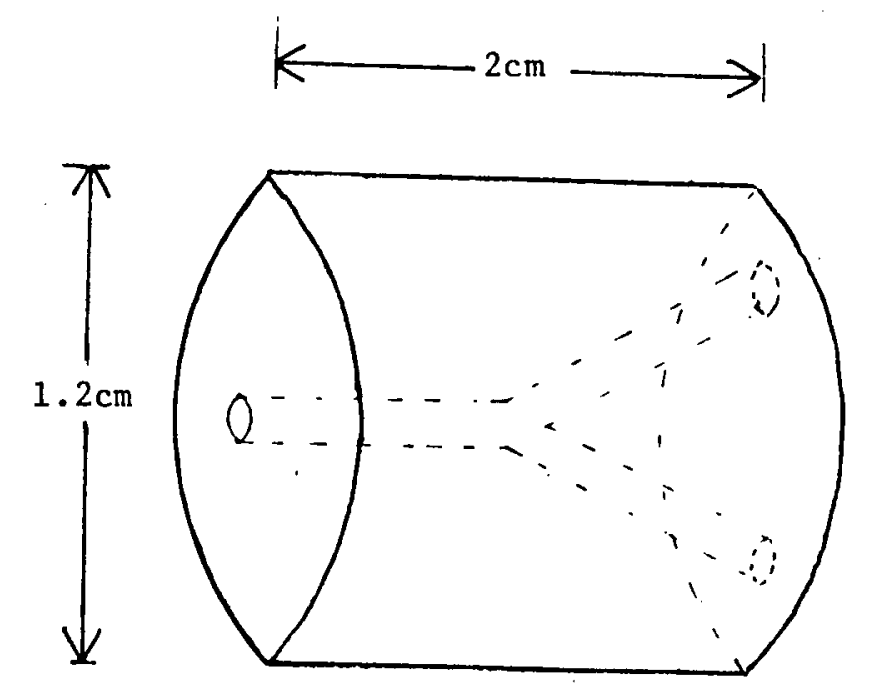

Figure 12. Post-deposition port mixing nozzle. 


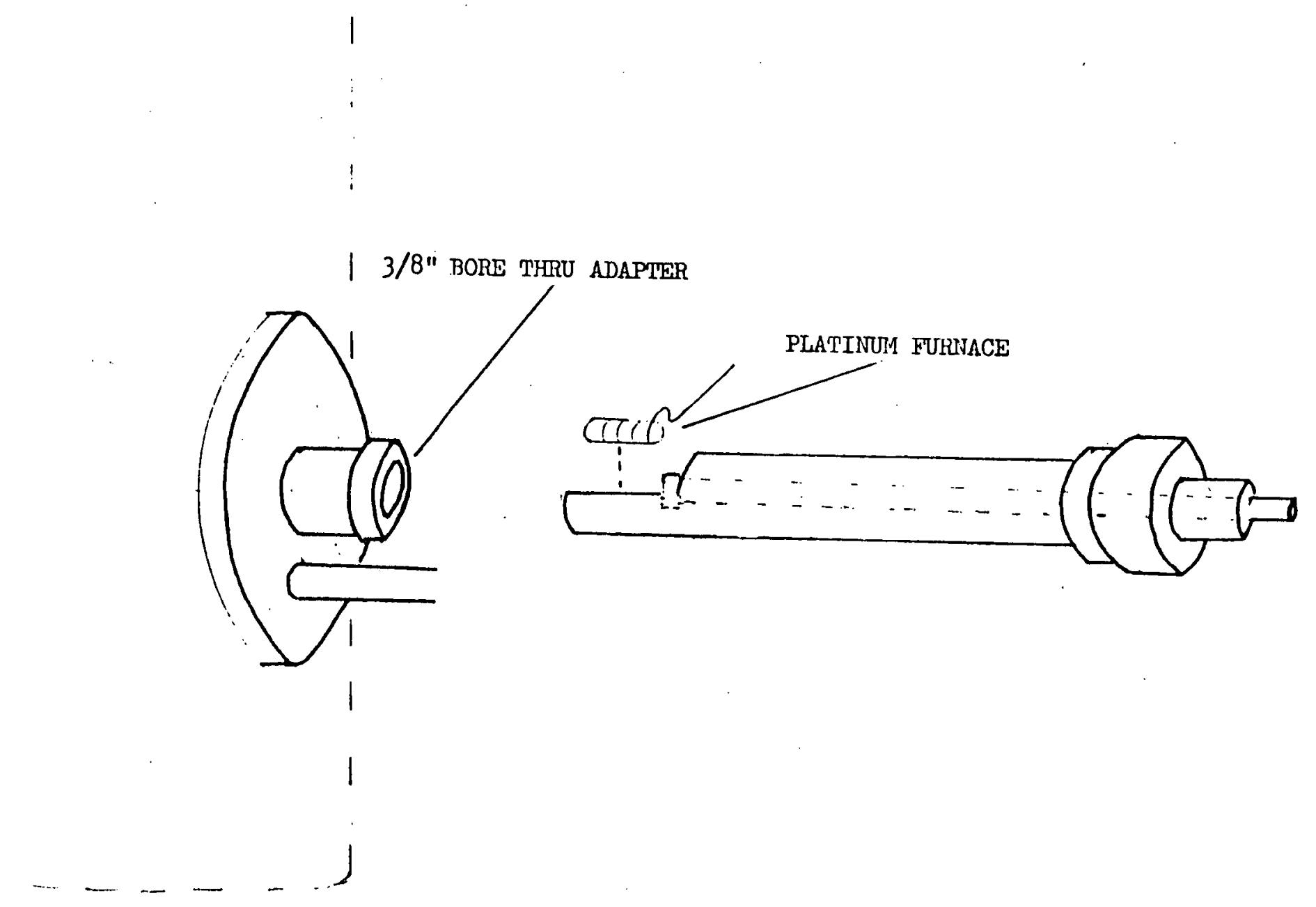

Figure 13. Deposition port and sample holder for $\mathrm{UOF}_{4}$ vapor studies. 


\section{EXPERIMENTAL PROCEDURE}

\section{A. Gas Phase Experiment}

An initial study was done with $\mathrm{UF}_{6}$ to test its propensity to react with air at room temperature. In this study a small cylinder was constructed from Teflon and fitted on the end with CsI windows and sealed with Viton 0-rings; a 1/4-inch stainless-steel tube fitted with an Autoclave Engineers valve was used to admit and remove the sample gas from the cylinder. First, the cylinder was evacuated to a very low pressure (ca. $10^{-6}$ torr) and then pressurized with a small amount of $\mathrm{UF}_{6}$; pressures from 10 to 50 torr were admitted to the cylinder. The sample compartment of the Digilab FTS-20C/V spectrometer was sealed with plastic, and the cylinder was placed in the sample compartment with the stainless-steel tube directed through a slit in the plastic. Nitrogen gas was pumped through the sample compartment in order to purge the compartment of atmospheric gases which absorb in the infrared. The flow of nitrogen gas was continued during the course of the experiment. First, the pure $\mathrm{UF}_{6}$ gas sample was scanned with approximately 500 scans at a resolution of $1 \mathrm{~cm}^{-1}$. After the Initial scan, a small amount of air was admitted to the cylinder. This was accomplished by opening the valve on the tube for approximately one second. This new mixture was then scanned at the same resolution as the inftial mixture. The air-admission procedure was repeated several times until the $\mathrm{UF}_{6}$ was depleted. Two variables that were controlled during the 
course of the experiment were the initial pressure of the $\mathrm{UF}_{6}$ gas and the length of time that the regulating valve was opened. As stated earlier, inftial $\mathrm{UF}_{6}$ pressures of 10 to 50 torr were used. The time lengths used were from one to five seconds; the time lengths could be kept constant through the course of the experiment or they could be changed.

\section{B. Matrix-Isolated Water in Argon}

The intial matrix-isolation experiments were performed with water and argon. In order to obtain the cleanest spectrum possible, it was necessary to degas the water. This was accomplished by freezing the water with liquid nitrogen and then pumping on the bulb while the water was frozen. After the presure gauge had stabilized, the bulb was shut-off and the water was allowed to heat up. When the water had melted, it was refrozen with liquid nitrogen and the process repeated. Doing this several times removed most of the gas from the water. A 1000:1 Ar: $\mathrm{H}_{2} \mathrm{O}$ mixture was made. This was done by using a carbon tetrachloride slush bath $\left(-23^{\circ} \mathrm{C}\right)$. Carbon tetrachloride was placed in a Dewar and then cooled down to its freezing point by pouring in small amounts of liquid nitrogen, then stirring with a wooden stick. It is important to stir the slush bath while adding the nitrogen in order to achieve the proper consistency. When the proper consistency was achieved the Dewar was placed around the water bulb. The Dewar remained there for about 30 minutes to ensure that a proper equilibrium was reached. Since the temperature of the carbon tetrachloride slush bath was about $-23^{\circ} \mathrm{C}$, 
this produced an-1ce vapor pressure of about 0.58 torr. The water side of the manifold was evacuated and then the water bulb was opened to the mixing tank for about five minutes to allow the pressure to stabilize. Then about 580 torr of argon (Matheson, 99.9995\%) was allowed into the mixing tank and this gave a 1000:1 ratio.

The temperature controller was calibrated and zeroed in the low temperature range (up to about $25^{\circ} \mathrm{K}$ ) by using an $\mathrm{H}_{2}$ vapor pressure gauge which was located on the cryostat. It was calibrated in the high range (room temperature) when the refrigeration unit was shut-off. It had to be recalibrated periodically.

The temperature read $15.5^{\circ} \mathrm{K}$ after the cooldown was completed. About 30 torr of the mixture was deposited on the CsI window in about forty minutes. In matrix-isolation experiments it is important to deposit the sample as "cleanly" as possible to ensure maxImum transmittance of the infrared beam. A fast deposit sometimes leads to a "cloudy" matrix. Therefore, as the sample was being deposited, it was examined intermittently with a flashlight. A glassy appearance usually indicated a good'deposition. Also, in these experiments, the amount of sample which was deposited during the course of the experiment was measured using a Robertshaw Acragage. If 1 t is stated that 30 torr was deposited, then the pressure dropped 30 torr in the manifold during the deposition. The sample was scanned at a resolution of $1 \mathrm{~cm}^{-1}$ with 500 scans.

After the initial spectrum was recorded, an annealing exper1ment was performed. The compressor was turned off momentarily and 
the sample was allowed to warm to approximately $25^{\circ} \mathrm{K}$ and then recooled. (The diffusion point of argon is approximately $35^{\circ} \mathrm{K}$ ). This sample was then rescanned under the same conditions. The procedure was then repeated except that the sample was warmed a 11 thle higher each time up to a temperature of about $35^{\circ} \mathrm{K}$.

This experiment was repeated several times with several variables. The matrix gas-water ratio was changed from 1000:1 to 100:1. The smaller ratios were made by using an 1ce-slush bath. The deposition time and the amount deposited were also varied. Longer deposition times usually led to cleaner looking sample deposits. Amounts were varied so that the percent transmittance varied from about $20 \%$ to about $30 \%$.

\section{Matrix-Isolated $\mathrm{UF}_{6}$ in Argon}

The $\mathrm{UF}_{6}$ side of the manifold was passivated with pure fluorine. This was accomplished by fllling a small stainless-steel vessel with fluorine gas. The mixing tank on the $U_{6}$ side was heated while being evacuated. The vessel was cooled with liquid nitrogen and connected to the utility outlet on the UF 6 'side. The heating was continued while the fluorine was opened to the manifold for approximately two days.

The inftial Ar:UF 6 ratio made was approximately 100:1. This was easily accomplished since the vapor pressure of $\mathrm{UF}_{6}$ at room temperature is about 110 torr, and the lead $\mathrm{UF}_{6}$ container had a regulating valve. The sample window was cooled to about $16^{\circ} \mathrm{K}$, and about 50 torr of the initial mixture was deposited in 30 minutes. The 
same annealing procedure that was performed for the $\mathrm{H}_{2} \mathrm{O}: \mathrm{Ar}$ exper1ments was also repeated here. The same varlables that were present with the water experiments were also present here.

\section{Matrix-Isolated $\mathrm{UF}_{6}$ and Water in Argon}

The same procedures that were followed in the independent deposition experiments on matrix-isolated $\mathrm{UF}_{6}$ and water were performed simultaneously in the next series of experiments. Initially, a $A r: \mathrm{UF}_{6}$ ratio of $500: 1$ and an $\mathrm{Ar}: \mathrm{H}_{2} \mathrm{O}$ of $100: 1$ were used. The mixtures were deposited simultaneously at approximately the same deposition rates and approximately the same amounts. The amount deposited was solely determined by trial and error. The criterion was a moderately strong transmittance between 20 and 50 percent. It must be noted that there are many more parameters associated with co-deposition experiments than with single-deposition experiments. Not only can one vary the deposition time, matrix ratio, and amount deposited of each sample mixture, but one can also vary their concentrations in relation to one another. For example, one can have the same rate of deposition, etc., for both mixtures or change one and leave the other the same or change both in the same or opposite directions. Another varlable that was not used initially but which was incorporated into the experiments later was the temperature of the window at the time of deposition. The initial deposit was usually scanned at a resolution of $1 \mathrm{~cm}^{-1}$ and 500 scans. After the sample was annealed and then recooled, subsequent spectral measurements involved only 200 scans. There were two different modes of 
temperature control used during the annealing studies. The first method was previousiy described; the cooling compressor would be momentarily shut-off while the temperature rose, and then would be restarted, and the spectrum would not be recorded until the sample had recooled to $16^{\circ} \mathrm{K}$. Another method of performing the annealing studies was to use a heating tape which was cemented to the refrigeration unit and controlled by the temperature controller. The controller could be dialed to the approximate temperature desired up to about $50^{\circ} \mathrm{K}$. The controller would then heat the sample window up to this temperature and hold it there indefinitely. Using this method the spectra were recorded while the temperature was elevated to about $35^{\circ} \mathrm{K}$.

\section{E. Matrix-Isolated Water in Nitrogen}

In the matrix-isolation studies involving $\mathrm{H}_{2} \mathrm{O}$ and nitrogen, the same matrix ratios, deposition times, and sample amounts as in the $\mathrm{H}_{2} \mathrm{O}$ and argon studies were used. However, there were some additional problems which the new matrix material presented. First, the liquid-nitrogen trap was much less efficient since the nitrogen carried much of the sample through the trap with it. Second, since the nitrogen matrix allowed guest molecules to diffuse easier than in the argon, the CsI window would contain debris that was left over after the experiment was completed, and, consequently, the CsI window would have to be cleaned and polished more often.

In the annealing experiments, the compressor would be shut-off or the temperature controller would be activated and the sample 
allowed to warm for a few moments. The sample was then recooled and a spectrum recorded. Also, if the controller was fed only small amounts of current, the spectra could actually be recorded while the sample was warming. At a resolution of $1 \mathrm{~cm}^{-1}$, the spectrum could be scanned and the data computed in approximately 15 minutes. This time would correspond to about a 15 degree rise in temperature. Since sample debris did remain on the window after the diffusion point of nitrogen was reached, it was felt that the annealing experiments could be continued past the diffusion temperature in order to see if any reaction would occur. Also, the compressor could be restarted for a few minutes during the course of the annealing experiment with the purpose of slowing down the warming process.

\section{F. Matrix-Isolated $\mathrm{UF}_{6}$ in Nitrogen}

The same general procedures were followed in the $\mathrm{UF}_{6}: \mathrm{N}_{2}$ studies that were used in the $\mathrm{H}_{2} \mathrm{O}: \mathrm{N}_{2}$ studies.

$$
\text { G. Matrix-Isolated } \mathrm{UF}_{6} \text { and Water in Nitrogen }
$$

In the co-deposition experiments involving nitrogen as the matrix material the same conditions used in the co-deposition studies with argon were utilized here. Also, the procedures used in the annealing experiments with $\mathrm{N}_{2}: \mathrm{H}_{2} \mathrm{O}$ and $\mathrm{N}_{2}: \mathrm{UF}_{6}$ were utilized here. 
H. Matrix-Isolated UF 6 and Water in Xenon

No independent $\mathrm{UF}_{6}-\mathrm{in-xenon}$ or $\mathrm{H}_{2} \mathrm{O}-\mathrm{In}$-xenon experiments were performed, only studies in which they were deposited simultaneously. The Xe:UF 6 and $\mathrm{Xe}: \mathrm{UF}_{6}$ matrix ratios were both approximately 100:1. The deposition times and amounts were approximately one hour and 50 torr respectively. The initial deposition temperature was at $16^{\circ} \mathrm{K}$ and the annealing studies were performed to about $200^{\circ} \mathrm{K}$.

\section{Pure $\mathrm{UF}_{6}$ and Water}

In this serles of studies pure $\mathrm{UF}_{6}$ and pure water were deposited on the CsI sample window simultaneously and mid-IR spectra recorded. In this series of experiments the mixing tanks were not used; on the water side of the manifold, the flask (water bulb) was opened to the manifold during the course of the experiment. This would only cause a slight deflection on the Robertshaw pressure gauge, but, since the vapor pressure of water is approximately 17 torr at about $298^{\circ} \mathrm{K}$ this figure was used. On the $\mathrm{UF}_{6}$ side, about 25 torr of $\mathrm{UF}_{6}$ gas would be leaked into the tubing and usually the deposition would end as soon as all the $\mathrm{UF}_{6}$ was gone.

Several problems arose with these studies that were not present with the matrix-isolation studies. First, since the water flask was opened to the line continuously it would be difficult to approximate how much water had actually been deposited. It was assumed therefore that if the deposition rates were kept approximately equal then the same amounts would be deposited on the sample window. But, this 
assumption entails another problem. That $18,$. how does one set the.. deposition rate equal to that of the UF 6 if the pressure on the water is continuously maintained? This problem was eliminated by the following procedure. First, the water flask was opened to the manifold, and the flow meter set to a previously-decided flow rate. As the sample was being deposited, the pressure in the cryostat would rise slightly and would give a deflection on the Penning gauge. When the pressure stabilized, the gauge reading would be recorded and the flow stopped on the water side. Next, the flow would be started on the $\mathrm{UF}_{6}$ side and adjusted so that the pressure on the Penning gauge matched the previously recorded reading. Then the flow on the water side would be restarted, and the flow meter would be set to its original rate. Therefore, the flow on both sides should be approximately equal.

Another problem which arose is that since no matrix gas was being used which could provide a protective layer between the CsI window and the reacting material, there would be some material left on the window after the experiment was finished. Therefore, the windows had to be repolished after each experiment.

After the sample was deposited at $16^{\circ} \mathrm{K}$, the compressor was turned off and the sample allowed to warm. Scans were started at about $100^{\circ} \mathrm{K}$; the temperatures were recorded at the beginning and ending of each spectrum. 
J. Merging Streams of $\mathrm{UF}_{6}$ and. Water.

In this series of experiments, dilute samples of argon and $\mathrm{UF}_{6}$ and argon and water were merged into one deposition tube prior to being deposited on the CsI window in the cryostat. Matrix ratios of 100:1 were used for both $\mathrm{UF}_{6}$ and $\mathrm{H}_{2} \mathrm{O}$. The apparatus used is shown in Figure 11 and described in Chapter II, Section B.

The methods for making the sample mixtures and deposition procedures were basically the same as in the previous experiments. However, some unexpected problems did occur. It was believed that when the streams merged at the " $t$ " intersection, that they would be cryo-pumped toward the sample window. This, in fact, was difficult to achieve. In order to achieve a clean deposition with as little spectral band broadening as possible, it was necessary to adjust the deposition rates on each side to be as nearly equal as possible. Also, the deposition rates had to be slow in order not to overrun the single line's capacity. If one mixture was being deposited at a slower rate than the other, then this tended to cause one of the Ifnes to back-up and reacted material would be absorbed on the inner surface of the deposition 1ine. This material would usually be freed by passing pure argon through the lines, baking the lines with heating tape, and then evacuating for several days.

In the initial experiments the length of tubing from the " $t$ " intersection to the deposition port was approximately $30 \mathrm{~cm}$. Later, sections of tubing that ranged from $100 \mathrm{~cm}$ in length to $300 \mathrm{~cm}$ in length were installed in order for the mixtures to have more time to react. Also, the tubing was heated while the deposition was 
occuring in order to prevent any material from. being adsorbed. on the inner surfaces of the deposition lines. After the sample was deposited at $16^{\circ} \mathrm{K}$, the CsI window would be warmed and spectra recorded in order to see if any additional reaction would take place.

\section{K. Low-Ratio Deposition Studies}

In the low-ratio deposition experiments sample ratios for $\mathrm{Ar}: \mathrm{UF}_{6}$ and $\mathrm{Ar}: \mathrm{H}_{2} \mathrm{O}$ ranged from $2: 1$ to $6: 1$. The apparatus was the same as in the original deposition experiments except that the deposition tubes inside the cryostat sample chamber were angled toward one another to insure that good mixing of the sample streams occurred in the small space between the tubes and the CsI window. The mixtures were made inside the manifold lines, and the mixing tanks were not used because only very small volumes were made; in fact, they were so small that the entire mixture was deposited on the window in a single experiment. Much of the work in this series of experiments was more art than science, because the apparatus was not designed to manipulate mixtures of such a small volume. The entire volume would be deposited in about 40 minutes and would usually give IR transmittance of about 30 to 40 percent. After the sample was deposited at $16^{\circ} \mathrm{K}$ it was then warmed to about $200^{\circ} \mathrm{K}$ and IR spectra recorded as in the previous experiments.

Actually, when this series of experiments was started, it was hoped that a reaction sequence could be produced by merely manipulating the sample ratios and deposition rates. (Only a single spectrum would be recorded after the deposition, and no annealing 
experiment was to be performed.) ... When it was discovered that this could not be accomplished with this apparatus, then the experiment was redesigned. Sample mixtures having ratios of $3: 1$ ( $\mathrm{Ar}: \mathrm{X}, \mathrm{X}=\mathrm{UF}_{6}$, $\mathrm{H}_{2} \mathrm{O}$ ) were deposited on the window at $16^{\circ} \mathrm{K}$, and then a series of annealing experiments were performed similar to previous annealing series. In this case, the only purpose of the matrix gas was to act as a solvent. The initial spectrum recorded at $16^{\circ} \mathrm{K}$ was one of a matrix-isolated sample, but since argon's diffusion point occurs at approximately $35^{\circ} \mathrm{K}$ and the boiling point occurs at $87.3^{\circ} \mathrm{K}$, the subsequent spectra recorded during the annealing experiments were not matrix-isolated or possibly only partially matrix-isolated.

\section{Low-Ratio Mixing Nozzle Experiments}

This series of experiments was mainly designed in order to verify the low-ratio deposition studies. In these experiments lowratio samples were used as in the case of the previous low-ratio experiments. The only alteration to the apparatus was a small aluminum nozzle (Figure 12) that essentially insured that the two streams were well mixed before they reached the CsI window. The same conditions were used in the annealing studies as in previous annealing experiments. The only problem encountered in this experiment was that the radiation shield that almost totally surrounded the CsI window was removed to allow room for the nozzle. 
M. UOF $_{4}$ Volatility Study

Uranium oxide tetrafluoride was prepared from $\mathrm{UF}_{6}$ in the laboratory by means of the procedure described by Paine and associates. 10 An IR spectrum of the sample in a $\mathrm{KBr}$ disc correlated very well with the IR spectrum by Paine and associates.10

UOF $_{4}$ was transferred from an air-tight container to a glass sample cell in a dry bag flushed with dry nitrogen. The glass sample cell had been heated in an oven at $350^{\circ} \mathrm{C}$ for several hours to remove water. The cell was transferred to a platinum-wire resistance-heating furnace located on the tip of the conductor rod. The furnace was then inserted through the deposition port on the cryostat head by means of a Cajon Bore-Thru adapter. While transfering the furnace from the dry bag to the cryostat, it was covered with a small plastic bag in order to keep the sample dry. Also, the cryostat had been continuously flushed with dry argon in order to exclude moisture. After the furnace had been located in the deposition port, the cryostat was evacuated and then the CsI window was cooled. The furnace was then heated and the sample vaporized onto the CsI window. An FT-IR spectrum was then recorded at $4 \mathrm{~cm}^{-1}$ resolution. 
CHAPTER IV

RESULTS AND DISCUSSION

\section{A. Results}

\section{Preliminary UF6 Vapor Experiments}

The following discussion pertains to the experiments on the interaction of $\mathrm{UF}_{6}$ vapor with ambient (moist) air, and the experimental prodcedures are those discussed in Chapter III, Section A.

Figure 14 represents a spectrum of a sample of $\mathrm{UF}_{6}$ gas at 10-torr pressure placed in a sample cell. There are many sharp peaks occupying the $3960-3540 \mathrm{~cm}^{-1}$ region, two weak peaks between 3000 and $2800 \mathrm{~cm}^{-1}$, two weak peaks surounding $2360 \mathrm{~cm}^{-1}$, many sharp peaks occupying the 1920-1400 $\mathrm{cm}^{-1}$ region, a broad band with several spikes out the top in the $1400-1240 \mathrm{~cm}^{-1}$ region, a weak peak at $1160 \mathrm{~cm}^{-1}$, a weak peak at $1030 \mathrm{~cm}^{-1}$, a weak peak at $821 \mathrm{~cm}^{-1}$, a weak peak at $667 \mathrm{~cm}^{-1}$, a strong peak at $619 \mathrm{~cm}^{-1}$, and a broad band from 600 to $480 \mathrm{~cm}^{-1}$. The sharp peaks in the 3960-3540 and 1920-1400 $\mathrm{cm}^{-1}$ region are typical $\mathrm{H}_{2} \mathrm{O}$ gas-phase absorptions quite comparable to numerous other data in the literature.65 No obvious assignment can be made of the two weak peaks between 3010 and 2800 $\mathrm{cm}^{-1}$. The two weak peaks surrounding $2360 \mathrm{~cm}^{-1}$ and the peak at 667 $\mathrm{cm}^{-1}$ fit the pattern for $\mathrm{CO}_{2}$ absorptions which are well-known.65 The weak peak at $1160 \mathrm{~cm}^{-1}$ is due to $\mathrm{UF}_{6}{ }^{1-3}$, and the one at 1030 $\mathrm{cm}^{-1}$ is characteristic of absorption by $\mathrm{SiF}_{4}, 66$ both the wavenumber and shape fitting previous observations. The peak at $821 \mathrm{~cm}^{-1}$ could 


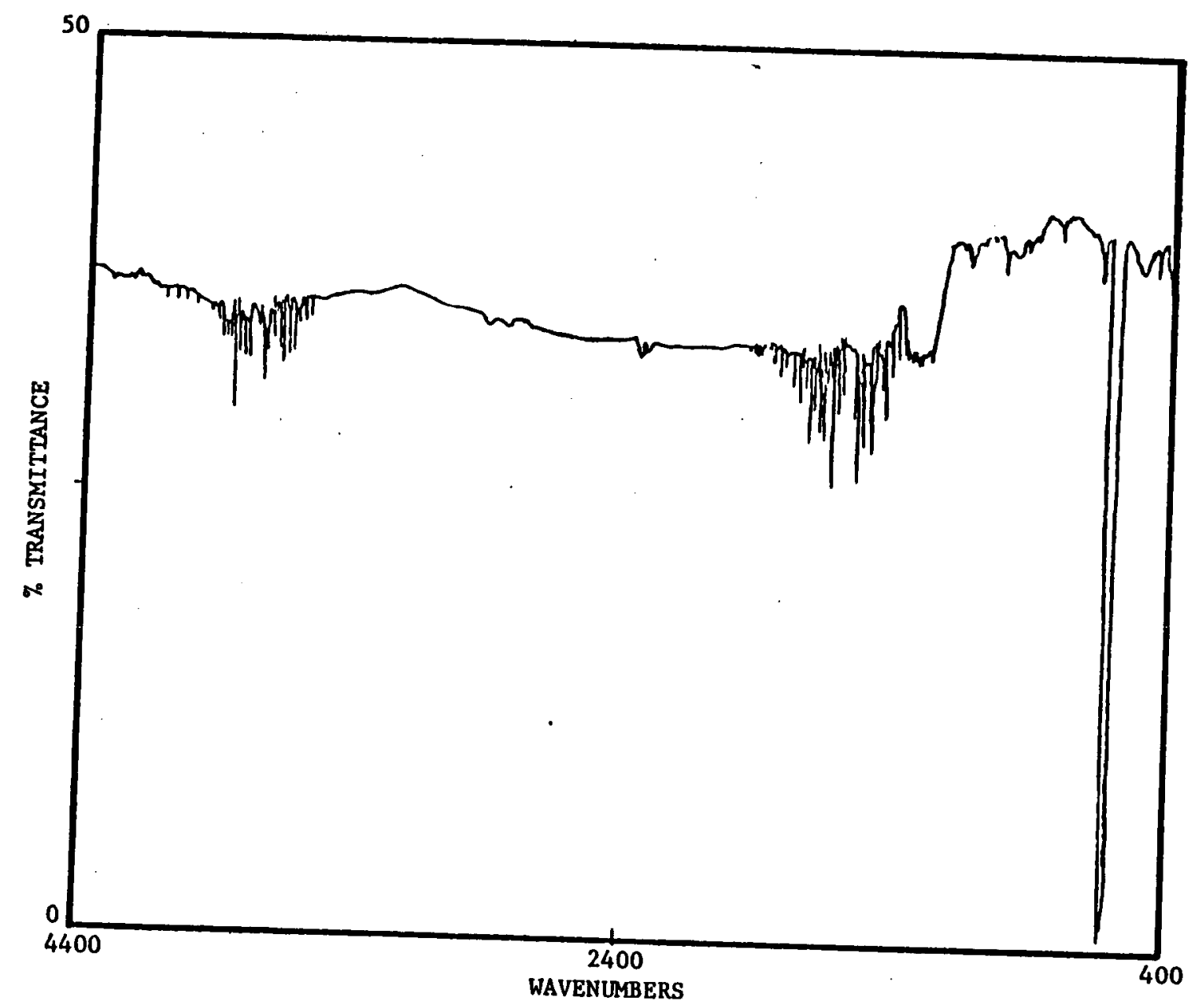

Figure 14. FT-IR spectrum of initial sample of $\mathrm{UF}_{6}$ gas at 10-torr placed in sample cell. 
not be characterized, but the strong absorption at $619 . \mathrm{cm}^{-1}$ is believed to be due to $\mathrm{UF}_{6}$. Previous investigations on $\mathrm{UF}_{6}$ have assigned absorptions to the $U-F$ stretch in $U_{6}$ to values very close to $620 \mathrm{~cm}^{-1}$ ( \pm no more than $7 \mathrm{~cm}^{-1}$ ) $\cdot 1-3$ Because no appreciable reaction of $\mathrm{UF}_{6}$ with water has yet taken place one could probably conclude that the $\mathrm{H}_{2} \mathrm{O}$ absorptions are due only to water that is in the spectrometer beam but not in the sample. After several admissions of relatively small amounts of air into the cell (see Figure 15), there seem to be only slight changes in the subsequent spectra; the water and $\mathrm{CO}_{2}$ absorptions are apparently disappearing somewhat. Also, small sharp bands are apparently appearing between 4000 and $4200 \mathrm{~cm}^{-1}$. Bands having these shapes and appearing in this region have been previously assigned to $\mathrm{HF}$ absorptions by other investigators. 67 In addition, bands in the $1200-800 \mathrm{~cm}^{-1}$ region have apparently been growing. Figure 16 represents the sample after several large pulses of air were introduced into the cell. The bands between 4200 and $3600 \mathrm{~cm}^{-1}$, and the bands in the 1200-800 $\mathrm{cm}^{-1}$ region have continued to grow. Also, the $\mathrm{UF}_{6}$ peak has decreased somewhat in intensity. The final spectrum (Figure 17) shows that the $\mathrm{UF}_{6}$ band $\left(619 \mathrm{~cm}^{-1}\right)$ has decreased markedly and the bands between 1200 and $800 \mathrm{~cm}^{-1}$ have increased, the greatest increase occuring at 1030 and $980 \mathrm{~cm}^{-1}$ where two sharp bands are located. Again, the band at $1030 \mathrm{~cm}^{-1}$ is typical of an $\mathrm{SiF}_{4}$ absorption that has been assigned previously to an Si-F stretch by 


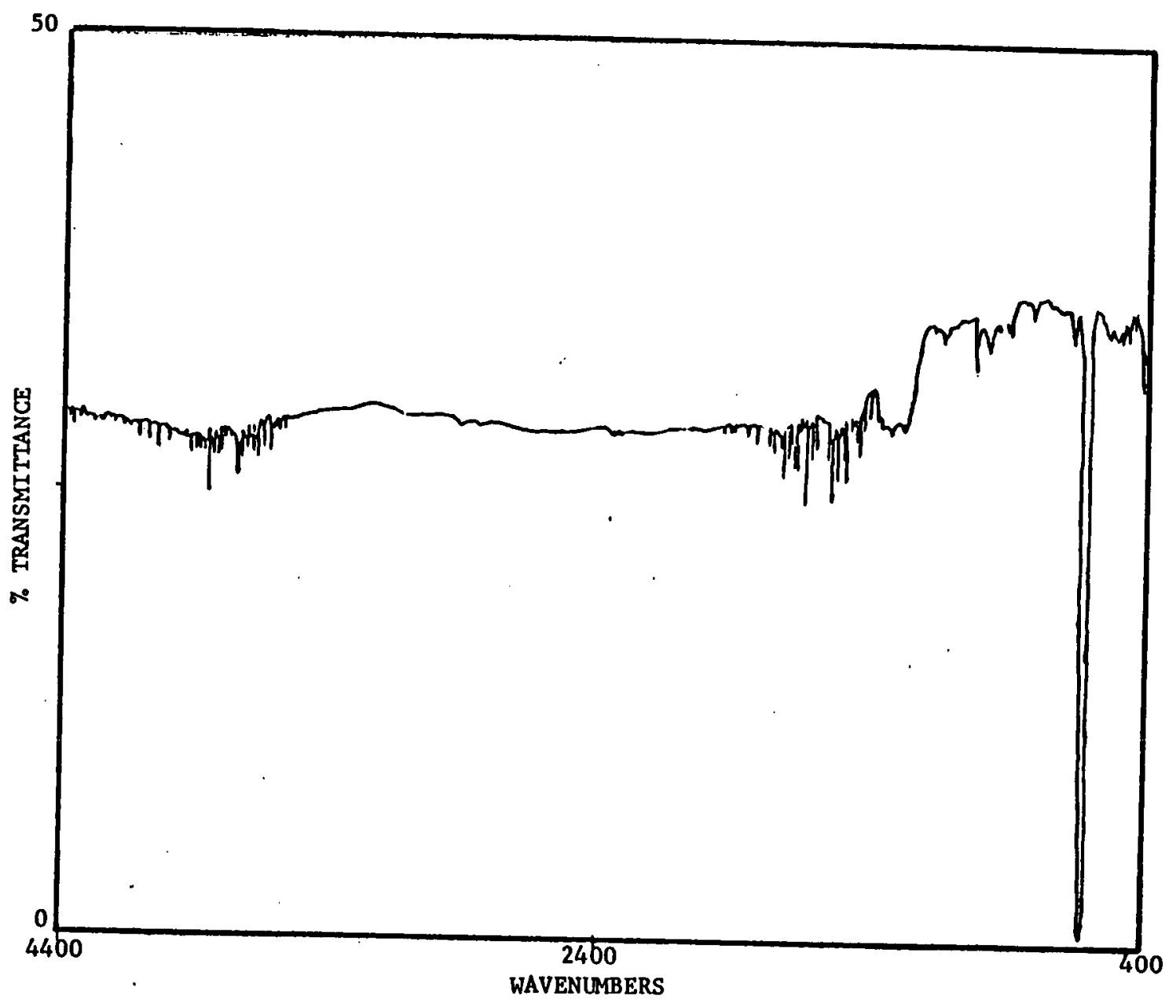

Figure 15. FT-IR spectrum after several admissions of small amounts of air. 


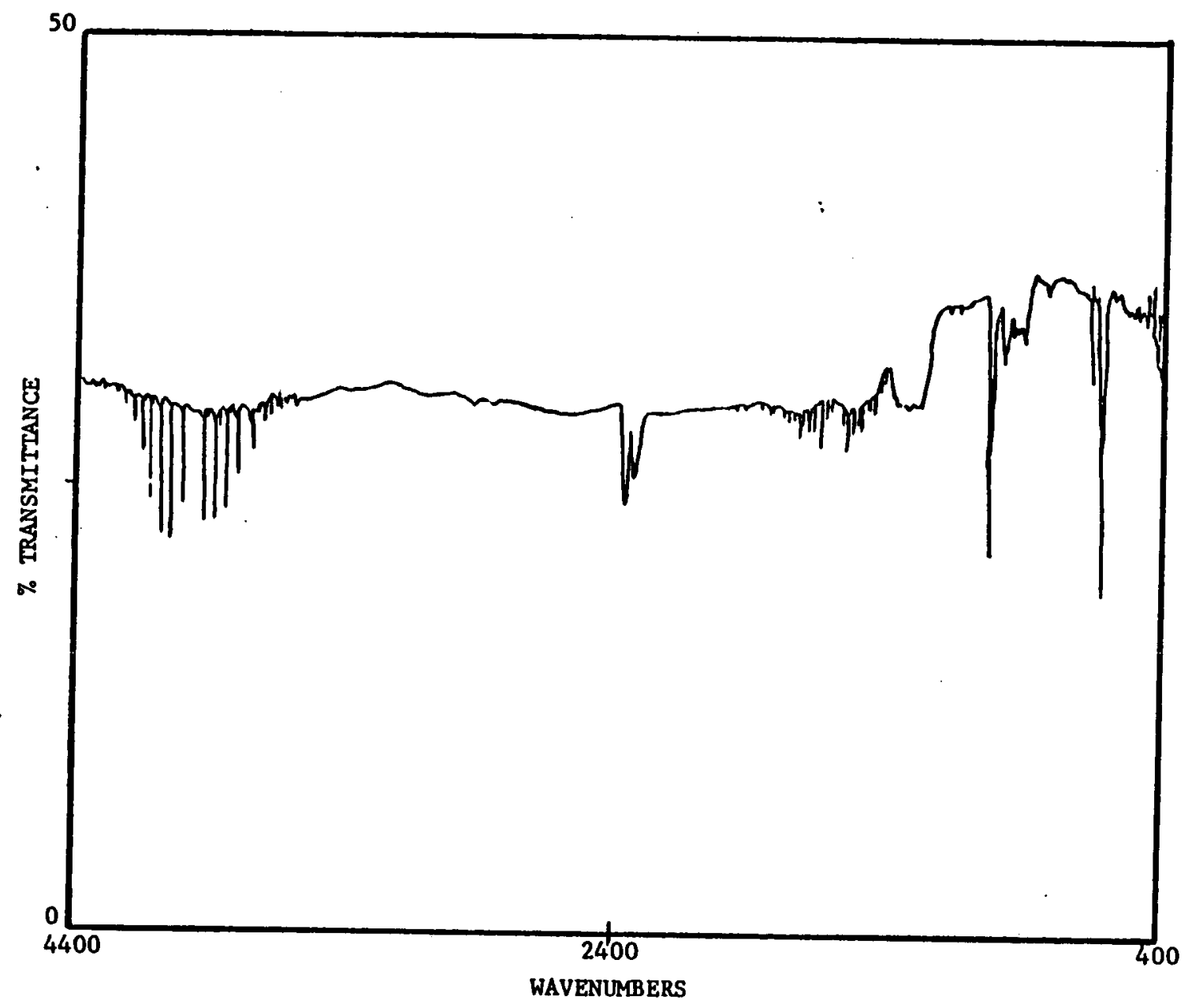

Figure 16. FT-IR spectrum after several large pulseis of air. 


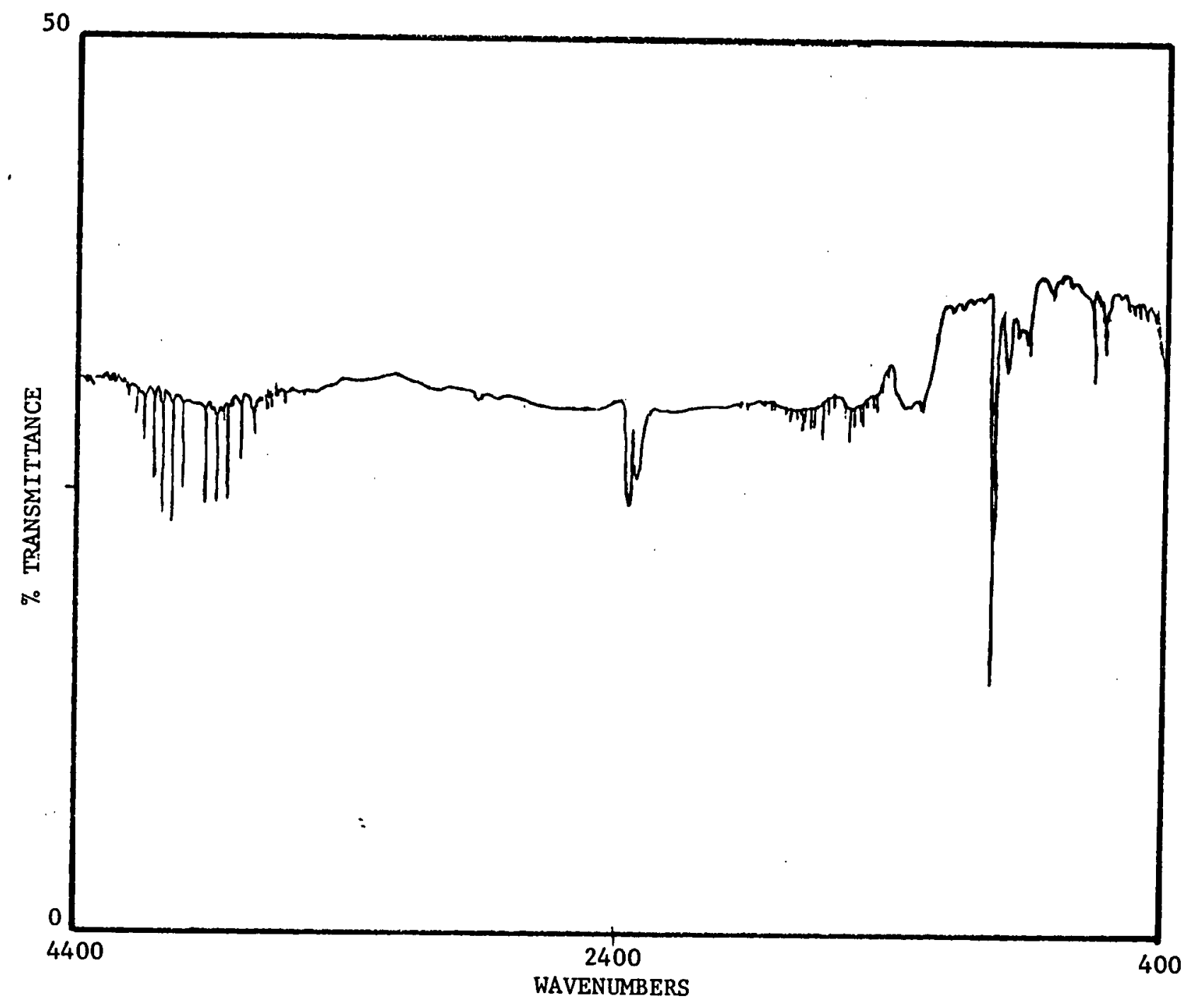

Figure 17. FT-IR spectrum after cell was pressurized to atmosphere. 
numerous investigators.65 Silicon tetrafluoride, which might be present, was probably generated from $\mathrm{UF}_{6}$ or $\mathrm{HF}$ reacting with the silicon-based stopcock grease that was used to lubricate the Viton 0-rings which sealed the CsI windows. The emerging band at $980 \mathrm{~cm}^{-1}$ could possibly be assigned to a $\mathrm{UO}_{2}$ stretch arising from $\mathrm{UO}_{2} \mathrm{~F}_{2}$, which is a product of the reaction of $\mathrm{UF}_{6}$ with water. Several investigators have previously assigned bands in that region (990-930 $\mathrm{cm}^{-1}$ ) to a $\mathrm{UO}_{2}$ stretch.20 Clearly, these experiments were somewhat primitive, but they were instructive. It must be noted here that a very important parameter which could not be controlled with the apparatus employed was the water content of the air. The main purpose of this primitive experiment was to try to obtain some Idea of the reactivity of UF 6 with moist air. It also must be noted that no detectable reaction of $\mathrm{UF}_{6}$ occurred until larger amounts of air were admitted into the cell.

The next series of spectra represent a 50-torr sample of $\mathrm{UF}_{6}$ interacting with moist air. The first spectrum (Figure 18) was one taken before any air had been admitted, and it shows some HF to be present (4200-3600 $\left.\mathrm{cm}^{-1}\right) .67$ Two new sharp bands appear at 1292 and $1158 \mathrm{~cm}^{-1}$ which are probably due to $\mathrm{UF}_{6} \cdot 1$ other weaker bands appear at $1030,938,855,821 \mathrm{~cm}^{-1}$ and finally two strong bands appear at 667 and $620 \mathrm{~cm}^{-1}$. As in the case of the 10-torr experiment, only relatively small amounts of air were introduced into the sample cell initially. However, unlike the 10-torr sample, the 50-torr sample (Figure 19) seemed to react when only small amounts of air were admitted. The HF bands continued to grow. 


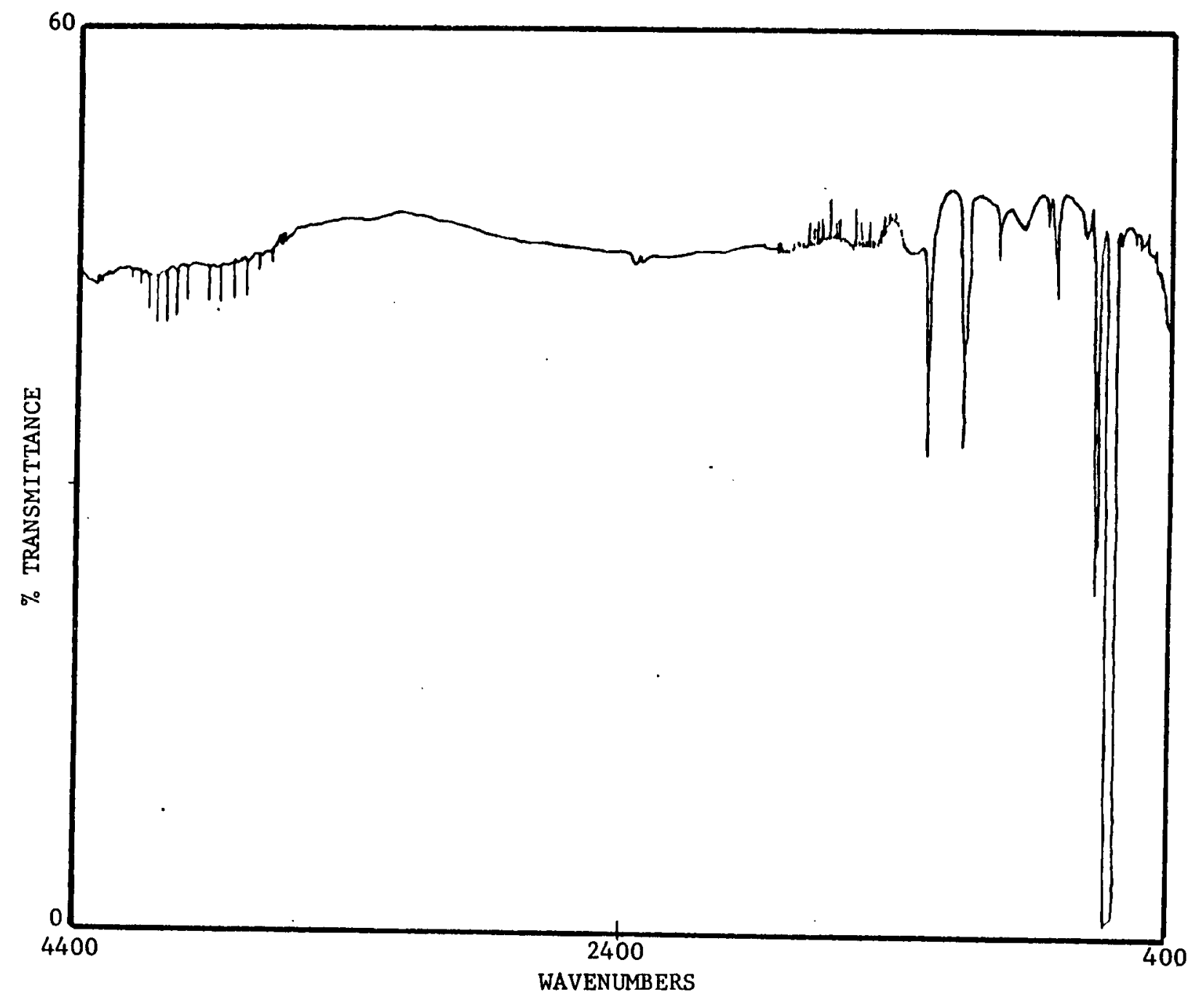

Figure 18. FT-IR spectrum of initial sample of $\mathrm{UF}_{6}$ gas at 50-torr placed in sample cell. 


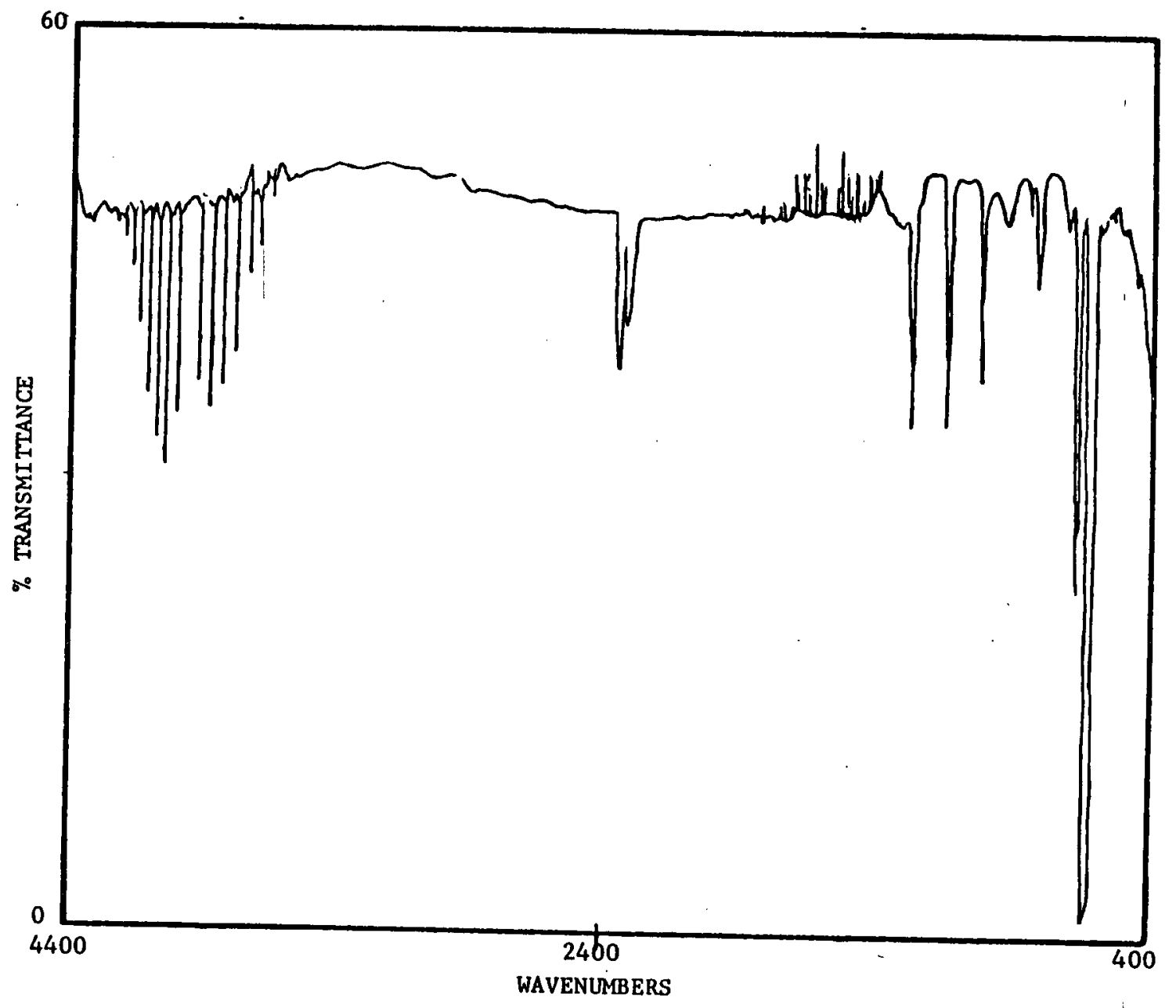

Figure 19. FT-IR spectrum of sample after only small pulses of air were admitted. 
Later, (Figure 20) larger amounts of air were admitted into the cell, and after the sample had been exposed to air for a relatively long time. ( $1 \mathrm{~min}$ ), the spectrum showed that the HF bands had continued to grow as had the $1030 \mathrm{~cm}^{-1}$ band. The bands at 1292 and $1158 \mathrm{~cm}^{-1}$ are due to $\mathrm{UF}_{6} \cdot 1$ The bands at 855 , and $821 \mathrm{~cm}^{-1}$ are not immediately identifiable. Again the $1030 \mathrm{~cm}^{-1}$ band can be assigned to $\mathrm{SiF}_{4}$. The new band at $935 \mathrm{~cm}^{-1}$ is in a region in which investigators have assigned simflar bands to a UO 2 stretch. The 667 and $620 \mathrm{~cm}^{-1}$ bands can again be assigned to $\mathrm{CO}_{2}$ and $\mathrm{UF}_{6}$, respectively. The easiest observation that can be made when comparing these two samples is that the 50-torr sample reacted more readily when only small amounts of air were introduced into the sample cell. Also, although there were many similarities in the two different sets of spectra, there were several dissimilarities. New bands appeared at $1292,1158,855$, and $821 \mathrm{~cm}^{-1}$ in the higher-concentration sample, but they do not seem to change much in their intensities as the experiment progresses. Also, another interesting aspect of the experiment is the $980 \mathrm{~cm}^{-1}$ band in the 10-torr experiment, and the absence of a band at this wavenumber in the 50-torr experiment, but the emergence of a new band at $935 \mathrm{~cm}^{-1}$. According to past investigations, 10,20 either or both bands could possibly be assigned to a $\mathrm{UO}_{2}$ stretch, but no obvious reason for the change in wavenumber can be given. It can be further noted that - the bands are approximately the same shape (breadth and general contour). 


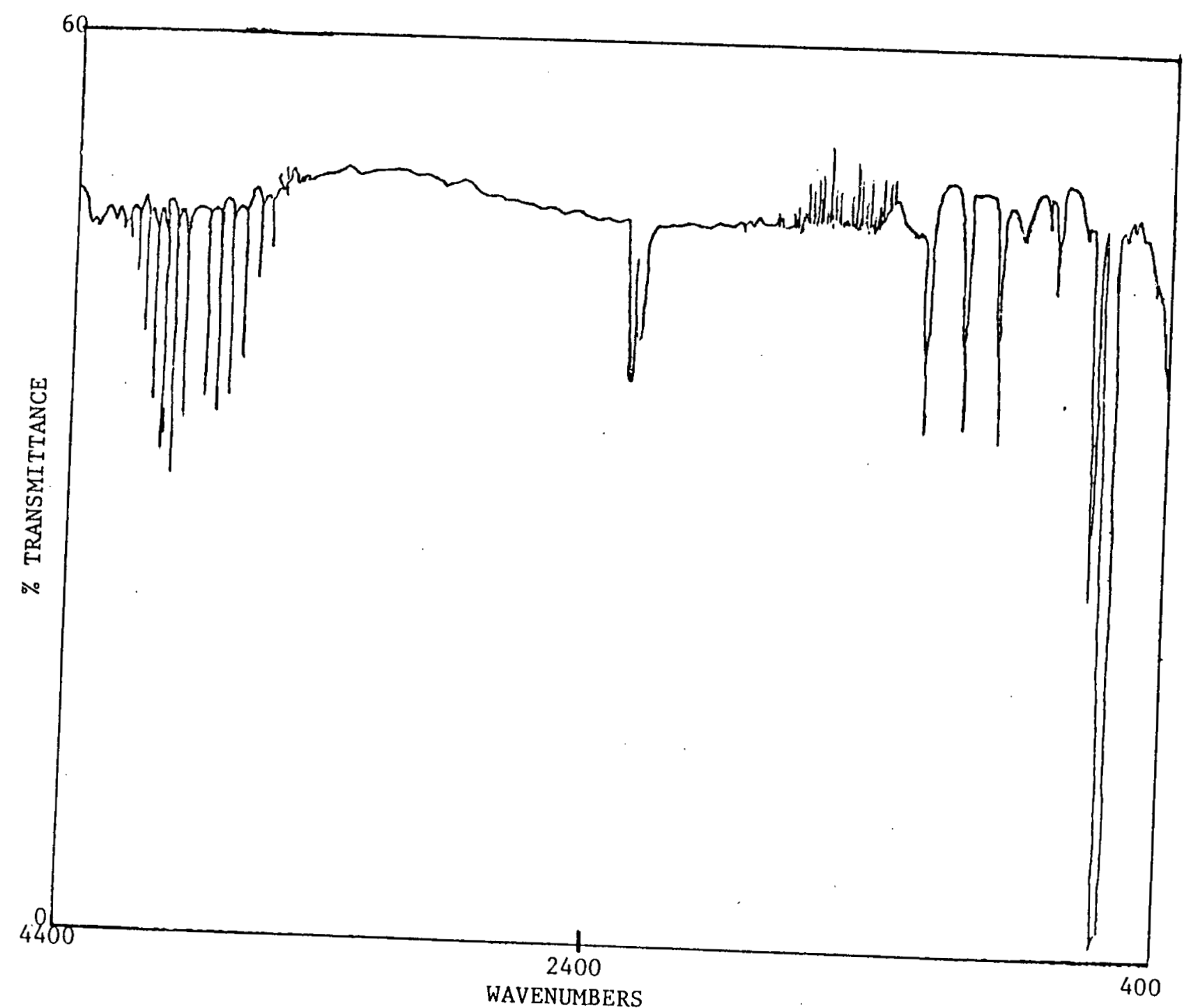

Figure 20. FT-IR spectrum of sample which was recorded after the sample cell was exposed to air
for approximately one minute. 
2. $\underline{\mathrm{UF}}_{6}-\mathrm{Ar}$ Matrix-Isolation Studies

A series of $\mathrm{UF}_{6}: \mathrm{Ar}$ matrix-isolation studies were performed under conditions discussed in Chapter III, Section C. The first spectrum (Figure 21) is of a $\mathrm{UF}_{6}$-argon sample which had an Ar-to$\mathrm{UF}_{6}\left(\mathrm{Ar}: \mathrm{UF}_{6}\right)$ ratio of $500: 1$. A close inspection of the spectrum reveals that there were some impurities in the sample. The weak bands between 4000 and $3600 \mathrm{~cm}^{-1}$ are characteristic of $\mathrm{H}_{2} \mathrm{O}$ absorptions. Also, there are traces of $\mathrm{CO}_{2}$ impurity (peak at 2340 $\mathrm{cm}^{-1}$ ). There are also a few weak bands in the $1200-800 \mathrm{~cm}^{-1}$ region. And, finally there is the strong $U_{6}$ band which occurs at $619 \mathrm{~cm}^{-1}$. On closer inspection of an enlargement of the UF 6 band at 619 $\mathrm{cm}^{-1}$ (Figure 22), one can see that it actually is composed of a strong band at $619 \mathrm{~cm}^{-1}$ surrounded by six weaker satellite bands. They occur at $627,623,621,617.5,614$, and $609 \mathrm{~cm}^{-1}$. Also, an enlargement of the spectral region between 1000 and $700 \mathrm{~cm}^{-1} \mathrm{can}$ be seen in Figure 23. This permits one to see the unidentified bands which occur at 935,901 and $820 \mathrm{~cm}^{-1}$.

Next, annealing experiments were performed. The temperature of the sample was elevated to about $35^{\circ} \mathrm{K}$, but no significant changes in the spectrum were noticed. If diffusion had occurred, one would expect that the $\mathrm{UF}_{6}$ molecules might form aggregates and the band at $619 \mathrm{~cm}^{-1}$ might broaden, and its fine structure become obscured.

Figure 24 represents a spectrum of a $A r: U_{6}$ sample having a ratio of $100: 1$. If one compares this spectrum to Figure 21 , one can see that the intensities of the impurities have increased somewhat. There is also an additional band at $1030 \mathrm{~cm}^{-1}$ which is due to $\mathrm{SiF}_{4}$. 


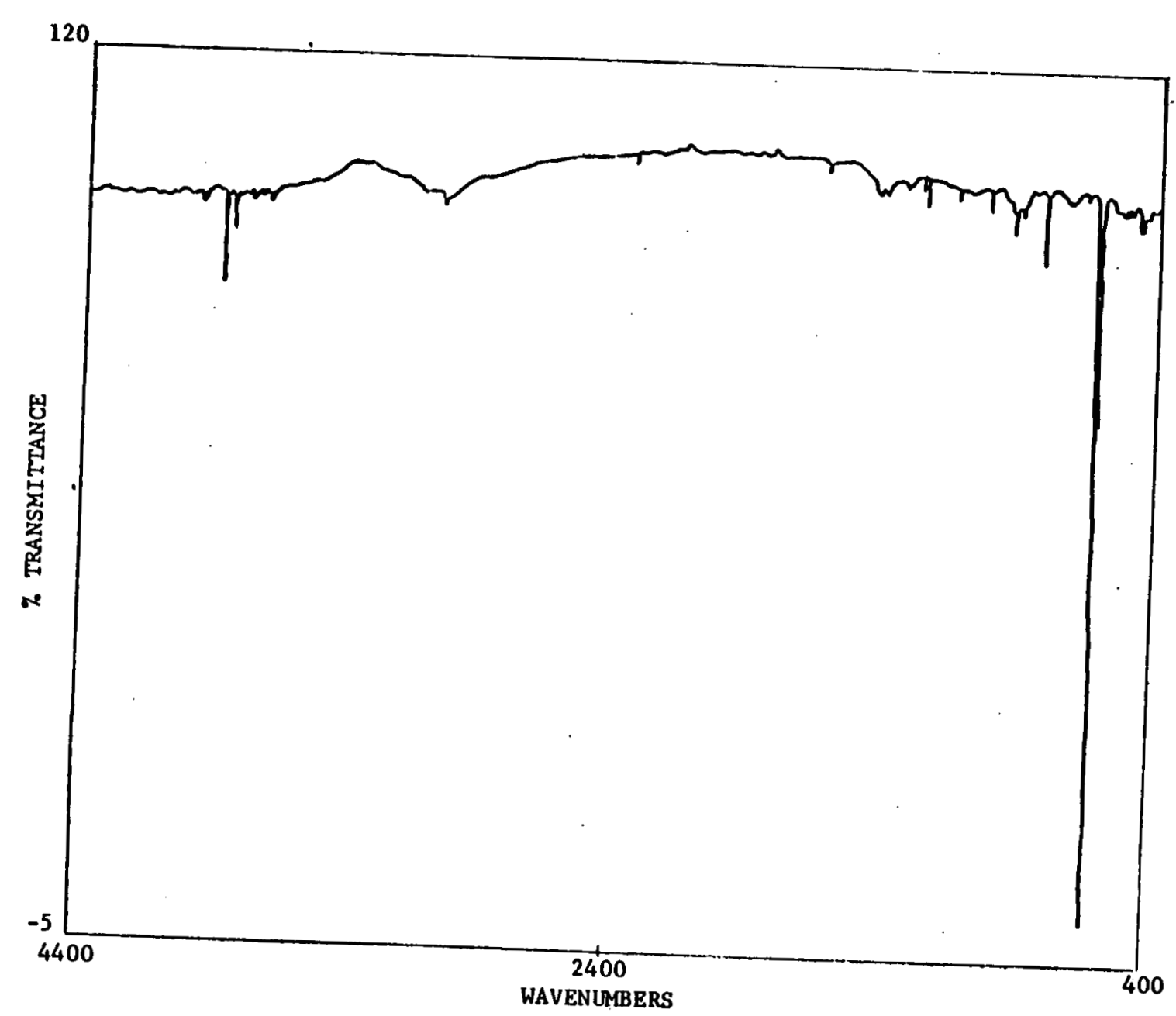

Figure 21. Matrix-isolated FT-IR spectrum of Ar:UF 6 at 500:1. 


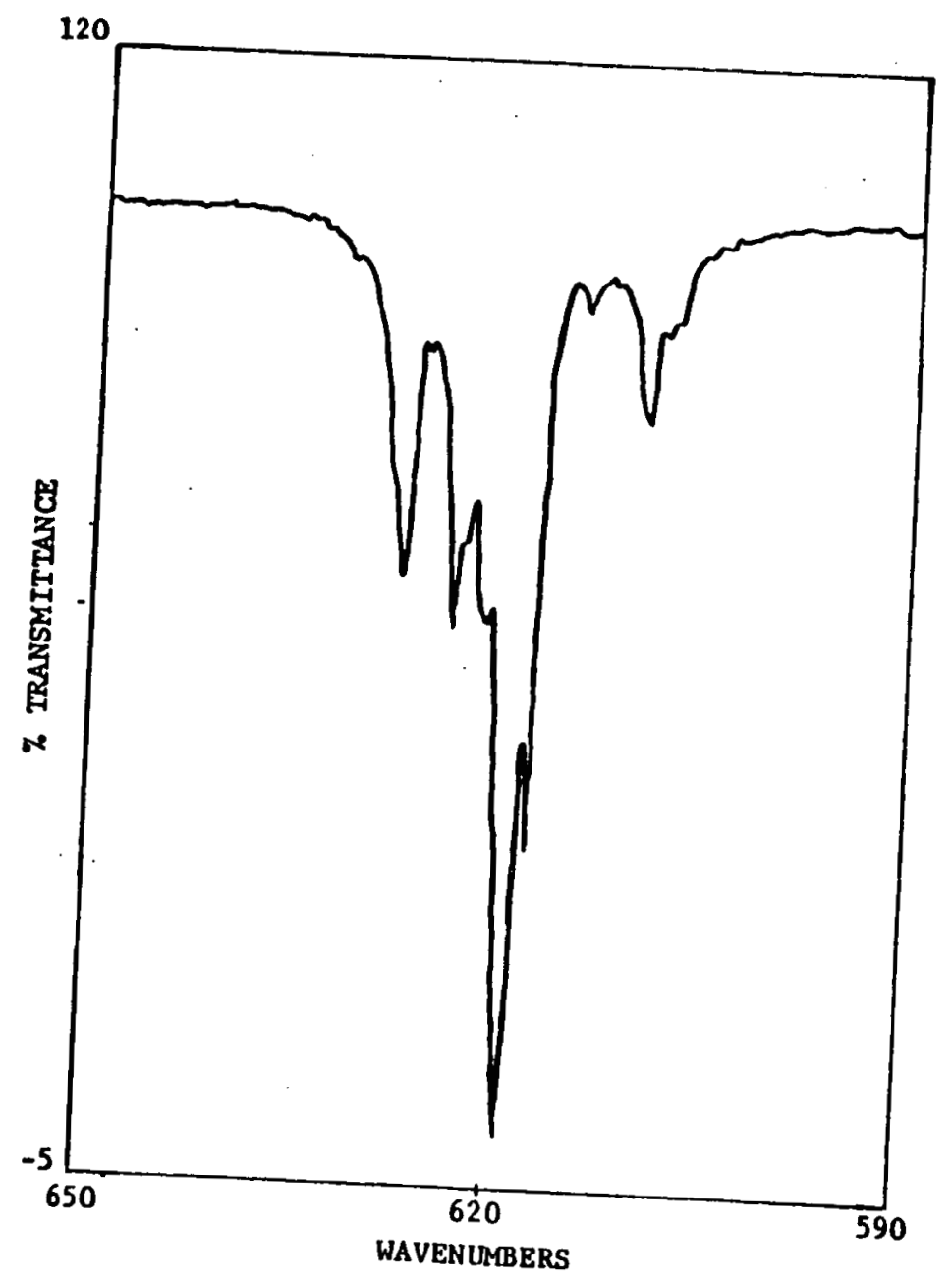

Figure 22. Enlargement of $\mathrm{UF}_{G}$ absorption. 


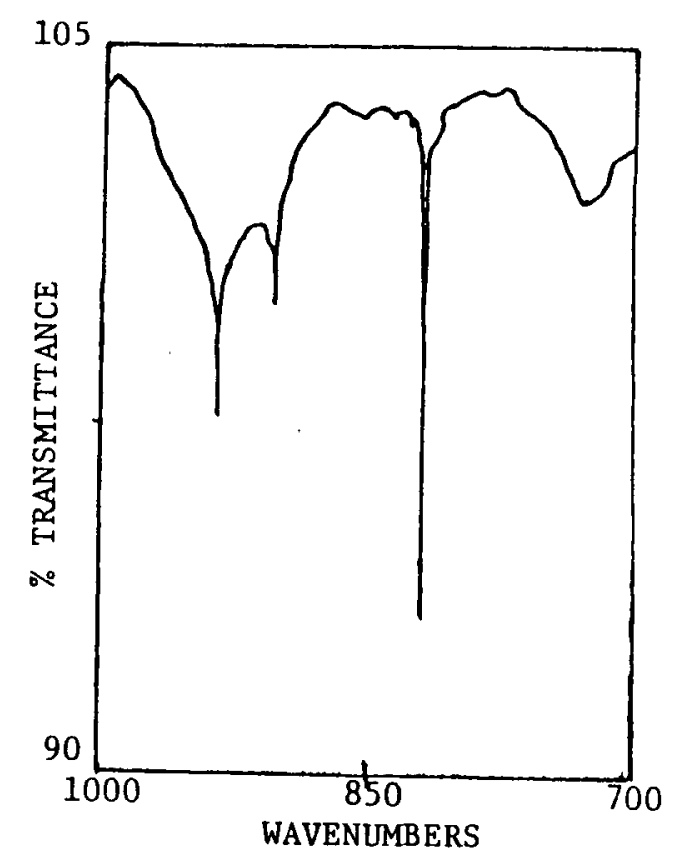

Figure 23. Enlargement of impurity region. 


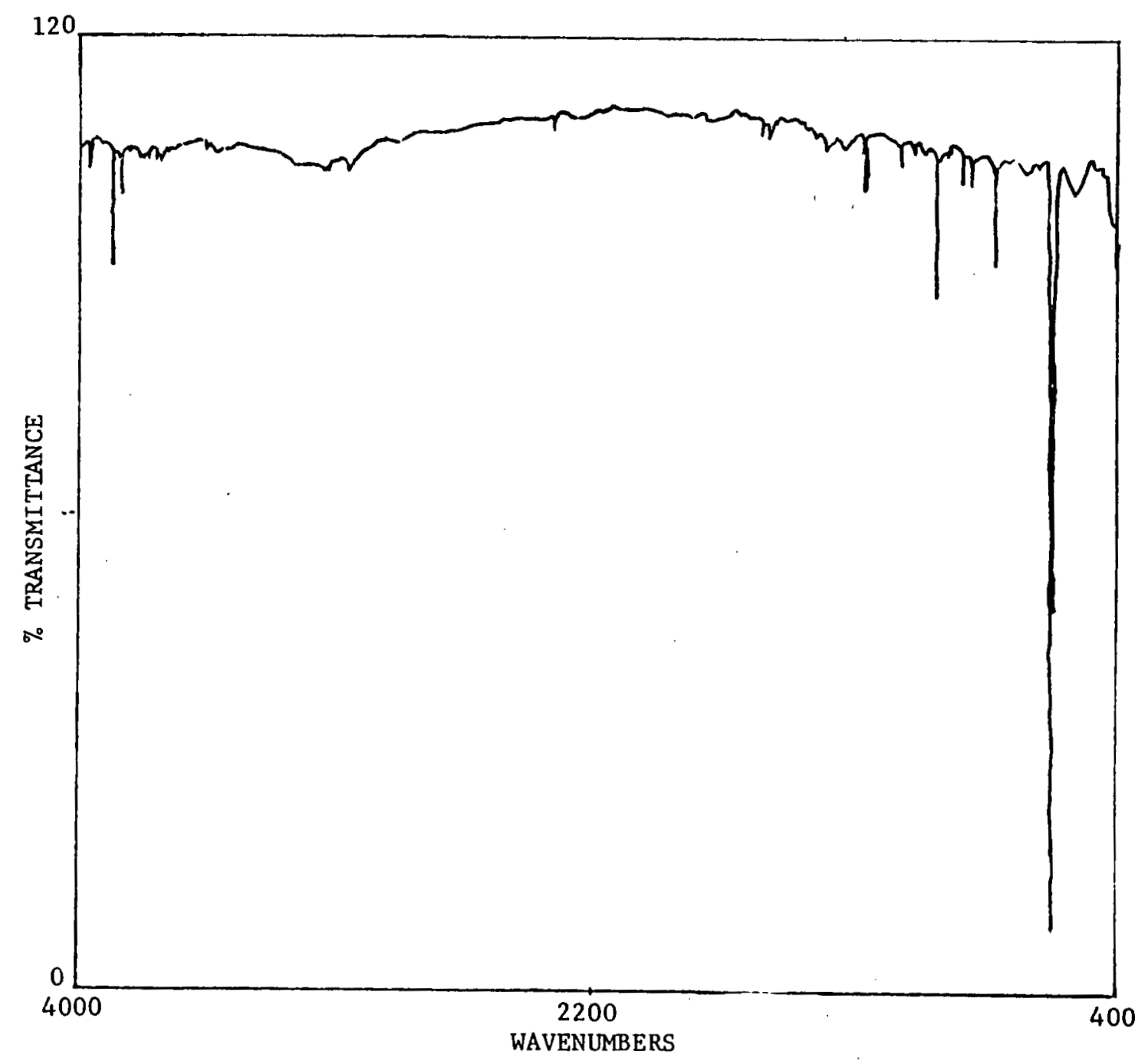

Figure 24. Matrix-isolated FT-IR spectrum of Ar:UF 6 at 100:1. 
Close inspection of the $\mathrm{UF}_{6}$ band at $619 \mathrm{~cm}^{-1}$ (Figure 25a) indicates that the satellite bands surrounding the $619 \mathrm{~cm}^{-1}$ peak have increased in intensity.

The spectrum of the same sample after having been annealed to $25^{\circ} \mathrm{K}$ is shown in Figure 25b. One can see that the spectrum is basically the same. There are no intensity changes or peak shifts.

One or two conclusions can be drawn from these experimental results. A characteristic of annealed samples in which clustering occurs is that the spectral bands tend to broaden and lose their sharpness. Keeping this fact in mind, one can probably conclude that no significant aggregation of matrix-isolated $\mathrm{UF}_{6}$ molecules occurs in argon in these temperature ranges. Another interesting feature of this experiment is the resemblance of the unidentified impurity bands in the 1000 to $600 \mathrm{~cm}^{-1}$ region to the unidentified bands in the same region in the $\mathrm{UF}_{6}$-vapor interaction with moist air experiment. It will be instructive to keep this phenomenon in mind as one reads further.

3. Matrix-Isolated $\underline{\mathrm{H}}_{2} \mathrm{O}$ in Argon

Next, a series of $\mathrm{H}_{2} \mathrm{O}: \mathrm{Ar}$ matrix-isolation experiments were performed under experimental conditions discussed in Chapter III, Section B. Figure 26 is a spectrum of a 1000:1 matrix-isolated sample of $\mathrm{Ar}: \mathrm{H}_{2} \mathrm{O}$. In previous investigations of matrix-isolated IR experiments with water, most authors examined two spectral regions.68,69 They are the 4000 to $3000 \mathrm{~cm}^{-1}$ and the 1650 to 1550 

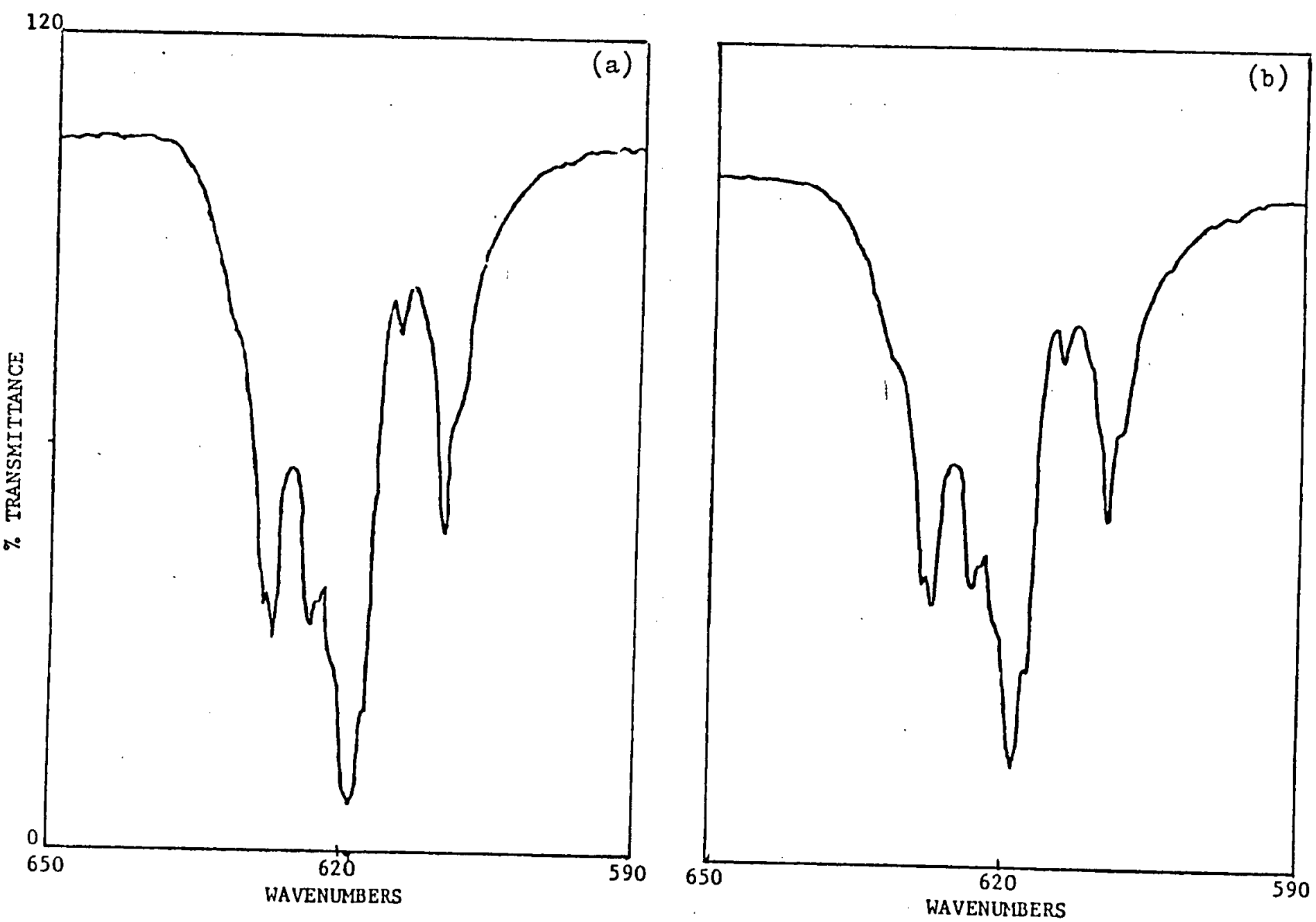

Figure 25. (a) Enlargement of $\mathrm{UF}_{6}$ absorption before annealing. (b) Enlargement of UF 6 absorption after annealing to $25^{6} \mathrm{~K}$. 


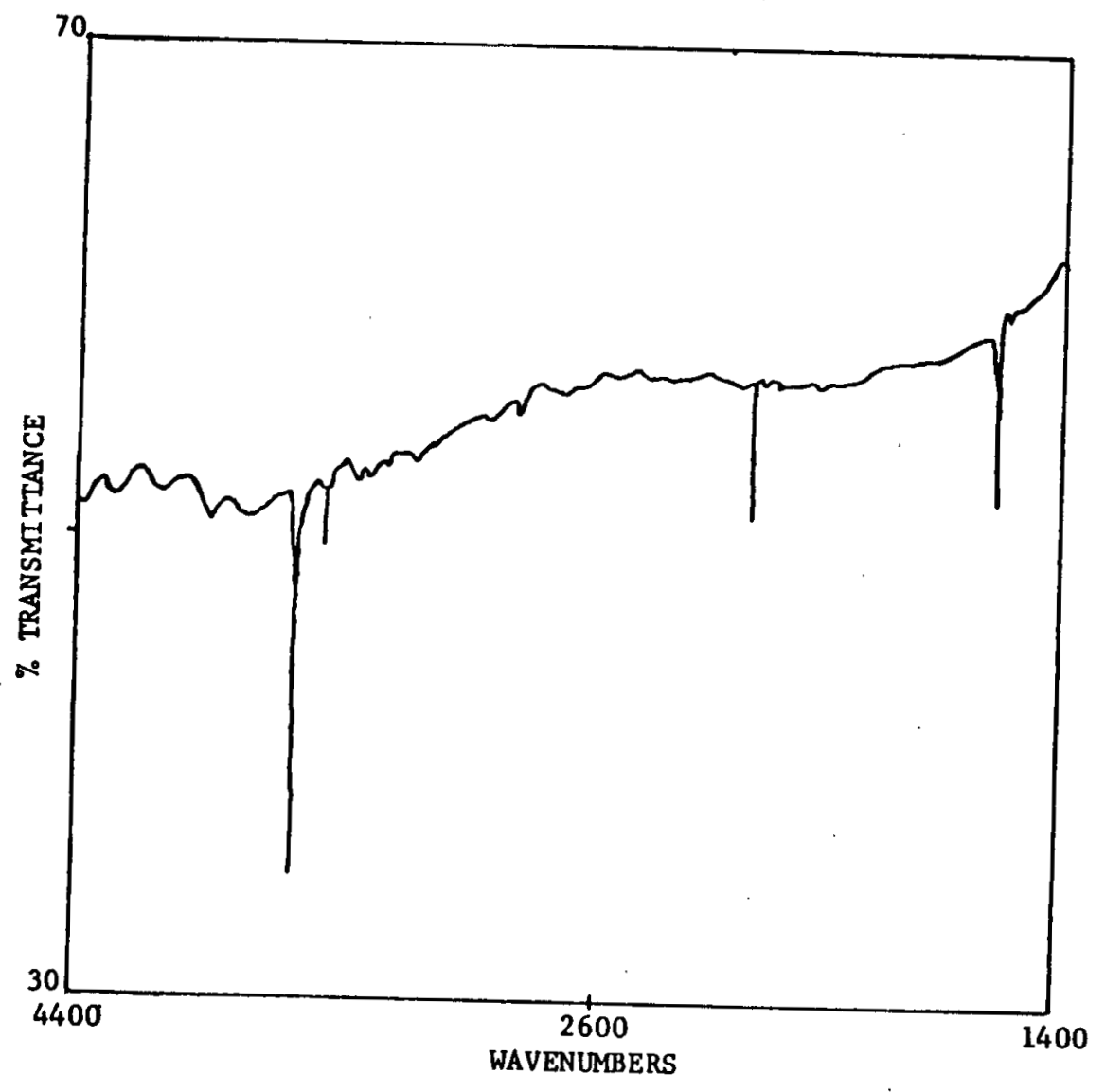

Figure 26. Matrix-isolated FT-IR spectrum of a $1000: 1$ sample of $\mathrm{Ar}: \mathrm{H}_{2} \mathrm{O}$. 
$\mathrm{cm}^{-1}$ regions. Figure 27 is an enlargement of the $3800-3500$ wavenumber region. Two bands appear at 3730 and $3640 \mathrm{~cm}^{-1}$. These bands have previously been assigned by other investigators to Ar matrix1solated water molecules.68,69 The next spectrum (Figure 28) is an enlargement of the 1650 to $1550 \mathrm{~cm}^{-1}$ spectral region. Absorptions appear at $1611.5,1601,1599$, and $1593 \mathrm{~cm}^{-1}$. These bands are also similar to absorptions that have been previously assigned to $\mathrm{Ar}$ matrix-isolated water molecules.68,69 The next two spectra (Figures $29 \& 30$ ) show enlargements of the same two regions after the samples had been annealed to $32^{\circ} \mathrm{K}$. The peak intensities and shapes are roughly the same as in the initial spectra.

The next spectrum (Figure 31) is of a 100:1 matrix-isolated sample of $\mathrm{Ar}: \mathrm{H}_{2} \mathrm{O}$. The two aforementioned spectral regions will be analyzed. In the $3800-3400 \mathrm{~cm}^{-1}$ region (Figure 32) several new bands have emerged that were not present with the 1000:1 sample. Peaks at $3776,3755,3730,3724,3705,3699,3696,3633,3573,3565$, $3563,3556,3552,3523$, and $3516 \mathrm{~cm}^{-1}$ are present and the most intense seem to be the 3705,3699 , and $3696 \mathrm{~cm}^{-1}$ peaks. In the other region (Figure 33) several new peaks have also emerged. They are at $1623,1613.5,1611.5,1608.5,1604,1603,1601,1597,1593$ and $1572 \mathrm{~cm}^{-1}$. These bands closely resemble and are in relatively good agreement with matrix-isolated IR spectra of $\mathrm{H}_{2} \mathrm{O}$ that were obtained by Brentwood and associates.69 They assigned most of the bands in the $3800-3400 \mathrm{~cm}^{-1}$ region to dimers and trimers and the bands in the $1650-1580 \mathrm{~cm}^{-1}$ region were assigned mostly to monomers and dimers. Figures 34 and 35 reveal that after annealing to $30^{\circ} \mathrm{K}$ 
C

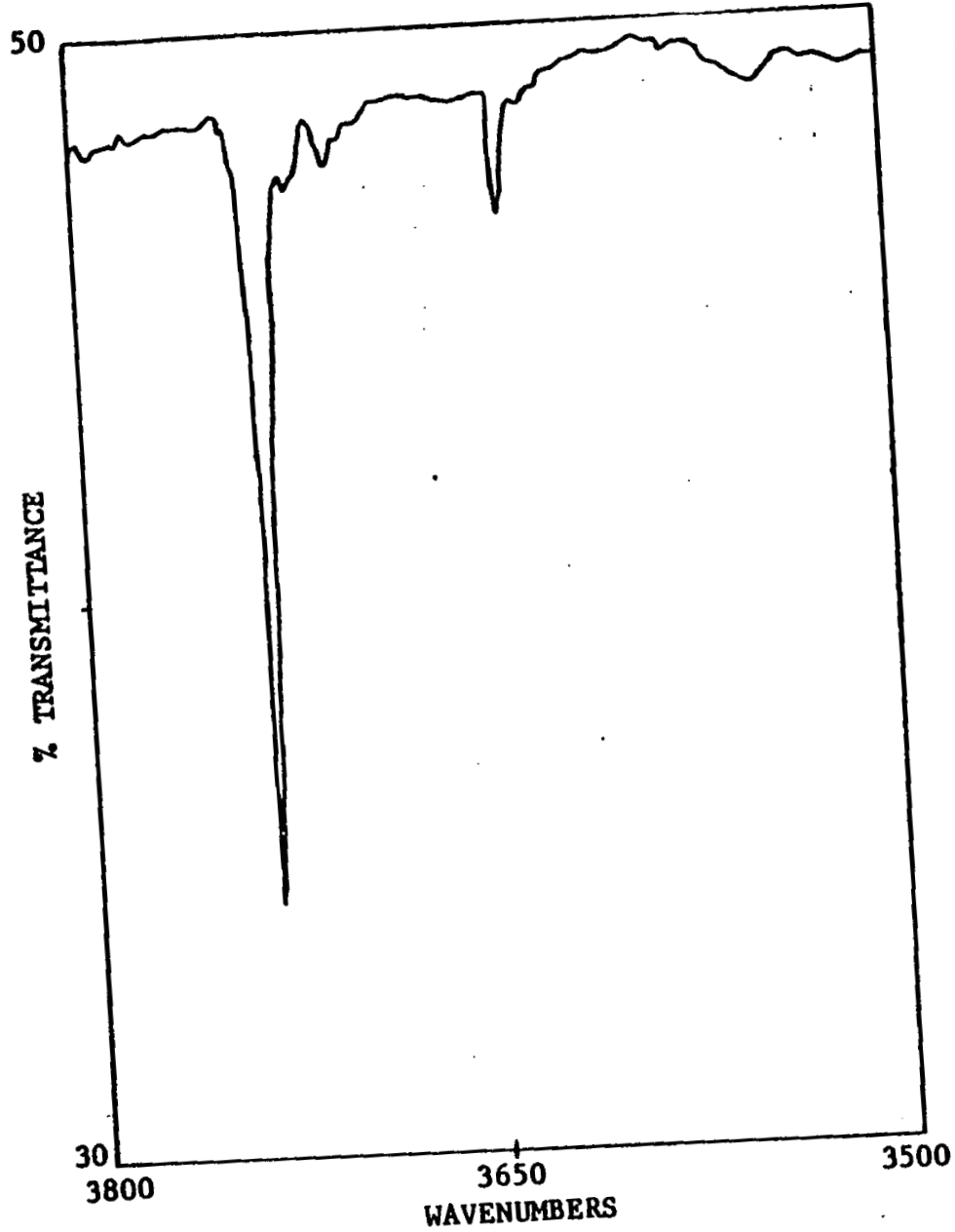

Figure 27. Enlargement of 3800-3500 wavenumber region.

อี 


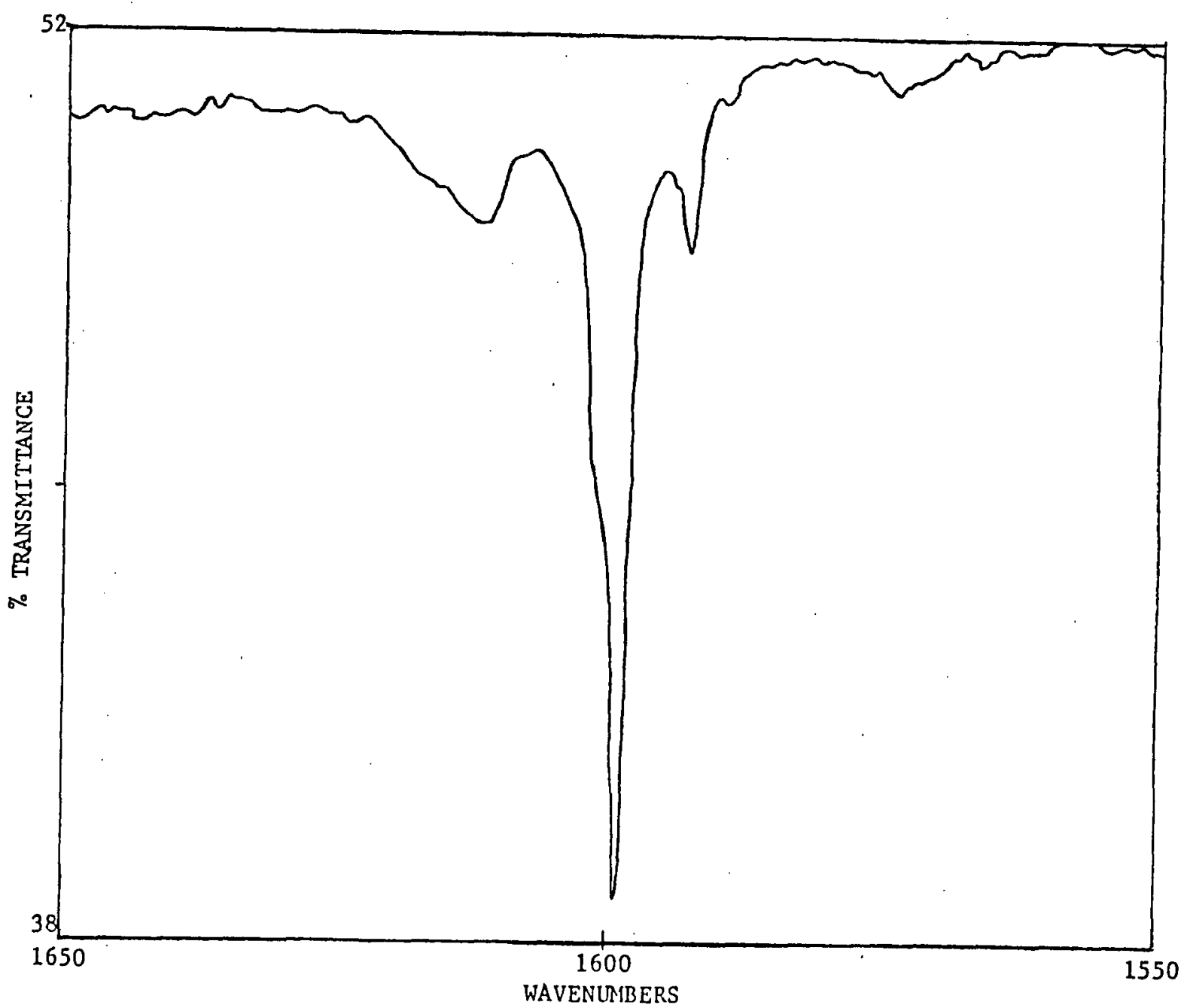

Figure 28. Enlargement of the 1650-1550 wavenumber region, $A r: \mathrm{H}_{2} \mathrm{O}=1000: 1$. 


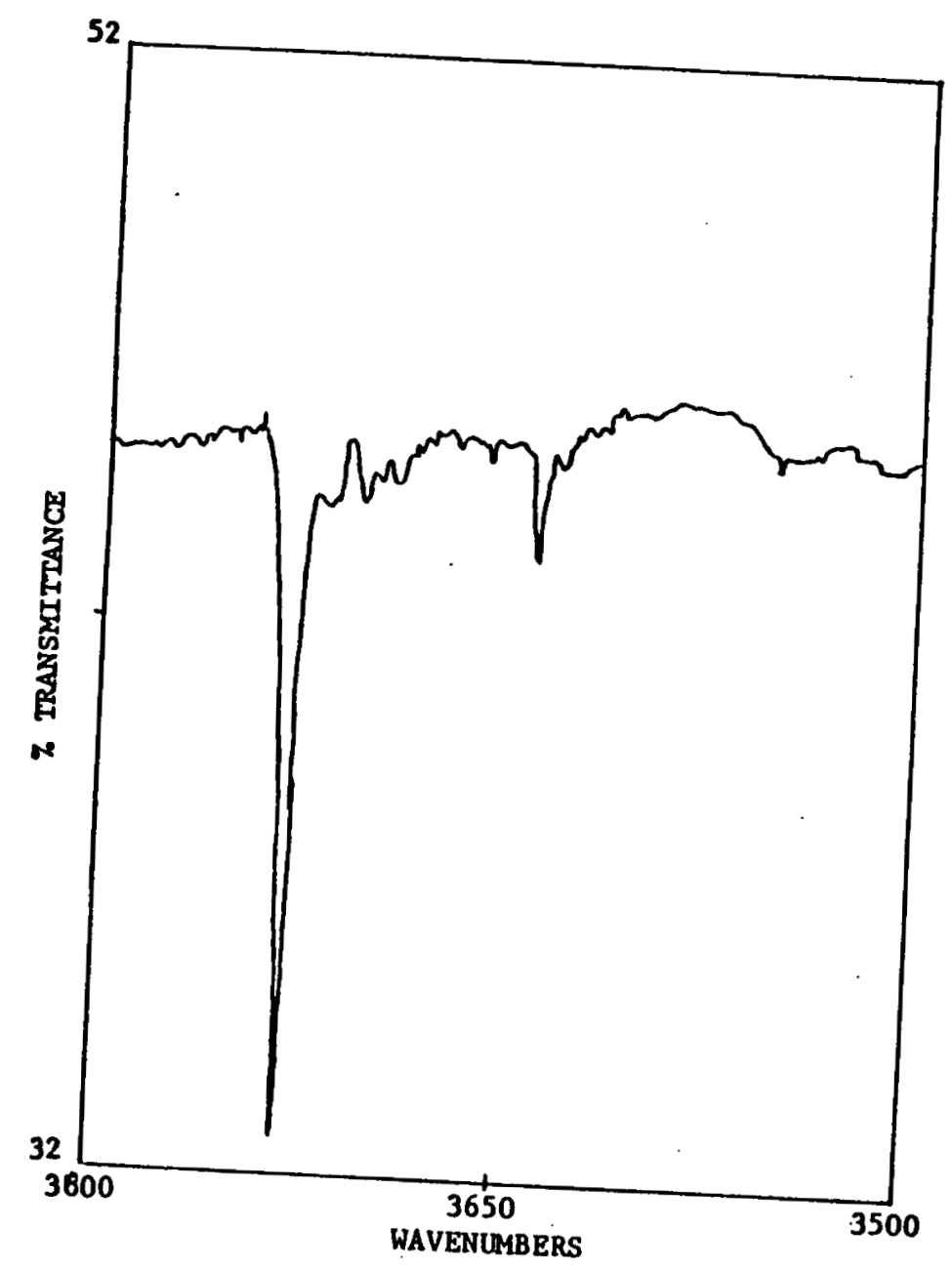

Figure 29. Enlargement of 3800-3500 wavenumber region after annealing to $32^{\circ} \mathrm{K}$, 


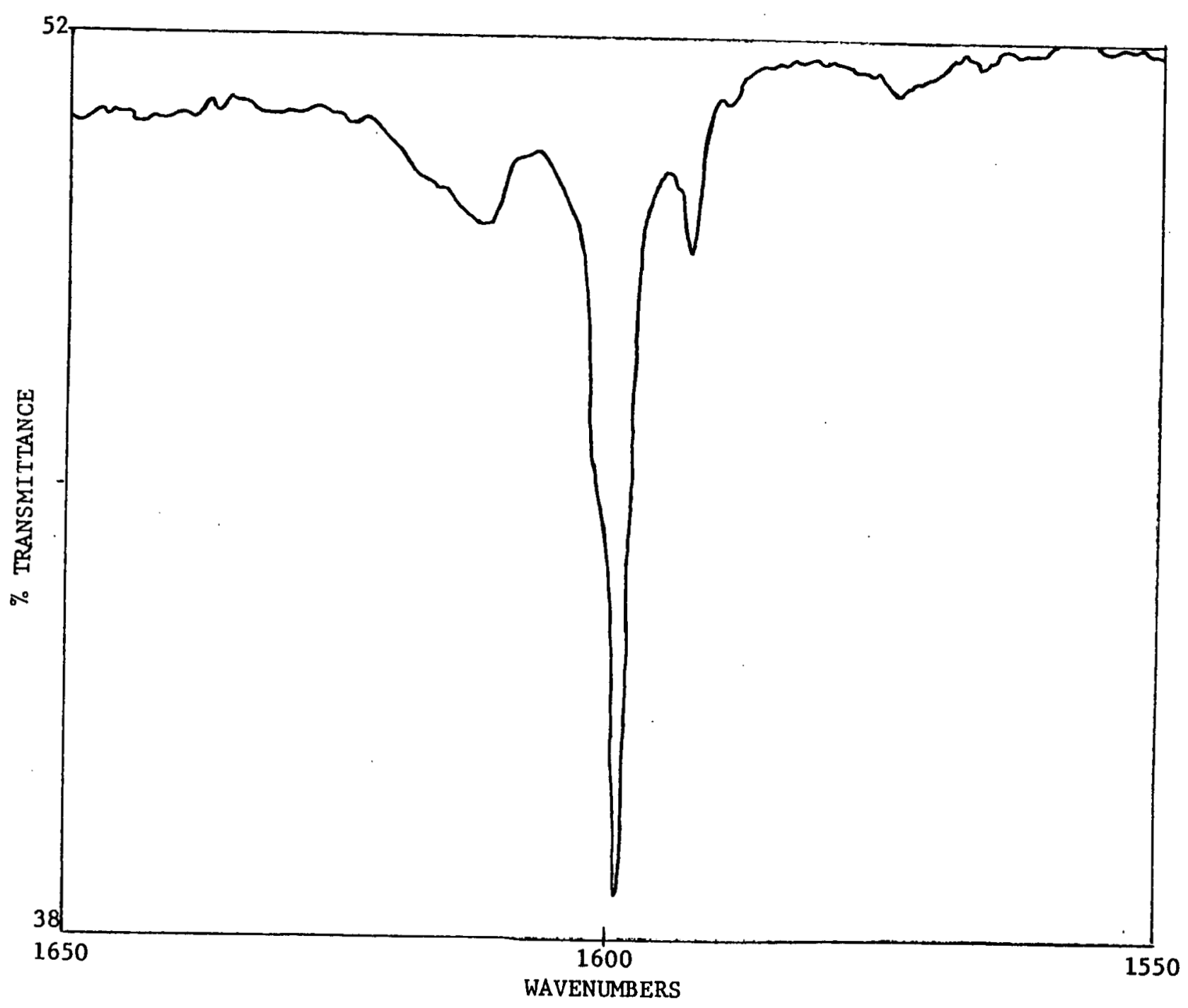

Figure 30. Enlargement of 1650-1550 wavenumber region after annealing to $32^{\circ} \mathrm{K}$. 


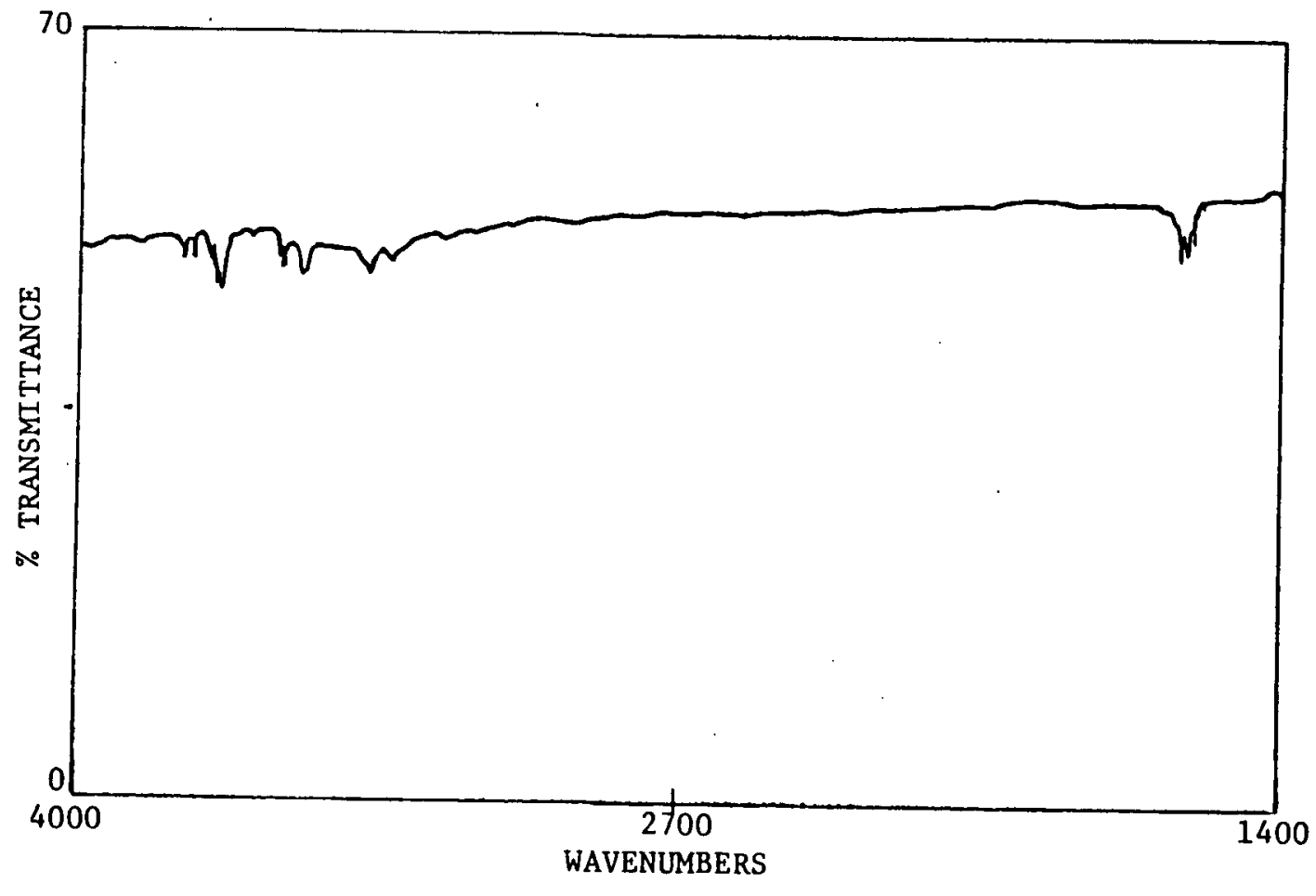

Figure 31. Matrix-isolated FT-IR spectrum of a $100: 1$ sample of $\mathrm{Ar}: \mathrm{H}_{2} \mathrm{O}$. 


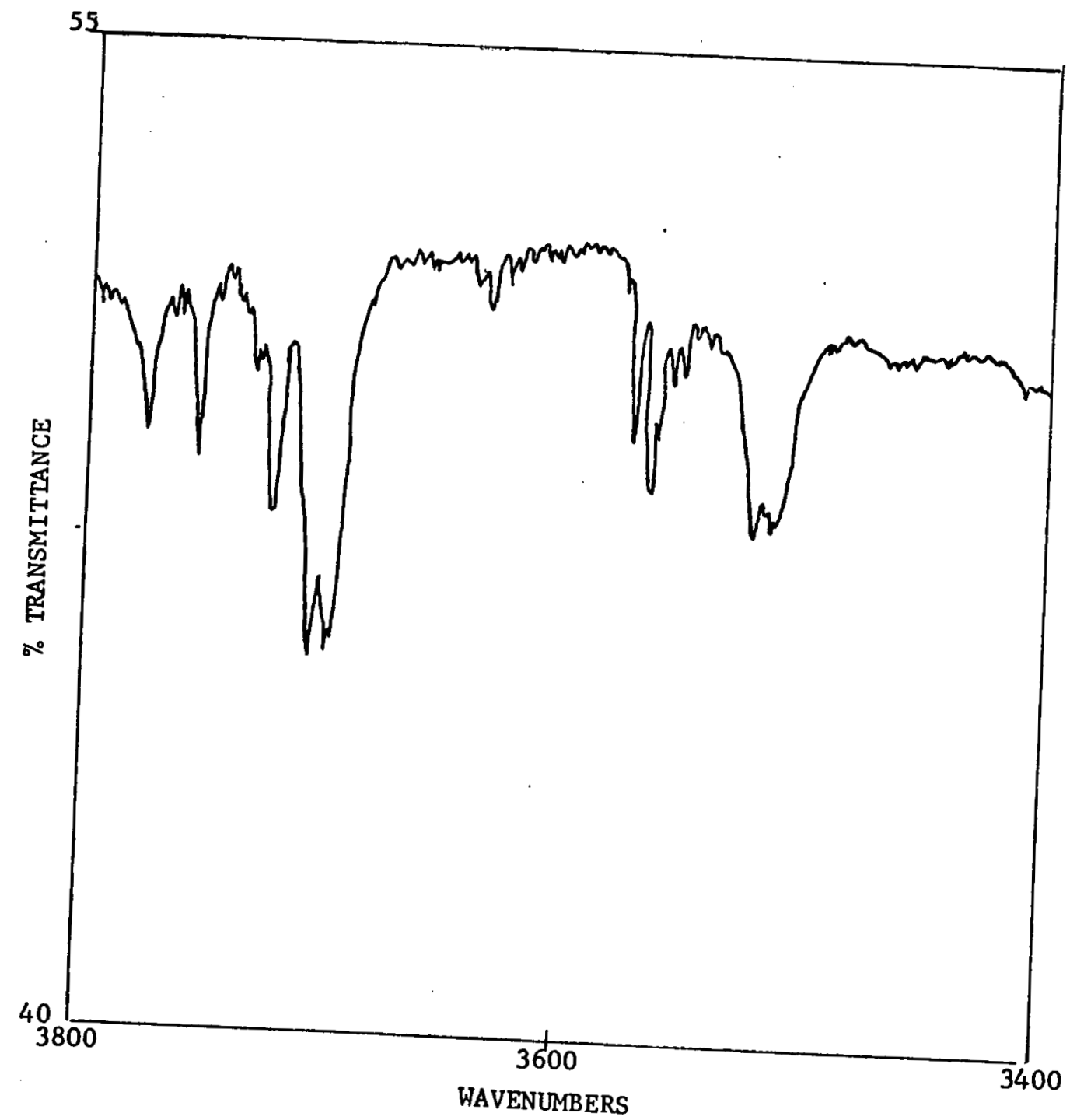

Figure 32. Enlargement of 3800-3400 wavenumber region. 


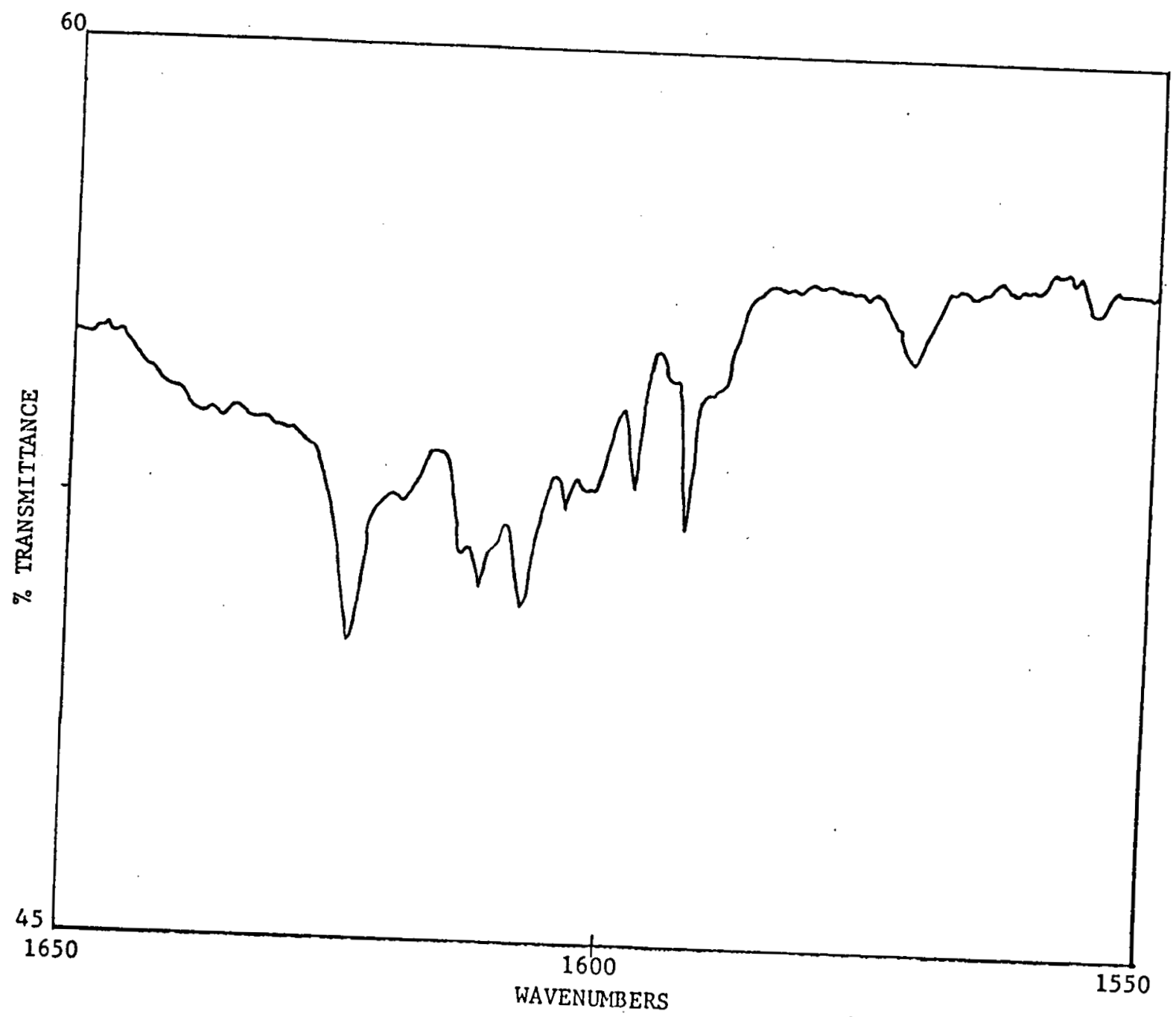

Figure 33. Enlargement of the 1650-1550 wavenumber region, $\mathrm{Ar}_{i} \mathrm{H}_{2} \mathrm{O}=100: 1$. 


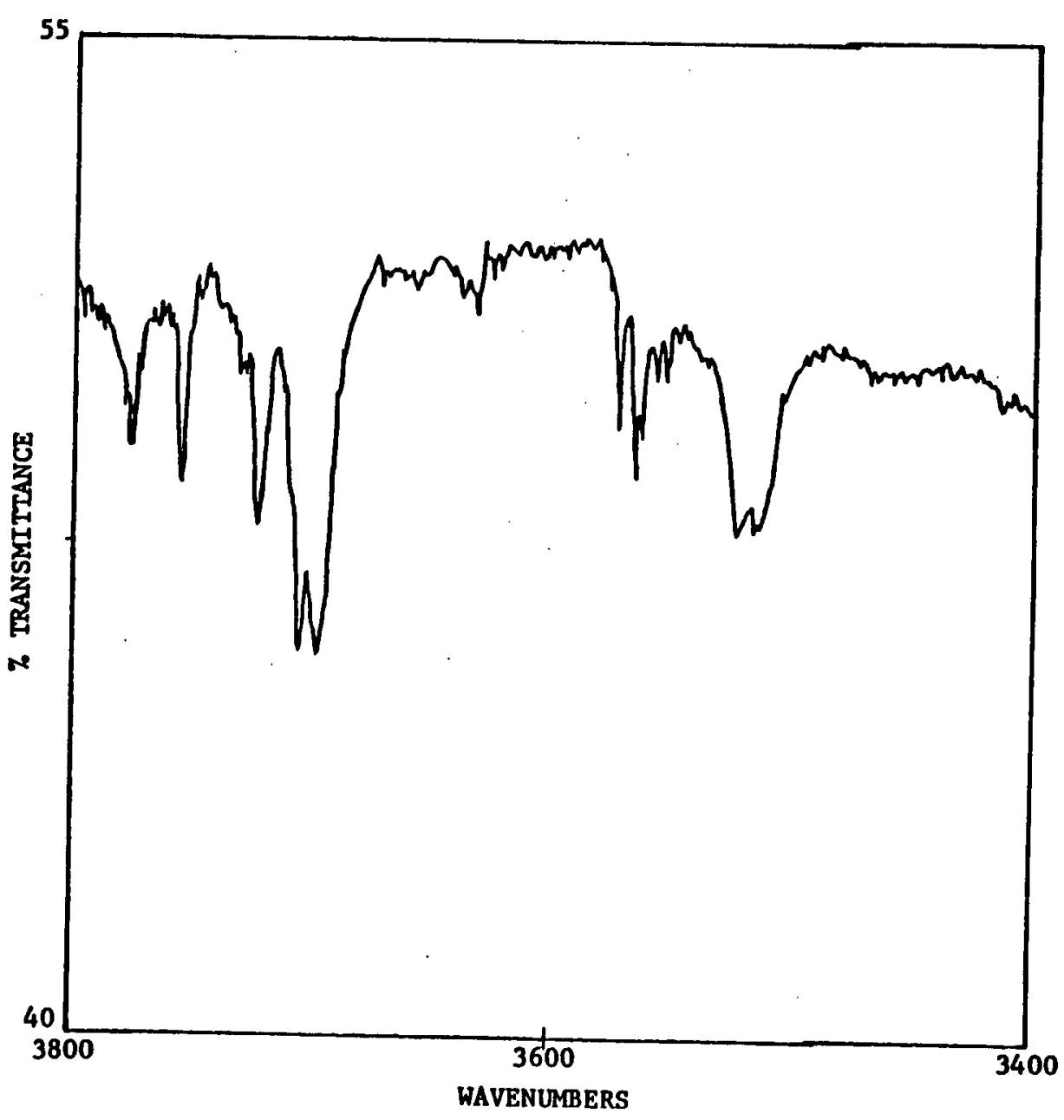

Figure 34. Enlargement of 3800-3400 wavenumber region after annealing to $30^{\circ} \mathrm{K}$. 


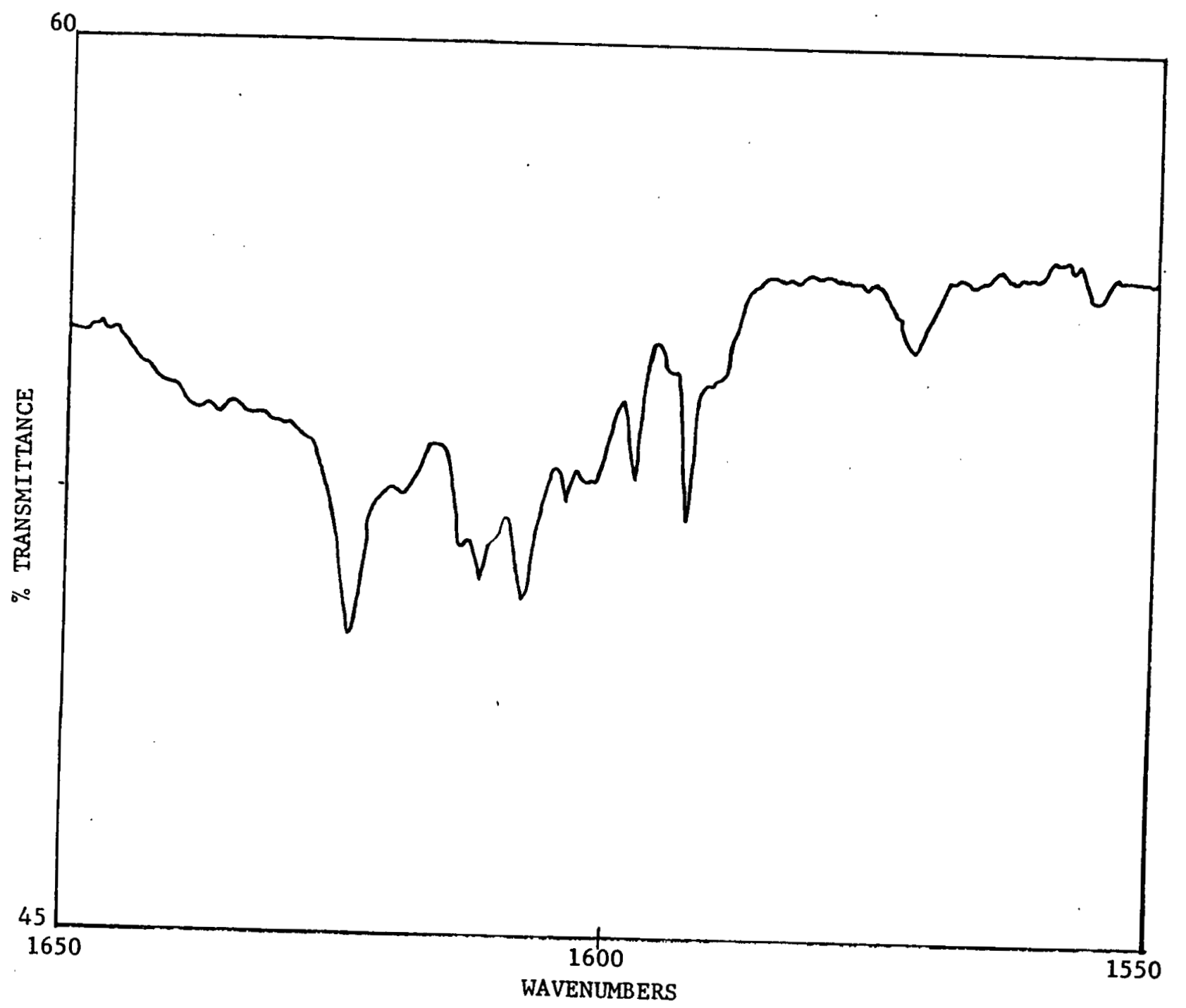

Figure 35. Enlargement of 1650-1550 wavenumber region after annealing to $30^{\circ} \mathrm{K}$. 
most of the peaks lose some intensity but no new peaks seem to appear. Also, the peaks remain relatively sharp.

Figure 36 represents a spectrum of a 20:1 $\mathrm{Ar}: \mathrm{H}_{2} \mathrm{O}$ sample. The two aforementioned spectral reglons will be examined. Figure 37 is an enlargement of the $3800-3100 \mathrm{~cm}^{-1}$ region. There is a strong absorption located at $3697 \mathrm{~cm}^{-1}$ and also a broad band that ranges from 3600 to about $3100 \mathrm{~cm}^{-1}$ with spikes appearing at 3573,3516 , 3375, 3325, and $3205 \mathrm{~cm}^{-1}$. Also, in the other region (Figure 38) there is a broad band ranging from about 1650 to $1605 \mathrm{~cm}^{-1}$ and other weaker bands located at 1601.5 and $1593 \mathrm{~cm}^{-1}$. Annealing the sample to $35^{\circ} \mathrm{K}$ leads to little change in the spectra.

Several observations can be made from these experimental results. First, as one progresses from the 1000:1 Ar: $\mathrm{H}_{2} \mathrm{O}$ sample to the 20:1 ratio sample, more peaks begin to appear in the two aforementioned spectral regions (namely the 3800-3400 and 1650-1553 $\left.\mathrm{cm}^{-1}\right)$. As mentioned earlier, these peaks are due to agglomerated water molecules. The bands in these two regions tend to broaden and coalesce as the concentration increases. A 20:1 sample is very similar spectrally (IR) to a pure water sample. Also, since aggregation of sample molecules upon annealing usually leads to broader, less-resolved peaks, one can probably conclude that little or no diffusion or aggregation occurs in argon in these temperature ranges. 


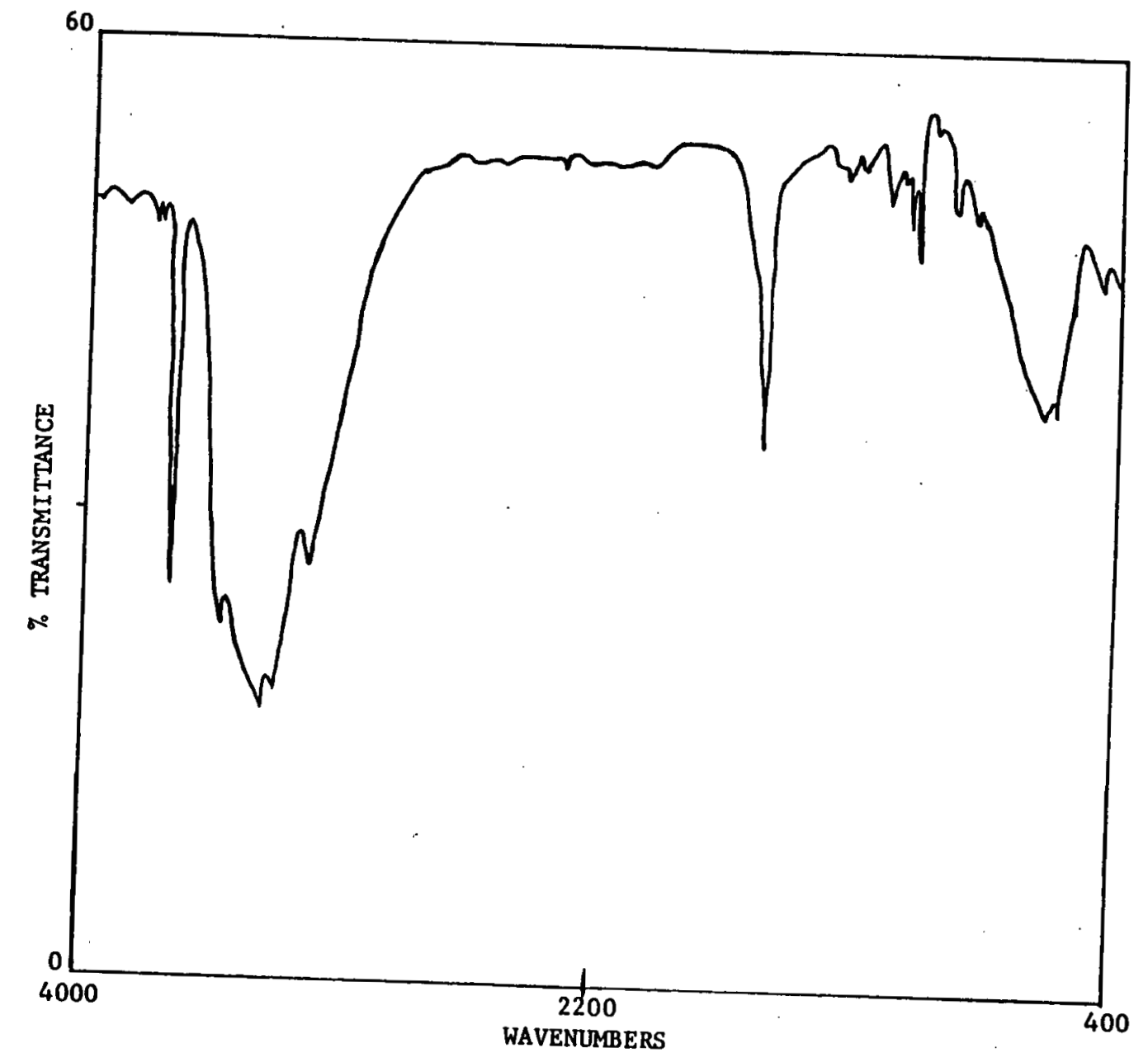

Figure 36. Hatrix-isolated FT-IR spectrum of $20: 1$ sample of Ar: $\mathrm{H}_{2} \mathrm{O}$. 
C

C

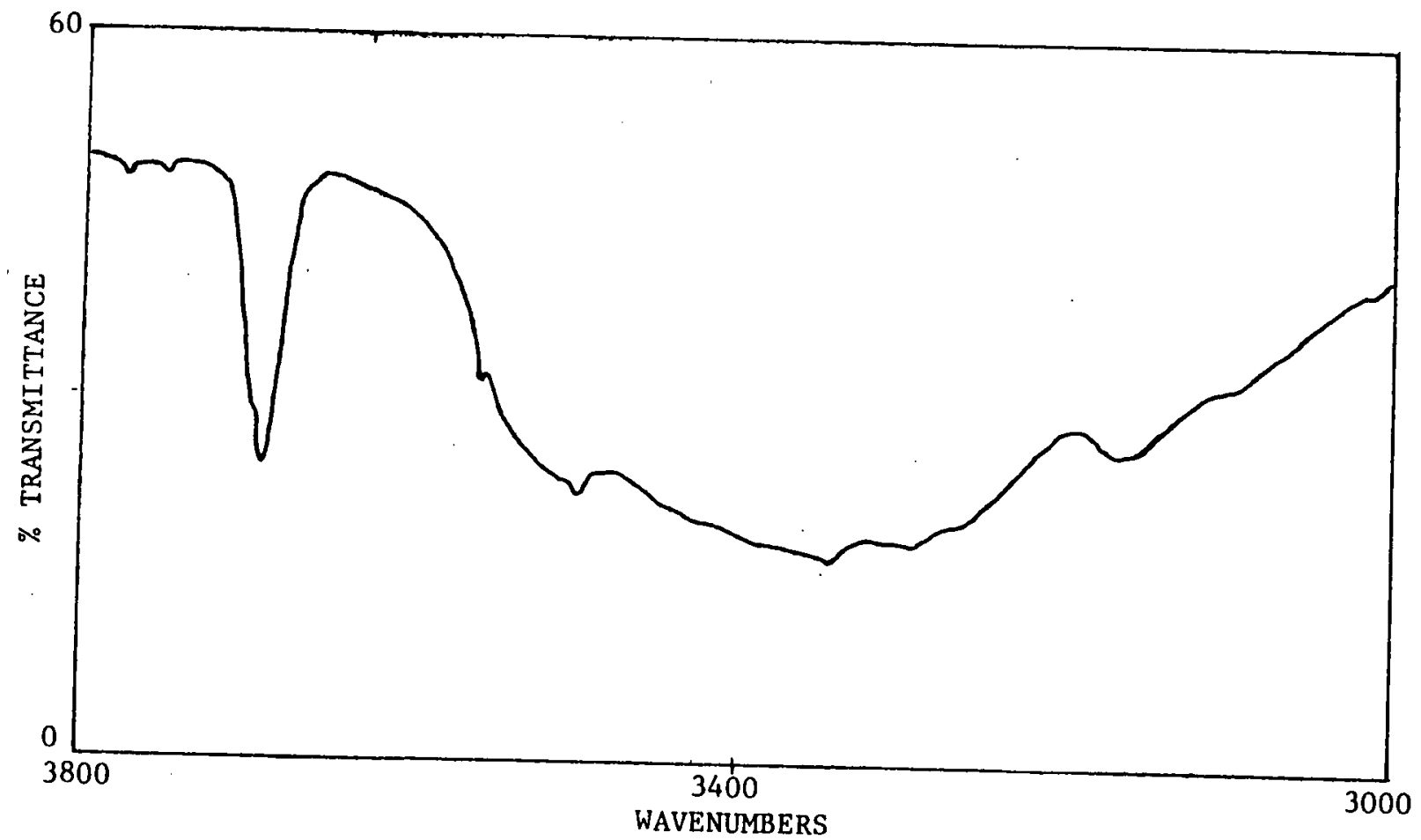

Figure 37. Enlargement of 3800-3000 wavenumber region.

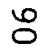




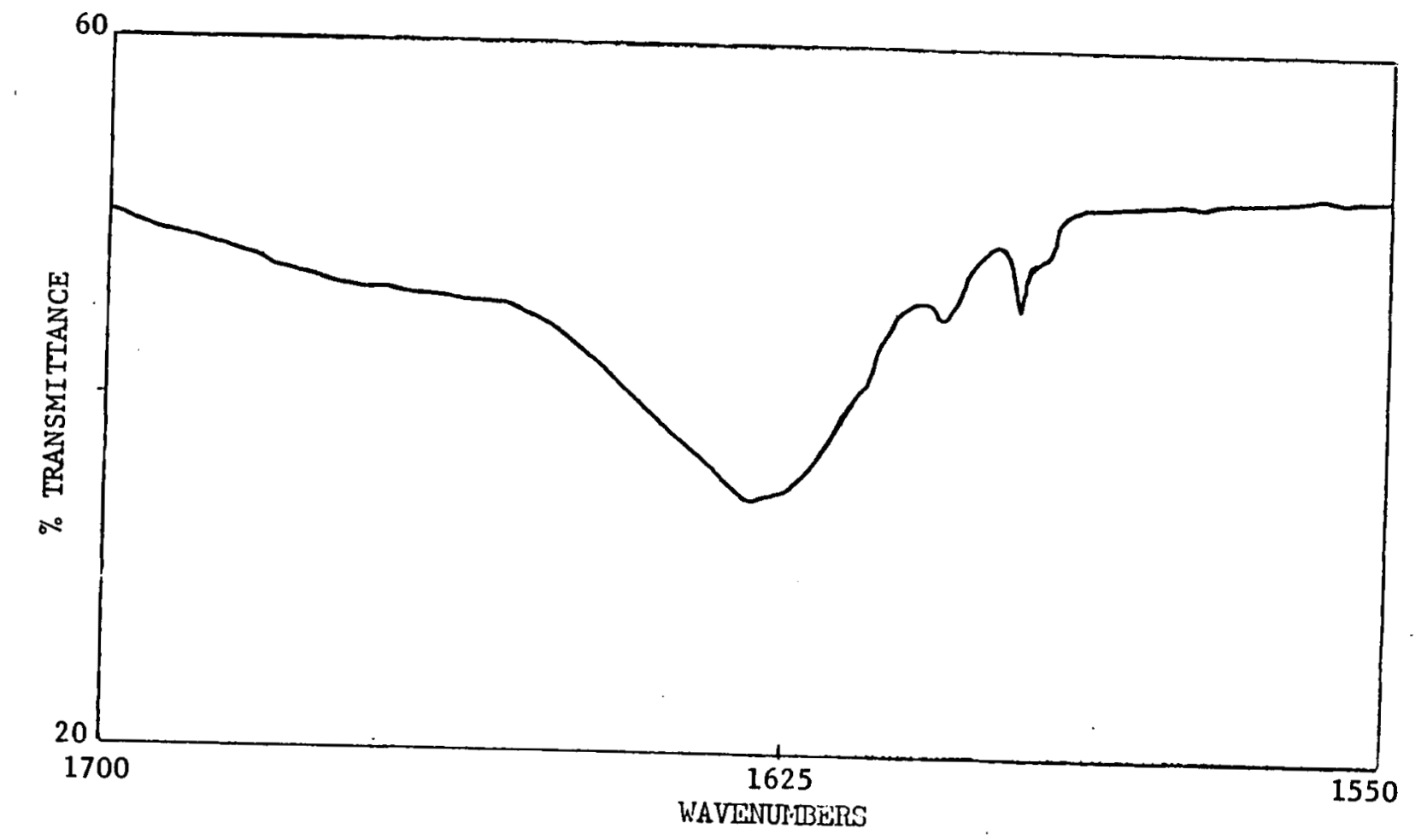

Figure 38. Enlargement of 1700-1550 wavenumber region. 
4. $\underline{\mathrm{UF}}_{6}$ and $\mathrm{H}_{2} \mathrm{O}$ Co-deposited in Argon

This section will detail the results obtained from the co-deposition of $\mathrm{UF}_{6}$ and $\mathrm{H}_{2} \mathrm{O}$ in an argon matrix. The experimental details are those discussed in Chapter III, Section D. Only one series of spectra will be analyzed. The matrix-to-sample ratios were 500:1 for $A r: U_{6}$ and 100:1 for $A r: H_{2} O$. This series of spectra was chosen because the deposits were made "cleanly" and most of the spectral bands which need to be examined are fairly well resolved. The $\mathrm{UF}_{6}: \mathrm{Ar}$ and $\mathrm{H}_{2} \mathrm{O}: \mathrm{Ar}$ samples were deposited in approximately equal amounts. The first spectrum shown (Figure 39) is of the inftial deposit before any annealing was done $\left(16^{\circ} \mathrm{K}\right)$. Upon examination of the spectrum, one readily notices the strong $\mathrm{UF}_{6}$ absorption at 619 $\mathrm{cm}^{-1}$. Also, one can compare the $3800-3400 \mathrm{~cm}^{-1}$ and $1650-1550$ $\mathrm{cm}^{-1}$ regions in Figure 39 to the ones that were previously examined in Section 3 and realize that they compare very well to a $100: 1$ $\mathrm{Ar}: \mathrm{H}_{2} \mathrm{O}$ sample. In order to allow easier examination of the annealing experiments, only the $1800-500 \mathrm{~cm}^{-1}$ region will be plotted. Figure 40 is a spectrum of the initial deposit in the 1800-500 $\mathrm{cm}^{-1}$ region. Figure 41 represents the sample after having been annealed to $26^{\circ} \mathrm{K}$. If one compares this spectrum to Figure 40 , one can see that the sample has remained virtually unchanged. The next spectrum (Figure 42) was taken after the sample had been annealed to $34^{\circ} \mathrm{K}$. Clearly the intensities of both the water bands and the $\mathrm{UF}_{6}$ bands are diminishing somewhat. However, no new bands seem to be appearing in this spectral region. Finally, Figure 43 represents the sample after it had been annealed to $37^{\circ} \mathrm{K}$. Both the 
C

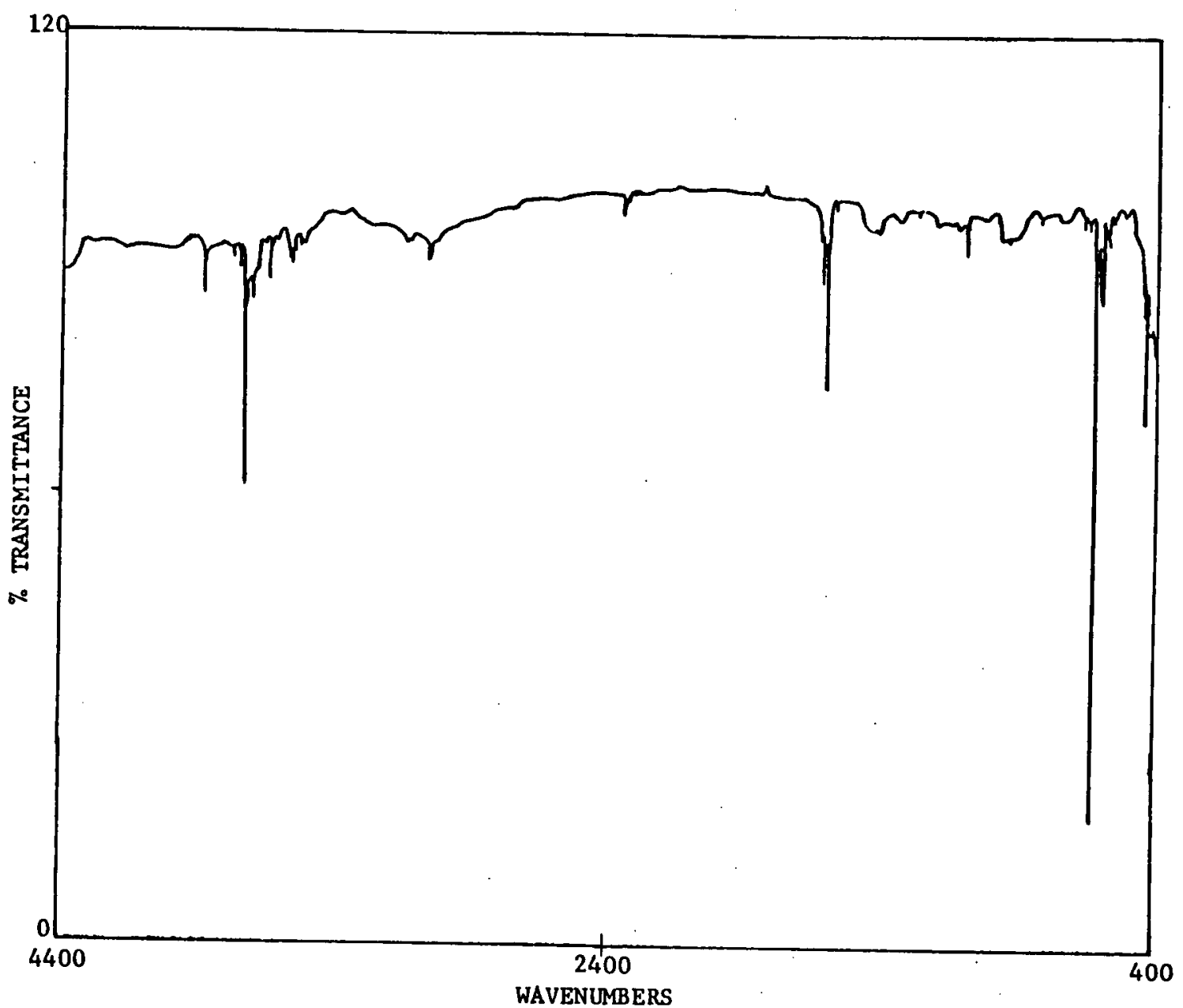

Figure 39. Matrix-isolated FT-IR spectrum of $\mathrm{Ar}: \mathrm{UF}_{6}(500: 1)$ and $\mathrm{Ar}: \mathrm{H}_{2} \mathrm{O}(100: 1)$ held at $16^{\circ} \mathrm{K}$.

$\stackrel{\circ}{\omega}$ 


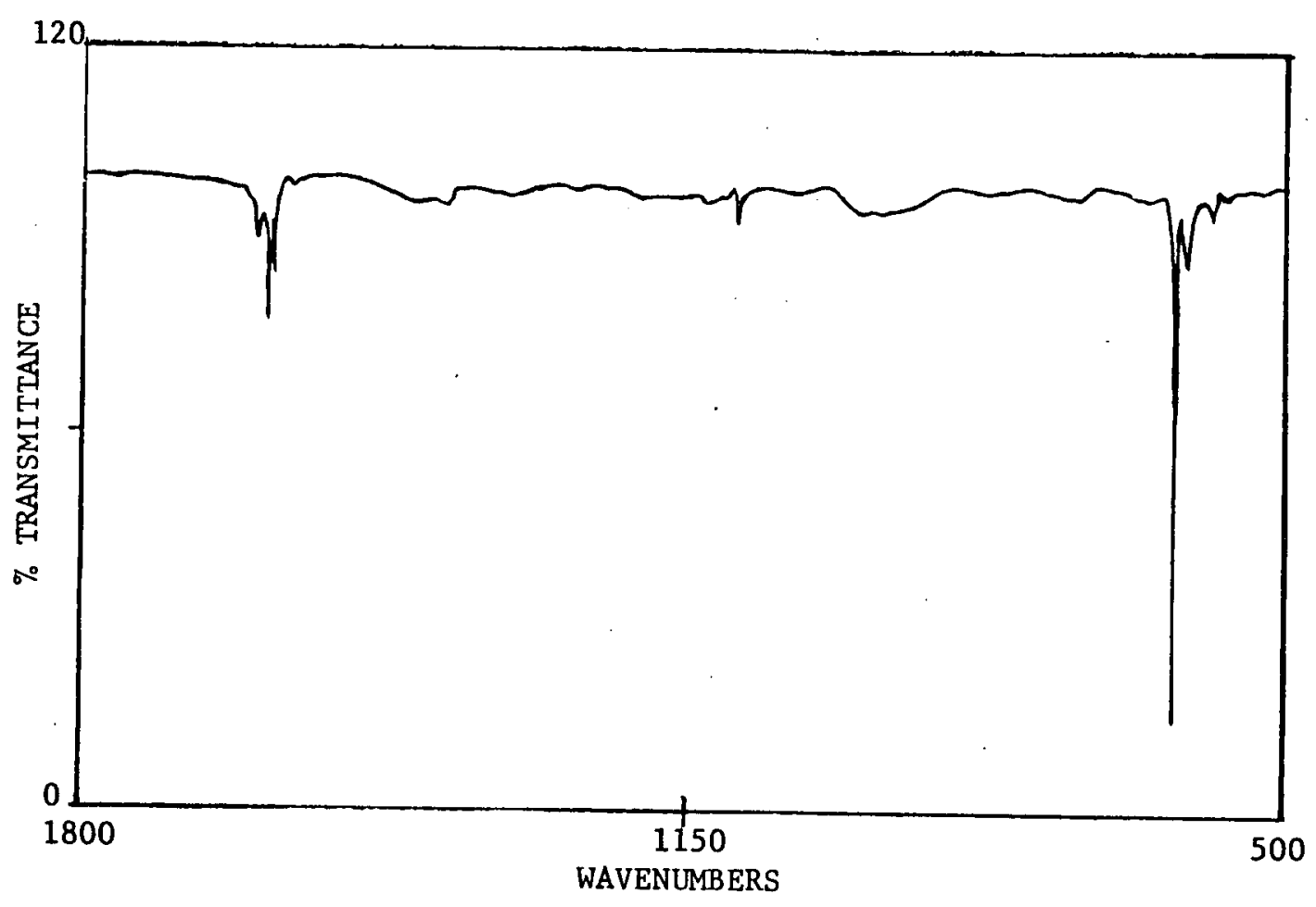

Figure 40. Enlargement of the $1800-500$ wavenumber region at $10^{\circ} \mathrm{K}$. 


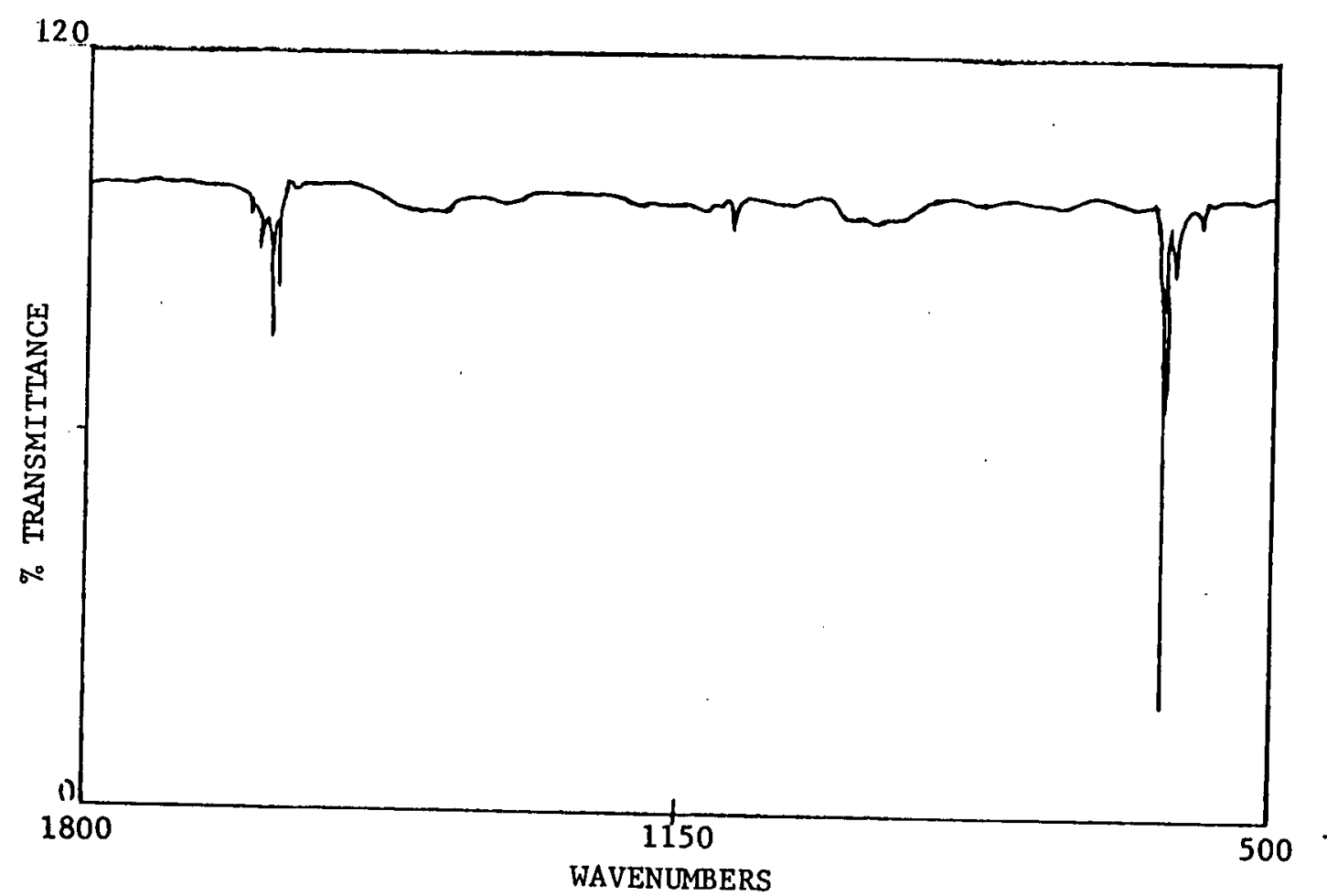

Figure 41. Enlargement of 1800-500 wavenumber region after annealing to $26^{\circ} \mathrm{K}$. 


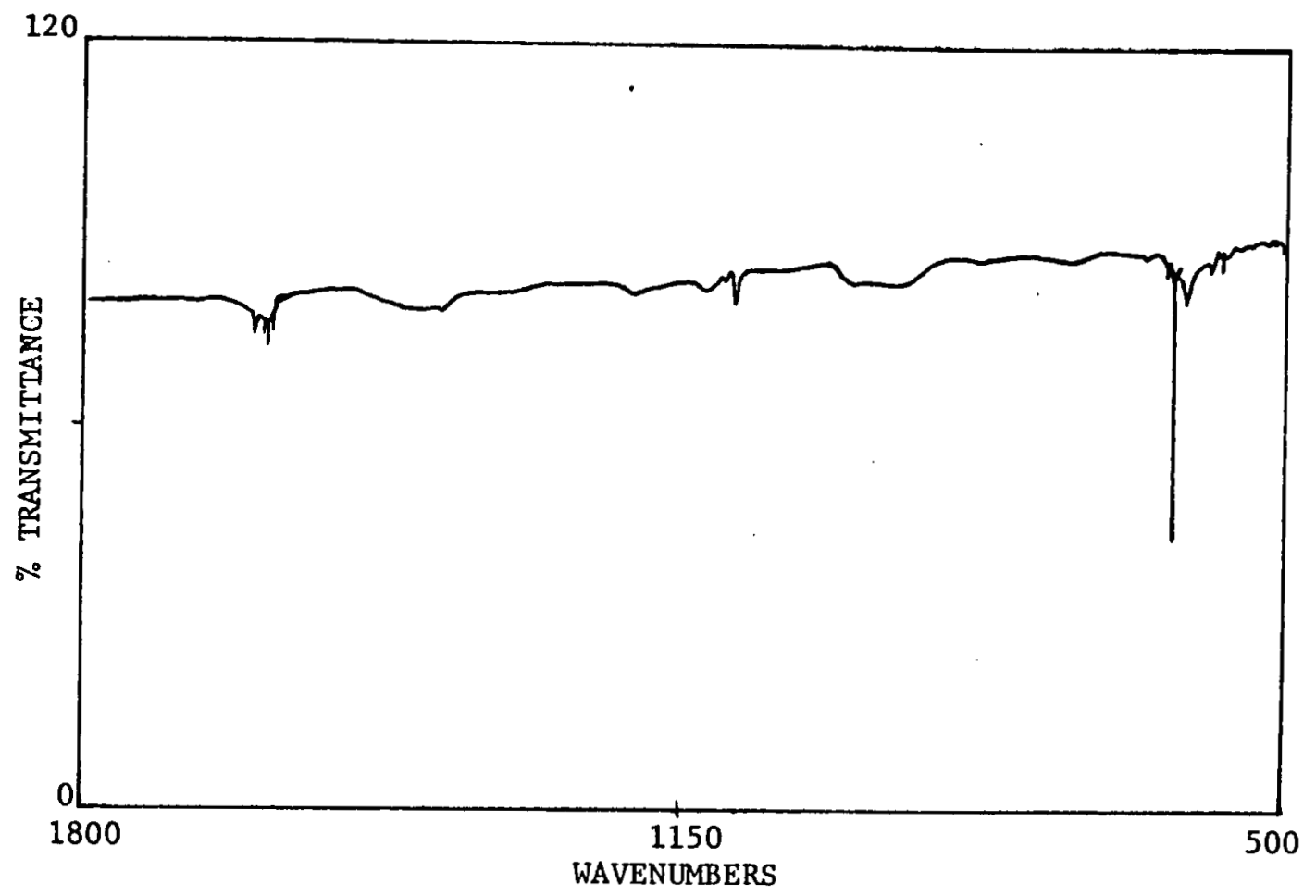

Figure 42. Enlargement of the 1800-500 wavenumber region after annealing to $34^{\circ} \mathrm{K}$. 


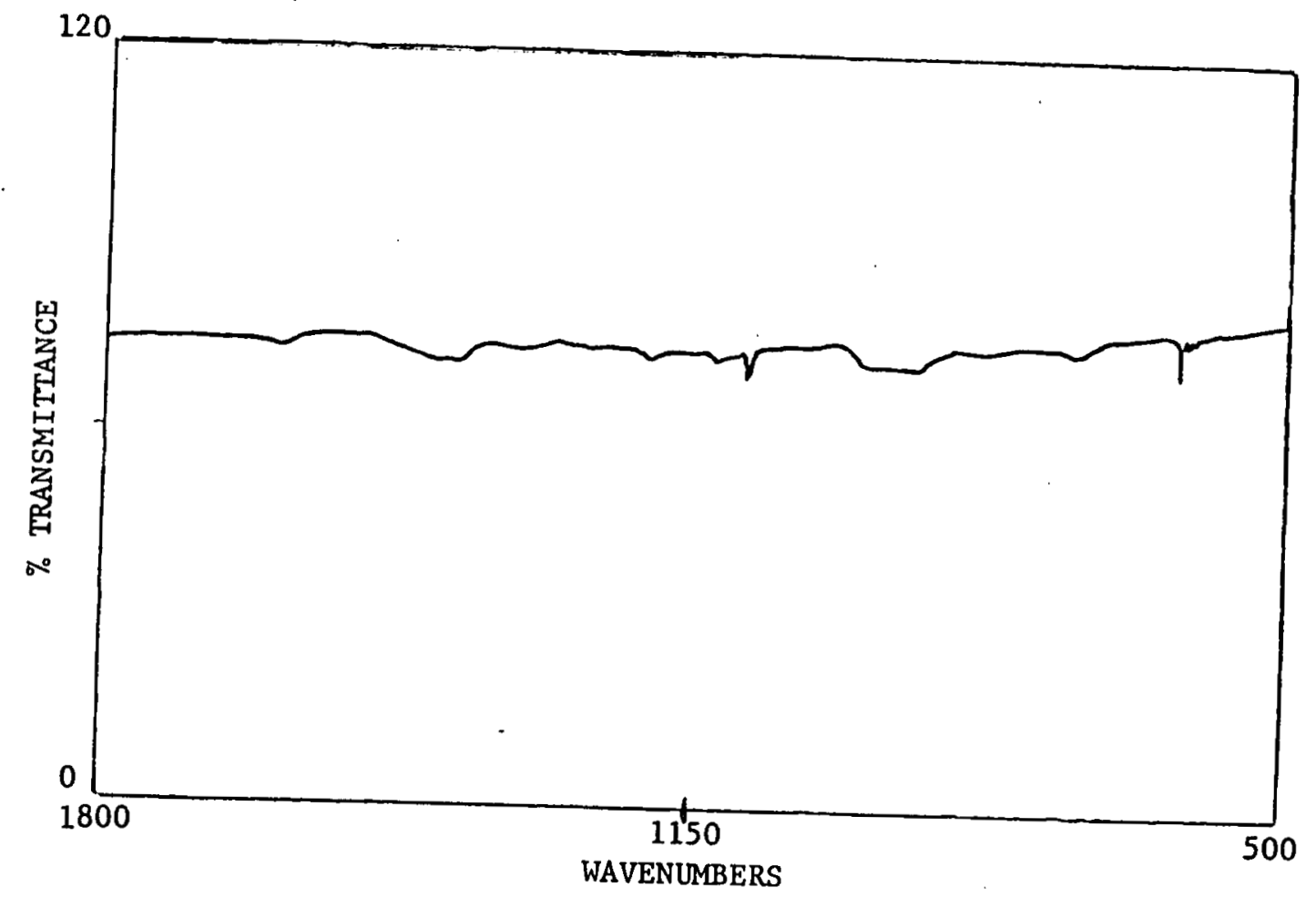

Figure 43. Enlargement of the 1300-500 wavenumber region after annealing to $37^{\circ} \mathrm{K}$. 
water bands and the $\mathrm{UF}_{6}$ band have virtually disappeared. Again no new bands have shown up in this spectral region.

A few conclusions might be drawn from this experiment; that is, there might be several reasons that no $\mathrm{UF}_{6}$ and water reaction was observed. Among the several possibilities are: (1) they reacted to produce species that are not IR active, (2) the reacted species were evacuated away from the window (with the argon), (3) they did not react. If the third conclusion is correct, then there could be several reasons for 1t. These reasons are: (1) they did not react because no diffusion occurred, (2) they did not react because higher temperatures might be needed thermodynamically, and (3) they did not react because their concentrations might be too low. Some of these conclusions might be eliminated if pure water and pure $\mathrm{UF}_{6}$ are deposited simultaneously and subsequent annealing experiments performed.

\section{Matrix-Isolated $\underline{U F}_{6}$ in Nitrogen}

The following discussion pertains to the experiments on the matrix isolation of $\mathrm{UF}_{6}$ in nitrogen which were performed under experimental conditions discussed in Chapter III, Section E. Figure 44 represents a spectrum of a $\mathrm{N}_{2}: \mathrm{UF}_{6}$ sample having a ratio of $100: 1$. Again, the $\mathrm{UF}_{6}$ absorption in the $650-600 \mathrm{~cm}^{-1}$ spectral region will be detailed. The $\mathrm{UF}_{6}$ absorption actually consists of five peaks under these experimental conditions. There is a weak peak at 627 $\mathrm{cm}^{-1}$, a strong peak at 624 , a strong peak at 623 , a medium peak at 617.5, and a weak peak at $610 \mathrm{~cm}^{-1}$. If one compares this spectrum 


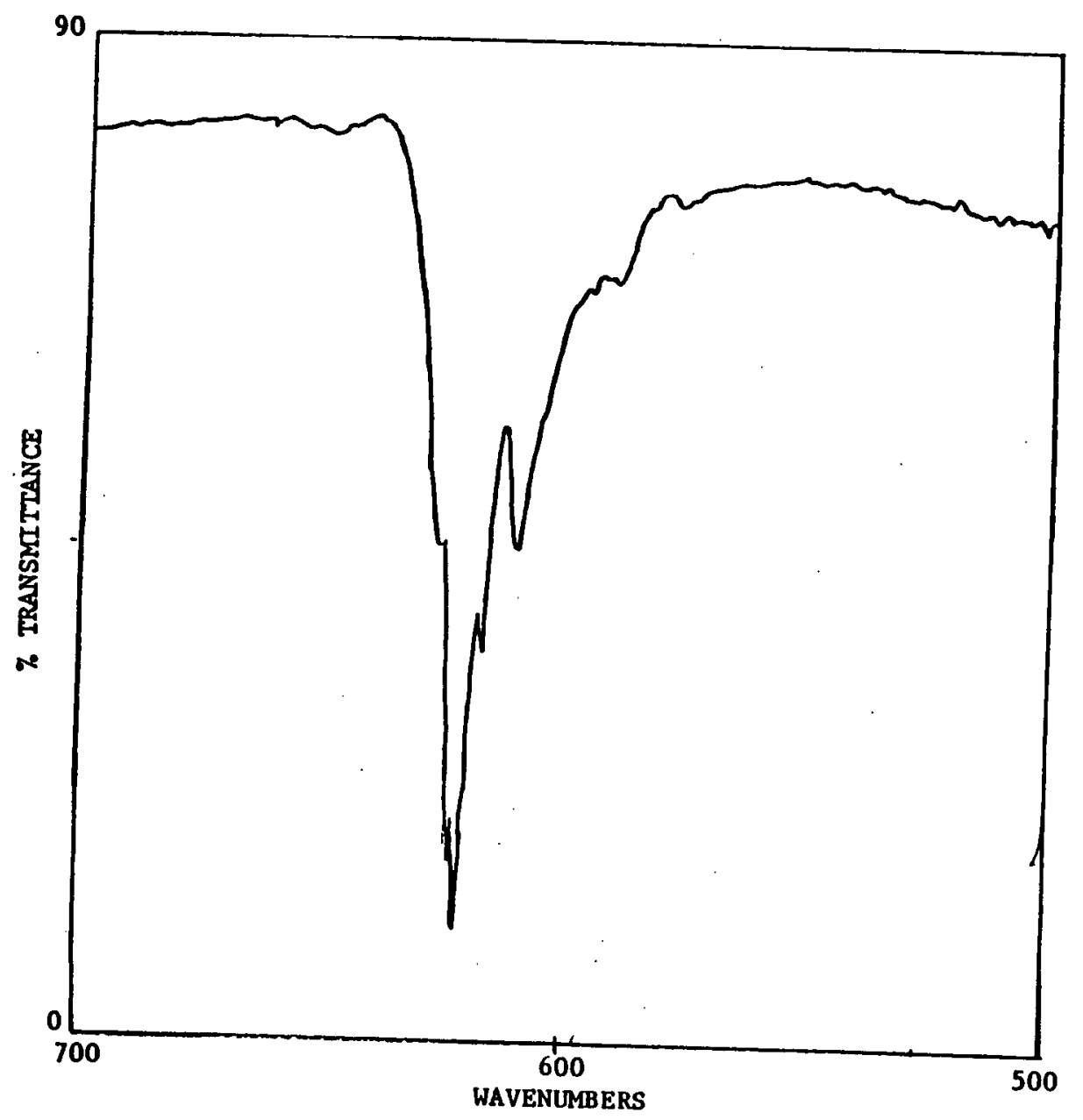

Figure 44. Matxix-isolated FT-IR spectrum of 700-500 wavenumber region of 100:1 sample of $\mathrm{N}_{2}: \mathrm{UF}_{6} \cdot$ 
to Figure 21 one can see that the $\mathrm{UF}_{6}$ in argon and $\mathrm{UF}_{6}$ in nitrogen IR absorptions are somewhat dissimilar. Frequency shifts for molecules in different matrix materials have been previously discussed by Moskovits and 0zin.70 Figure 45 shows a spectrum after the sample had been annealed to $24^{\circ} \mathrm{K}$. One can see that the peak intensities have slightly decreased but are also slightly better resolved. Figure 46 is a spectrum of the same sample after it was annealed to about $28^{\circ} \mathrm{K}$. The band previously assigned to the $\mathrm{UF}_{6}$ stretch and its satellites has undergone considerable broadening. It was then decided that the matrix ratio would not be increased because spectra were already being complicated by sample aggregation. It was therefore decided to proceed with a codeposition experiment of $\mathrm{UF}_{6}$ and $\mathrm{H}_{2} \mathrm{O}$ in nitrogen.

6. $\underline{U F}_{6}$ and $\underline{\mathrm{H}}_{2} \mathrm{O}$ Matrix-Isolated in Nitrogen

The following is a discussion of the $\mathrm{UF}_{6}$ and $\mathrm{H}_{2} \mathrm{O}$ co-deposition experiments in nitrogen which were performed under experimental conditions discussed in Chapter III, Section G. Figure 47 is a spectrum of a sample of $\mathrm{UF}_{6}: \mathrm{N}_{2}$ at $1: 100$ and $\mathrm{H}_{2} \mathrm{O}: \mathrm{N}_{2}$ at $1: 500$ which was recorded at $16^{\circ} \mathrm{K}$. Again, bands in the $3800-3200 \mathrm{~cm}^{-1}$ and 1650-1550 $\mathrm{cm}^{-1}$ reglons are typical of water absorptions that have been observed by previous researchers.68,69 The strongest peaks appear at $3730,3795,3360$, and $1598 \mathrm{~cm}^{-1}$. The peak at $2360 \mathrm{~cm}^{-1}$ is consistent with an absorption which has previously been assigned to $\mathrm{CO}_{2}$. There are also peaks at 1395,1350 , and $1235 \mathrm{~cm}^{-1}$ that have 


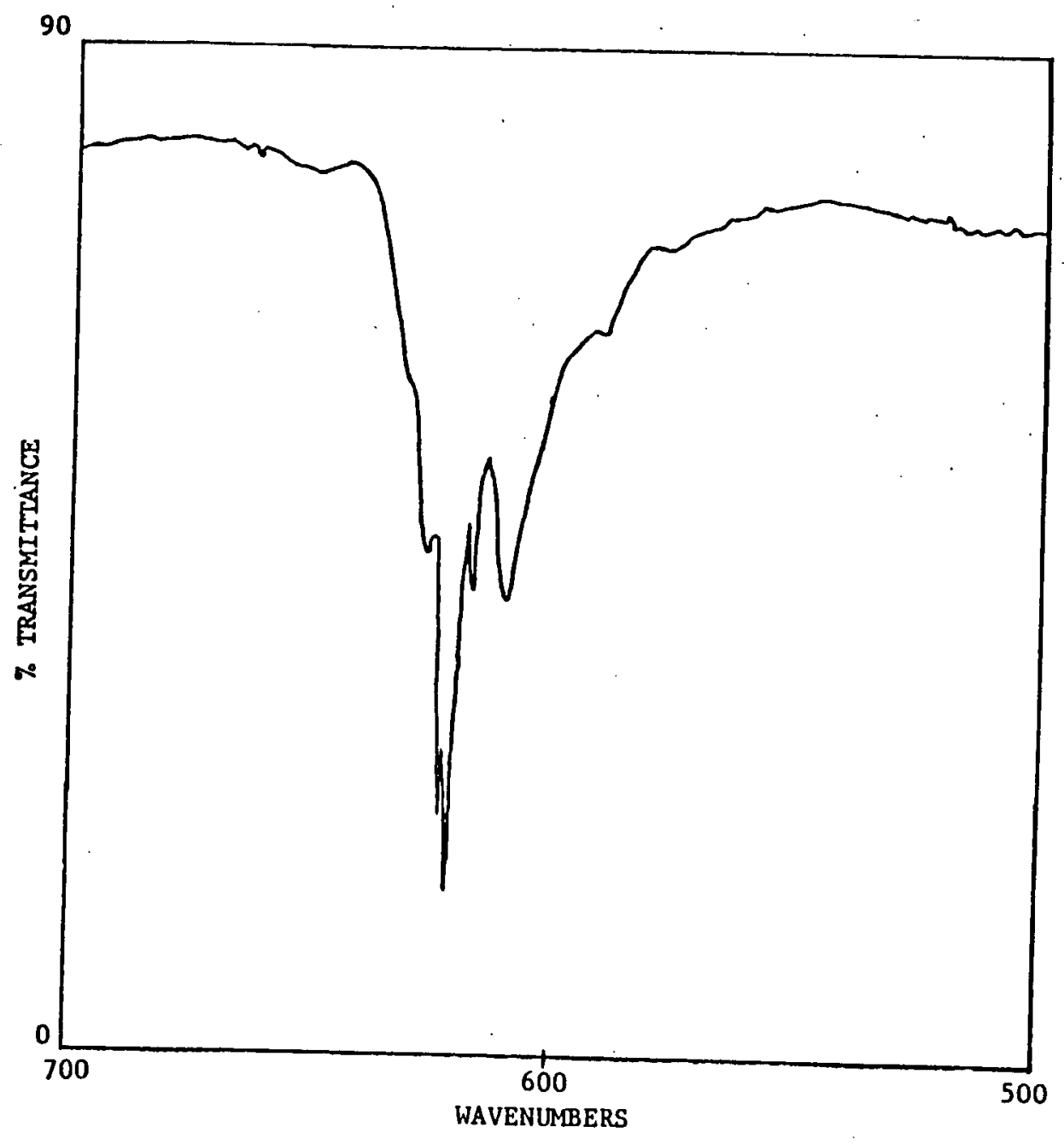

Figure 45. Same region after sample was annealed to $24^{\circ} \mathrm{K}$. 


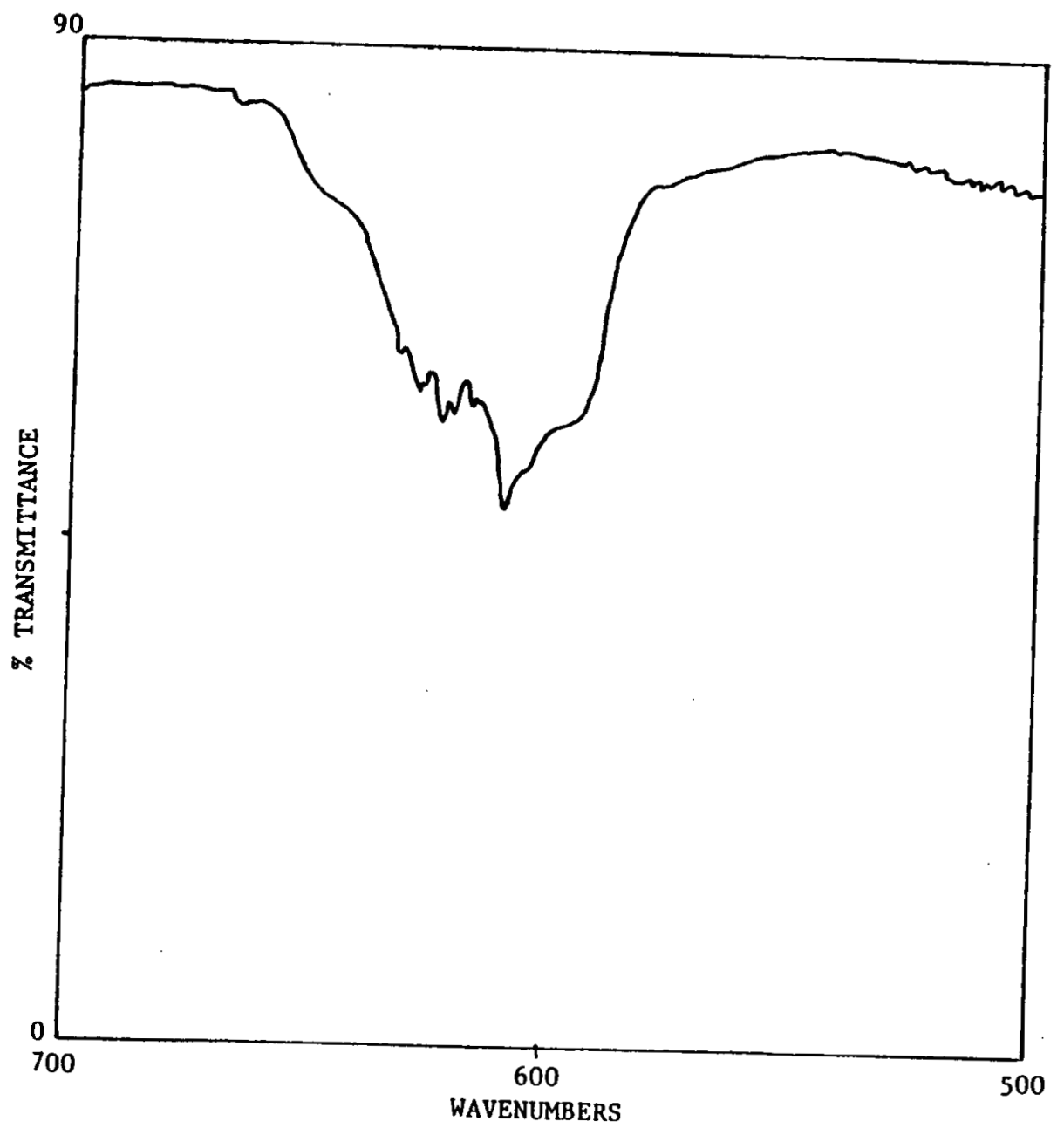

Figure 46. Spectrum of same sample after it was annealed to $20^{\circ} \mathrm{K}$. 


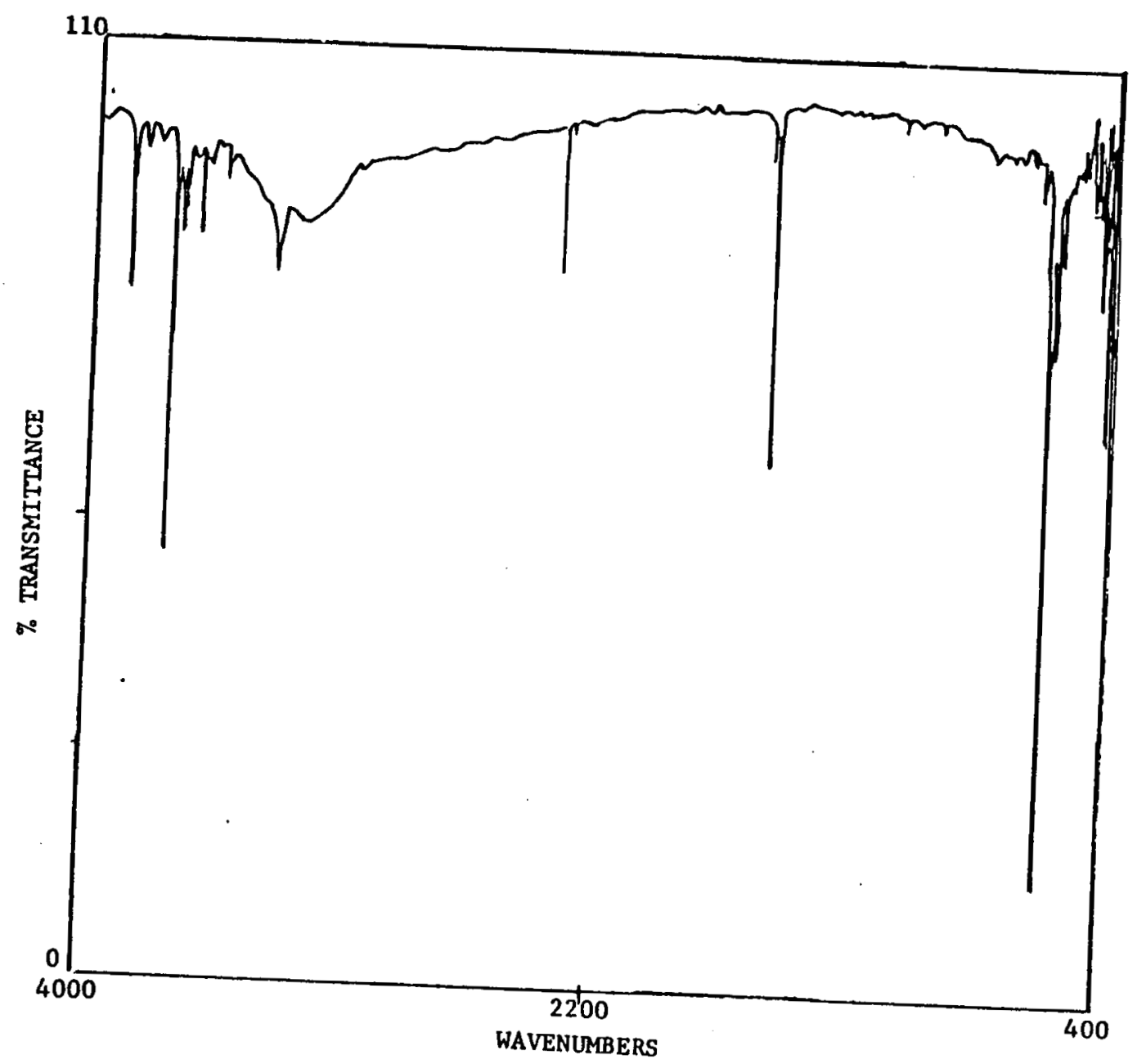

Figure 47. Matrix-isolated FT-IR spectrum of $\mathrm{UF}_{6}: \mathrm{N}_{2}(1: 100)$ and $\mathrm{H}_{2} \mathrm{O}: \mathrm{N}_{2}(1: 500)$ at $16^{\circ} \mathrm{K}$. 
yet to be identified. And, finally there is the strong $\mathrm{UF}_{6}$ absorption which occurs at $623 \mathrm{~cm}^{-1}$. Figure 48 is an enlargement of the $\mathrm{H}_{2} \mathrm{O}$ absorption at $1598 \mathrm{~cm}^{-1}$. If one compares it to Figure 28 , which is an enlargement of the $1650-1550 \mathrm{~cm}^{-1}$ region of water isolated in argon, then one can see that it is somewhat different. The next spectrum (Figure 49) was taken after the sample had been annealed to approximately $30^{\circ} \mathrm{K}$. One can see that there is a striking difference between this spectrum and the one shown in Figure 48. In the 3800-3200 $\mathrm{cm}^{-1}$ region (not pictured) there is only one broad band centering at $3250 \mathrm{~cm}^{-1}$. One can see that the band at $1598 \mathrm{~cm}^{-1}$ has diminished somewhat. Although the $\mathrm{UF}_{6}$ absorption is not included, the original spectrum showed that it had disappeared.

Some hypotheses might be drawn from these results. The $\mathrm{UF}_{6}$ band at $623 \mathrm{~cm}^{-1}$ is obviously disappearing and it might be because the $\mathrm{UF}_{6}$ is not diffusing or reacting and is being carried away as the sample is evacuated away from the window. Another conclusion might be that the $\mathrm{UF}_{6}$ is reacting with the CsI window because, after the experiment was completed, there was usually some debris remaining on the window. And, one can conclude that the $\mathrm{H}_{2} \mathrm{O}$ is probably also diffusing because the absorptions in the $3800-3200$ $\mathrm{cm}^{-1}$ region are broadening and coalescing. A strong, broad absorption in this region is indicative of agglomerated water.65 It also must be noted here that the changes in the water bands are occurring while the $\mathrm{UF}_{6}$ band still remains intact. Therefore, it is possible that $\mathrm{UF}_{6}$ and water molecules are coming into contact with one another during the annealing experiment. However, no UOF 4 or 


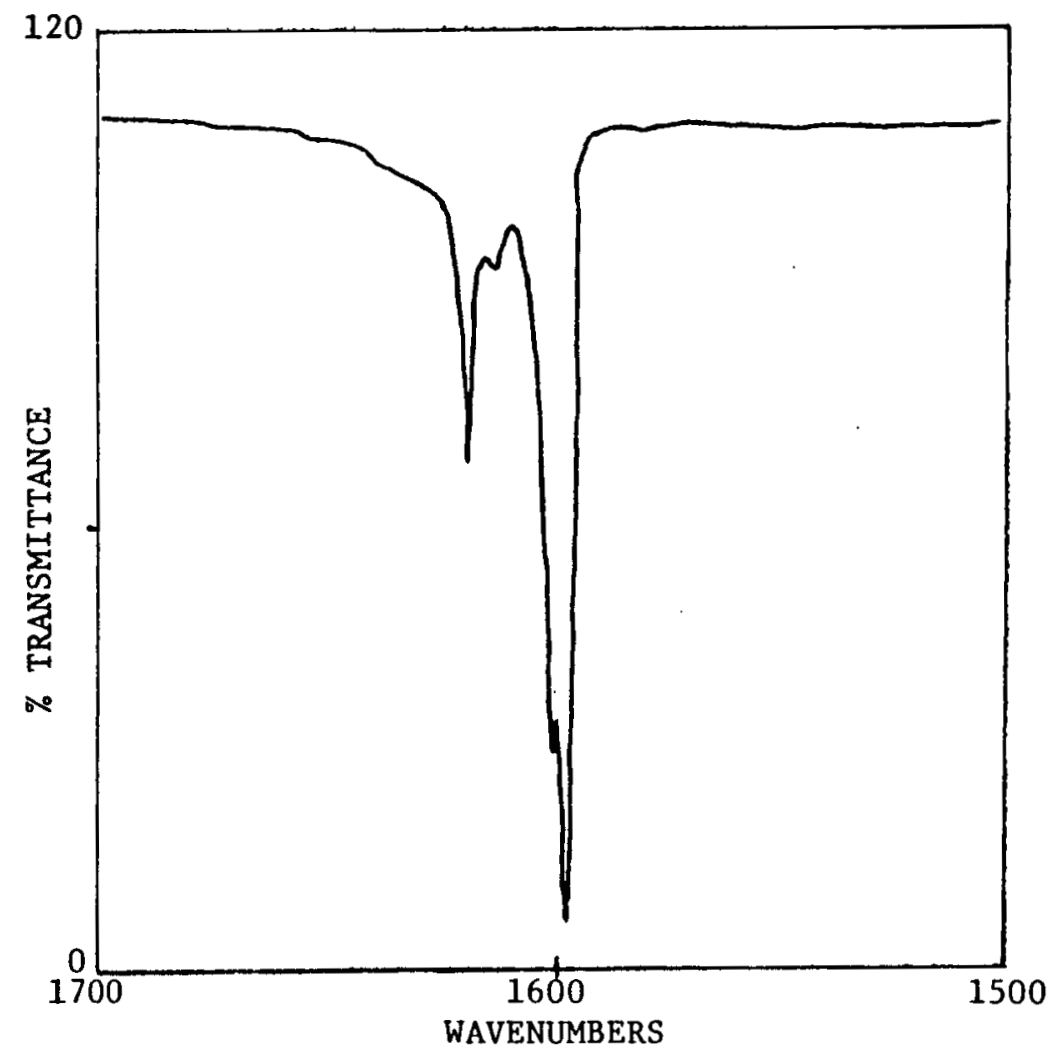

Figure 48. Enlargement of $\mathrm{H}_{2} \mathrm{O}$ absorptions. 
C

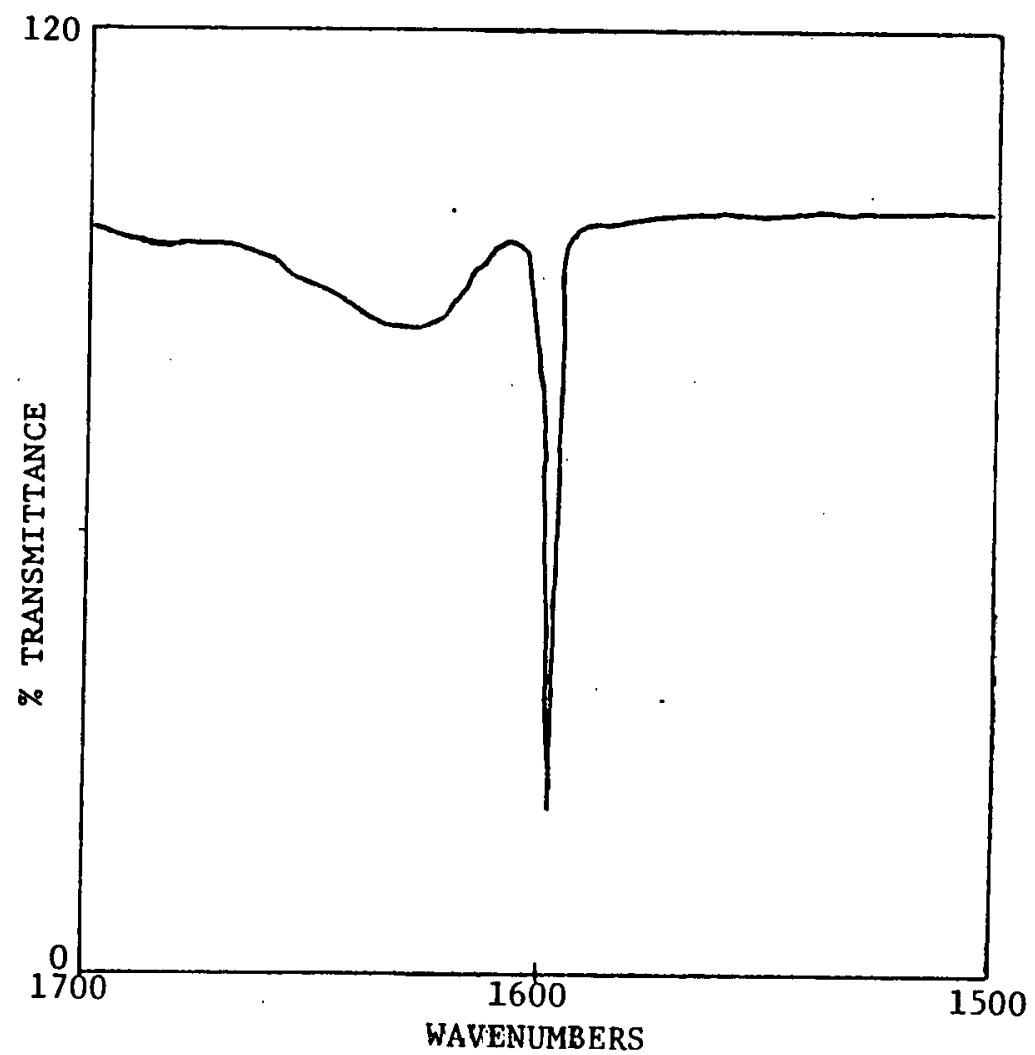

Figure 49. Enlargement of 1700-1500 wavenumber region after sample was annealed to $30^{\circ} \mathrm{K}$.

용 
$\mathrm{UO}_{2} \mathrm{~F}_{2}$ molecules are apparently forming since no bands appear in the $1000-700 \mathrm{~cm}^{-1}$ region.

7. Co-deposition of $\underline{U F}_{6}$ and $\underline{\mathrm{H}}_{2} \mathrm{O}$ Sans Matrix

The following section will detail the result obtained in the experiments in which $\mathrm{UF}_{6}$ and $\mathrm{H}_{2} \mathrm{O}$ were deposited simultaneously and then annealing experiments performed. The experimental details were those discussed in Chapter III, Section I. Figure 50 represents a spectrum of the sample held at $16^{\circ} \mathrm{K}$ prior to any annealing. If one examines the $3800-3200 \mathrm{~cm}^{-1}$ and $1650-1550 \mathrm{~cm}^{-1}$ regions one can see the broad absorptions that are characteristic of agglomerated water.65 There are also absorptions located in the $1000-400 \mathrm{~cm}^{-1}$ spectral region. Figure 51 is an enlargement of this region. There is a strong band located at $865 \mathrm{~cm}^{-1}$ and two weaker absorptions centering at 780 and $710 \mathrm{~cm}^{-1}$. Final1y, there is the strong UF 6 absorption located at $620 \mathrm{~cm}^{-1}$. The next spectrum (Figure 52) was taken after the sample had been warmed to about $150^{\circ} \mathrm{K}$. The changes in the spectrum are that the absorption at $865 \mathrm{~cm}^{-1}$ has increased, the absorption in the 600-550 $\mathrm{cm}^{-1}$ region has decreased, and the 780 and $710 \mathrm{~cm}^{-1}$ absorptions may have receded somewhat. The next spectrum (Figure 53) was taken after the sample had been warmed to about $165^{\circ} \mathrm{K}$. There is a slight absorption appearing at about 940 $\mathrm{cm}^{-1}$. The other bands seem to be the same, but the shoulder on the right side of the $\mathrm{UF}_{6}$ absorption, located at about $590 \mathrm{~cm}^{-1}$, seems to be decreasing. The next spectrum (Figure 54) was taken after the sample was warmed to about $180^{\circ} \mathrm{K}$. Clearly the band located at 


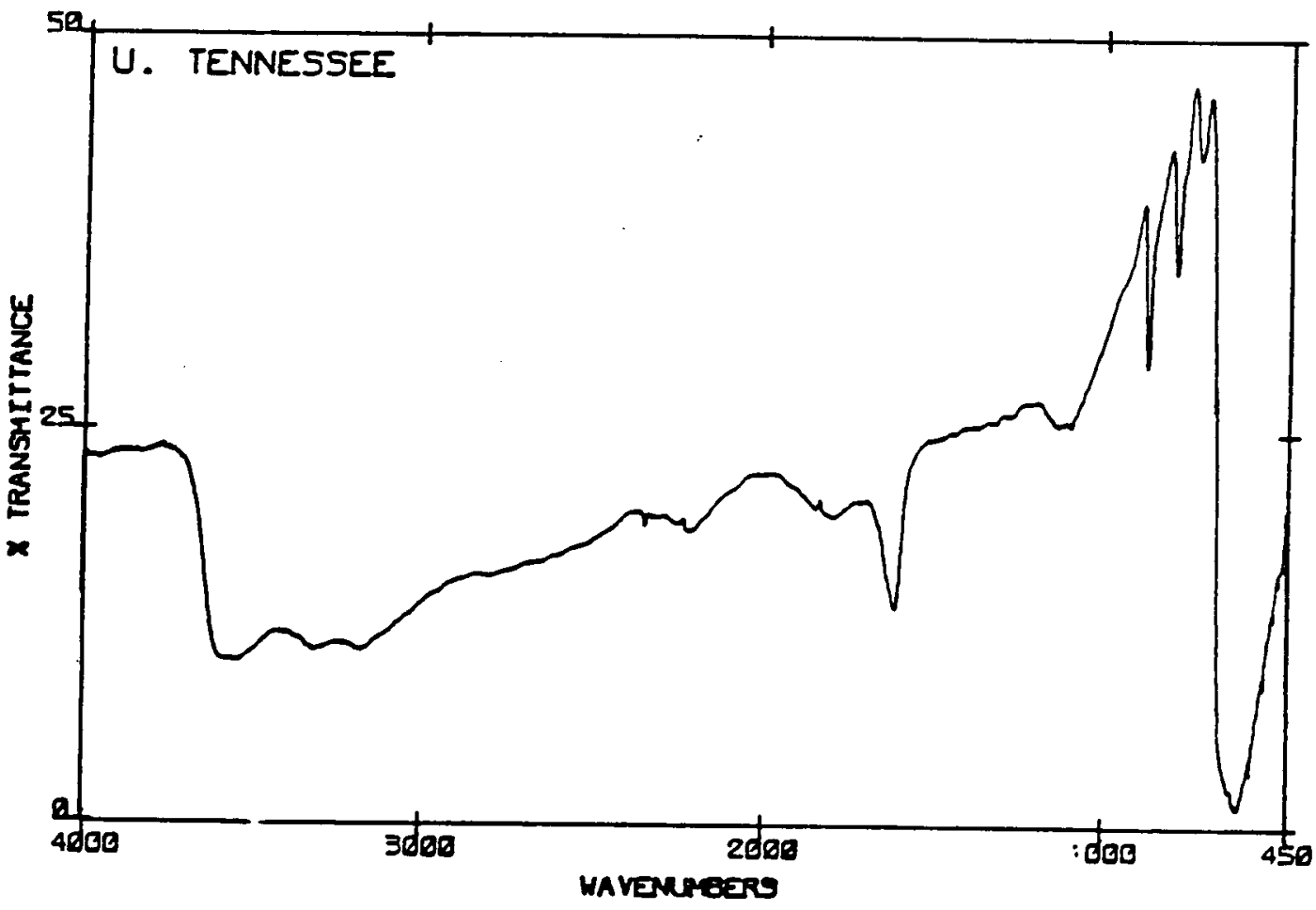
Figure 50. FT-IR spectrum of neat deposited sample of $\mathrm{UF}_{6}$ and $\mathrm{H}_{2} \mathrm{O}$
prior to any annealing. 


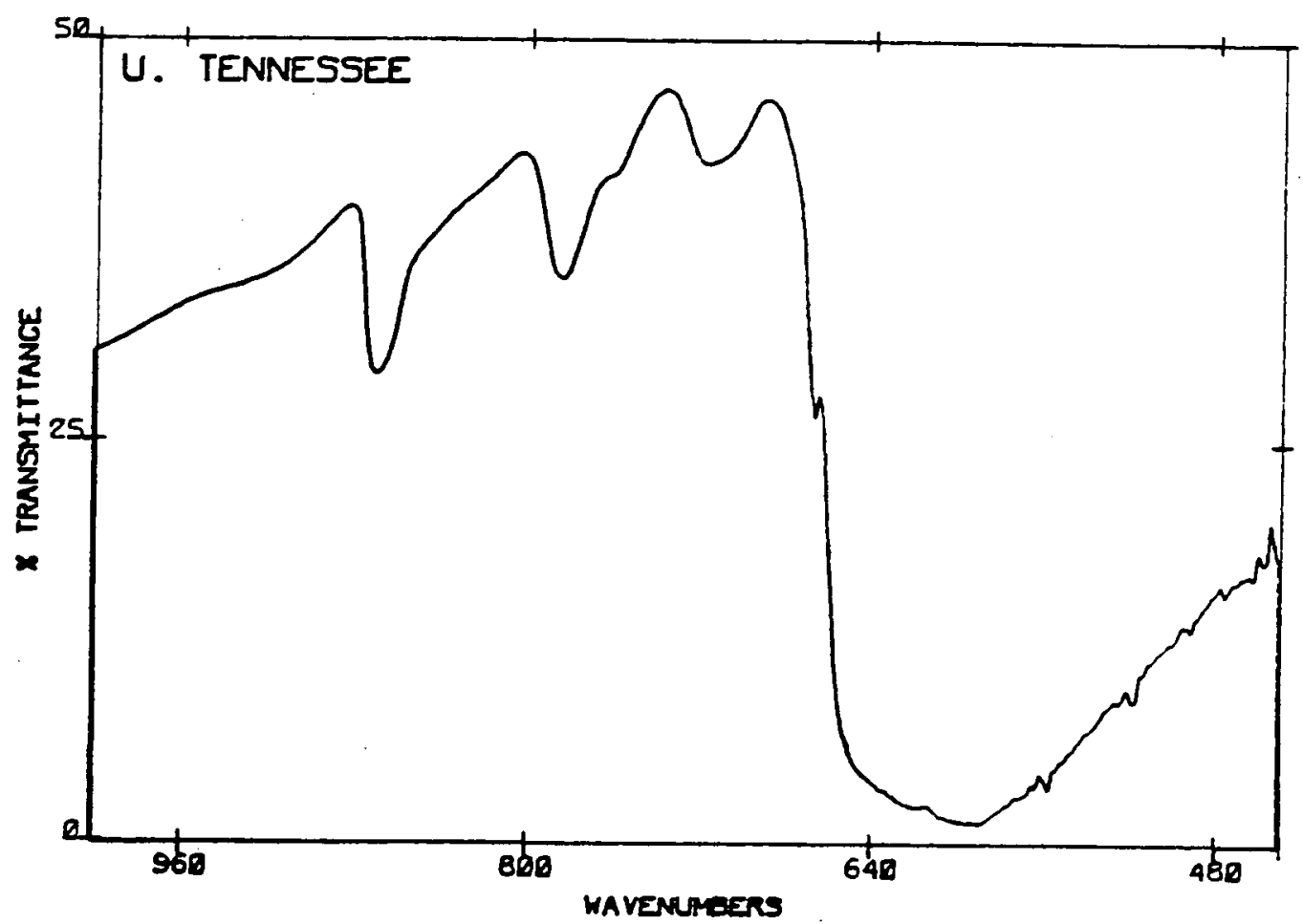

Figure 51. Enlargement of the 1000-400 wavenumber region prior to annealing. 


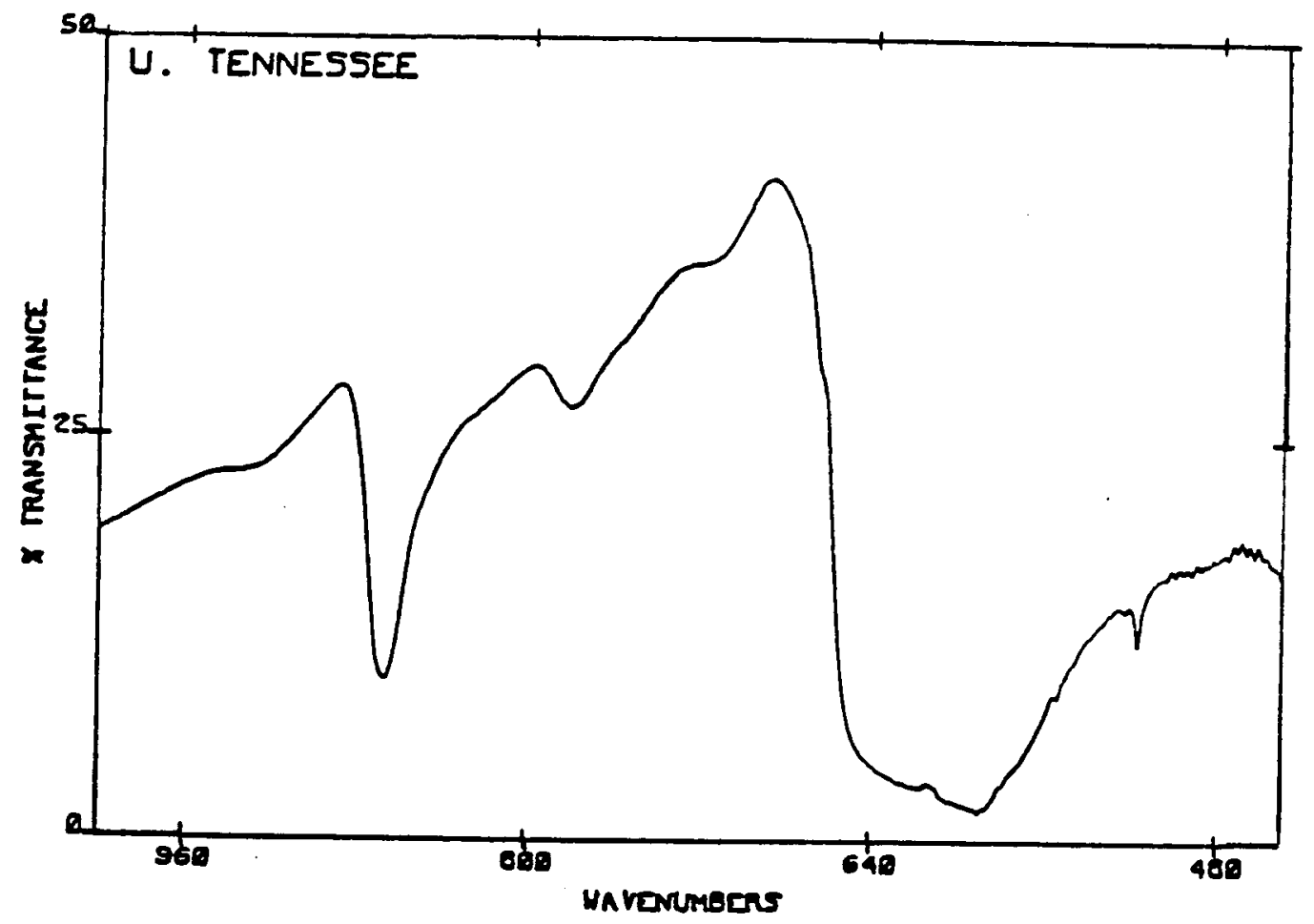

Figure 52. Enlargement of 1000-400 vavenumber region after sample had been annealed to $150^{\circ} \mathrm{K}$. 


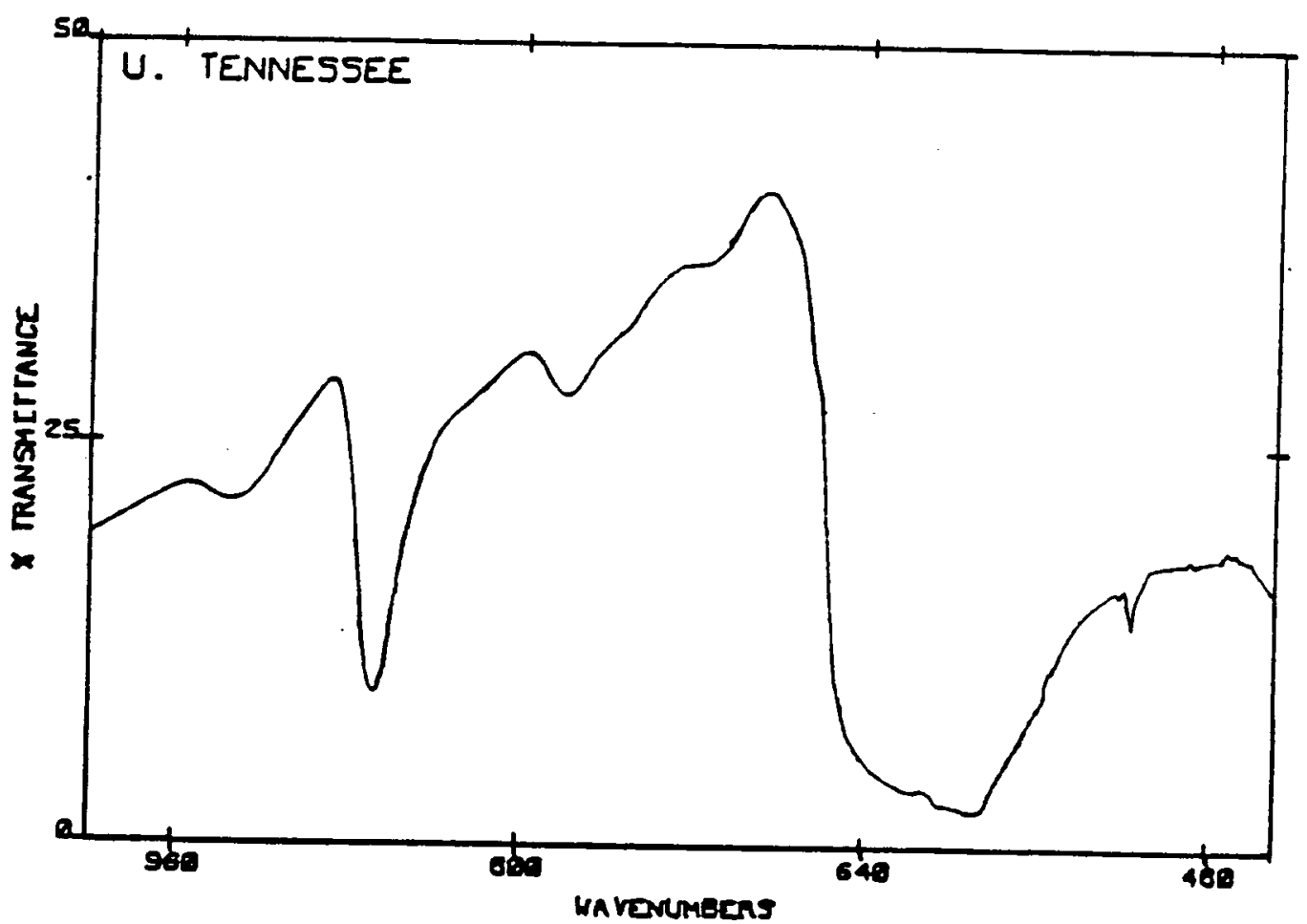

Figure 53. Enlargement of 1000-400 wavenumber region after sample had been annealed to about $165^{\circ} \mathrm{K}$. 


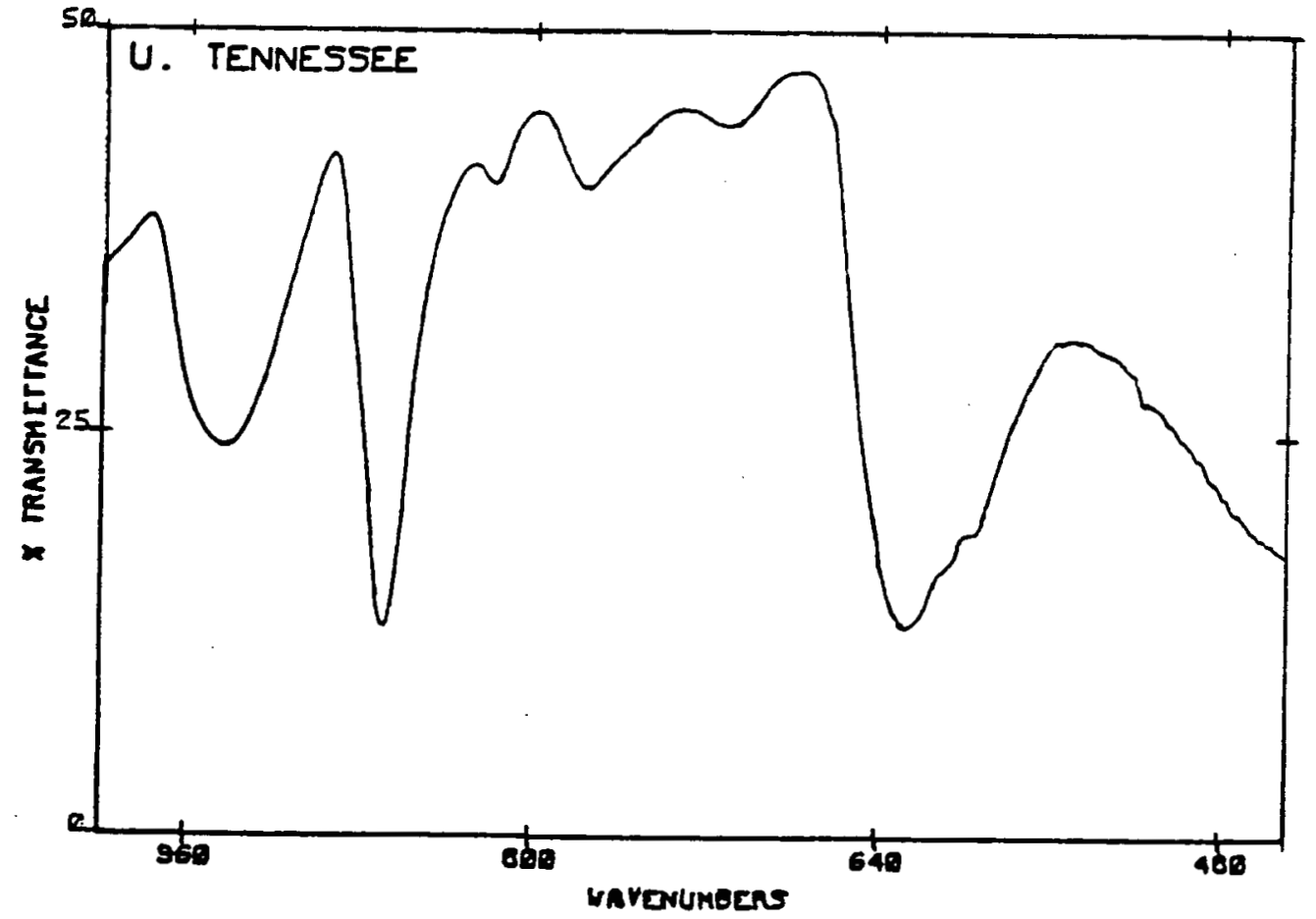

Figure 54. Enlargement of 1000-400 vavenumber region after sample had been annealed to about $180^{\circ} \mathrm{K}$. 
$940 \mathrm{~cm}^{-1}$ has increased in intensity and likewise has the band at 865 $\mathrm{cm}^{-1}$. The absorptions at 780 and $710 \mathrm{~cm}^{-1}$ have remained the same or possibly slightly decreased. Also, the shoulder at $590 \mathrm{~cm}^{-1}$ has disappeared. The next spectrum (Figure 55) was taken after the sample had been warmed to about $195^{\circ} \mathrm{K}$. The band at $940 \mathrm{~cm}^{-1}$ is clearly the strongest absorption. The $865 \mathrm{~cm}^{-1}$ band is now smaller than the $940 \mathrm{~cm}^{-1}$ band and the bands at 780 and $710 \mathrm{~cm}^{-1}$ have receded. Also the $\mathrm{UF}_{6}$ absorption at $620 \mathrm{~cm}^{-1}$ has decreased measurably in intensity. The final spectrum (Figure 56) was taken after the sample had been warmed past $220^{\circ} \mathrm{K}$. The band at 940 $\mathrm{cm}^{-1}$ is very strong now. The band at $864 \mathrm{~cm}^{-1}$ may have receded and is overlapped by the $940 \mathrm{~cm}^{-1}$ band, but the bands at 780,710 , and $620 \mathrm{~cm}^{-1}$ cannot be located.

This experiment supports the belief that even, if diffusion had occurred in the co-deposition experiments in argon, no reaction would have occurred because of thermodynamic factors at those temperatures. The $\mathrm{UF}_{6}$ and $\mathrm{H}_{2} \mathrm{O}$ were obviously in contact with one another during deposition and on the window since they were both in concentrated form and also because products were formed on the initial deposit which is evidenced by the bands at 865,780 , and 710 $\mathrm{cm}^{-1}$. These products were probably formed during the mixing of the $\mathrm{UF}_{6}$ and $\mathrm{H}_{2} \mathrm{O}$ streams between the deposition tubes and the CsI window, since no new bands appeared during the annealing experiment until the sample had been warmed to about $160^{\circ} \mathrm{K}$; then, the new band at 940 $\mathrm{cm}^{-1}$ appeared, and the others receded. Obviously the band at 940 $\mathrm{cm}^{-1}$ acts independently of the 865,780 , and $710 \mathrm{~cm}^{-1}$ bands. But, 


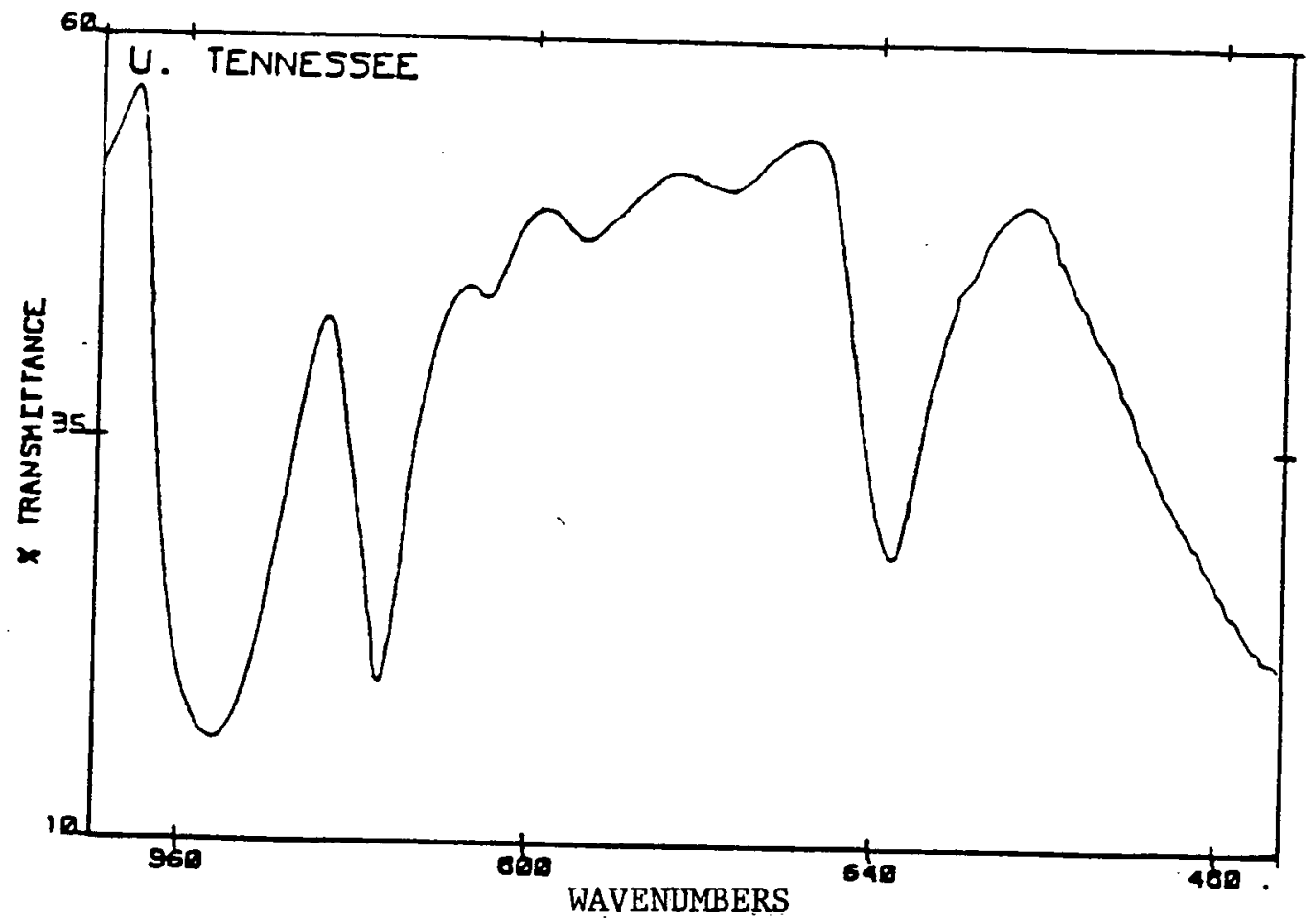

Figure 55. Enlargement of 1000-400 wavenumber region after sample had been annealed to about $195^{\circ} \mathrm{K}$. 


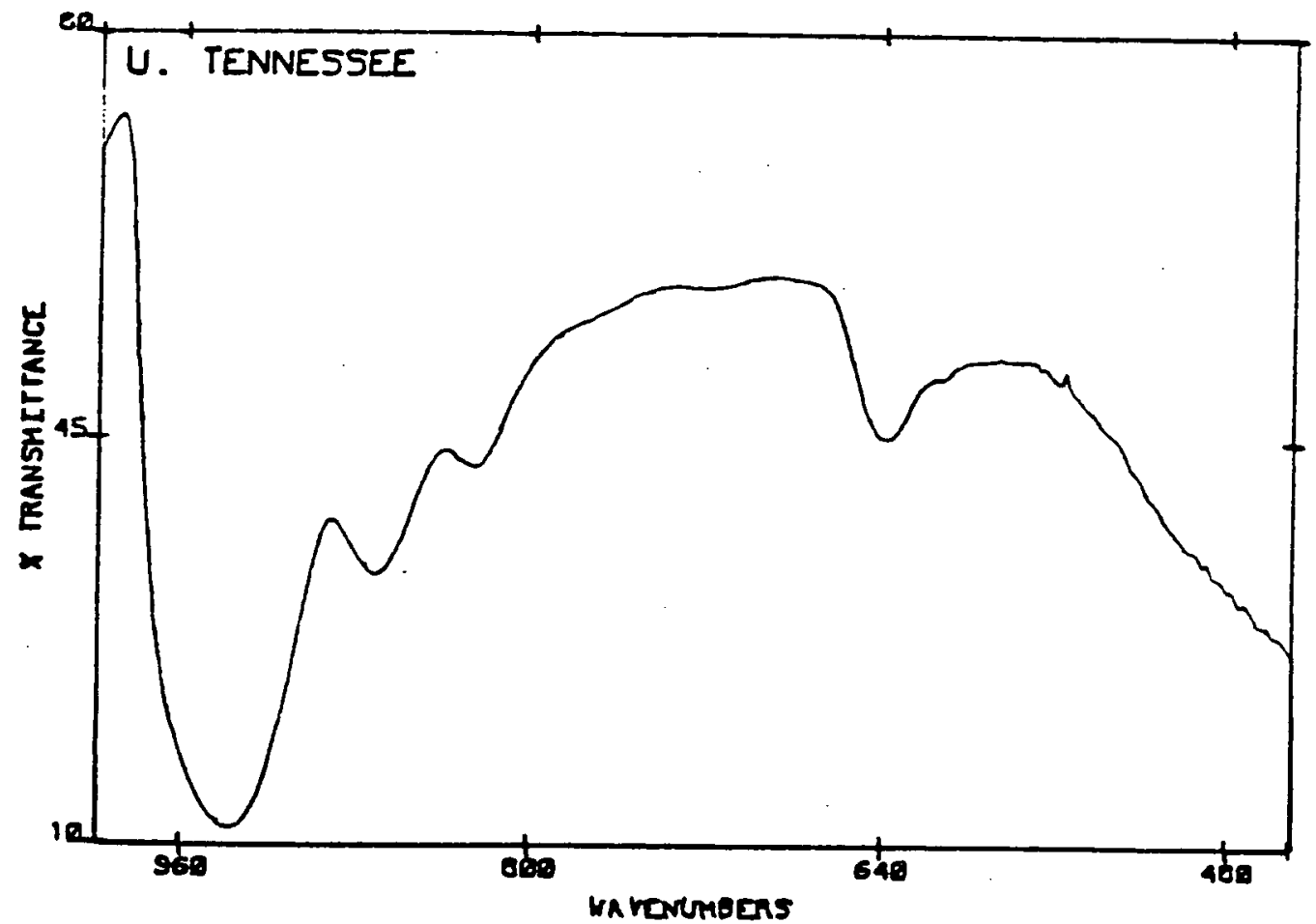

Figure 56. Enlargement of 1000-400 wavenumber region after sample had been annealed past $220^{\circ} \mathrm{K}$. 
how are the 865,780 , and $710 \mathrm{~cm}^{-1}$ bands interrelated? Also, the shoulder on the right-hand side $\left(590 \mathrm{~cm}^{-1}\right)$ of the $\mathrm{UF}_{6}$ band seems to act independently. The $940 \mathrm{~cm}^{-1}$ band is in a region and also has a shape that has been previously assigned to a $\mathrm{UO}_{2}$ stretch by prior investigators. 10 In a study conducted by Hoekstra,71 it was determined that uranyl fluoride dihydrate $\left(\mathrm{UO}_{2} \mathrm{~F}_{2} \cdot 2 \mathrm{H}_{2} \mathrm{O}\right)$ has a $\mathrm{UO}_{2}$ stretch which occurs at $935 \mathrm{~cm}^{-1}$. The other bands cannot be definitively assigned at this time. The nitrogen experiments helped to support the fact that probably little or no diffusion was observed during the argon-matrix experiments. The pure studies have supported the belief that there are thermodynamic factors involved also. But, is there also a concentration effect? This question cannot be answered at this point.

8. Matrix-Isolated $\underline{\mathrm{UF}}_{6}$ and $\underline{\mathrm{H}}_{2} \mathrm{O}$ in Xenon

The following is a discussion of the results obtained in the co-deposition experiment of $\mathrm{UF}_{6}$ and $\mathrm{H}_{2} \mathrm{O}$ in xenon which was performed under experimental conditions discussed in Chapter III, Section $\mathrm{H}$. Before proceeding with the discussion, some reservations about the experiment must be noted. During the annealing, the pressure would sometimes start to rise drastically at about $30^{\circ} \mathrm{K}$, and then lower to its initial value. This process would also tend to, cause the annealing to proceed faster than was desired. It was felt that the xenon had some impurities, possibly wet air. Also, the experiments were difficult to duplicate. Sometimes when the matrix sublimed it carried the sample with it, and at other times some of the sample 
remained. The few spectra that will be shown are examples of experiments in which some $\mathrm{UF}_{6}$ and $\mathrm{H}_{2} \mathrm{O}$ remained and subsequently underwent hydrolysis. The first spectrum (Figure 57a) was taken while the sample was being held at $16^{\circ} \mathrm{K}$. The two peaks in the 1650-1600 $\mathrm{cm}^{-1}$ spectral region are indicative of $\mathrm{H}_{2} \mathrm{O}$ absorptions. Other peaks occur at approximately $1250,940,850$, and $615 \mathrm{~cm}^{-1}$. The band at $615 \mathrm{~cm}^{-1}$ can be assigned to the $\mathrm{UF}_{6}$ absorption. The next spectrum (Figure 57b) was taken after the sample had warmed past $150^{\circ} \mathrm{K}$. Notice how the peaks at 940,850 , and $800 \mathrm{~cm}^{-1}$ have increased in intensity. But, also notice how the background baseline has shifted due to scattering. The next spectrum shown (Figure 58a) reveals that the $\mathrm{UF}_{6}$ absorption has decreased in intensity relative to the peaks at 940,850 , and $800 \mathrm{~cm}^{-1}$. The final spectrum (Figure 58b) shows that the $\mathrm{UF}_{6}$ absorption at $615 \mathrm{~cm}^{-1}$ has almost gone, and the absorptions at 940,850 , and $800 \mathrm{~cm}^{-1}$ have apparently intensified.

The peaks in the $1000-600 \mathrm{~cm}^{-1}$ region in the xenon-matrix study are similar to the ones located in the same regions in the neat experiment (pure $\mathrm{UF}_{6}$ and pure $\mathrm{H}_{2} \mathrm{O}$ ). In the neat experiment peaks were located at $940,865,780$, and $710 \mathrm{~cm}^{-1}$. It would probably be safe to assume that the peak located at $940 \mathrm{~cm}^{-1}$-in both experiments could be assigned to a $\mathrm{UO}_{2}$ stretch. As for the others, no assignments can be made at this point.

9. $\underline{\mathrm{UF}}_{6}$ and $\underline{\mathrm{H}}_{2} \mathrm{O}$ Merging Streams Co-deposition Experiment

In this section the results of the $\mathrm{UF}_{6}-\mathrm{H}_{2} \mathrm{O}$ merging-streams study will be presented and discussed. The experimental details 

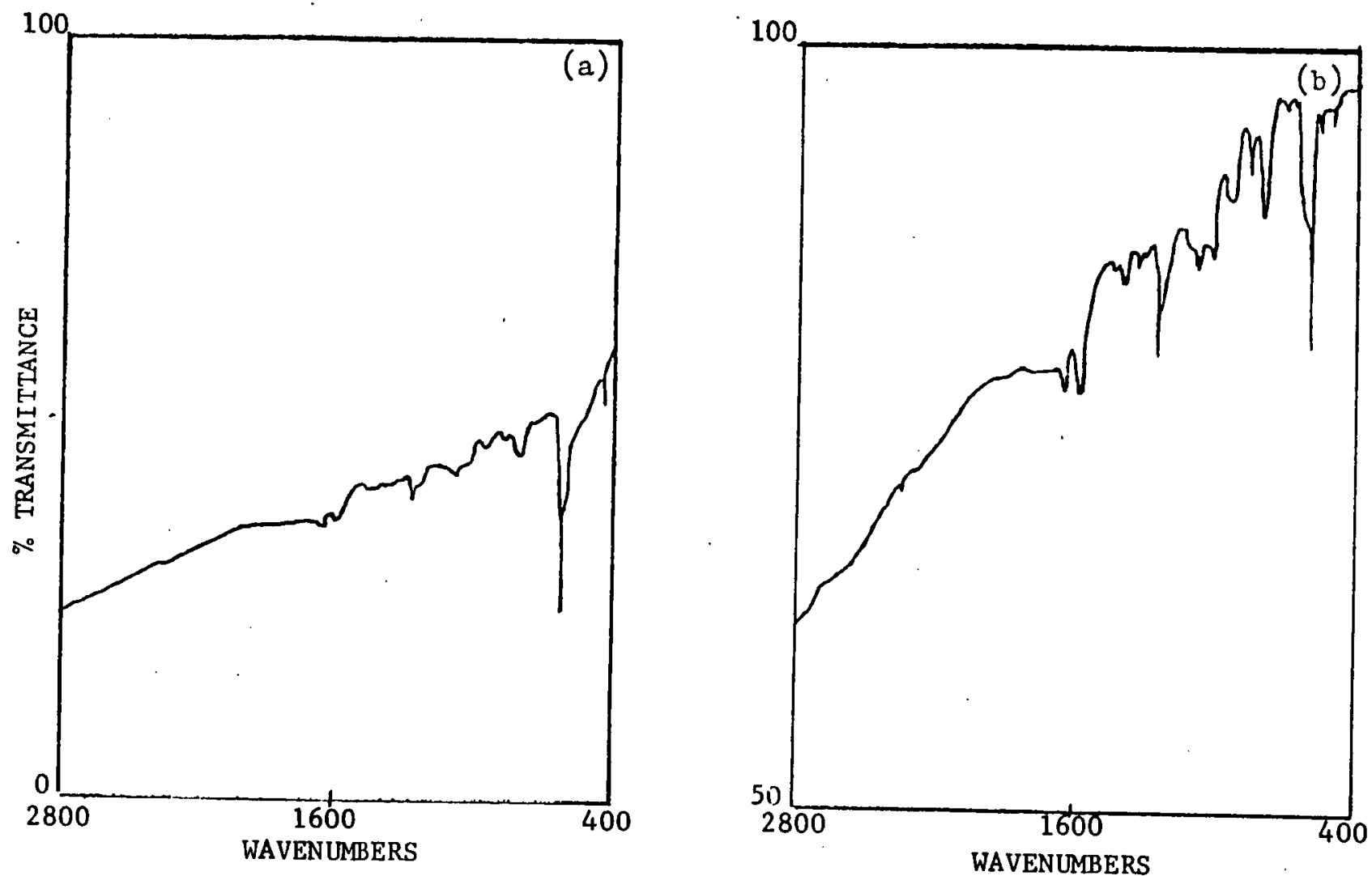

Figure 57. (a) Matrix-isolated FT-IR spectrum of Xe:UF 6 and Xe: $\mathrm{H}_{2} \mathrm{O}$ held at $16^{\circ} \mathrm{K}$. (b) Spectrum taken after sample was annealed past $150^{\circ} \mathrm{K}$. 

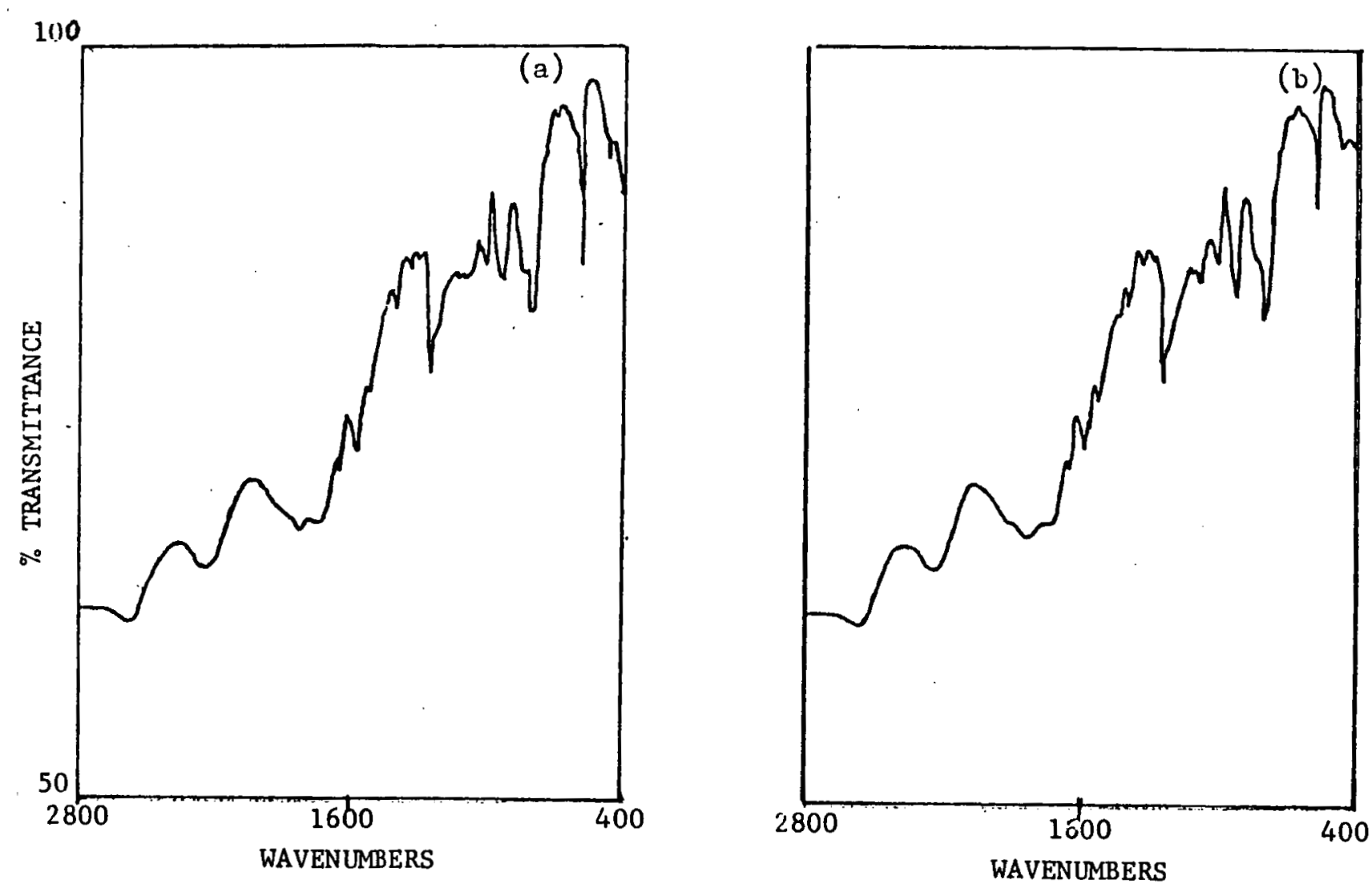

Figure 58. (a) Spectrum of same region after annealing further. (b) Spectrum of same region after annealing past $200^{\circ} \mathrm{K}$. 
were those discussed in Chapter III, Section J. The first spectrum (Figure 59) was taken after 100:1 samples of $\mathrm{Ar}_{\mathrm{U}} \mathrm{UF}_{6}$ and $\mathrm{Ar}: \mathrm{H}_{2} \mathrm{O}$ were mixed prior to deposition at $16^{\circ} \mathrm{K}$ in a tube back $30 \mathrm{~cm}$ from the deposition inlet. In order to simplify the discussion, only the $1000-500 \mathrm{~cm}^{-1}$ region will be examined. Figure 59 reveals only one peak in this region, and it is centered at approximately $800 \mathrm{~cm}^{-1}$. The next spectrum (Figure 60) was also taken at $16^{\circ} \mathrm{K}$ after a $100: 1$ sample deposit, and it discloses the same $800 \mathrm{~cm}^{-1}$ band. After obtaining these results there was some uncertainty as to whether the samples were depositing cleanly. There was some fear that the streams might have been backing up and absorbing on the inner surfaces of the tubes since only a small peak was observed. Figure 61 represents a spectrum that was taken after the $\mathrm{UF}_{6}$ and $\mathrm{H}_{2} \mathrm{O}$ 100:1 argon samples were deposited separately. Notice the broad band which extends from about 950 to $750 \mathrm{~cm}^{-1}$. It centers at about 850 $\mathrm{cm}^{-1}$ and, since the streams were deposited separately, the broad band should not have appeared. Since there were no water lines present in the spectrum (Figure 61), it was felt the $\mathrm{H}_{2} \mathrm{O}$ was reacting with some debris that had been adsorbed on the inner walls of the $\mathrm{H}_{2} \mathrm{O}$ deposition lines. There is also the $\mathrm{UF}_{6}$ absorption located at about $600 \mathrm{~cm}^{-1}$. The next spectrum (Figure 62) was recorded after only pure argon was passed through the $\mathrm{H}_{2} \mathrm{O}$ side of the lines. Again, notice the broad peak. Since passing a $U_{6}$ :Ar sample through the $\mathrm{UF}_{6}$ deposition tube produced a spectrum having only a $\mathrm{UF}_{6}$ absorption, this indicated that there might be some contaminants in the $\mathrm{H}_{2} \mathrm{O}$ deposition line and not in the $\mathrm{UF}_{6}$ side. Therefore heating 


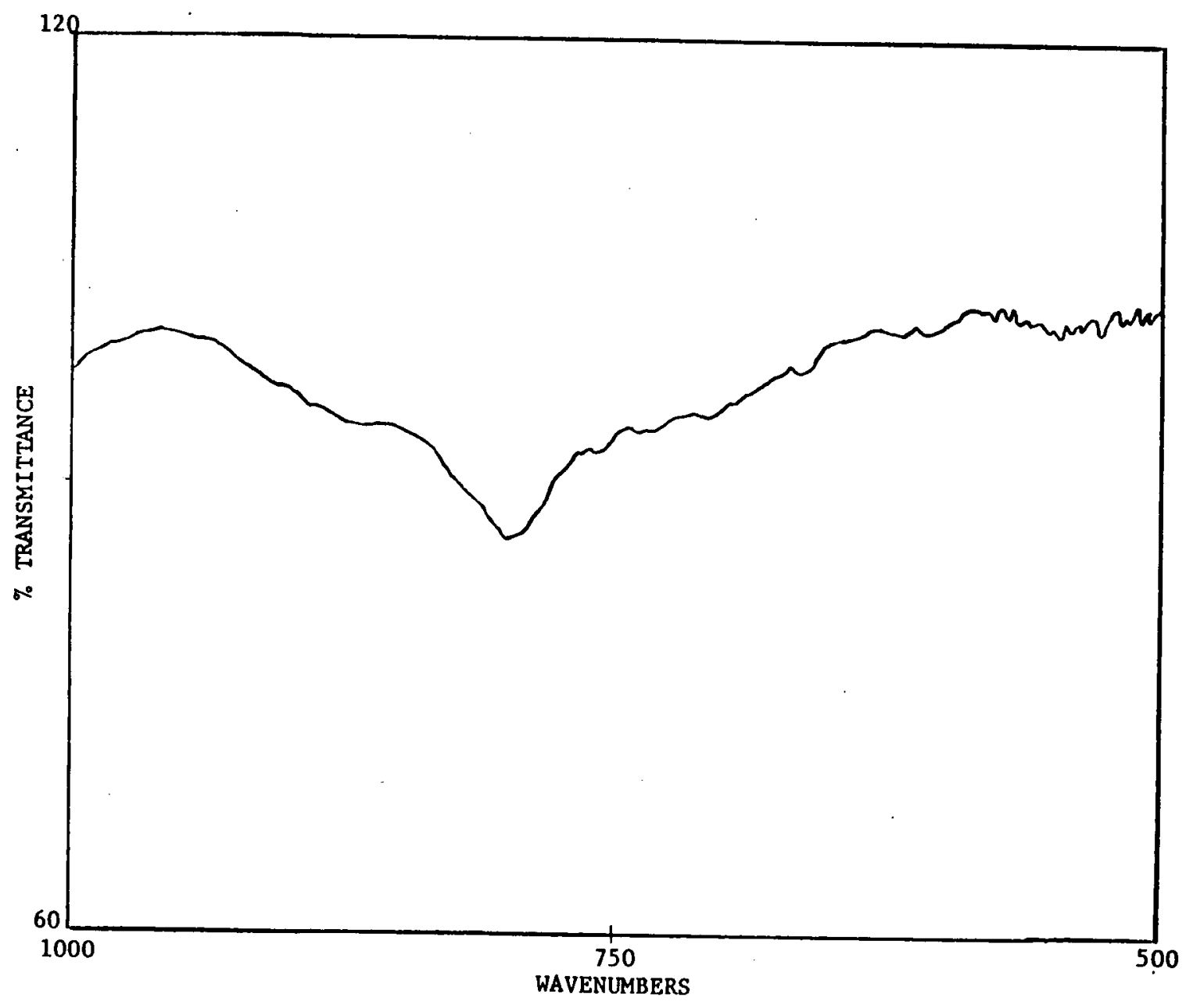
Figure 59. Matrix-isolated FT-IR spectrum of sample of $\mathrm{UF}_{6}: \mathrm{H}_{2} \mathrm{O}: \mathrm{Ar}(1: 1: 100)$ that was mixed in-
line prior to deposition. 


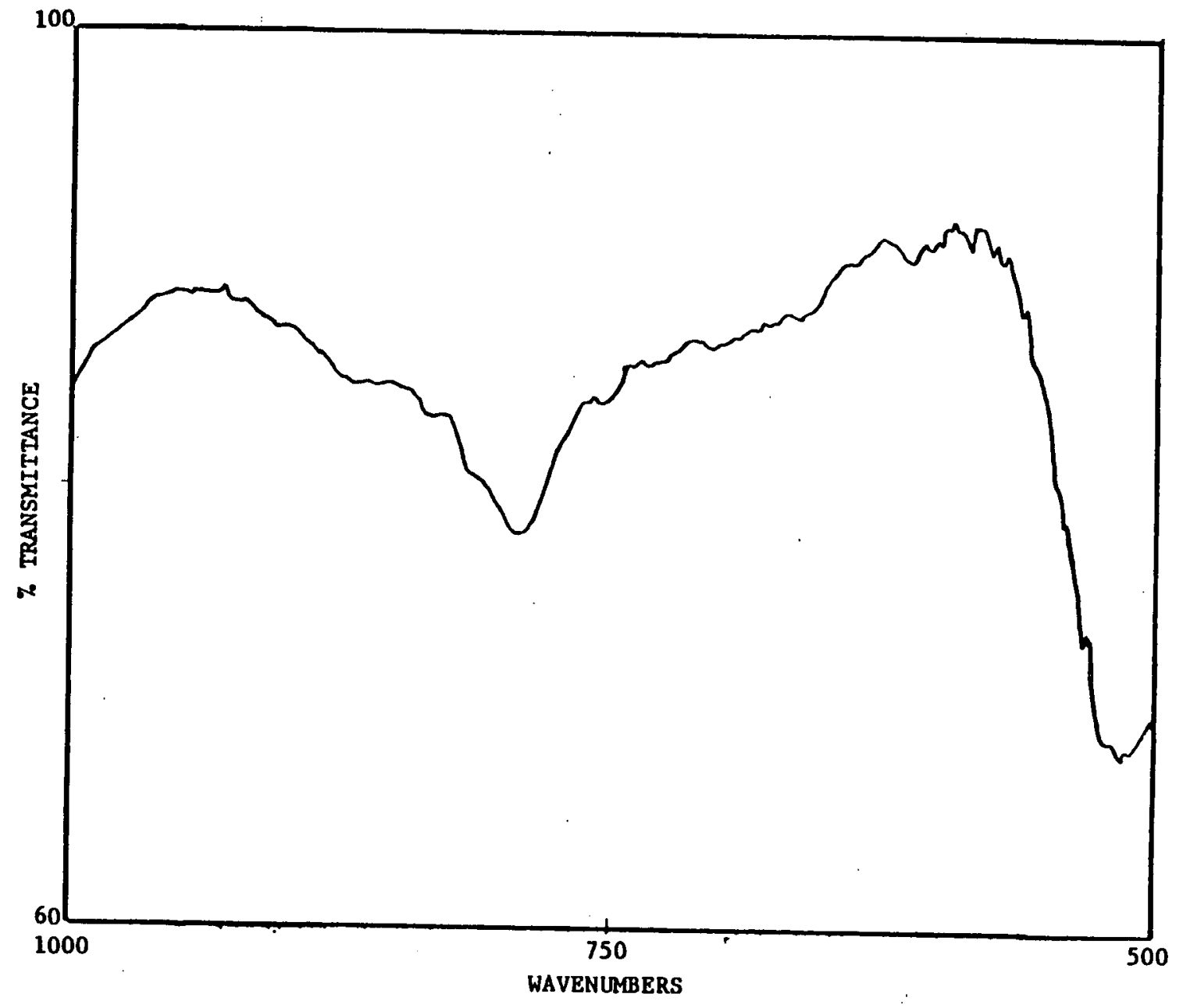

Figure 60. Matrix-isolated FT-IR spectrum of identical sample that was mixed in-line prior to deposition. 


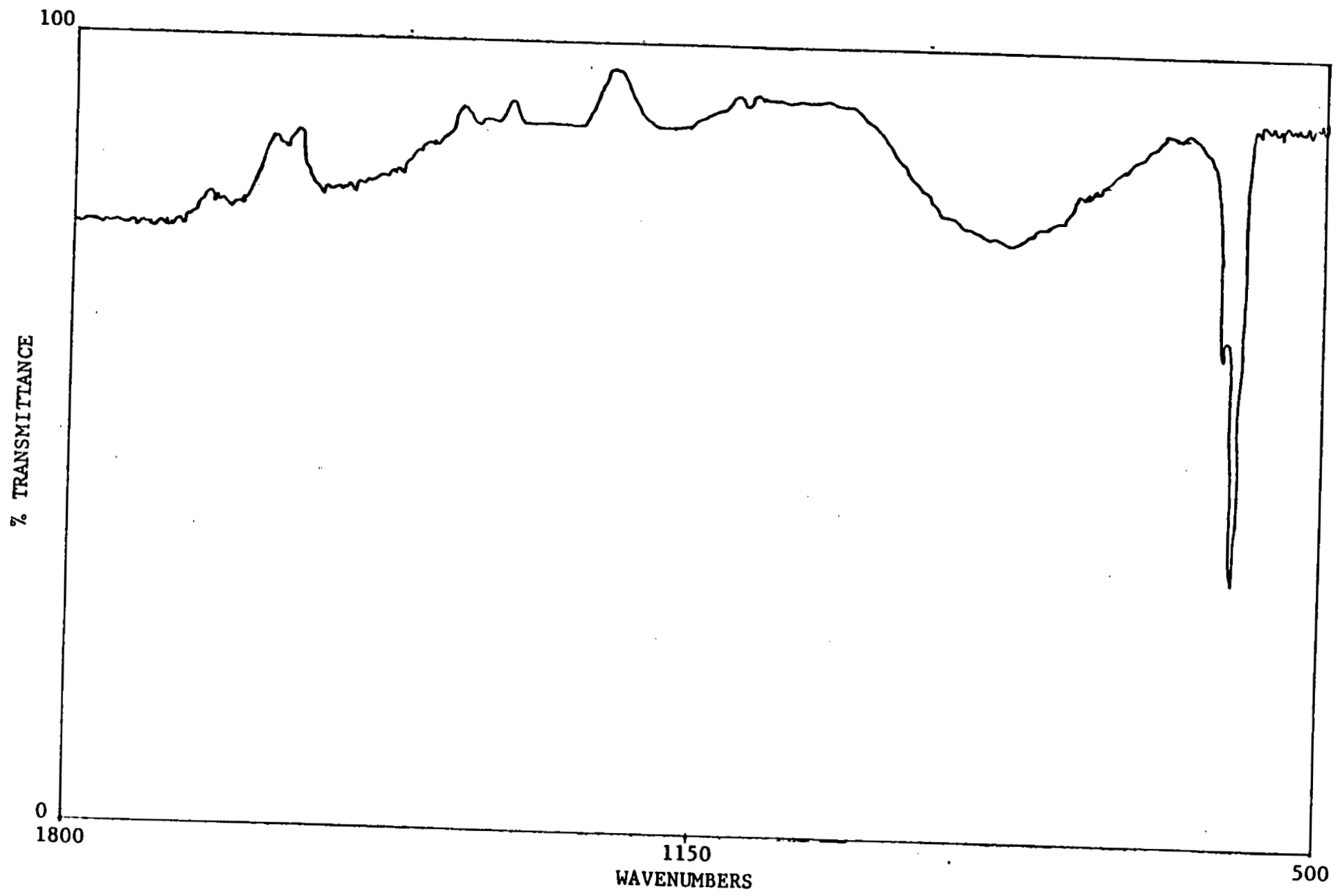

Figure 61. Matrix-isolated FT-IR spectrum of similar sample in which the $\mathrm{UF}_{6}$ and $\mathrm{H}_{2} \mathrm{O}$ were
deposited sequentially. 


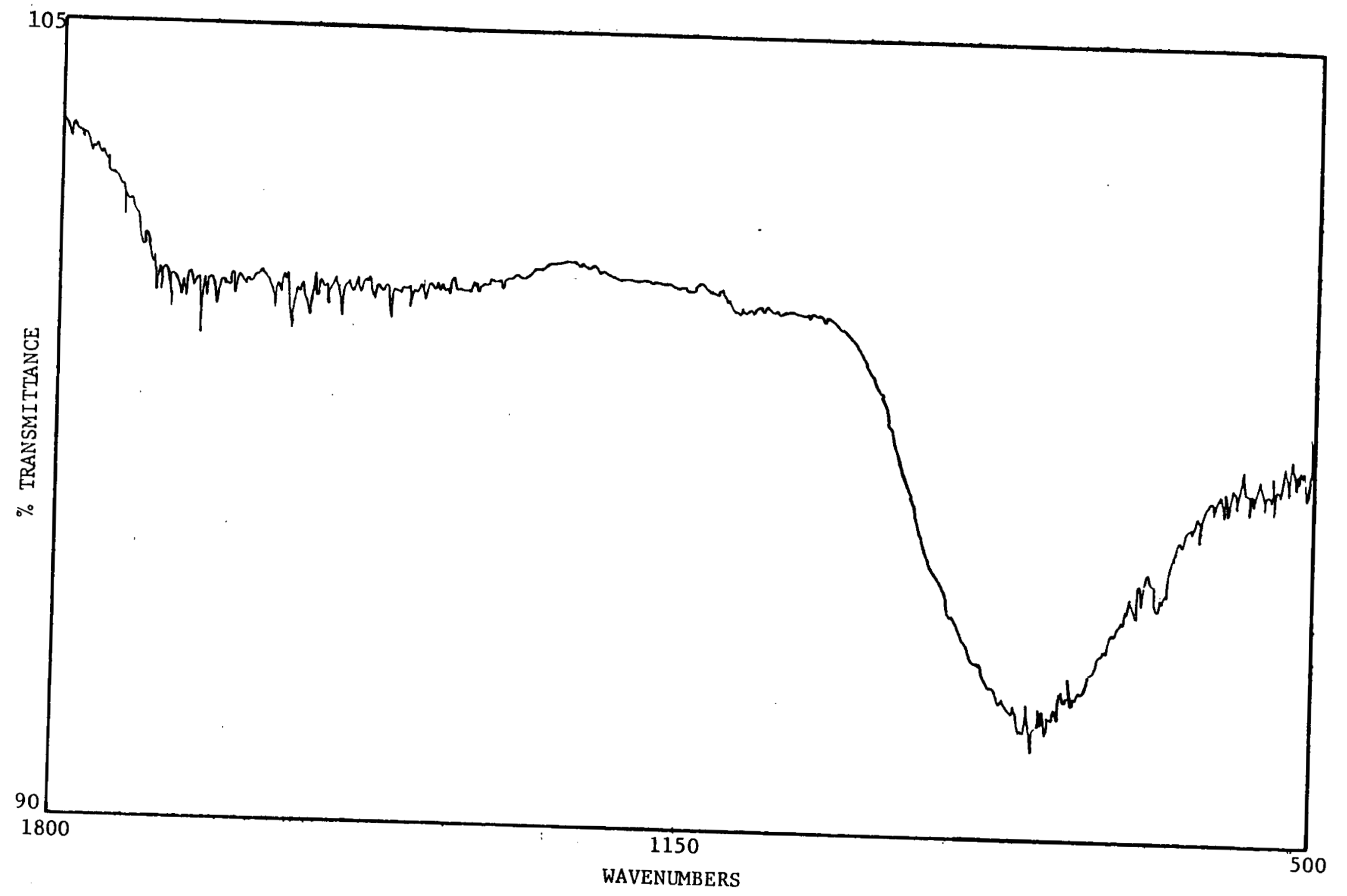

Figure 62. FT-IR spectrum that was recorded after only pure Ar was passed through the $\mathrm{H}_{2} \mathrm{O}$ side and $\underset{\sim}{\mathrm{N}}$
deposited. 
tape was wrapped around the tube, and the tube was evacuated for several days in order to remove the debris. It was then decided to decrease the water concentration to possibly help eliminate some of the debris. The next spectrum (Figure 63) was recorded after 100:1 $\mathrm{Ar}: \mathrm{UF}_{6}$ and 1000:1 Ar: $\mathrm{H}_{2} \mathrm{O}$ samples were merged and deposited at $16^{\circ} \mathrm{K}$. Note the broad bands in the $3800-3200 \mathrm{~cm}^{-1}$ region indicating that some water had been deposited on the CsI windows. The only significant peak present in the $1000-600 \mathrm{~cm}^{-1}$ region is the $\mathrm{UF}_{6}$ absorption.

Next, the' $30-\mathrm{cm}$ tube was lengthened to $100 \mathrm{~cm}$. Figure 64 represents a spectrum that was taken after 100:1 samples of Ar:X $\left(\mathrm{X}=\mathrm{UF}_{6}, \mathrm{H}_{2} \mathrm{O}\right.$ ) were merged and deposited at $16^{\circ} \mathrm{K}$. There is a broad band which extends from about $950 \mathrm{~cm}^{-1}$ to about $750 \mathrm{~cm}^{-1}$ and is centered at about $840 \mathrm{~cm}^{-1}$. (It must be noted here that the tubes were heated during this experiment in order to prevent any material from adsorbing on their inner walls since a higher concentrated water sample was used.) There are also two other peaks located at $625 \mathrm{~cm}^{-1}$ and $595 \mathrm{~cm}^{-1}$. The next spectrum (Figure 65) was taken after the deposited sample had been warmed. The large band at $825 \mathrm{~cm}^{-1}$ has changed shape and possibly shifted somewhat (from 840 $\mathrm{cm}^{-1}$ ), and the bands at 625 and $59.5 \mathrm{~cm}^{-1}$ have virtually disappeared. However, no new bands have emerged. The next three figures $(66,67$, and 68) are basically a repeat of the same deposition and annealing experiment with esentially the same results. Later, 1000:1 samples of $\mathrm{Ar}: \mathrm{UF}_{6}$ and $\mathrm{Ar}: \mathrm{H}_{2} \mathrm{O}$ were tried with basically the same results (see Figure-69). - - It was then decided that the mixing tube would be 


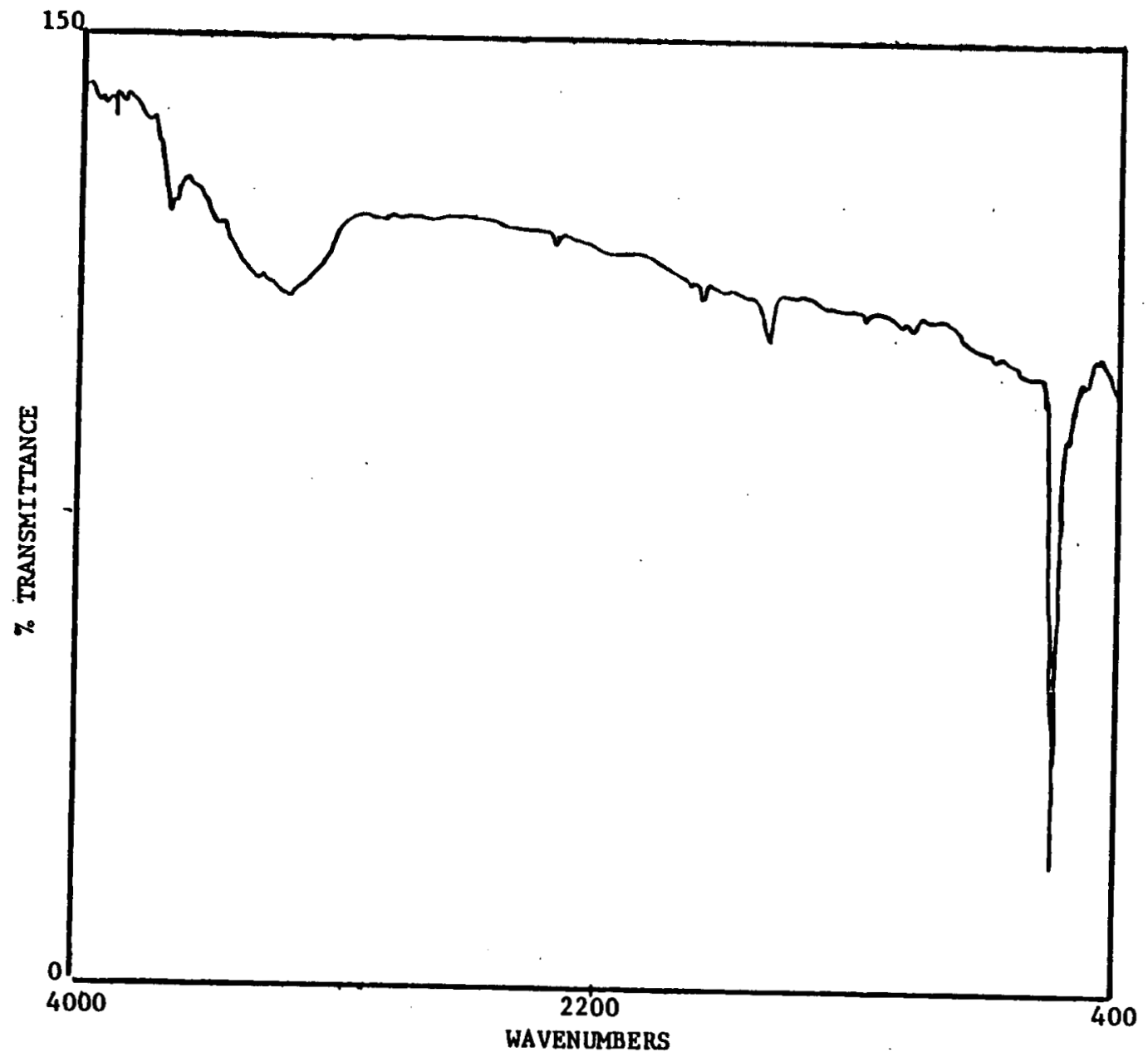

Figure 63. Matrix-isolated FT-IR spectrum of 100:1 Ar:UF 6 and $1000: 1 \mathrm{Ar}: \mathrm{H}_{2} \mathrm{O}$ samples were mixed and deposited at $16^{\circ} \mathrm{K}$.

๙ั 


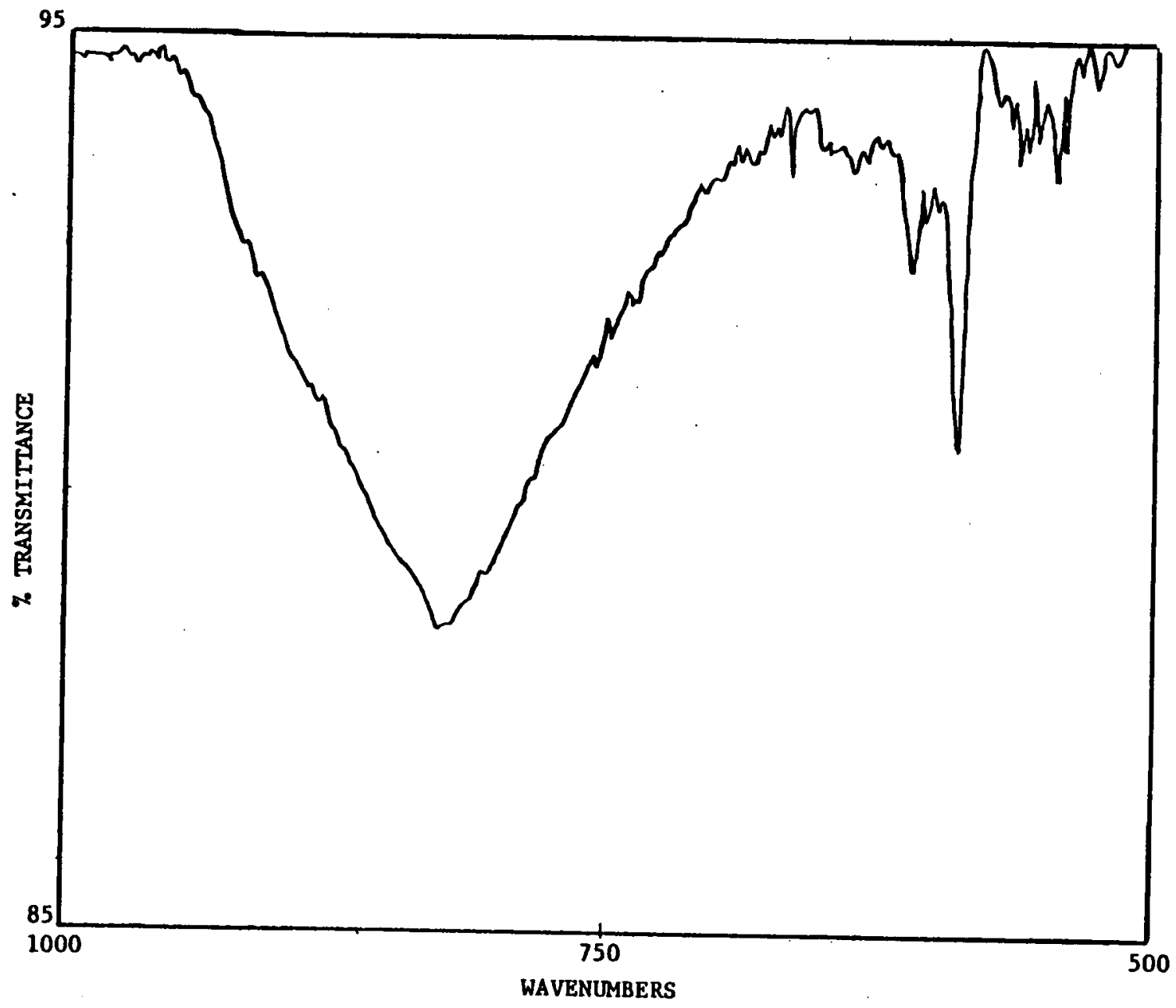

Figure 64. Matrix-isolated FT-IR spectrum of $\mathrm{Ar}: \mathrm{UF}_{6}: \mathrm{H}_{2} \mathrm{O}(100: 1: 1)$ sample in which the samples were mixed in a $100-\mathrm{cm}$ tube prior Eo deposition. 


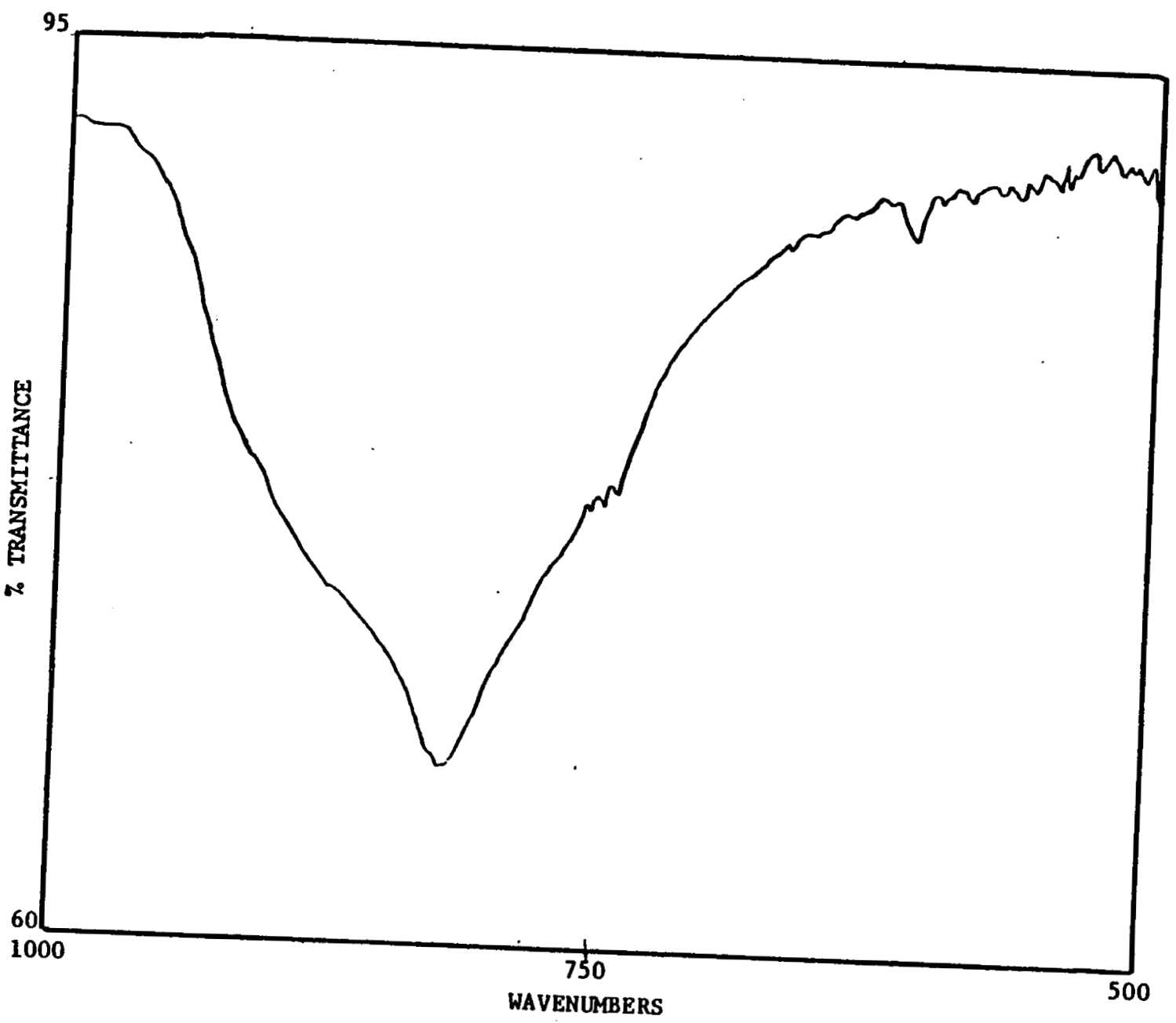

Figure 65. Spectrum recorded after sample had been annealed somewhat. 


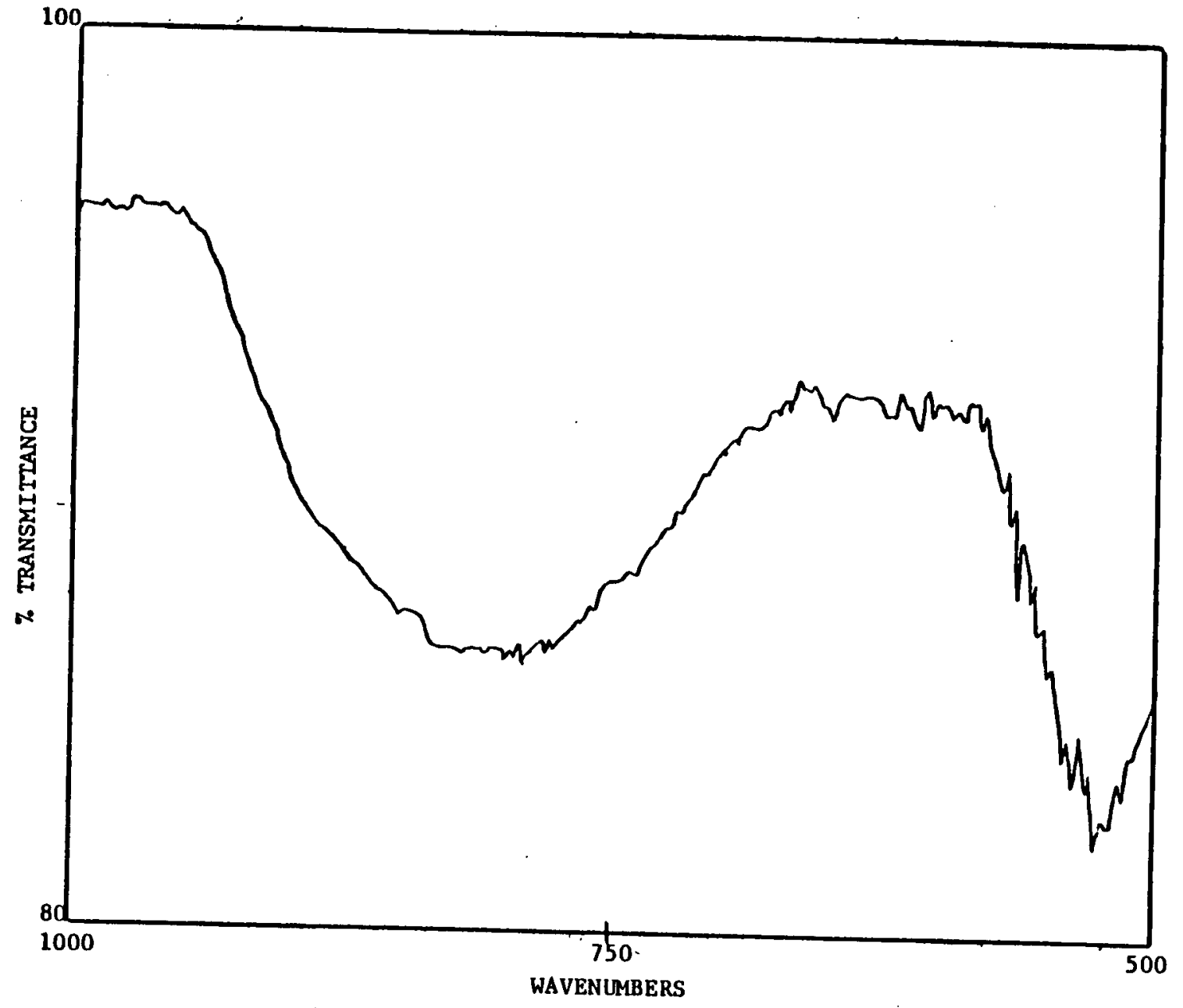

Figure 66. Matrix-isolated FT-IR spectrum of sample similar to the sample recorded in Figure 64. 


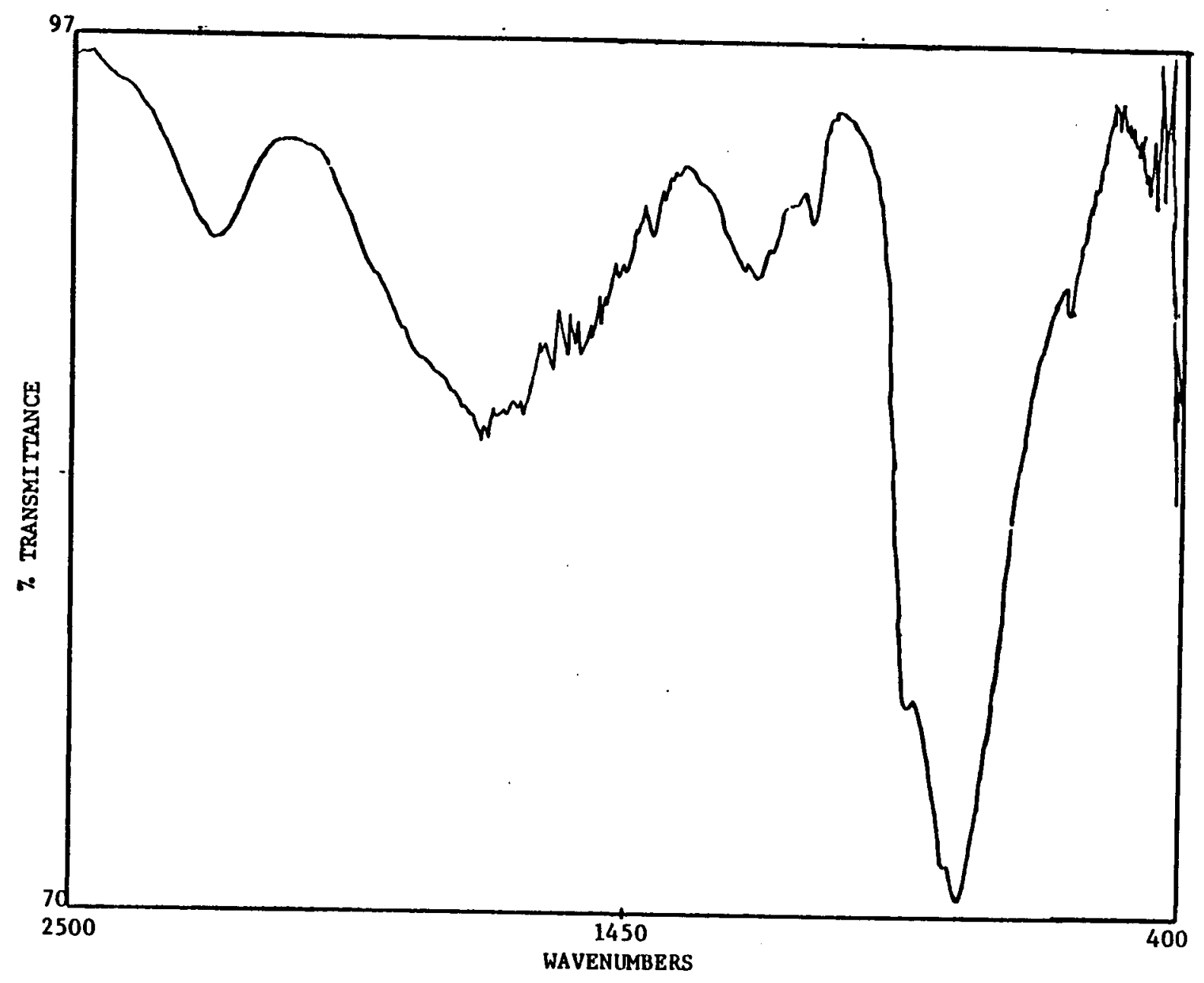

Figure 67. Spectrum recorded after sample annealed somewhat. 


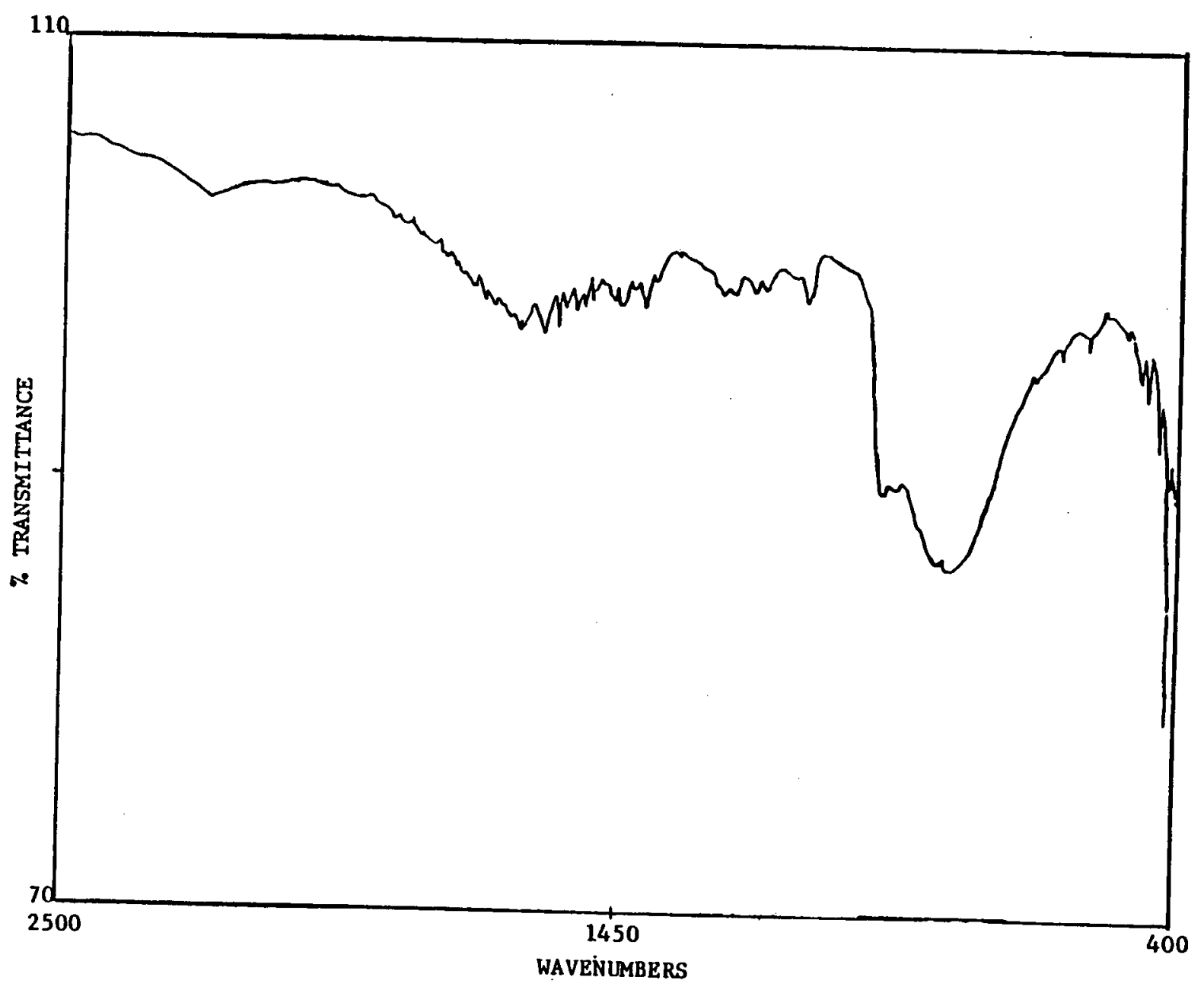

Figure 68. Spectrum recorded after sample had been annealed to about $35^{\circ} \mathrm{K}$. 


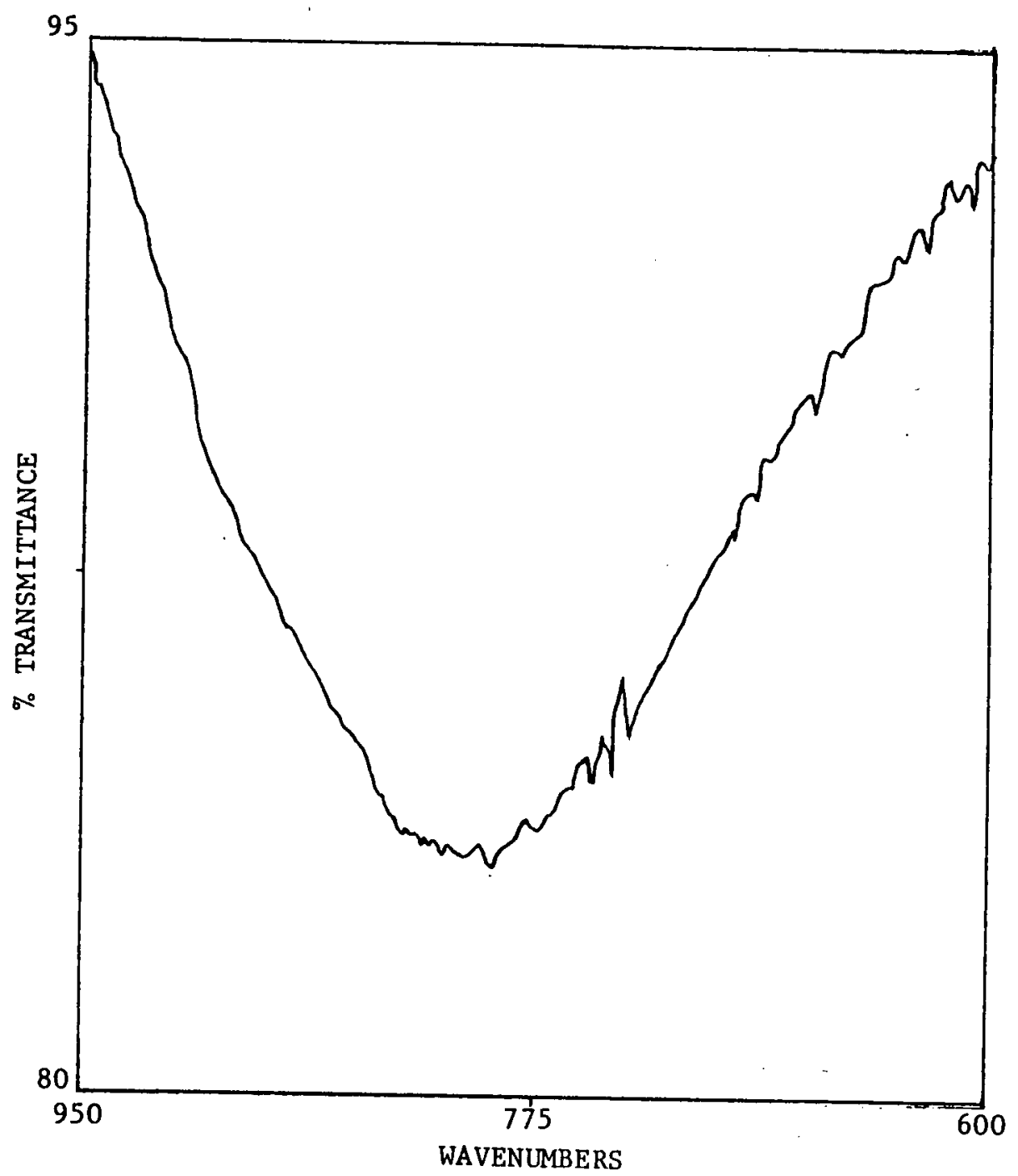

Figure 69. Enlargement of 950-600 wavenumber region of $1000: 1: 1$ of $\mathrm{Ar}: \mathrm{UF}_{6}: \mathrm{H}_{2} \mathrm{O}$ sample that was mixed in $100-\mathrm{cm}$ tube prior to deposition. 
lengthened to about $300 \mathrm{~cm}$ in order to allow more time for the $\mathrm{UF}_{6}$ and $\mathrm{H}_{2} \mathrm{O}$ samples to react. Also the tube would again be heated with heating tape during deposition. Most of the spectra recorded yielded basically the same results as the previous spectra. It was then decided to do something drastic in order to try to obtain a different result. Therefore, a 100:1 Ar:UF 6 and pure water were mixed in a $30-\mathrm{cm}$ heated tube and then co-deposited. Figure 70 represents a spectrum taken of that sample being held at $16^{\circ} \mathrm{K}$. And again the next spectrum, Figure 71 , is also of a similar sample. Notice the broad band $\left(950-750 \mathrm{~cm}^{-1}\right)$ has shoulders located at about $850 \mathrm{~cm}^{-1}$ and $940 \mathrm{~cm}^{-1}$. However, subsequent annealing of this sample produced no new peaks (Figure 72 ), and the broad peak (950-650 $\mathrm{cm}^{-1}$ ) receded.

What conclusions can be drawn from this set of experiments? One is that there is also a concentration factor that helps to determine the reaction of $\mathrm{UF}_{6}$ with water. Since during the neat studies (pure $\mathrm{UF}_{6}$ and $\mathrm{H}_{2} \mathrm{O}$ ) products were formed during the deposition, it was felt that, by lowering the concentration of the samples and allowing the samples more time to react that possibly some of the products which produced peaks at 865,780 , and $710 \mathrm{~cm}^{-1}$ could be isolated. However, this was not the case. What was found on the sample window was a sample whose IR spectrum showed one broad, weak peak between 950 and $650 \mathrm{~cm}^{-1}$ in which the apex shifted seemingly at random. However, as obtuse as this peak was, it never failed to show up. It does occur in the same region as the three peaks in the neat study. However, because of its broadness and also because of 


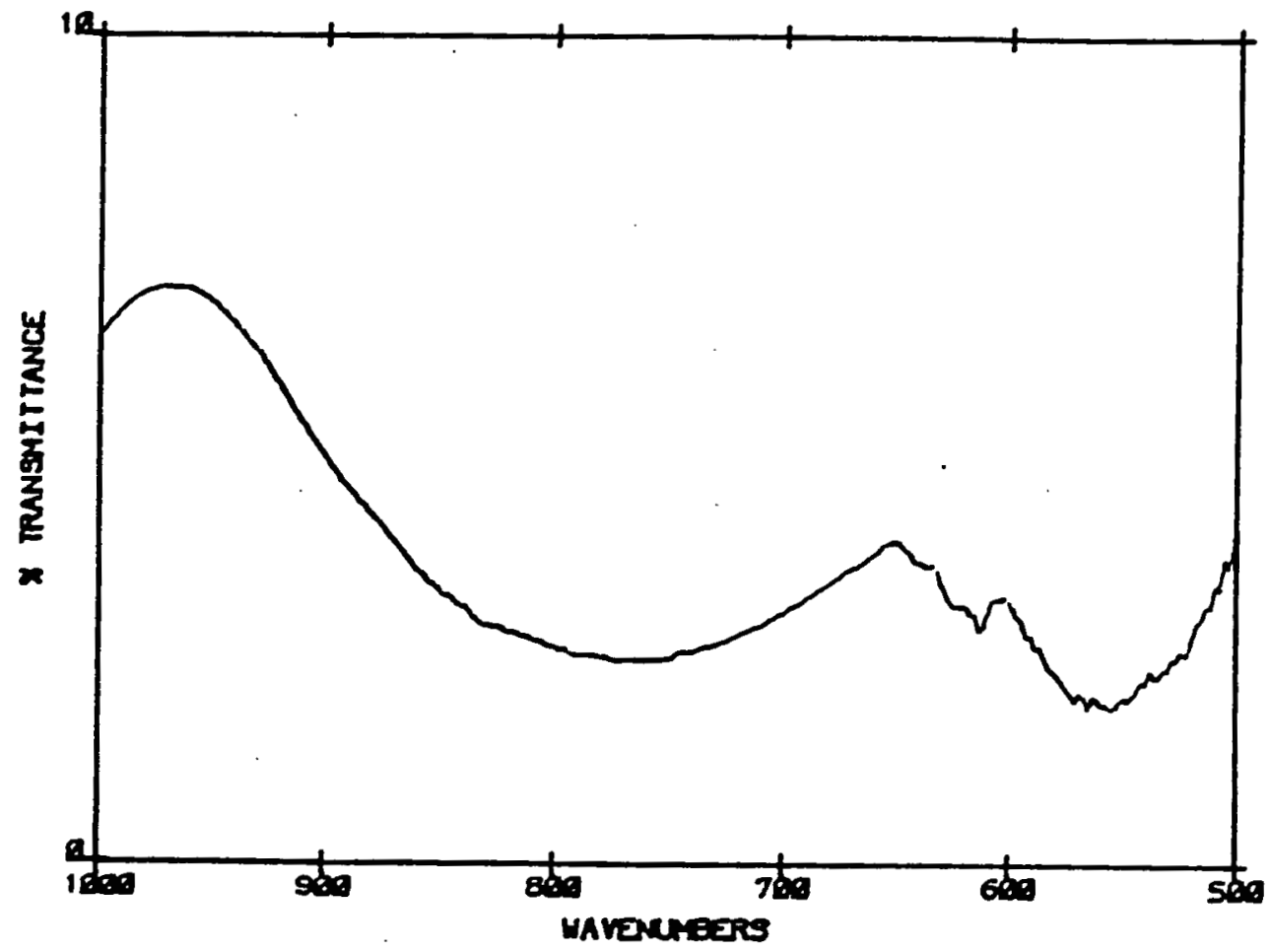

Figure 70. FT-IR spectrum of 100:1 $\mathrm{Ar}: \mathrm{UF}_{6}$ and pure water samples that were mixed in a heated $30-\mathrm{cm}$ tube prior to deposition. 


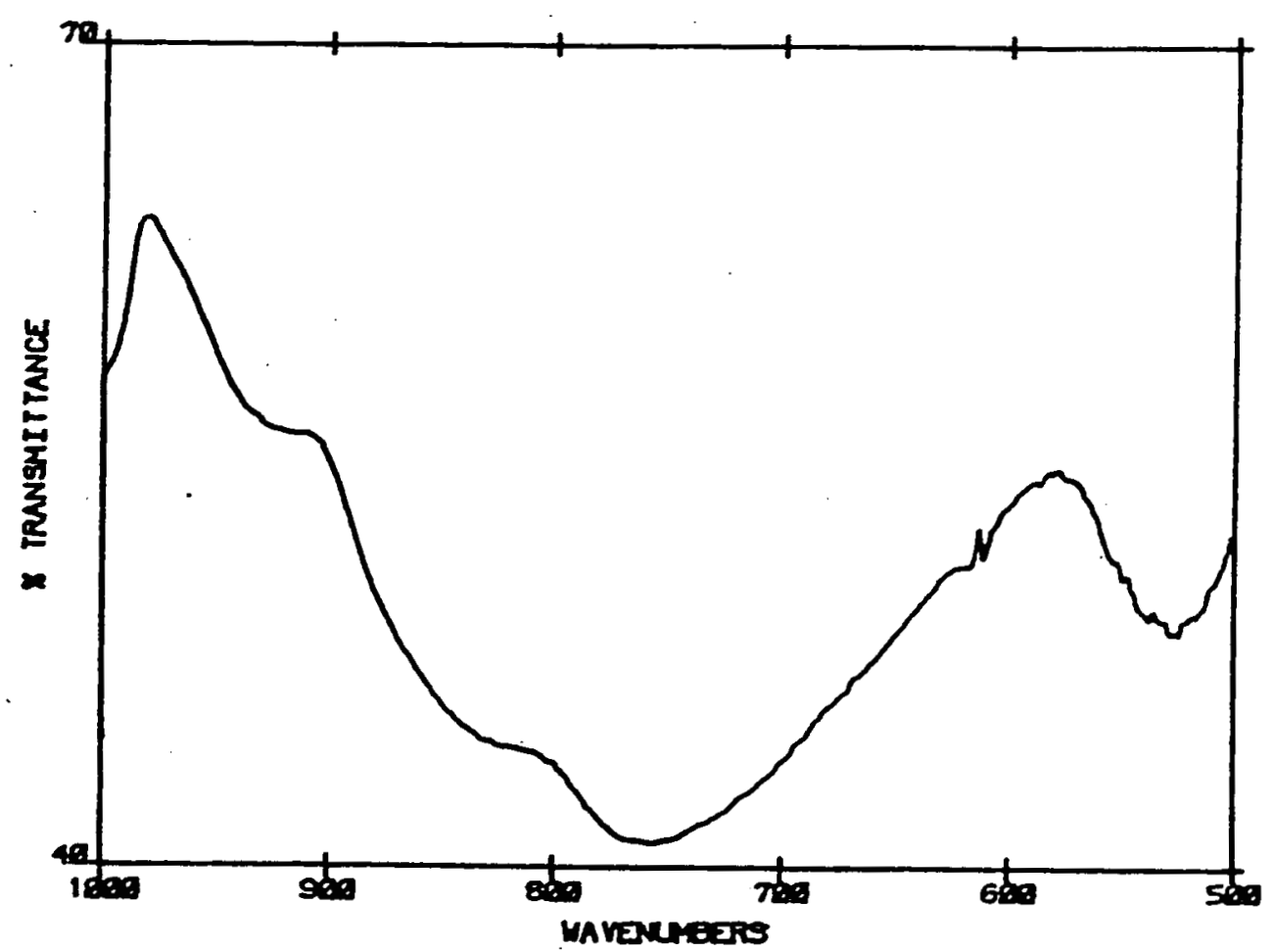

Figure 71. Spectrum of sample similar to the one recorded in Figure 70. 


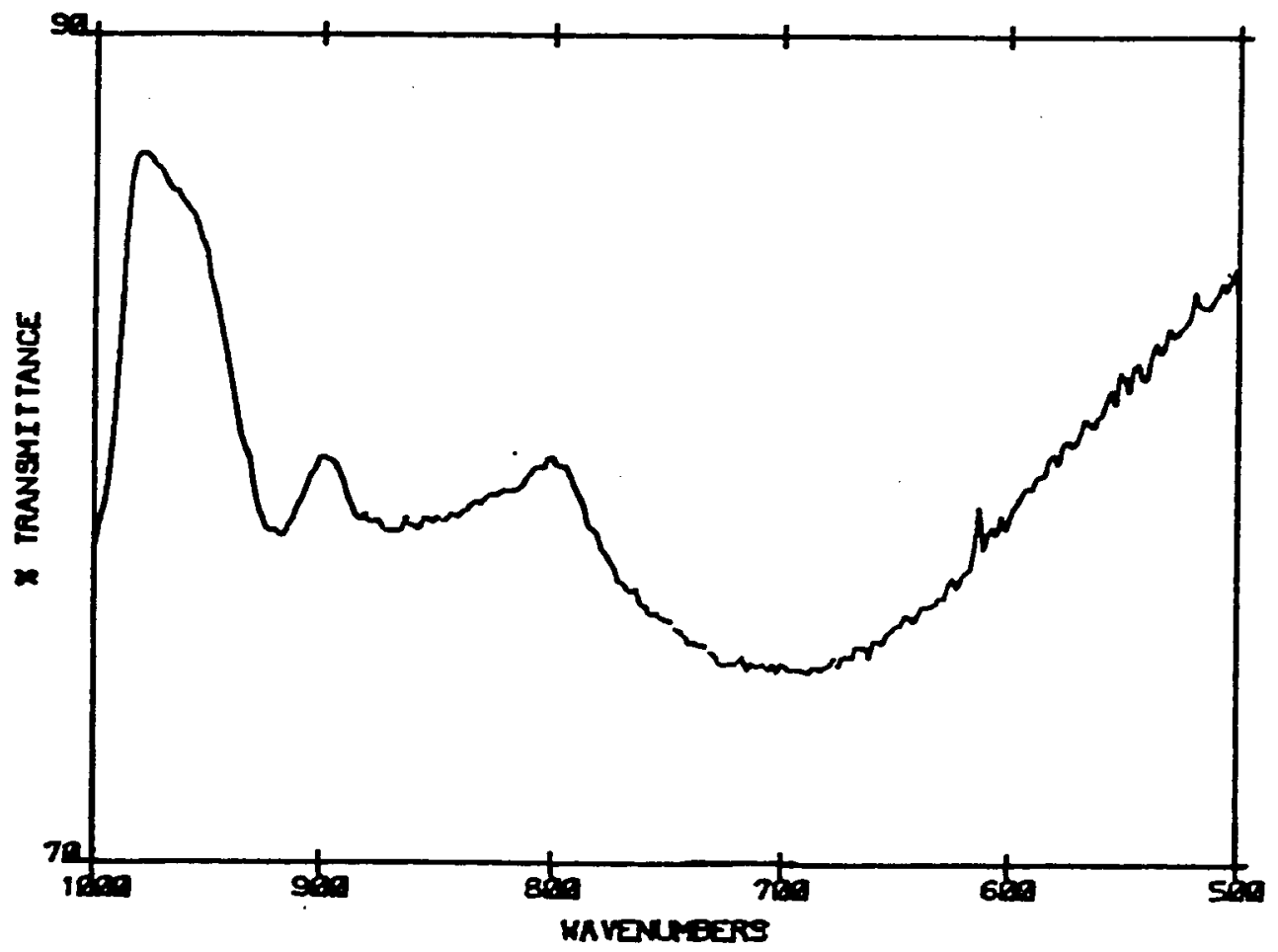

Figure 72. Spectrum of same sample after it was annealed somewhat. 
the other problems (back-up and adsorption), no more conclusions can be made.

10. Low-Ratio $\mathrm{UF}_{6}$ and $\mathrm{H}_{2} \mathrm{O}$ Experiment

This section will detail and analyze the results obtained in the low-ratio deposits of $\mathrm{UF}_{6}$ and $\mathrm{H}_{2} \mathrm{O}$ in argon in which the deposition tubes inside the cryostat sample chamber were angled toward one another. The experimental procedures were those described in Chapter III, Section K. As stated earlier, the purpose of angling the tubes toward one another was an attempt to help the $\mathrm{UF}_{6}$ and $\mathrm{H}_{2} \mathrm{O}$ mix better since the samples would be somewhat diluted. Actually this experiment is a mixture of the neat study and the mergingstream study. Unlike the neat study, pure samples were not used. And also, unlike the merging streams study, the back-up or adsorptions problems will not be evident. It was felt that, if the proper ratios of samples were used, the IR peaks which were unveiled in the neat studies could be further detailed and analyzed.

Figure 73 is a spectrum that was taken after 5:1 $\mathrm{Ar}_{\mathrm{U}} \mathrm{UF}_{6}$ and $2: 1$ $\mathrm{Ar}: \mathrm{H}_{2} \mathrm{O}$ samples were co-deposited on the CsI window at $16^{\circ} \mathrm{K}$. There are peaks occurring at 850,613 , and $570 \mathrm{~cm}^{-1}$. There are some similarities between the peak at $850 \mathrm{~cm}^{-1}$ and the band occurring in the same region in the merging-streams study. It is possible that the spike occurring at $613 \mathrm{~cm}^{-1}$ could be due to a $\mathrm{UF}_{6}$ absorption. The broad band centering at $570 \mathrm{~cm}^{-1}$ is unknown.

The next spectrum (Figure 74) was taken after 5:1 $\mathrm{Ar}: \mathrm{UF}_{6}$ and a 2:1 Ar: $\mathrm{H}_{2} \mathrm{O}$ samples were co-deposited at $16^{\circ} \mathrm{K}$. Notice that the peak at $850 \mathrm{~cm}^{-1}$ is much sharper than the one in the same region in the 


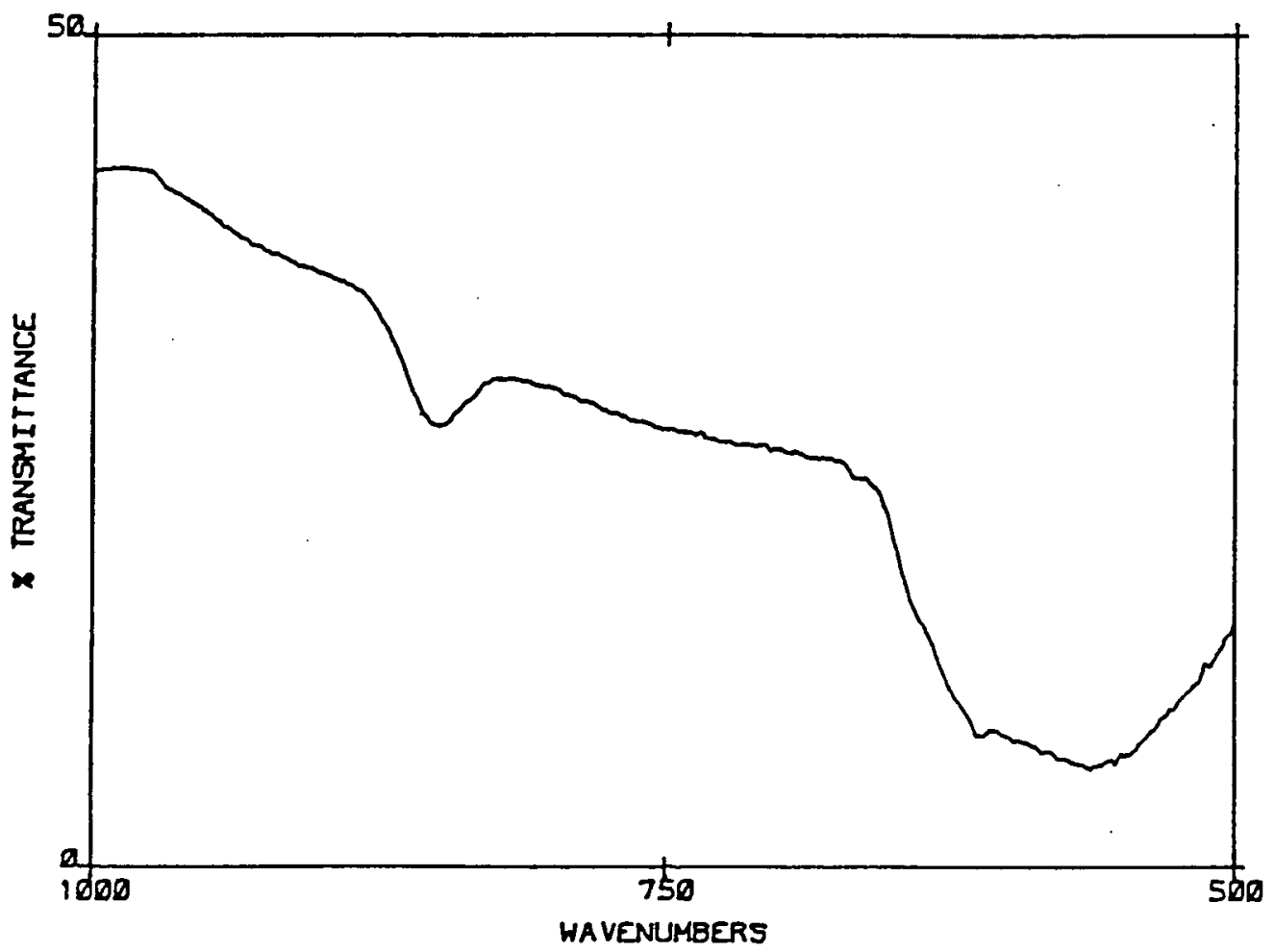

Figure 73. FT-IR spectrum of $5: 1 \mathrm{Ar}_{\mathrm{U}} \mathrm{UF}_{6}$ and a $2: 1 \mathrm{Ar}: \mathrm{H}_{2} \mathrm{O}$ sample that was co-deposited at $16^{\circ} \mathrm{K}$. 


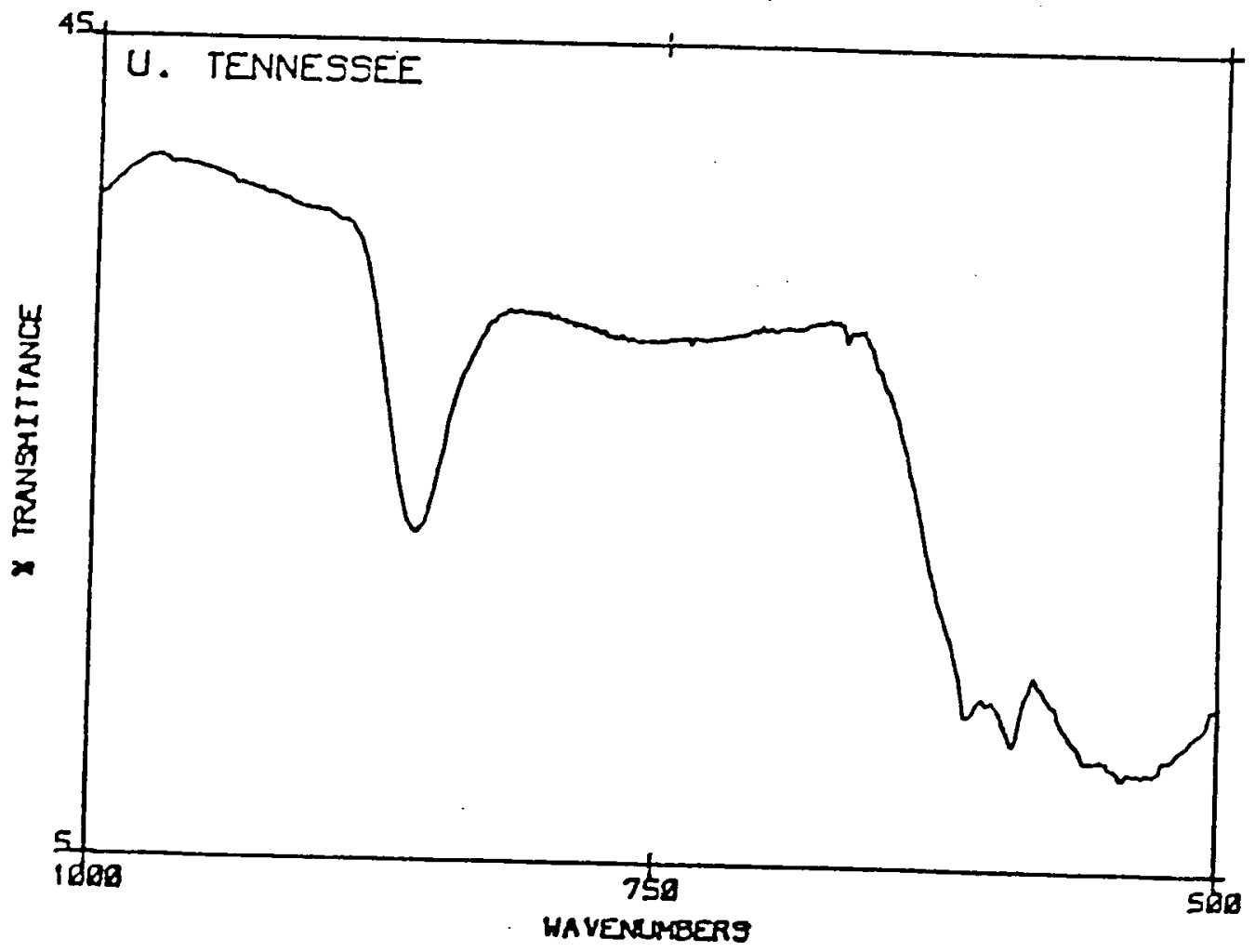

Figure 74. FT-IR spectrum of sample under same experimental conditions as in Figure 73. 
previous sample. Also there appears to be a weak, broad band between 800 and $700 \mathrm{~cm}^{-1}$. Other peaks occur at 610,591 , and 540 $\mathrm{cm}^{-1}$. The peak at $610 \mathrm{~cm}^{-1}$ is near the area in which peaks were previously assigned to $\mathrm{UF}_{6}$ absorptions. The bands at 591 , and 540 $\mathrm{cm}^{-1}$ are unidentified.

The next three spectra (Figures $75,76,77$ ) are representative of samples in which the $\mathrm{Ar}: \mathrm{UF}_{6}$ and $\mathrm{Ar}: \mathrm{H}_{2} \mathrm{O}$ ratios were both approximately $2: 1$. Since all three spectra are slightly different it is apparent that the apparatus that was used was not exactly designed for this type of experiment because fine tuning the deposit ratios was very difficult. It seems that a $2: 1$ ratio for both mixtures is the transition point between the species shown in Figure 75 and that obtained in the neat study. Figures 76 and 77 are the most similar, and bands occur at approximately $930,860,780,710,615$ and 570 $\mathrm{cm}^{-1}$. In Figure 75 bands occur at $865,782,710,610$, and $591 \mathrm{~cm}^{-1}$. This spectrum is very similar to the one observed (Figure 51) after the initial deposition in the neat study. This set of spectra would appear to indicate that the bands at $930,860,615(610), 591$, and $570 \mathrm{~cm}^{-1}$ act independently, and also the bands at 780 and $710 \mathrm{~cm}^{-1}$ act together and independently from the others. It was apparent that an annealing study might help further solve this problem.

Figure 78 was taken after $3: 1 \quad \mathrm{Ar}^{\mathrm{U}} \mathrm{UF}_{6}$ and $2: 1 \mathrm{Ar}: \mathrm{H}_{2} \mathrm{O}$ samples were co-deposited on the window at $16^{\circ} \mathrm{K}$. Peaks occur at approximately $860,605,591$, and $540 \mathrm{~cm}^{-1}$. The next spectrum (Figure 79) was recorded after the sample had been warmed to approximately $130^{\circ} \mathrm{K}$. Notice that a new peak has emerged at about $935 \mathrm{~cm}^{-1}$ and also the 


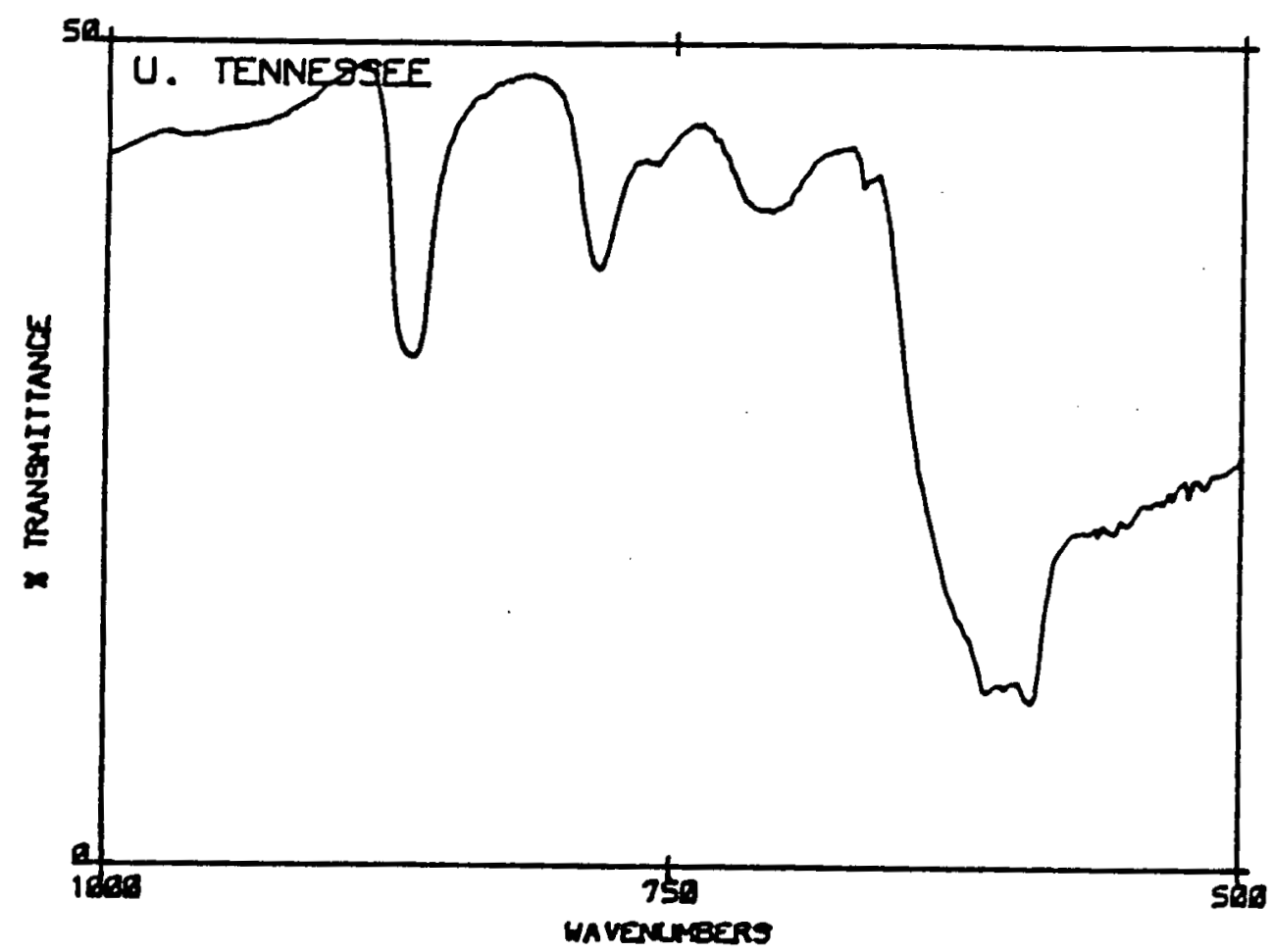

Figure 75. FT-IR spectrum of $\mathrm{UF}_{6}: \mathrm{h}_{2} \mathrm{O}: \mathrm{Ar}(1: 1: 2)$ sample recorded at $16^{\circ} \mathrm{K}$. 


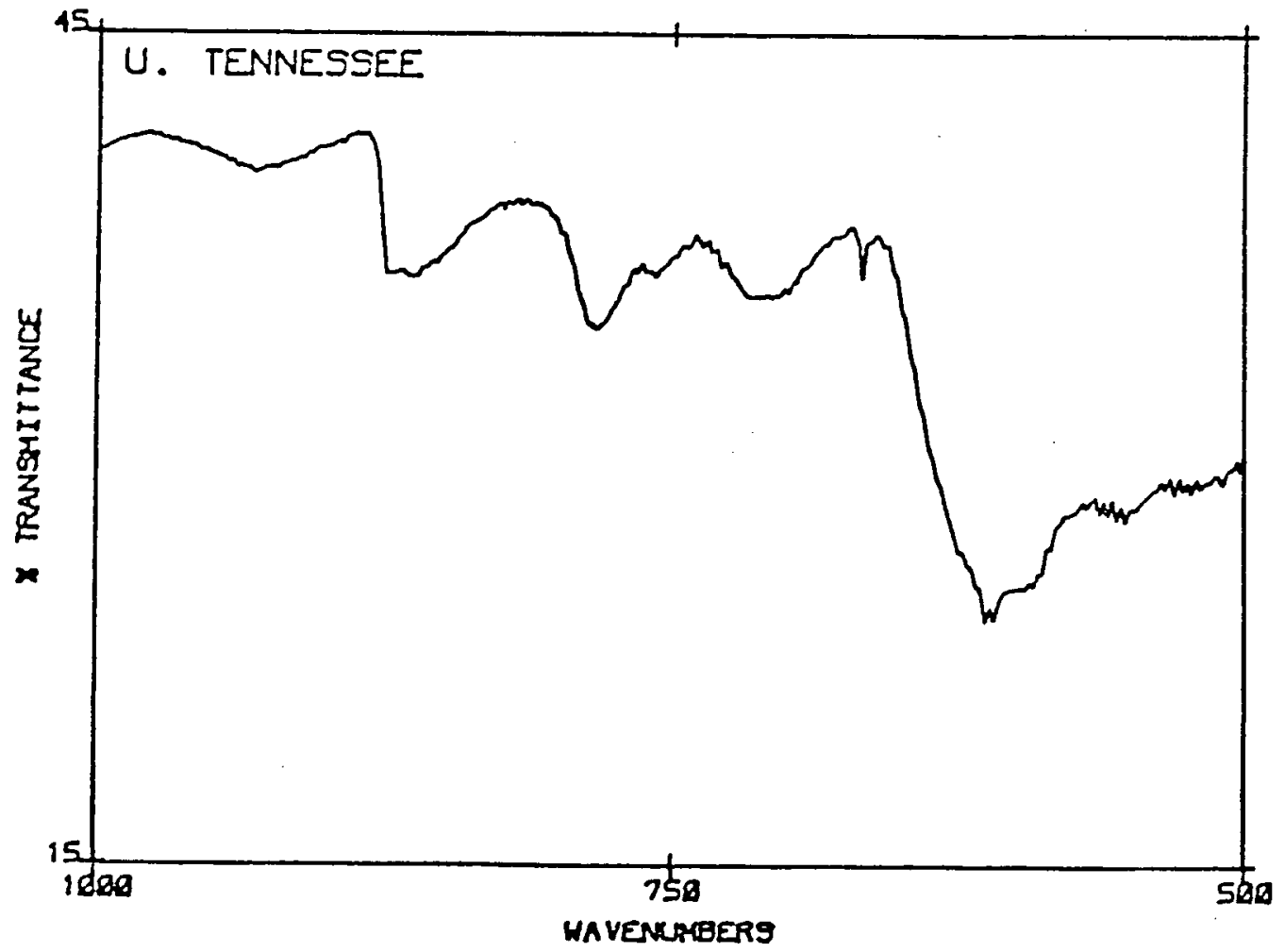

Figure 76. FT-IR spectrum of sample under same experimental conditions as in Figure 75. 


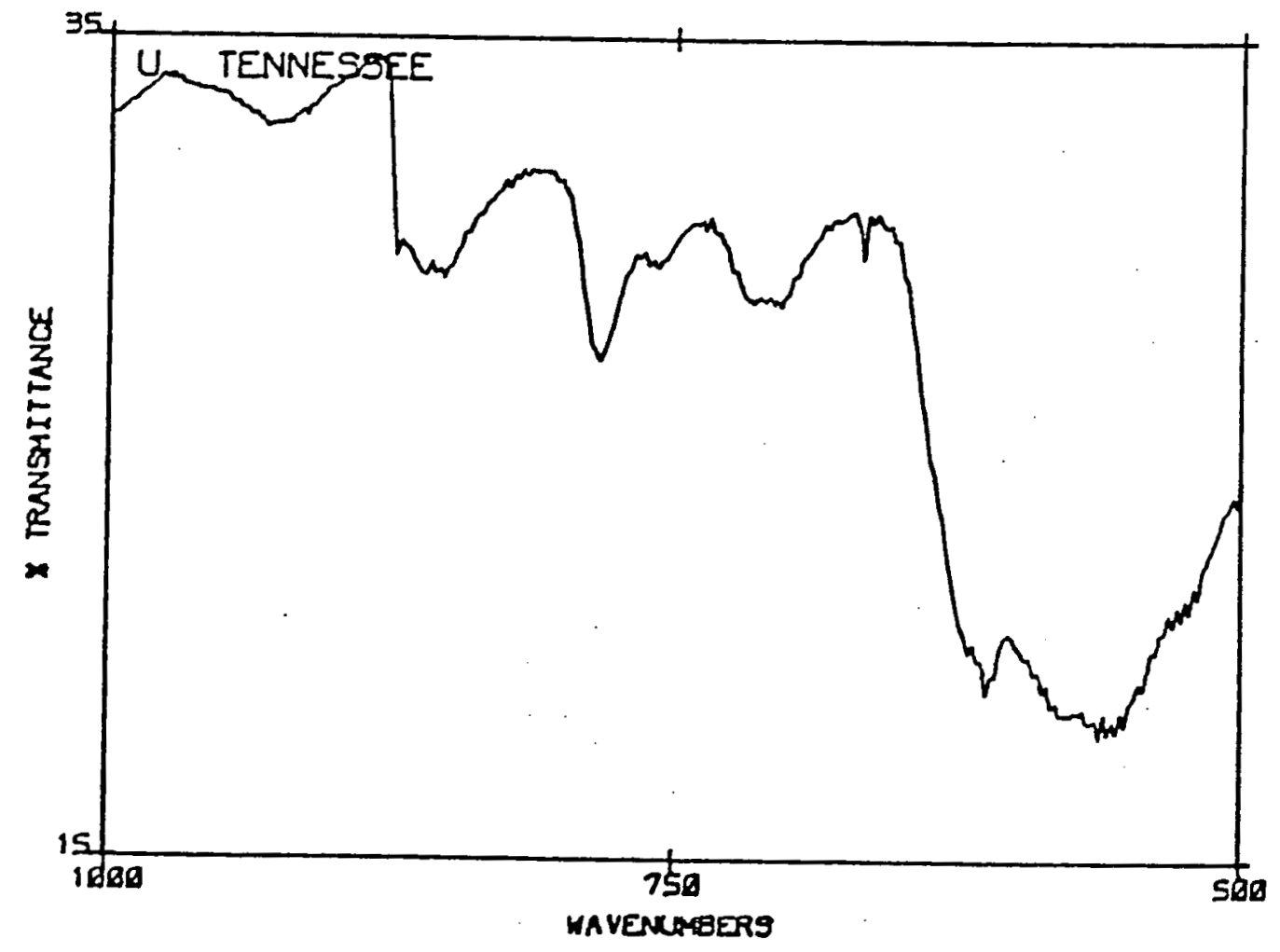

Figure 77. FT-IR spectrum of sample under same experimental conditions as in Figure 76. 


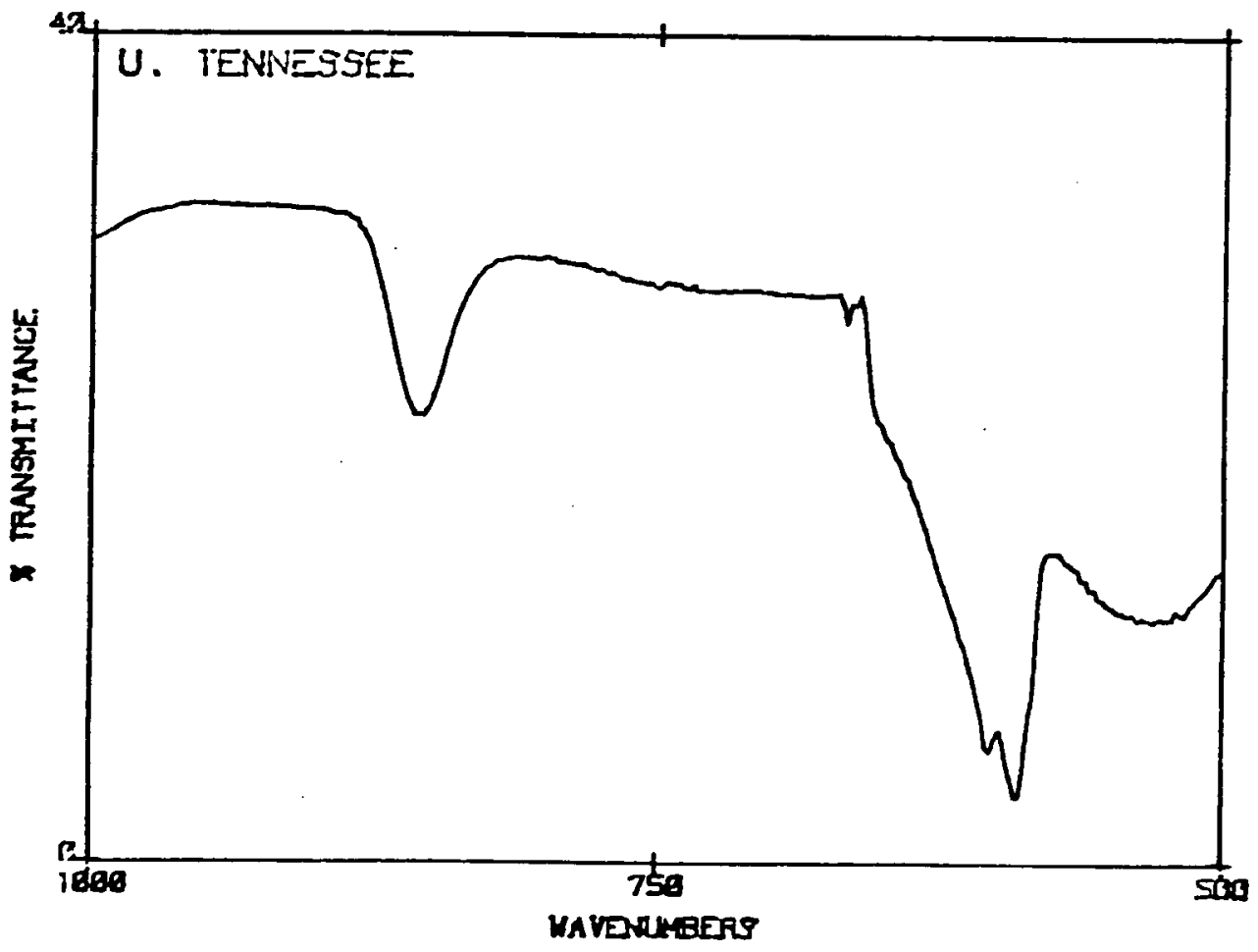

Figure 78. FT-IR spectrum of $3: 1 \mathrm{Ar}: \mathrm{UF}_{6}$ and $2: 1 \mathrm{Ar}: \mathrm{H}_{2} \mathrm{O}$ samples which were co-deposited at $16^{\circ} \mathrm{K}$. 


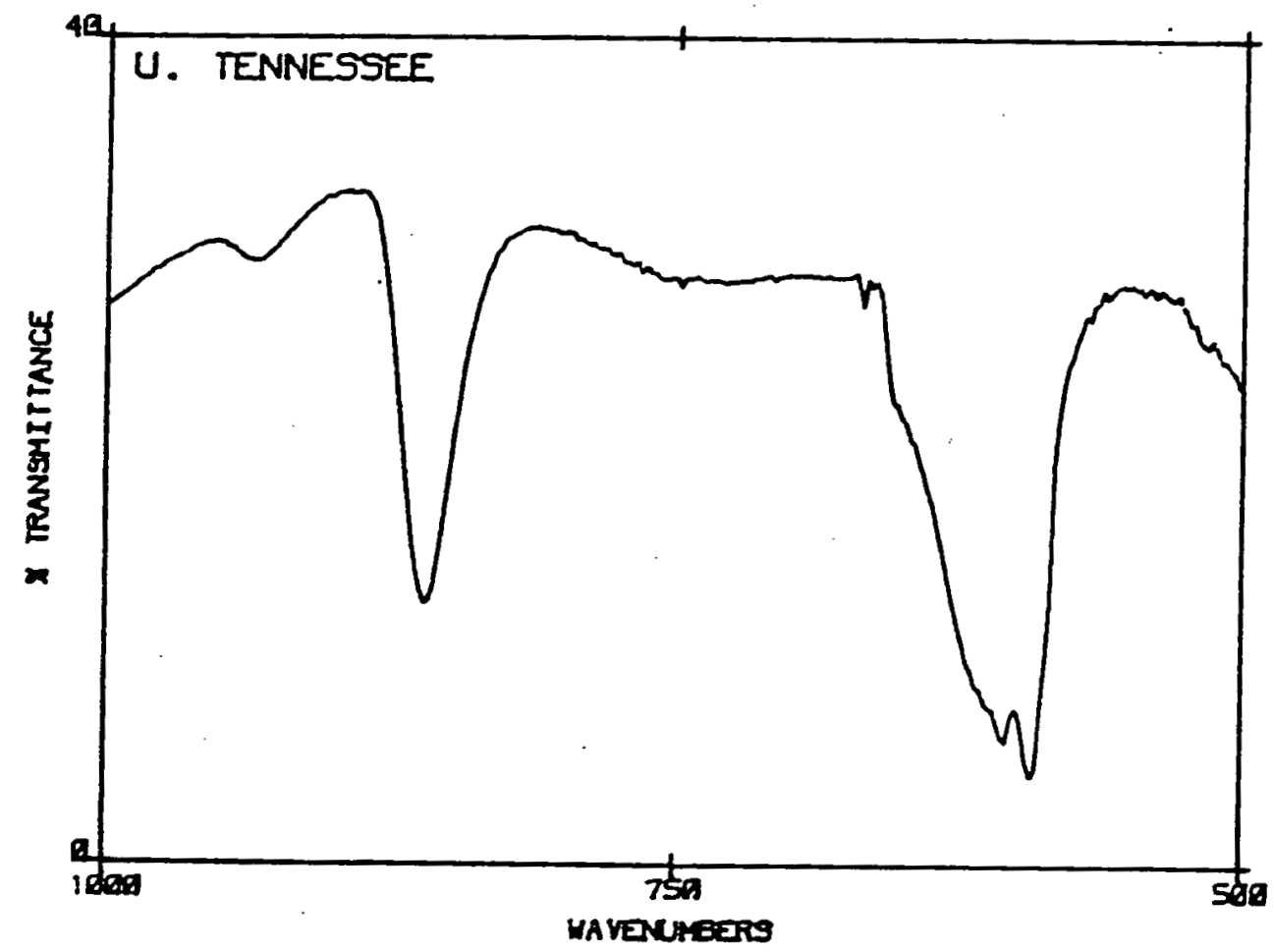

Figure 79. FT-IR spectrum of the sample after it had been warmed to approximately $130^{\circ} \mathrm{K}$. 
peak at $540 \mathrm{~cm}^{-1}$ has disappeared. The $860 \mathrm{~cm}^{-1}$ band has increased in intensity and a weak, broad band is appearing to emerge between 850 and $750 \mathrm{~cm}^{-1}$. The next spectrum (Figure 80 ) was recorded after the sample had been warmed to $180^{\circ} \mathrm{K}$. The $935,860 \mathrm{~cm}^{-1}$ peaks have grown and two new peaks appear to be emerging at 780 and $710 \mathrm{~cm}^{-1}$. Also, a new peak at about $615 \mathrm{~cm}^{-1}$ has appeared. It apparently was observed earlier as a shoulder on the $605 \mathrm{~cm}^{-1}$ peak. The $605 \mathrm{~cm}^{-1}$ and $591 \mathrm{~cm}^{-1}$ peaks have receded somewhat but are still there. The next spectrum (Figure 81 ) was taken after the sample had been warmed further. Notice that the 935 (now $940 \mathrm{~cm}^{-1}$ ), $865(860), 780$, and 710 $\mathrm{cm}^{-1}$ peaks are growing. But, the peaks at 605 and $591 \mathrm{~cm}^{-1}$ have almost disappeared. Figure 82, which was recorded at about $200^{\circ} \mathrm{K}$, shows that the absorptions at $865,780,710$, and $615 \mathrm{~cm}^{-1}$ have decreased but that the $940 \mathrm{~cm}^{-1}$ has continued to grow. The final spectrum (Figure 83 ) in the series shows that the 780 and $710 \mathrm{~cm}^{-1}$ bands are gone, the $865 \mathrm{~cm}^{-1}$ band is very weak, and there is a slight absorption at $610 \mathrm{~cm}^{-1}$. The $940 \mathrm{~cm}^{-1}$ band has continued to grow.

What conclusions can be drawn from these annealing experiments? The annealing experiments appear to further support the fact that there might be a number of chemical intermediates which are producing the emerging and receding bands observed in Figures 78 through 83. The bands which appear to act independently are the $940,865,620,605,591$, and $570 \mathrm{~cm}^{-1}$, but the 780 and $710 \mathrm{~cm}^{-1}$ bands act together. But, what are the possible intermediates? 


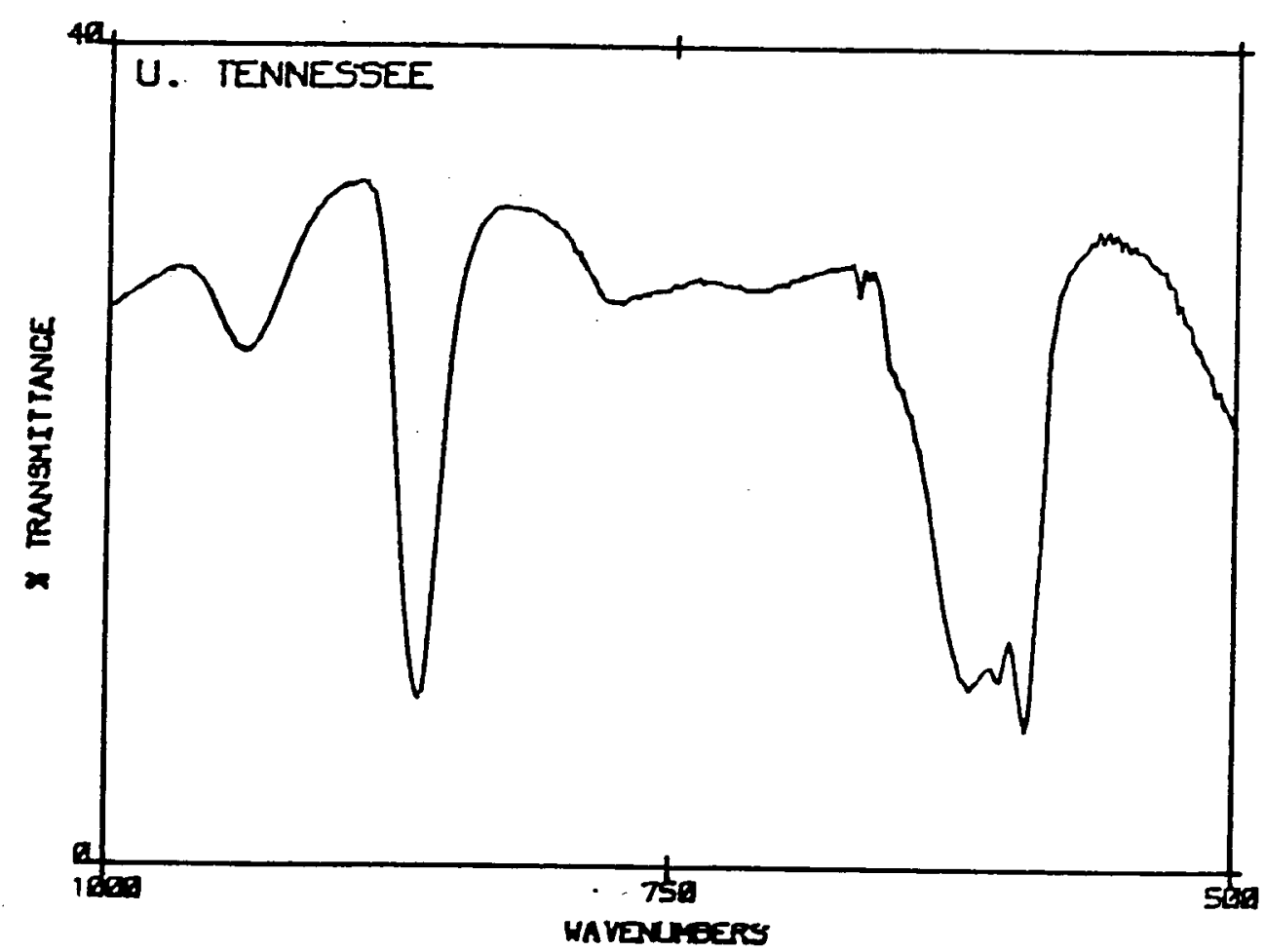

Figure 80. Spectrum recorded after sample had been warmed to about $180^{\circ} \mathrm{K}$. 


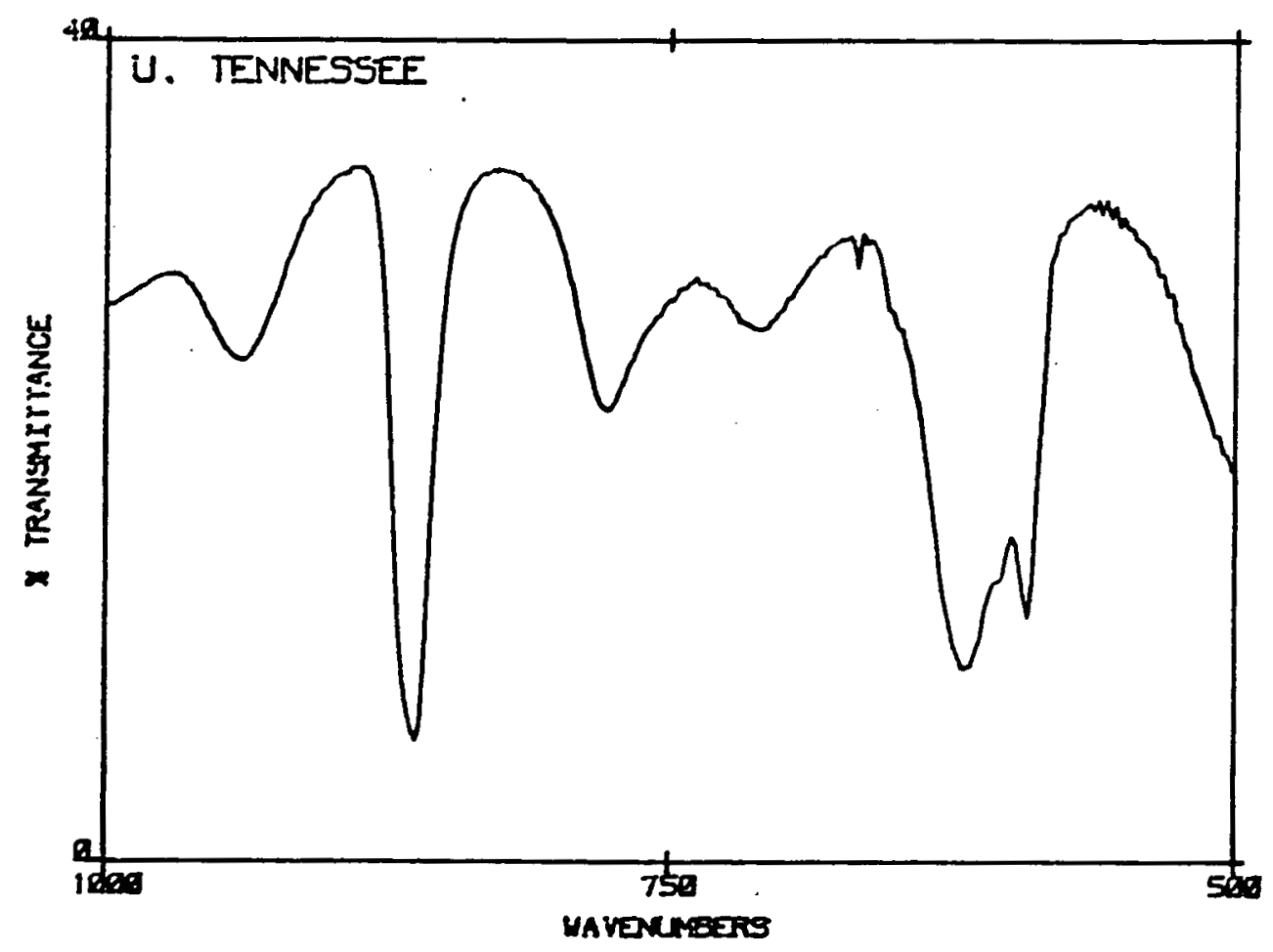

Figure 81. Spectrum recorded after sample had been warmed further. 


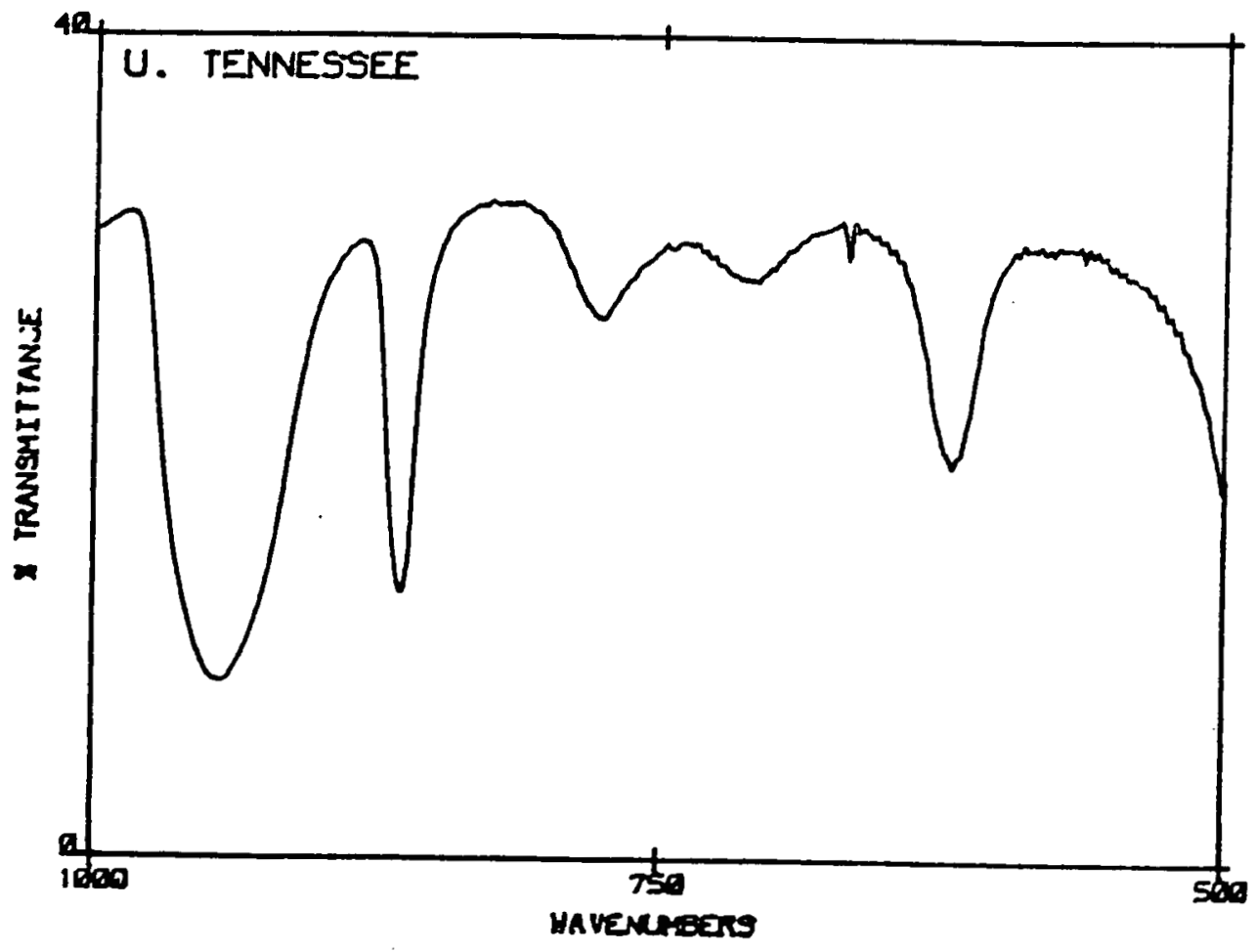

Figure 82. Spectrum recorded after sample had been warmed to about $200^{\circ} \mathrm{K}$. 


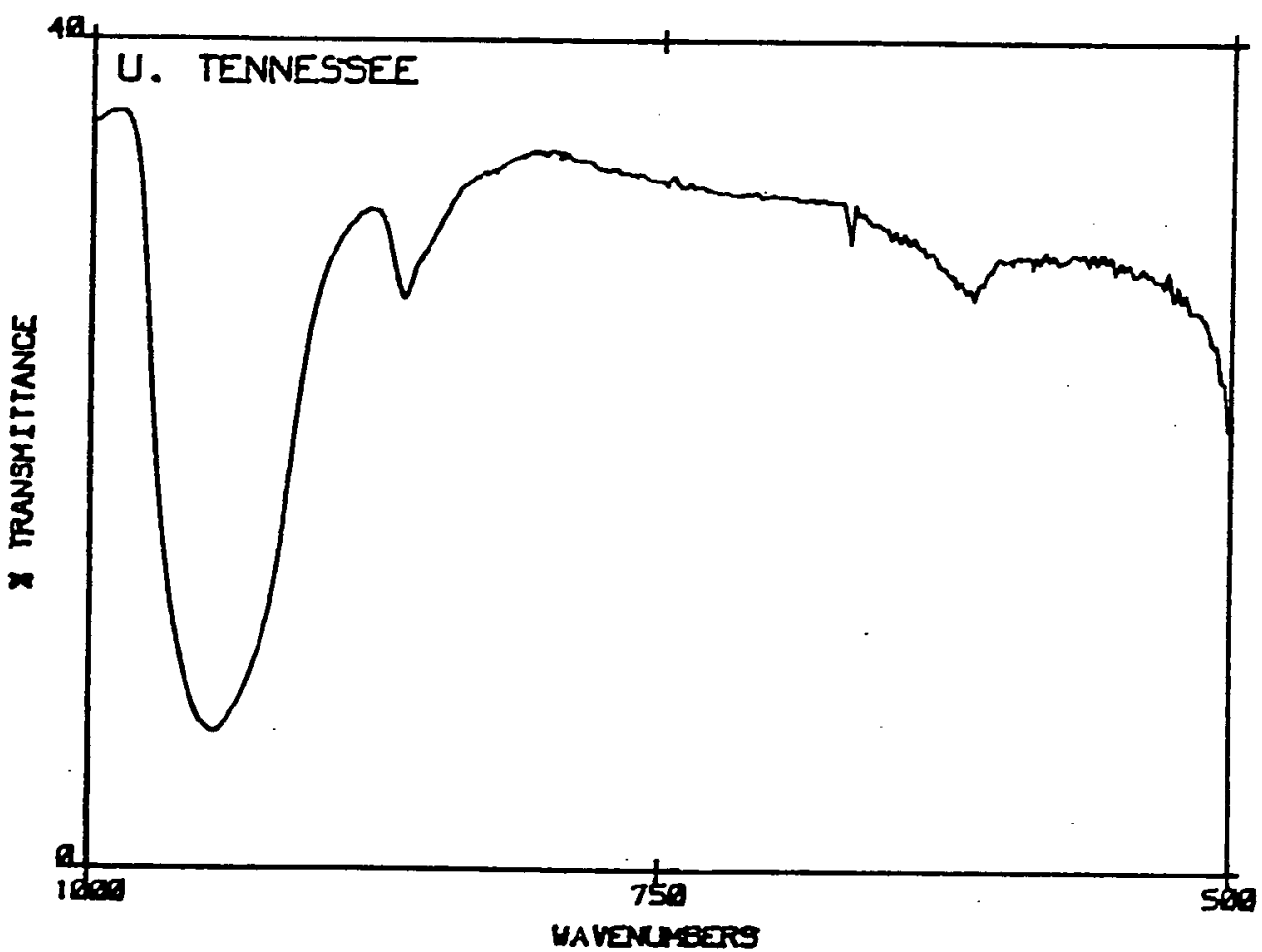

Figure 83. Spectrum recorded after sample had been warmed past $220^{\circ} \mathrm{K}$. 
First, it is necessary to determine the possible intermediate pathway that would be followed on going from $\mathrm{UF}_{6}$ to $\mathrm{UO}_{2} \mathrm{~F}_{2}$ via a $\mathrm{UF}_{6}$ molecule's interaction with an $\mathrm{H}_{2} \mathrm{O}$ molecule. First, a single water molecule might react in this fashion:

$$
\mathrm{UF}_{6}+\mathrm{H}_{2} \mathrm{O} \rightarrow \mathrm{UF}_{6} \cdot \mathrm{H}_{2} \mathrm{O}
$$

Here, water forms an adduct with $\mathrm{UF}_{6}$. Or it might react in this fashion:

$$
\mathrm{UF}_{6}+\mathrm{H}_{2} \mathrm{O} \rightarrow \mathrm{UF}_{5} \mathrm{OH} \cdot \mathrm{HF} \quad\left(\mathrm{H}^{+} \mathrm{UOF}_{5}-\cdot \mathrm{HF}\right) .
$$

Another possibility is that an ionic intermediate is formed:

$$
\mathrm{UF}_{6}+\mathrm{H}_{2} \mathrm{O} \rightarrow \mathrm{H}^{+} \mathrm{UF}_{6} \mathrm{OH}^{-} \text {. }
$$

And these products might then dissociate:

$$
\begin{aligned}
& \mathrm{UF}_{6} \cdot \mathrm{H}_{2} \mathrm{O} \\
& \mathrm{UF}_{5} \mathrm{OH}^{\circ} \cdot \mathrm{HF} \\
& \mathrm{H}^{+} \mathrm{UF}_{6} \mathrm{OH}^{-}
\end{aligned} \quad+\mathrm{UF}_{5} \mathrm{OH}+\mathrm{HF} .
$$

Then $\mathrm{UF}_{5} \mathrm{OH}$ could react with another water molecule via:

$$
\begin{aligned}
& \mathrm{UF}_{5} \mathrm{OH}+\mathrm{H}_{2} \mathrm{O} \rightarrow \mathrm{UF}_{5} \mathrm{OH} \cdot \mathrm{H}_{2} \mathrm{O} \text { or } \\
& \mathrm{UF}_{5} \mathrm{OH}+\mathrm{H}_{2} \mathrm{O} \rightarrow \mathrm{UOF} 4 \cdot \mathrm{HF} \cdot \mathrm{H}_{2} \mathrm{O}\left(\mathrm{H}^{+} \mathrm{UOF}_{5}{ }^{-} \cdot \mathrm{H}_{2} \mathrm{O}\right) \text { or } \\
& \mathrm{UF}_{5} \mathrm{OH}+\mathrm{H}_{2} \mathrm{O} \rightarrow \mathrm{UF}_{4}(\mathrm{OH})_{2} \cdot \mathrm{HF} \text {. }
\end{aligned}
$$

and, then these products may dissociate:

$$
\begin{aligned}
& \mathrm{UF}_{5} \mathrm{OH} \cdot \mathrm{H}_{2} \mathrm{O} \\
& \mathrm{UOF}_{4} \cdot \mathrm{HF} \cdot \mathrm{H}_{2} \mathrm{O}+\mathrm{UOF}_{4}+\mathrm{HF}+\mathrm{H}_{2} \mathrm{O} \\
& \mathrm{UF}_{4}(\mathrm{OH})_{2} \cdot \mathrm{HF}
\end{aligned}
$$

If one uses this scheme then a possible reaction sequence might be:

$$
\begin{aligned}
& \mathrm{UF}_{6} \cdot \mathrm{X}+\mathrm{UF}_{5} \mathrm{OH} \cdot \mathrm{X}+\mathrm{UF}_{4}(\mathrm{OH})_{2} \cdot \mathrm{X} \rightarrow \mathrm{UF}_{3}(\mathrm{OH})_{3} \cdot \mathrm{X} \\
& \mathrm{UOF}_{4} \cdot \mathrm{H}_{2} \mathrm{O} \cdot \mathrm{X} \quad \mathrm{UOF}_{3}(\mathrm{OH}) \cdot \mathrm{H}_{2} \mathrm{O} \cdot \mathrm{X} \\
& +\mathrm{UF}_{2}(\mathrm{OH})_{4} \cdot \mathrm{X} \quad\left(\mathrm{X}=\mathrm{H}_{2} \mathrm{O} \text {, or } \mathrm{HF} .\right) \\
& \mathrm{UO}_{2} \mathrm{~F}_{2} \cdot 2 \mathrm{H}_{2} \mathrm{O} \cdot \mathrm{X}
\end{aligned}
$$


If one examines this scheme one realizes that many possible intermediates might have been omitted. Ionic intermediates are a strong possibility because some oxofluoro uranium ionic compounds have been synthesized. Now, can these possible intermediates fit the bands in question in this series of spectra?

In the first few spectra several products are possibly present. $\mathrm{UF}_{6}$ is most certainly present. Other possibilities are $\mathrm{UF}_{6} \cdot \mathrm{X}$ $\mathrm{UF}_{5} \mathrm{OH} \cdot \mathrm{X}, \quad \mathrm{UF}_{4}(\mathrm{OH})_{2} \cdot \mathrm{X}, \mathrm{UOF}_{4} \cdot \mathrm{H}_{2} \mathrm{O} \cdot \mathrm{X}$, etc $\left(\mathrm{X}=\mathrm{H}_{2} \mathrm{O}\right.$, or $\left.\mathrm{HF}\right)$. The band at $865 \mathrm{~cm}^{-1}$ is very near the $893 \mathrm{~cm}^{-1}$ band that has been previously assigned to a U-O stretch in solid UOF $_{4}$. It is possible that this band may be due to a U-O stretch in an isolated UOF 4 molecule or some similar adducted or non-adducted intermediate. Also, the bands at 605 , and $591 \mathrm{~cm}^{-1}$ are very close to the U-F stretch at $619 \mathrm{~cm}^{-1}$ due to $\mathrm{UF}_{6}$. Either band at 605 or $591 \mathrm{~cm}^{-1}$ could be due to a U-F vibrational mode caused by a UF 5 X type molecule. Since the broad band at $540 \mathrm{~cm}^{-1}$ disappears rather quickly, it is possible that it could be due to an intermediate that is relatively unstable and perhaps partially reacted. Since it does not remain, then one must assume that it is not part of the reaction sequence; it is only formed on the intial deposit. The peaks at 606 and $591 \mathrm{~cm}^{-1}$ appear to be feeding the $940,865,780$, and $710 \mathrm{~cm}^{-1}$ bands; as the 606 and $591 \mathrm{~cm}^{-1}$ bands are receding, the others are emerging. The bands at 780 and $710 \mathrm{~cm}^{-1}$ appear to emerge at the same time as the $940 \mathrm{~cm}^{-1}$ band but recede while the $940 \mathrm{~cm}^{-1}$ continues to grow. Also, the $865 \mathrm{~cm}^{-1}$ band recedes simultaneously with the 780 and $710 \mathrm{~cm}^{-1}$ bands and they do so only after the 606 and $591 \mathrm{~cm}^{-1}$ bands disappear. The 
780 and $710 \mathrm{~cm}^{-1}$ bands could posibly be assigned to an intermediate such as $\mathrm{UF}_{3}(\mathrm{OH})_{3} \cdot \mathrm{X}$ or $\mathrm{UOF} \mathrm{OH}_{3} \cdot \mathrm{H}_{2} \mathrm{O} \cdot \mathrm{X}$, etc. These intermediates appear further along in the reaction sequence. The band which appears at $940 \mathrm{~cm}^{-1}$ is very close to the region that has been previously assigned to a $\mathrm{UO}_{2}$ stretch in solid $\mathrm{UO}_{2} \mathrm{~F}_{2} \cdot 2 \mathrm{H}_{2} \mathrm{O} .71$ It is also in the same region as a similar peak that was previously assigned to $\mathrm{UO}_{2} \mathrm{~F}_{2}$ impurity in a $\mathrm{KBr}$ pellet of $\mathrm{UOF}_{4}$ by Paine and associates.10 Since in Figure 82 the $619 \mathrm{~cm}^{-1} \mathrm{UF}_{6}$ peak is still present, one can conclude that it apparently does not feed the 606 and $591 \mathrm{~cm}^{-1}$ bands and it might not feed the 865,780 , and $710 \mathrm{~cm}^{-1}$ bands. But, it apparently does feed the $940 \mathrm{~cm}^{-1}$. Here are two possible combinations. The $619 \mathrm{~cm}^{-1}$ band feeds the $940,865,780$, and $710 \mathrm{~cm}^{-1}$ bands, and the 606 and $591 \mathrm{~cm}^{-1}$ bands feed them also. Or, the 606 and $591 \mathrm{~cm}^{-1}$ bands feed the $940,865,780$, and $710 \mathrm{~cm}^{-1}$ bands, and the $615 \mathrm{~cm}^{-1}$ band feeds only the $940 \mathrm{~cm}^{-1}$ band.

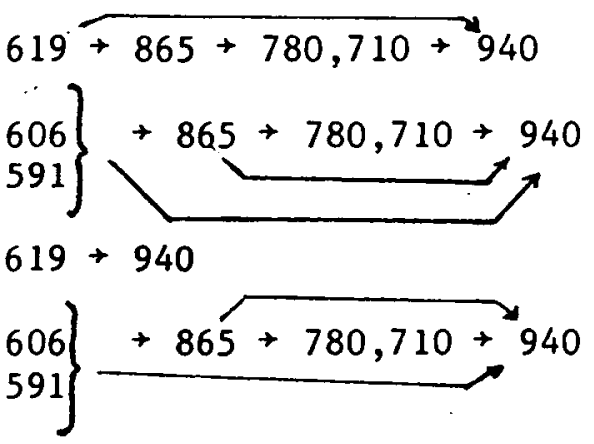

Is it really possible that the second reaction sequence might be correct? Yes, because two $\mathrm{H}_{2} \mathrm{O}$ molecules could simultaneously attack a $\mathrm{UF}_{6}$ molecule and react to form $\mathrm{UO}_{2} \mathrm{~F}_{2}$. At the higher temperatures, the appearance of the other intermediates might be less favorable. Also, one might ask why the $865 \mathrm{~cm}^{-1}$ peak still remained (Figure 83) after the 780 , and $710 \mathrm{~cm}^{-1}$ peaks have 
disappeared. One could only conclude that the $865 \mathrm{~cm}^{-1}$ peak is due to a relatively more stable molecule. Also, the $865 \mathrm{~cm}^{-1}$ peak could be directly feeding the $940 \mathrm{~cm}^{-1}$ peak. And, any of the other peaks could well have been directly feeding the $940 \mathrm{~cm}^{-1}$ peak. But, why then, if the $865 \mathrm{~cm}^{-1}$ peak was feeding the $940 \mathrm{~cm}^{-1}$ peak, did the $940 \mathrm{~cm}^{-1}$ peak not continue to grow when the $865 \mathrm{~cm}^{-1}$ st1ll remained? One answer might be that there were no more $\mathrm{H}_{2} \mathrm{O}$ molecules available at this point for any species to react with. Therefore, what one can conclude is that a fairly complex reaction sequence might be present. It is possible that it is only initiated because the proper products are formed on deposition, and that, as the temperature of the sample is increased, these products (intermediates) cannot so readily be maintained. Also, it is more than likely that neither sequence presented is correct; but that it is more complex and, in all probability, a mixture of the two, especially as the temperature increases. Every species (band) present might be feeding the $940 \mathrm{~cm}^{-1}$ band.

Another question one might ask is why the 865, 780, and 710 $\mathrm{cm}^{-1}$ bands could not be due to $U-F$ vibrational modes. They very well could be. They could also be combination bands of $\mathrm{UF}_{6}$ that were proposed by investigators. 72 However, it is not likely since the bands in question are fairly strong. Also, in UF 6 , only the totally symmetric U-F stretch or combination bands are IR active in that region, and in a molecule such as UOF 4 , only U-F bridging modes are IR active in the region under examination. Probably no U-F 
bridging modes might be present because the concentrations are very low, and only small aggregates or individual molecules are forming. That is, the molecules forming might be very different from the usual crystal or lattice type molecules and possibly absorb differently in the infrared region.

Next, examine the spectrum shown in Figure 84 and compare it to Figures 78 through 83 . Figure 84 represents a spectrum of a $\mathrm{K}^{+} \mathrm{UOF}_{5}{ }^{-}$sample recorded by $\mathrm{W}$. W. Wilson and associates. ${ }^{73}$ Notice that they are remarkably similar. What does this similarity mean? It could mean that their $\mathrm{K}^{+} \mathrm{UOF}_{5}{ }^{-}$sample was not pure but had a mixture of impurities. The assignments made to these bands were adopted from those previously proposed in a study by Jaubert and associ-ates. 74 These assignments will be discussed later. It might be possible to tentatively adopt some of these assignments for the bands observed in sections 9 and 10 , but they are slightly more complex and do not occur in the same positions as those found in the Wilson and Jaubert studies.

\section{Low-Ratio Nozzle Studies.}

The low-ratio nozzle studies added no new insights into the problem of solving the identities of the bands in question. It did, however, reveal that there was good sample mixing in the low ratio studies without the nozzle since the spectra are basically the same. It can also be seen that, in Figure 85 , the spectra are somewhat sharper than those found in the annealing experiment; therefore, locations of the peaks are more clearly established. 


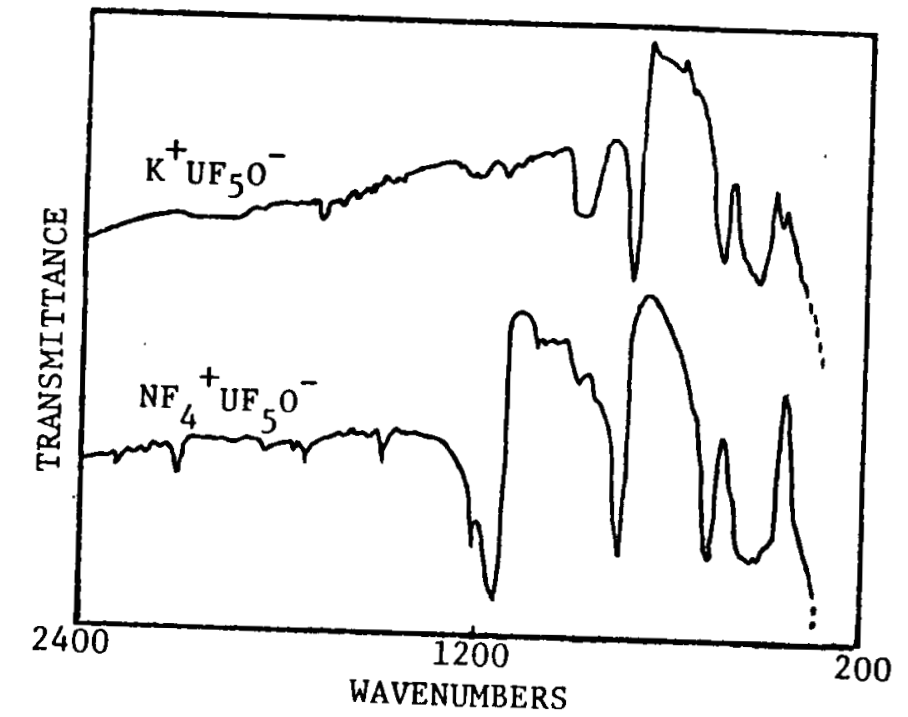

Figure 84. Infrared spectrum of $\mathrm{K}^{+} \mathrm{UF}_{5} \mathrm{O}^{-}$and $\mathrm{NF}_{4}^{+} \mathrm{UF}_{5} \mathrm{O}^{-}$samples recorded by Wilson and
associates. 73 


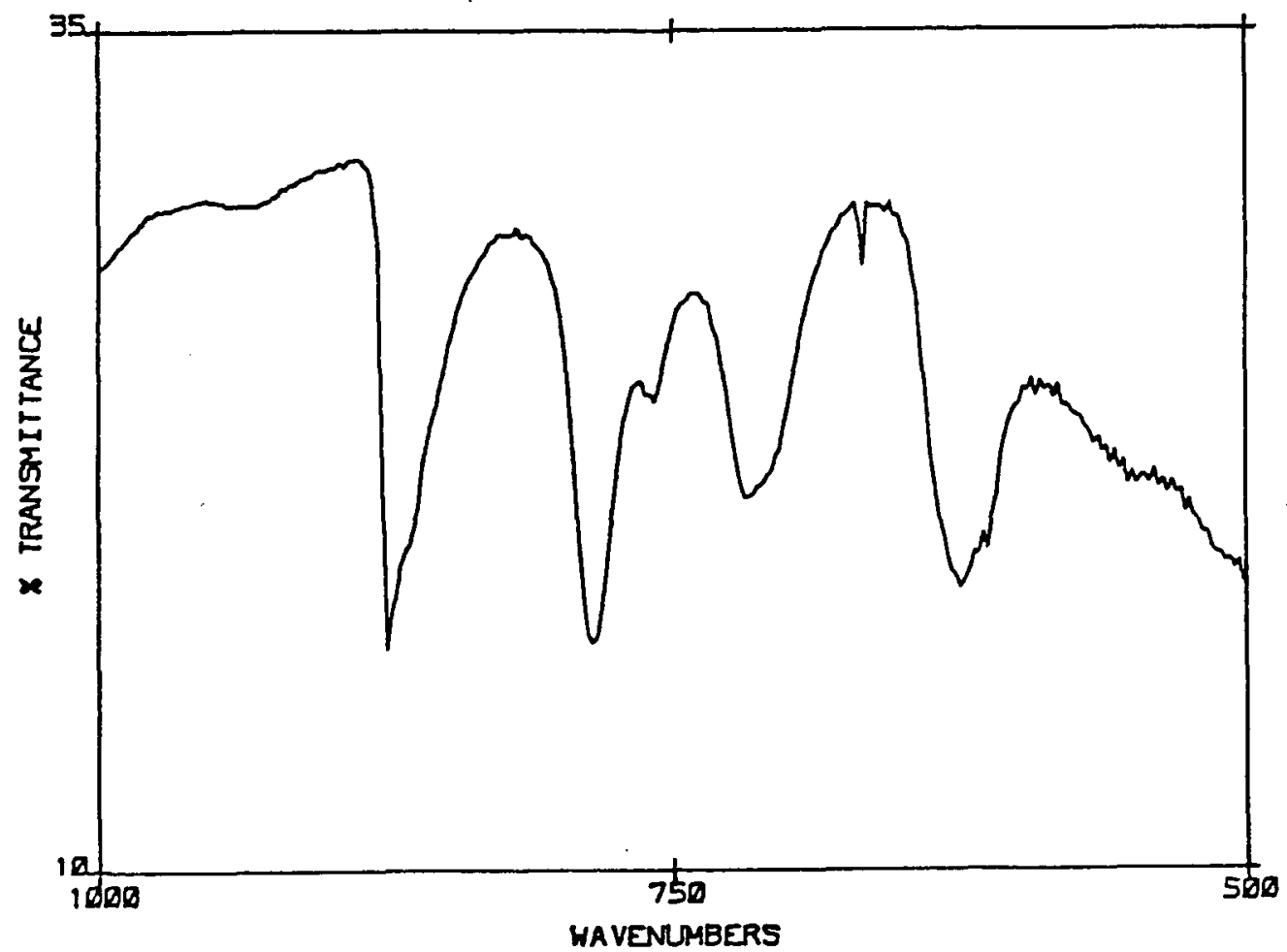

Figure 85. FT-IR spectrum of $2: 1 \mathrm{Ar}: \mathrm{UF}_{6}$ and $2: 1 \mathrm{Ar}: \mathrm{H}_{2} \mathrm{O}$ sample that was co-deposited through nozzle at $16^{\circ} \mathrm{K}$. 
12. $\underline{U O F}_{4}$ Volatility Studies

The following is a discussion of the volatilization experiments performed on $\mathrm{UOF}_{4}$. The experimental details were those discussed in Chapter III, Section G. Figure 86 is a spectrum which was recorded after a sample of $\mathrm{UOF}_{4}$ was heated and volatilized, and then absorbed onto the sample window. There is a broad band with shoulders located at approximately $600 \mathrm{~cm}^{-1}$. This, in all probability, could be assigned to the $\mathrm{UF}_{6}$ stretch. Repetition of this experiment with either slow heating or fast heating yielded basically the same results. It was also observed that some debris remained on the glass sample tube, but, because of the blackening of the glass, it was difficult to discern the color of the debris. However, it can probably be concluded that the $\mathrm{UOF}_{4}$ underwent decomposition to $\mathrm{UF}_{6}$ and that the remaining debris was probably $\mathrm{UO}_{2} \mathrm{~F}_{2}$ in accordance with the TGA trace of Paine and associates. 10

\section{B. Discussion}

The results of the matrix-isolation and neat $\mathrm{UF}_{6}-\mathrm{H}_{2} \mathrm{O}$ studies revealed that $\mathrm{UF}_{6}$ and $\mathrm{H}_{2} \mathrm{O}$ would not react at cryogenic temperatures, and in fact, showed no propensity to react until temperatures above $150^{\circ} \mathrm{K}$ were reached. Calculations of Gibbs free, energies from literature values $75,76,77$ for the reaction of $\mathrm{UF}_{6}$ with $\mathrm{H}_{2} \mathrm{O}$, showed the reaction to be favorable for the formation of $\mathrm{UO}_{2} \mathrm{~F}_{2}$ but unfavorable for the formation of $\mathrm{UOF}_{4}$ at $298^{\circ} \mathrm{K}$. Also, calculations were done for the reaction of $\mathrm{MoF}_{6}$ and $\mathrm{WF}_{6}$ with $\mathrm{H}_{2} \mathrm{O}$. They revealed that the formation of $\mathrm{MOOF}_{4}$ and $\mathrm{WOF}_{4}$ to be favorable at $298^{\circ} \mathrm{K}$, but that 


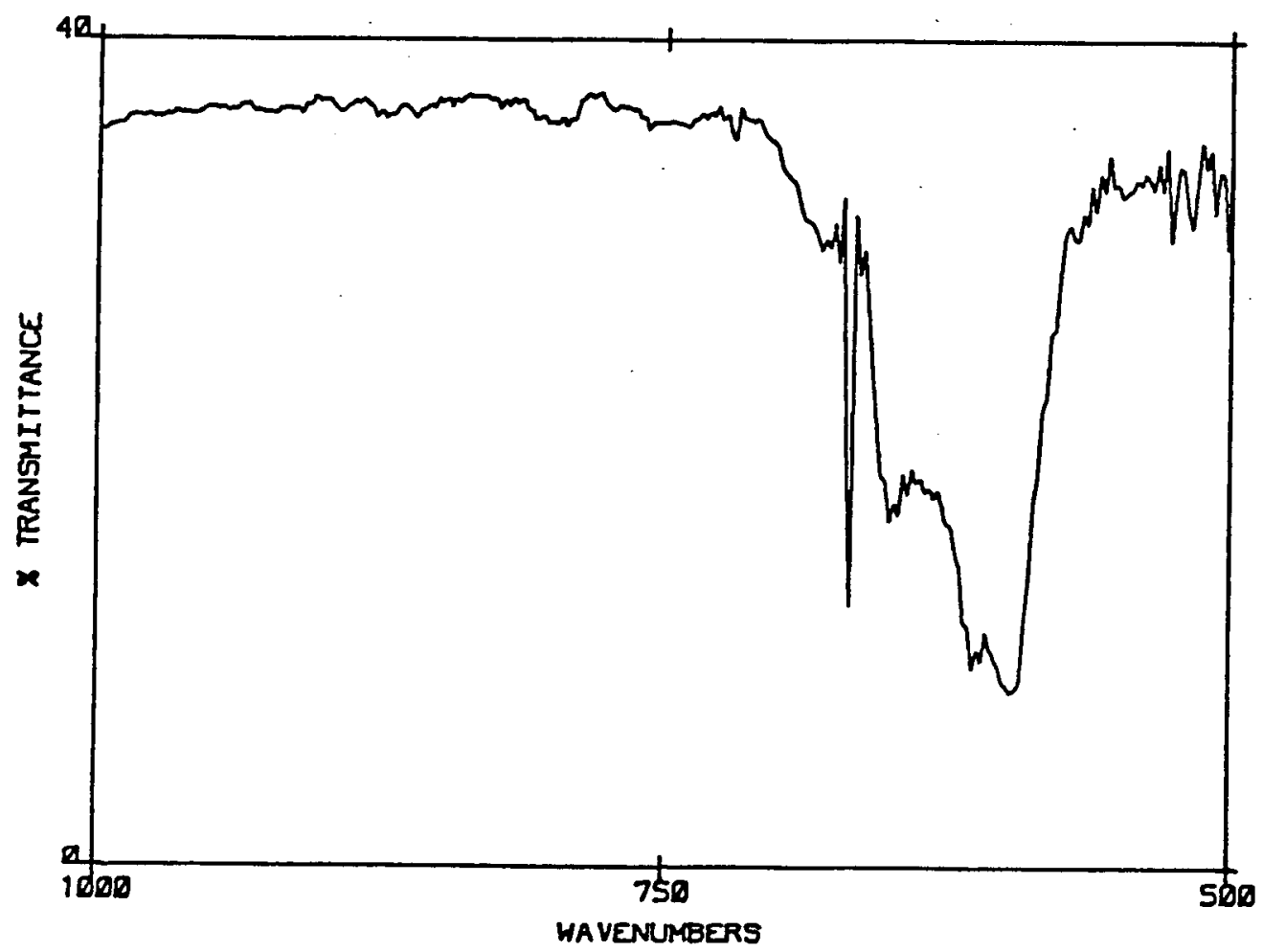

Figure 86. FT-IR spectrum of volatilized UOF ${ }_{4}$ sample at $20^{\circ} \mathrm{K}$. 
this propensity decreased as the temperature decreased. Therefore, from a thermodynamic standpoint, one might expect $\mathrm{UF}_{6}$ to act similarly. And, analogous experiments with $\mathrm{MoF}_{6}$ or $\mathrm{WF}_{6}$ might prove helpful.

In Table VII there are listed IR bands of $\mathrm{UF}_{6}, \mathrm{UOF}_{5}, \mathrm{UOF}_{4}$, $\mathrm{UO}_{3}, \mathrm{UO}_{3}, \mathrm{UO}_{2}$, and $\mathrm{UO}$ which were obtained in previous studies as well as IR bands which were observed in this study. During the course of this discussion, it might be helpful to refer to this table as an aid to understanding.

In the $\mathrm{UF}_{6}$ and $\mathrm{H}_{2} \mathrm{O}$ co-deposition matrix-isolation annealing experiments, it was seen that the samples either reacted to products that were not IR active (because no new bands appeared), reacted but then evacuated away from the window, or did not react. Visual observation of a sample deposited on the window while it was being heated to $50^{\circ} \mathrm{K}$ lends evidence to the belief that the sample boiled off the window. Plus, a rise in pressure also indicated that the sample boiled off. This evidence, coupled with the fact that during the neat experiment in which pure UF 6 and pure water were co-deposited and showed no reaction at low temperatures since the respective $\mathrm{UF}_{6}$ and $\mathrm{H}_{2} \mathrm{O}$ IR bands remained intact, lent support to the belief that no reaction occurred in the matrix. In fact, no reaction was observed for the neat $\mathrm{UF}_{6}$ and water codeposition study until the sample had been warmed past $150^{\circ} \mathrm{K}$. What does this evidence tell us? It tells us that the thermodynamics do not favor a reaction at these low temperatures. But, then another question one might ask, is if the thermodynamics had been favorable, 
TABLE VII

IR ABSORPTIONS $\left(\mathrm{cm}^{-1}\right)$ OF IMPORTANT SPECIES FOUND IN PREVIOUS INVESTIGATIONS AND UF 6 HYDROLYSIS STUDY

A. Previous investigations

1. Uranium compounds

$$
\begin{aligned}
& \mathrm{UF}_{6} ; 1293,1160,624,1861-3 \\
& \mathrm{UOF}_{4} ; 893,667,558,478,375^{10} \\
& \mathrm{UO}_{2} \mathrm{~F}_{2} ; 990,260,234,146^{6}, 21 \\
& \mathrm{UO}_{2} \mathrm{~F}_{2} \cdot 2 \mathrm{H}_{2} \mathrm{O} ; 935^{7} \\
& \mathrm{UOF}_{5} ; 820,602,593,480^{74} \\
& \mathrm{UO}_{3} ; 852,844,746,212,186,152 \text { (matrix-isolation) } 27,28,29 \\
& \mathrm{UO}_{2} ; 776,765 \text { (matrix-isolation) } 27,28,29 \\
& \text { UO: } 820 \text { (matrix-isolation) } 27,28,29
\end{aligned}
$$

2. Matrix-isolated water

$$
\begin{array}{ll}
1000: 1 ; & 3733,3638,1602,1593 \\
100: 1 ; & 3733,3726,3709,3700,3695,3634,3574,3565, \\
& 3565,3528,3516,1626,1615,1611,1602,1593
\end{array}
$$

B. UF 6 hydrolysis study

1. $\mathrm{UF}_{6}$ vapor

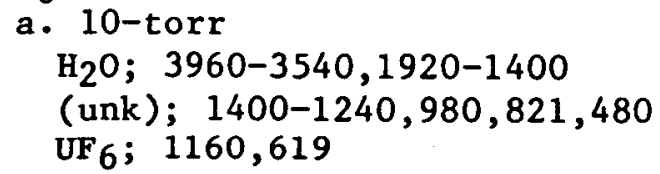

b. 50-torr

$\mathrm{H}_{2} \mathrm{O} ; 3960-3540,1920-1400$

(unk); $1400-1240,935,855,821$

$\mathrm{UF}_{6} ; 1292,1158,619$

2. $\mathrm{UF}_{6} / \mathrm{Ar}$ matrix-isolation

$\mathrm{UF}_{6} ; 619$ (f1ne structure-627,621,619,614,609)

3. $\mathrm{H}_{2} \mathrm{O} / \mathrm{Ar}$ matrix-isolation

a. $1: 1000$

$\mathrm{H}_{2} \mathrm{O} ; 3730,3640,1612,1601,1599,1593$

b. $1: 100$

$$
\begin{aligned}
\mathrm{H}_{2} \mathrm{O} ; & 3776,3755,3730,3724,3705,3699,3696,3633,3573,3565, \\
& 3563,3556,3552,3523,3516,1623,1614,1612,1609,1604, \\
& 1603,1601,1597,1593,1572
\end{aligned}
$$


TABLE VII (continued)

$$
\text { c. } \begin{aligned}
& 1: 20 \\
& \mathrm{H}_{2} \mathrm{O} ; 3697,3600-3100 \text { (broad), } 1650-1605,1602,1593
\end{aligned}
$$

4. $\mathrm{UF}_{6} / \mathrm{H}_{2} \mathrm{O} / \mathrm{Ar}$ matrix-isolation

Similar to 2.a and 3.a combined

5. $\mathrm{UF}_{6} / \mathrm{N}_{2}$ matrix-isolation

$\mathrm{UF}_{6} ; 627,624,623,618,610$

6. $\mathrm{UF}_{6} / \mathrm{H}_{2} \mathrm{O}$ pure

a. Before annealing

$\mathrm{H}_{2} \mathrm{O} ; 3800-3200,1650-1550$

$\mathrm{UF}_{6} ; 620$

(unk); $865,780,710,620$

b. After annealing

$\mathrm{H}_{2} \mathrm{O} ; 3800-3200,1650-1550$

$\mathrm{UO}_{2} \mathrm{~F}_{2} \cdot 2 \mathrm{H}_{2} \mathrm{O} ; 940$

(unk); 865

7. $\mathrm{UF}_{6} / \mathrm{H}_{2} \mathrm{O}$ merging streams

$\mathrm{UF}_{6} ; 625$

(unk); 950-650,595

8. $\mathrm{UF}_{6} / \mathrm{H}_{2} \mathrm{O}$ low ratio
a. $5: 1 / 2: 1 ; 850,613,570$
b. $5: 1 / 2: 1 ; 850,610,591,540$
c. $2: 1 / 2: 1 ; 930,860,780,710,615,591$
d. $3: 1 / 2: 1$; (before annealing): $860,605,591,540$
$3: 1 / 2: 1$; (intermediate): $940,860,780,710,615,591$
$3: 1 / 2: 1$; (after annealing): 940,860 
then might a reaction have occurred? That 18 , would the reaction have been kinetically favorable?

The answer to this question can be found by examining the results of the low-ratio deposition studies. As the concentrations of the samples were increased, more reaction occurred. That is, more peaks were observed in the $900-700 \mathrm{~cm}^{-1}$ region. But, no 940 $\mathrm{cm}^{-1}$ (uranyl) band appeared, as in the case of the neat study, until the sample had been annealed. Two conclusions can probably be drawn from these facts. First, that there is also a concentration factor as well as a thermodynamic factor which governs UF6 hydrolysis. Second, that the hydrolysis pathway has some relatively stable intermediates and would probably be a two or more step process.

The neat study lent support to the fact that there are probably intermediates between $\mathrm{UF}_{6}$ and $\mathrm{UO}_{2} \mathrm{~F}_{2}$ in the hydrolysis reaction. But, it did not help to determine if the $865,780,710$, bands acted together or separately. The low-ratio studies together with data from previous studies may help solve this puzzle.

In the low-ratio annealing study, bands were initially observed at $860,605,591$, and $540 \mathrm{~cm}^{-1}$. It was previously decided that the band at $865 \mathrm{~cm}^{-1}$ could be due to a U-O stretch in UOF 4 or to something very similar. Also, the 605 and $591 \mathrm{~cm}^{-1}$ bands could be due to a $U-F$ or $U-O H$ mode. In the previously referenced study which was conducted by Jaubert and associates 74 on $\mathrm{UOF}_{5}^{-}$ion, they assigned peaks, located at 602 and $593 \mathrm{~cm}^{-1}$, to $a v_{2}\left(a_{1}\right) \quad \mathrm{UF}_{4}$ symmetrical elongation and a $v_{3}\left(a_{1}\right) \quad U-F$ (equatorial fluorine) elongation respectively in the $\mathrm{UOF}_{5}{ }^{-}$ion. They made these assignments by 
relating force-constanst calculations to experimental IR and Raman data on the $\mathrm{KUOF}_{5}, \mathrm{RbUOF}_{5}, \mathrm{NH}_{4} \mathrm{UOF}_{5}, \mathrm{CsUOF}_{5}$, and [Ph4 $\mathrm{Ph}_{4}$ UOF $_{5}$ molecules. Their assignments correlate very well with the present results. A UOF $_{5}{ }^{-}$ion or some similar molecule is a very reasonable intermediate to assume in this reaction sequence. It is possible to go one step further and surmise that an $\mathrm{UOF}_{5}{ }^{-} \mathrm{H}^{+}\left(\mathrm{UOF}_{4} \cdot \mathrm{HF}\right)$ molecule might be present. An $820 \mathrm{~cm}^{-1}$ band in $\mathrm{UOF}_{5}{ }^{-}$was assigned to a $\nu_{1}\left(a_{1}\right)$ U-O elongation. Notice that the $865 \mathrm{~cm}^{-1}$ band found in this study is located between this band and the $893 \mathrm{~cm}^{-1}$ band assigned to the U-O stretch in $\mathrm{UOF}_{4}$ by Paine and associates. 10 But, what happened next during the annealing experiment seems to be even more complicated.

The series of spectra upon annealing showed that the 605 and $591 \mathrm{~cm}^{-1}$ bands receded and that the $865 \mathrm{~cm}^{-1}$ band continued to grow as would be expected, but also new bands emerged at 780 and $710 \mathrm{~cm}^{-1}$ as well as a band at $940 \mathrm{~cm}^{-1}$. The $940 \mathrm{~cm}^{-1}$ band has already been tentatively assigned to a $\mathrm{UO}_{2}$ mode in $\mathrm{UO}_{2} \mathrm{~F}_{2} \cdot \mathrm{H}_{2} \mathrm{O}$. But, what about the 780 and $710 \mathrm{~cm}^{-1}$ bands? In a study by Gabelnick and associates, 27-29 they recorded FT-IR spectra of uranium oxide species vaporized from tungsten and iridium Knudsen cells and deposited in $\mathrm{Ar}$ and $\mathrm{Kr}$ matrices. They made assignments of $\mathrm{U}^{16} \mathrm{O}_{3}, \mathrm{U}^{16} \mathrm{O}_{2}$, and $\mathrm{U}^{16} \mathrm{O}$ (which are listed in Table VII), based on force-constant calculations and mass spectrometry data.78 Notice that the 776 and 765 $\mathrm{cm}^{-1}$ bands for $\mathrm{UO}_{2}$ are very close to the $780 \mathrm{~cm}^{-1}$ band found in this study. One would expect the $\mathrm{UO}_{2}$ species to form after the $\mathrm{U}-\mathrm{O}$ in a $\mathrm{UF}_{6}$ hydrolysis reaction and, it therefore might correlate to this 
study. The $710 \mathrm{~cm}^{-1}$ band cannot be correlated with any known study. It is probably due to the same species that elfcits the 780 $\mathrm{cm}^{-1}$ band since it occurs simultaneously with $1 \mathrm{t}$.

From the low-ratio annealing study it can probably be concluded that there are at least two relatively stable intermediates in the UF 6 hydrolysis reaction. These are the intermediates due to the $865 \mathrm{~cm}^{-1}$ and the 606 and $591 \mathrm{~cm}^{-1}$ bands. There might also be one or more intermediates of lesser stability due to the 780 and 710 $\mathrm{cm}^{-1}$ bands. It can also be concluded that the reaction might be more complex than just a sequential-step process. But, one might ask what can be further done to solve this problem?

One answer is to conduct this same study with similar molecules such as $\mathrm{MoF}_{6}$ and $\mathrm{WF}_{6}$. The IR and Raman spectra of $\mathrm{MoOF}_{4}, \mathrm{MoO}_{2} \mathrm{~F}_{2}$, and $\mathrm{WO}_{2} \mathrm{~F}_{2}$ have been well-established, and it might be valuable to correlate answers found in a hydrolysis study on $\mathrm{WF}_{6}$ and $\mathrm{MoF}_{6}$ to this study.

Another answer is to use isotopic substitution in the same study of $\mathrm{UF}_{6}$ hydrolysis with water. In order to do this, one could use $\mathrm{H}_{2}{ }^{18} \mathrm{O}$ and $\mathrm{D}_{2} \mathrm{O}$ to react with $\mathrm{UF}_{6}$. If the water was of a certain percent abundance 180 and a certain percent abundance $16_{0}$, IR bands due to $U-18_{0}$ stretches would be shifted from the $U-16_{0}$ stretches. Also, a U-OD band or a $\mathrm{UO}_{2} \mathrm{~F}_{2} \cdot \mathrm{D}_{2} \mathrm{O}$ band would be shifted from a U-OH or $\mathrm{UO}_{2} \mathrm{~F}_{2} \cdot \mathrm{H}_{2} \mathrm{O}$.

Also, Raman spectroscopy might help with some of the band assignments. 


\section{LIST OF REFERENCES}


1. Katz, J. J.; Rabinowitch, E. "The Chemistry of Uranium"; Dover: New York, 1951; p. 404.

2. Brown, D. "Halides of the Lanthanides and Actinides"; Wiley-Interscience: New York, 1968; p. 26.

3. Bailar, J. C.; Emeleus, H. J.; Nyholm, R.; Trotman-Dickenson, A. F. "Comprehensive Inorganic Chemistry"; Compendium: New York, 1973; p. 168.

4. Taylor, J. C.; Wilson, P. W. J. Solid State Chem. 1977, 14, $378-82$.

5. Claassen, H. H.; Weinstock, B.; Malm, J. G. J. Chem Phys. $1956,25,426-7$.

6. Bailar, J. C.; Emeleus, H. J.; Nyholm, R.; Trotman-Dickenson, A. F. "Comprehensive Inorganic Chemistry"; Compendium: New York, 1973; p. 167.

7. Seppelt, V. K.; Bartlett, N. Z. Anorg. Allg. Chem. 1977, 436, $122-6$.

8. Paine, R. T.; Coleman, W. F.; Lewis, R. B.; McDowe1l, R. S. NBS Special Publ. 1978, 526, 253-5.

9. Wilson, P. W. J. Inorg. Nuc1. Chem. 1974, 36, 303-5.

10. Paine, R. T.; Ryan, R. R.; Asprey, L. B. Inorg. Chem. 1975, $14,1113-17$.

11. Bagnall, K. W. "Lanthanides and Actinides, MTP Intl. Rev. Sc1."; University Park: Baltimore, 1972; Vol. 7, p. 92.

12. Okamoto, J.; Kiyose, R. J. Nuc1. Sci. Tech. (Japan) 1978, $15(6), 455-60$.

13. Levy, J. H.; Taylor, J. C.; Wilson, P. W. J. Inorg. Nucl. Chem. 1977, 39, 1989-91.

14. Taylor, J. C.; Wilson, P. W. J. Chem. Soc., Chem. Commun. $1974,232-3$.

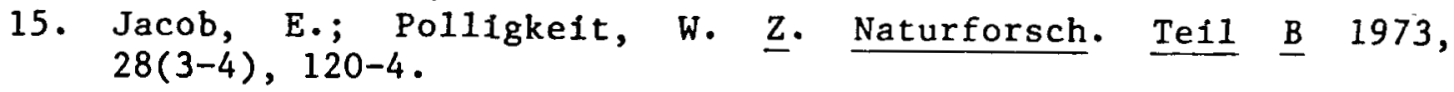

16. Mattson, V. L. "Kirk-Othmer Encyclopedia of Chemical Technology"; Wiley-Interscience: New York, 1970; Vol. 21, p. 34 . 
17. Gutmann, V. "Halogen Chemistry"; Academic: New York, 1967; Vo1. 3, p. 359.

18. Brooks, L. H.; Garner; E. V.; Whitehead, E. United Kingdom Atom. Energy Auth. [Rep.] 16R-TN/CA-277 1956, 1- 17 .

19. Taylor, J. C. Aust. A.E.C., AAEC/E [Rep.] No. 255 1973, 1-7.

20. Bailar, J. C.; Emeleus, H. J.; Nyholm, R; Trotman-Dickenson, A. F. "Comprehensive Inorganic Chemistry"; Compendium: New York, 1973 ; p. 178.

21. Ohwada, K. Inorg. Chem. 1971, 33(6), 1615-23.

22. Katz, J. J.; Rabinowitch, E. "The Chemistry of Uranium"; Dover: New York, 1951; p. 569.

23. Bagnall, K. W. "Lanthanides and Actinides, MTP Int1. Rev. Sci."; University Park: Baltimore, 1972; Vo1. 7, p. 92.

24. Gutmann, V. "Halogen Chemistry"; Academic: New York, 1967; Vo1. 3, p. 360.

25. Katz, J. J.; Rabinowitch, E. "The Chemistry of Uranium"; Dover: New York, 1951 ; p. 570.

26. Siegal, S.; Hoekstra, H. R.; Sherry, E. Acta Cryst. 1966, 20, 292 .

27. Gabelnick, S. D.; Reedy, G. T.; Chasanov, M. G. J. Chem. Phys. $1973,58(10), 4468-75$.

28. Gabelnick, S. D.; Reedy, G. T.; Chasanov, M. G. J. Chem. Phys. 1973 , 59(12), 6397-6403.

29. Gabelnick, S. D.; Reedy, G. T.; Green, D. W. J. Chem. Phys. $1980,73(9)$, 4207-12.

30. Carstens, D. H. N.; Gruen, D. M.; Kozlowski, J. F. High Temp Sc1. 1972, 4, 436 .

31. Bagnall, K. W. "Lanthanides and Actinides, MTP Intl. Rev. Sci."; University Park: Baltimore, 1972; Vol. 7, p. 92.

32. Gasner, E. L.; Frlec, B. J. Chem. Phys. 1968, 49(11), 5135.

33. Malm, J. G.; Weinstock, B.; Claassen J. Chem. Phys. 1968, $49(11), 5135$. 
34. Bagnall, K. W. "Lanthanides and Actinides, MTP Intl. Rev. Sci."; University Park: Baltimore, 1972; Vol. 7, p. 122.

35. Burns, R. C.; O'Donnel1, T. A.; Waugh, A. B. J. Fluor. Chem. $1975,12,505-17$.

36. Burns, R. C.; O'Donnell, T. A. Inorg. Nucl. Chem. Lett. 1977, $13,657-60$.

37. Barber, E. J.; Cady, G. H. J. Phys. Chem. 1956, 60, 505-6.

38. Gutmann, V. "Halogen Chemistry"; Academic: New York, 1967; Vol. 3, p. 279 .

39. Bernstein, E. R.; Meredith, G. R. J. Chem. Phys. 1977, 24, 289-99.

40. Selig, H.; Sunder, W. A.; Schilling, F. C.; Falconer, W. E. J. Fluor. Chem. 1978, 11, 629-55.

41. Canterford, J. H.; Colton, R. "Halides of the Second and Third Row Trans. Metals"; Wiley-Interscience: New York, 1968, Vol. 3 , p. 211 .

42. Peacock, R. D.; Edelstein, N. J. Inorg. Nucl. Chem. 1976, 38, 771-2.

43. Canterford, J. H.; Colton, R. "Halides of the Second and Third Row Trans. Metals"; Wiley-Interscience: New York, 1968; Vol. 3 , p. 214 .

44. Winfield, J. M. "Inorganic Chemistry, MTP. Int1. Rev. Sci. Ser. 1"; University Park: Baltimore, 1972; Vol. 5, p. 279.

45. Alexander, L. E.; Beattie, I. R.; Bukovszky, A.; Jones, P. J.; Marsden, C. J.; Van Schalkwyk, G. J. J. Chem. Soc., Dalton Trans. $1974,81-4$.

46. Paine, R. T.; McDowell, R. S. Inorg. Chem. 1974, 13(10), 2366-70.

47. Robiette, A. G. J. Mol. Struct. 1977, 37, 105.

48. Iijima, K. Bul1. Chem. Soc. Japan $1977,50,373$.

49. Atherton, M. J.; Holloway, J. H. J. Chem. Soc., Chem Commun. $1978,254$.

50. Atherton, M. J.; Holloway, J. H. J. Chem. Soc., Chem. Commun. 1978,41 . 
51. Brown, D. "Halides of the Lanthanides and Actinides"; Wiley-Interscience: New York, 1968; p. 31 .

52. Samsanov, G. V. "The Oxide Handbook"; P1enum: New York, 1973; p. 110 .

53. Elwell, W. T.; Wood, D. E. "Analytical Chemistry of Molybdenum and Tungsten"; Pergamon: New York, 1971; p. 6.

54. Samsanov, G. V. "The Oxide Handbook"; Plenum: New York, 1973; p. 112 .

55. Samsanov, G. V. "The Oxide Handbook"; Plenum: New York, 1973; p. 35 .

56. Samsanov, G. V. "The Oxide Handbook"; Plenum: New York, 1973; p. 32 .

57. Loopstra, B. 0.; Boldine, P. Acta Cryst. 1966, 21, 158.

58. Yampol'shii, V. I.; Mal'tsov, A. A. Russ. J. Inorg. Chem. 1970, $15(7), 1029$.

59. Mattes, R.; Schroeder, F. Z. Naturforsch. Teil B 1969, 24(9), 1095.

60. Krasser, W. Naturwissenchaften $1969,56(4), 213-4$.

61. Weltner, W.; McLeod, D. J. Mol. Spectr. 1965, 17, 276.

62. Norman, I.; Porter, 6. Nature 1954, 174, 508.

63. Whittle, E.; Dows, D. A.; Pimente1, G. C. J. Chem. Phys. 1954 , $22,1943$.

64. Downs, A. J.; Peake, S. C. "Molecular Spectroscopy"; The Chemical Society: London, 1973; Vol. 1, p. 533.

65. Daniels, F.; Alberty, R. A. "Physical Chemistry"; Wiley-Interscience: New York, 1975; p. 507.

66. Margrave, J. L.; Timms, P. L.; Jouette, M. B. Inorg. Chem. $1966,5,729$.

67. Mason, M. G.; Von Holle, W. G.; Robinson, D. W. J. Chem. Phys. $1971,54(8), 3491$.

68. Ayers, G. P.; Pullin, A. D. E. Spectrochim. Acta 1976, 32A, 1695-1704. 
69. Brentwood, R. M.; Barnes, A. J.; Orville-Thomas, W. J. J. Mo1. Spectr. $1980,84,391-404$.

70. Moskovits, M.; Ozin, G. A. "Cryochemistry"; Wiley-Interscience: New York, 1976; p. 306.

71. Hoekstra, H. R. Inorg. Chem. 1965, $2,492$.

72. McDowell, R. S.; Paine, R. T. J. Chem. Phys. 1976, 64(7), 3081.

73. Wilson, W. W.; Wilson, R. D; Christie, K. O. J. Inorg. Nuc1. Chem. $1981,43,1551-53$.

74. Jaubert, P.; Gaudreau, B. Can. J. Chem. 1977, 56, 1874-80.

75. Stull, D. R.; Prophet, H. "JANAF Thermochemical Tables"; 2nd ed., U.S. Government Printing Office: Washington, D.C., 1971; $1-1141$.

76. O'Hare, P. A.; Malm, J. G. J. Chem. Thermodynamics 1982, 14 , $331-6$.

77. Johnson, G. K. J. Chem. Thermodynamics $1979,11,483-90$.

78. Ackermann, R. J.; Rauh, E. G.; Chandras, M. S. J. Phys. Chem. 1969, 73, 762-9. 
Stephen Paul Anderson was born at Shaw Air Force Base in Sumter, South Carolina, on March 3, 1957. He is the son of the late Joseph Anderson and of Reba Stewart Anderson of Bristol, Tennessee. He graduated from Sullivan East High School in Sullivan County, Tennessee, June, 1975 with honors. He attended The University of Tennessee, Knoxville from September 1975 unt11 August 1980, at which time he received a Bachelor of Arts in Liberal Arts and a Bachelor of Science in Chemistry with honors.

In September of 1980 he entered graduate school at The University of Tennessee, Knoxville. He was awarded a research assistantship which was supported by a grant from the Union Carbide Nuclear Division, Oak Ridge Gaseous Diffusion Plant ( $K-25)$, Oak Ridge, Tennessee. He received the Master of Science in Chemistry in August, 1982 . 